\title{
Discipline-Specific or Academic? Acquisition, Role and Value of Higher Education Competencies
}

Citation for published version (APA):

Meng, C. M. (2006). Discipline-Specific or Academic? Acquisition, Role and Value of Higher Education Competencies. [Doctoral Thesis, Maastricht University]. ROA. https://doi.org/10.26481/dis.20060126cm

Document status and date:

Published: 01/01/2006

DOI:

$10.26481 /$ dis. $20060126 \mathrm{~cm}$

Document Version:

Publisher's PDF, also known as Version of record

\section{Please check the document version of this publication:}

- A submitted manuscript is the version of the article upon submission and before peer-review. There can be important differences between the submitted version and the official published version of record.

People interested in the research are advised to contact the author for the final version of the publication, or visit the DOI to the publisher's website.

- The final author version and the galley proof are versions of the publication after peer review.

- The final published version features the final layout of the paper including the volume, issue and page numbers.

Link to publication

\footnotetext{
General rights rights.

- You may freely distribute the URL identifying the publication in the public portal. please follow below link for the End User Agreement:

www.umlib.nl/taverne-license

Take down policy

If you believe that this document breaches copyright please contact us at:

repository@maastrichtuniversity.nl

providing details and we will investigate your claim.
}

Copyright and moral rights for the publications made accessible in the public portal are retained by the authors and/or other copyright owners and it is a condition of accessing publications that users recognise and abide by the legal requirements associated with these

- Users may download and print one copy of any publication from the public portal for the purpose of private study or research.

- You may not further distribute the material or use it for any profit-making activity or commercial gain

If the publication is distributed under the terms of Article $25 \mathrm{fa}$ of the Dutch Copyright Act, indicated by the "Taverne" license above, 
Discipline-Specific or Academic?

Acquilisition, Role and Value

of Higher Education

Competencies 
Christoph Meng, Maastricht 2005

All rights reserved. No part of this publication may be reproduced, stored in a retrieval system, or transmitred in any form, or by any means, electronic, mechanical, photocopying, recording or otherwise, without the prior permission in writing, from author.

Published by ROA

Postbus 6r6

6200 MD Maastricht

ISBN-Iro: $90-532 \mathrm{I}-423-2$

ISBN-13: 978-90-5321-423-7

Printed in the Netherlands by Unigraphic 


\title{
Discipline-Specific or Academic? Acquisition, Role and Value of Higher Education Competencies
}

\author{
Proefschrift
}

ter verkrijging van de graad van doctor aan de Universiteit Maastricht, op gezag van de Rector Magnificus, Prof. mr. G.P.M.F. Mols, volgens het besluit van het College van Decanen, in het openbaar te verdedigen op donderdag 26 januari 2006 om 14.00 uur

door

Christoph Michael Meng 


\section{Promotoren}

Prof. dr. J.A.M. Heiflke

Prof. dr. J. Muysken

\section{Co-promotor}

Dr. R.K.W. van der Velden

\section{Beoordelingscommissie}

Prof. dr. L.L.G. Soete (Voorzitter)

Prof. dr. J.-G. Mora Ruiz (Technical University of Valencia)

Dr. S. Schim van der Loeff

Prof. dr. C.P.M. van der Veuten 


\section{Acknowledgements}

First, I am deeply indebred to my promoters Hans Heijke and Joan Muysken and my copromoter Rolf van der Velden for their support and involvement. From the beginning, my meetings with Hans were stimulating and I profited tremendously from our discussions. For their indispensable support throughout this study and their immense valuable comments on the manuscript, I thank Joan and Rolf. I would also like to thank the review commitree, consisting of Luc Soete, Cees wan der Vleuten, Sybrand Schim wan der Loeff and José-Gines Mora Ruiz, for their careful reading of the manuscript and their valuable comments on it.

Furthermore, I owe much gratitude to Ger Ramaekers and Catherine Ris. Ger contributed to the paper An investigation into the role of human capital competencies and their pay-off. Catherine contributed to the paper "Fitting to the job: the role of generic and vocational competencies in adjustment and performance. Modified wersions of these papers form Chapter 5 of this study.

For their comments on earlier 'paper' versions of different chapters of this study, I would like to thank Jim Allen, Hans-Peter Blossfeld, Lex Borghans, Josep M. Masjuan Codina, Wim Gijselaers, Bart Golsteyn, Jeannette Hommes, Ben Kriechel, Ferrane Mane, Karl-Ulrich Mayer, Gerard Pfann, Jordi Planas, Harald Schomburg, Inge Sieben, Alexandra Spitz, Roy Thurik, Maarten Vendrik and Bruce Weinberg.

I would also like to acknowledge participants at the following conferences: ROA/SKOPE conference in Maastricht 2oor; ILM conference in Aberdeen 2002; the $5^{\text {th }}$ IZA Summer school in Munich 2002; the EALE conferences in Paris 2002, Lisbon 2004 and the combined EALE/SOLE conference in San Francisco 2005; the Transition in Youth Network Meetings in Florence 2002, Madeira 2003 and Nuremberg 2004; ORD in Gent 2005. Moreover, 1 benefited from discussions at seminars at Mastricht University (2002, 2003 and 2004), at the University of Barcelona (2003), at the EMM in Zoetermeer (2004), the LAB in Nurimberg (2004), at Bamberg University (2004) and the ZEWW in Mannheim (2005).

Other colleagues are greatly appreciated as well. Judith Semeijn, with whon II shared. a room, Paul Ghijsen as a regular lunch partner, Patrick van Lijs to talk about soccer and bicycle races in berween times of work, Tom van Veen as block co-ordinator of courses I often raught, Marielle Beenkens for doing the layout of the manuscript, Paul Nekeman for editing the English and of course Emid who greets me every morning with a smile.

Last but not least, I would like to thank my parents; without them I would not have been able to study in Maastricht, Bea who often had ard time during the last 5 years with a husband regularly taking his PhD thesis too serious, Mickey and Mouse for greeting me with all the love cats can give every time I come home. I dedicate this book to Rico who was born just after this thesis was finished.

Cloristoph Meng, Awrmn 2005 



\section{Contents}

Acknowledgements

Abbreviations used.

\section{Chapter 1}

Introduction

1.1 Motivation and aim $\quad 2$

1.2 Knowledge society and the role of higher education $\quad 2$

1.3 Higher education graduates and their competencies 4

1.4 The stage of transition from higher education to work 5

1.5 The place of this thesis in the licerarure, its aim, and some subquestions 7

1.6 A guide through the thesis 9

\section{Chapter 2}

Human capital - qualifications - competencies: A conceptual approach $\quad 13$

2.1. Introduction $\quad \mathbb{1 4}$

2.2 Impact of education on labour productivity: different approaches $\quad 14$

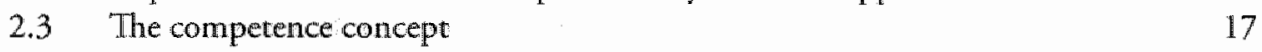

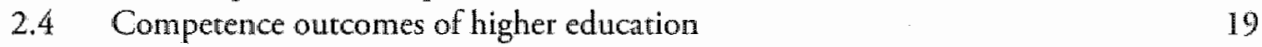

2.4.1 Discipline-specific competencies 20

2.4.2 Generic competencies 21

2.5. Concluding remarks $\quad 26$

Chapter 3

CHEERS survey and definition of academic and discipline-specific competencies 29

3.1 Introduction 30

3.2 The CHEERS survey 31

3.3 Discipline-specific and academic compertencies 34

3.3.1 Competence measurement $\quad 34$

3.3.2 Testing the validity of our competence constructs 38

3.3.3 Potential measurement errors and solutions used $\quad 43$

3.4 Who works and who doesn't 45

3.5 Concluding remarks $\quad 47$

Appendix 3A: The competencies questions in the CHEERS survey 48 


\section{Chapter 4}

Student time allocation, the learning environment and the acquisition of competencies

4.1 Introduction 50

4.2 Competence transformation at Higher Education 52

4.2.1 The production process

42.2 Learning environment 53

4.2.3 Time allocation $\quad 55$

4:2.4 A simple theoretical approach 56

4.3 Data and a first descriptive view 60

4.3.1 Discipline-specific and academic comperencies 61

4.3.2 Learning environment 61

4.3.3 Student time allocation 63

4.4 Empirical analyses 65

4.4.1 The stochastic frontier model 66

4.4.2 Results I: Acquisition of academic and discipline-specific competencies $\quad 70$

4.4.3 Results II: Mechanisms working inside a learning environment 76

4.5 Concluding remarks $\quad 82$

Appendix 4A: Definitions of variables used 84

Appendix 4B: Alternative estimations

Appendix 4C: Cobb-Douglas Functional Form 86

Appendix 4D: University versus higher vocational education 87

\section{Chapter 5}

Fitting to the job: the role of academic and discipline-specific competencies in adjustment and performance

5.1 Introduction 90

5.2 The data 92

5.2.1 A descriptive look at two types of competencies 94

5.3 The return to academic and discipline-specific competencies 97

5.3.1 Theoretical notion I 97

5.3.2 Results I: Wage rate 98

5.4 Allocation to on-the-job training and the return to competencies 101

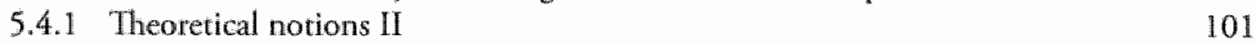

5.4 .2 Empirical specification 104

5.4.3 Empirical results II: Allocation and Training 106

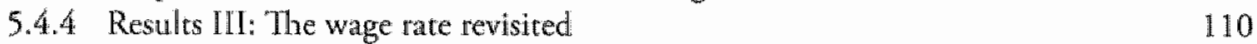

5.5 Concluding remarks 111

Appendix 5A: Characteristics of Dutch graduates 113

Appendix 5B: Robustness of allocation-training model? 113 


\section{Chapter 6}

The effects of higher education programme characteristics on the allocation and performance of the graduates

6.1 Introduction $\quad 116$

$\begin{array}{ll}6.2 \text { Theoretical framework } & 118\end{array}$

6.2.1 Labour market characterization: Three occuparional domains 118

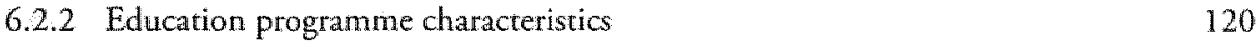

$\begin{array}{ll}6.3 \text { Data } & 124\end{array}$

6.3.1 The measurement of the occupational domain 125

6.3.2 The measurement of the education programme characteristics 125

$\begin{array}{lll}6.4 & \text { Empirical Analyses } & 128\end{array}$

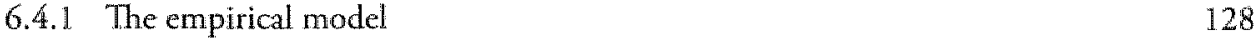

6.4.2. Results $\quad 130$

6.4.2.1 Allocation $\quad 130$

6.4.2.2 Wages $\quad 134$

6.5 Concluding remarks 137

Appendix 6A: Education programme characteristics $\quad 139$

Appendix 6B: First-stage model 1642

Appendix 6C: Robustness Tests 145

Chapter 7

$\begin{array}{ll}\text { Concluding remarks } & 147\end{array}$

$\begin{array}{ll}\text { Summary } & 153\end{array}$

$\begin{array}{lr}\text { Samenvatting } & 157\end{array}$

$\begin{array}{ll}\text { References } & 161\end{array}$

Annex: The CHEERS questionnaire $\quad 171$

$\begin{array}{ll}\text { Curriculum Vitae } & 191\end{array}$

Roa Dissertarion Series $\quad 193$ 



\title{
Abbreviations used
}

\author{
Countries \\ IT Italy \\ ES Spain \\ FR France \\ AT Austria \\ D Germany \\ NL Netherlands \\ UK United Kingdom \\ FI Finland \\ NO Norway
}

\section{Higher education institutions}

ITU Italian Universities

ESU Spanish universities

FRU French universities

FRGE French Grande Ecoles

ATU Austrian universities

DU German universities

DFH German Fachhochschulen

NLU Dutch universities

NLHBO Dutch higher vocational institutions

UKU United Kingdom oll universities

UKNU United Kingdom new universities

FIU Finish universities

NOU Norwegian universities

NOC Norwegian university colleges (former state colleges)

Field of study

AH Arts and humanities studies

SS Social sciences studies

BU Business studies

IA Law studies

NS Natural sciences studies

EN Engineering studies

HE Health sciences studies 



\section{Glossary}

Some definitions to facilitate the reading of this thesis

Competence: Learnable group of skills forming the condition to perform complex and varying tasks inside and outside the working sphere.

Discipline-specific competencies: Cognitive prerequisites that students acquire, which allow them to perform adequarely in a given, but mostly restricted, substantive area.

Generic competencies: Label used to cover a diversity of concepts, all indicating the subject, discipline or occupation independence of such competencies.

Academic competencies: Subset of generic competencies related to higher thinking and learning competencies

Higher education institute: Label used for a particular university or school of higher education (e.g. University of Maastricht)

Higher education institution: Label used for particular type of higher education (e.g. Fachhochschulen or Grande Écoles)

Occupational domain: Group of occupations in the labour market requiring the same type of competencies

Conventional teaching style: Fairly passive learning environment, in which faculties talk and students listen

Activating teaching style: Learning environment in which students gain concrete experience with learning independently, working in groups and approaching problems systematically 



\section{Chapter 1 \\ Introduction}

"Education... has produced a vast population able to read but unble to distinguish what is worth reading "

G.M. Trevelyan

"Es ist nicht genug zu wissen, man muss auch anwenden; es ist nicht genug zu wollen, man mots atach thon " Johann Wolfgang Goethe 


\subsection{Motivation and aim}

To take advantage of new and rapidly changing opportunities in a knowledge-driven cconomy, the acquisirion and maintenance of competencies that are valued in the labour market are crucial for school-leavers in general and higher education graduates in particular. Changes in the modern workplace, brought about by the high rate of technological, economical, social and cultural changes in the last decennia, intensified the debate concerning the kind of comperencies rhar are required in the labour market and the kind of competencies that are best acquired in edwcation. Concerns have been raised about the adequacy of workforce competencies (Stals, 1998), and discussions have emphasized the importance of certain competencies, blaming the education system for failing to provide them adequately. In line with this, the attention of policy-makers and analysts has recently shifted to the quality dimension of schooling and the understanding of the impact of qualiry differences in human capital on a graduates labour market success (see e.g. Hanushek, 2002, 2004).

The objective of this thesis is to add to this ongoing discussion on the measurement of human capital. More specifically, we propose a human capital output measurement of higher education that distinguishes explicity between two types of competencies acguired by students: discipline-specific competencies and academic competencies. Discipline-specific competencies refer to the cognitive prerequisites that srudents acquire in higher education and that allow them to perform properly in a given, but mostly restricted, substantive area. The term 'academic competencies" is used to label a group of abilities such as problem-solving abilities, knowing how to (re) learn or how to deal with information and ideas. Academic competencies are subset of generic comperencies that are generally applicable in the whole range of occupations open to graduates. In this sense, academic competencies are disciplineand/or occupation-independent, enabling graduates to adapt easily and flexibly to changes in the labour market and to acquire new competencies, as needed.

The measurement that we propose is derived directly from the actual level and type of comperencies acquired by graduates. It is both flexible and makes it possible to break open the black box of higher education outpur, which is otherwise generally cowered by static labels such ats the field of study or the rype of higher education. Accordinglly, it enables us to discuss in greater detail the acquisition of different types of human capital in higher education, their role in the transition to the labour market and dheir value in the labour market.

Before presenting the objectives of this thesis and its setup in more detail, we will briefly p. Hace the discussion in a broader context.

\subsection{Knowledge society and the role of higher education}

The change which the Western world has made towards a knowledge society has often been described as a paradigm change. As a successor for the agricultural, the industrial and the service sector stage, the non-location-bound knowledge-oriented economy has become an apparent and full-featured part of highly developed countries in the twenty-first century. The evolvement of Information and Communication Technology (ICT) not only changed the rules of the game, but its high rate of innovation has (and will concinue to have) major 
implications for the economy as a whole. Everywhere people will be contronted with these innowations. Looking into the crystal ball, we can still see in the near future that streets ane cleaned by streer sweepers and children taught by reachess. However, it all involwes new processes and techniques made available by the extraordinary progress in ICT.

Higher education, by its expansion in the $19905^{1}$, made a major contribution to the establishment of the knowledge society: a society in which lifelong learning is seen as crucial and the polarization berween the 'knowledge haves' and the "knowledge have-nots' is recognized. as a serious threat (OECD, 2004). Learning is no longer the privilege of the young, nor the monopoly of some specialized institutions; but lifelong learning and permanent education are necessary for everyone, to keep up with technological changes that are taking place more rapidly than ever before (Albeda, 1998). Large parts of this prolonged learning will not necessarily be formal and structured, but consist of learning-by-doing at the workplace. Accordingly, the widespread consensus in policy circles is that betrer education and taining inevitable yield economic success:

"The central issue for discussion in each and every industralized counry is the refore the manner. in which edwcation and training sytems can be improved and skills mised. Inwest in more avd. better skills... and prosperity will follow (Ashton and Green, 1996)

Education not only benefits the individual, but may benefic sociery as a whole: National income rises directly due to higher productivity of workers with more and better skills; better educated individuals are generally more civically involved and are more informed and responsible voters (Hanushek, 2002). An increase in the level of education is also associated with a reduction in crime rates (see e.g. Ehrtich, 1975, Lochner and Moretti, 20or) and with better health. Moreover, several studies have argued that the benefirs for sociery are larger than merely the sum of individual benefits and that education accelerates the growth rate of the economy ${ }^{2}$.

In this context, higher education is given a crucial role. More precisely, higher education is expected to progress on the frontier of knowledge, prowiding a substantial contribution to the basic knowledge that paves the roads to continued economic growth. Living in a global economy that enables manufactures of goods and providers of services to locate their operations wherever they expect the largest competitive advantage, a nation's human capital, in addition to renewable natural resources, is increasingly the stable source that industralized councries need to rely on.

"Fo" countries in the vanguard of the world economys the balance between knowledge and resounces has shifted so far towath whe former wat knowledge has become perbaps the most important factor deverwining the standard of liting - more wan land, than rools, than labown. Toddy's most technologically advanced conomies are truly knowledge-based "World Bank, 1998

i. The number of tertiary education students in the European Uaion increased by more than $40 \%$ in the last decade $\left(\mathrm{EC}_{\mathrm{n}} 2002\right)$.

2. For examples, see the analyses by Lucas, 1988; Romw; 1990; Barro, 1991; Jorgenson and Fraumeni, 1992; Barro and Sala-1-Martin, 995 ; The question with respect to the direction of the causality berween education and economic growth is addressed by, for instance, Bils and Klenow, 2000 . 
Acknowledging these developments and the crucial role that higher education plays in this process, this thesis focuses on the acquisition of competencies in higher education and their role and pay-off during the transition from higher education to the labour market.

\subsection{Higher education graduates and theîr competencies}

Higher education is given the key task to prepare the highly talented among the young to fulfil highly qualified roles in the labour market. Successful labour market performance of graduates is generally associated with the acquisition of the correct competencies. Education as an individual inwestment is a viewpoint dating back to the $17^{\text {th }}$ century and the writings of Sir William Petty (1662), and includes later work by Adam Smith (1776). The idea was formalized and brought into mainstream economics by Schultz (1961), Becker (1964) and Mincer $(1970,1974)$.

To grasp these benefits, it is of crucial importance for individuals to understand and recognize the rapidly changing opportunities and to acquire and maintain the related competencies. Given the breadth of the 'knowledge economy' concept, it is not surprising to find different conceptions of what a knowledge economy is and ambiguity of what is required from higher education graduates when they enter the labour market. Undoubtedly, high-quality education in a particular discipline can still prepare graduates for a high level of performance on entering the labour market, where advanced and often highly specialized knowledge is required. Law graduates are expected to know the law, graduates in architecture are expected to know how to build a house and economics graduates are expected to understand the reasons behind inflation. However, higher education needs to realise that firms expect more than just a graduate with narrow discipline-specific competencies. Sternberg (2003) proposes that the future needs a "generation of experts, whose expertise will extend well beyond technical knowledge" and hence, experts that possess competencies with which they can use the rechnical knowledge. In other words, the labour market expects to see responsible graduates who are able to address and judge unforesen circumstances, who possess analytical knowledge, address problens in a creative manner and have a broad wiew on a variety of topics. Graduates should be able to expand and adapt the potentialities of an existing job, shaping it proactively. Moreover, in a world in which discipline-specific knowledge is rendered obsolete at an increasing rate by the pace of technological progress (Teichler, 1999 ), graduation from higher education is no longer the frnal stage of schooling but should prepare for lifelong learning.

The tension between the demand for discipline-specific specialists, with their high direct productivity, and the 'active agents', with their (long-term) Aexibility is not new to economic literature. In fact, it relates to the question of specialist vs. generalist that dates back to preindustrialization literature. Whereas Adam Smith (1776), addressing the diwision of labour, stated:

3. Although nomenclature does not matter a grear deal if everybody agrees on what is mant, Borghans, Green and Mayhew (2003) correctly argue that it is of central concern for discussions on comperencies in the lighe of the significunt changes in the meaning of the tern and its different uses in a variaty of research felds. We will return to this point in Chaprer 2, where we will discuss thow human capital should be defined and measured if we regard certificates/qualifications no longer as ideal measures of the capabilities acquired in educarion. 
The greatest improwentent in the productive pawers of labow, and the greater part of the skill, dexterity and judgment with which in is any whe directed, or apthed seew to bawe been the effect of the division of tabour os (Smith. 1776$)$

Say ( 1802$)$ warned that such specialization often goes hand in hand with inflexibility:

"A man, whose whole life is devoted to the execution of a single opention, will wost assinedly acquire the faculty of execuring it better and quicker ban others but be will, at we sawne time. be rendered less fu for every other occupation, corporeal or intellectual... (Say, 1802)

Higher education faces the dilemma of how much emphasis to place on discipline-specific (vocational) competencies and how much emphasis on generic competencies. The former refers to cognitive prerequisites which an individual requires in order to perform properly in a given substantive area (Weinert, 20or), and hence to theorerical and mechodological knowledge of a particular discipline. The latter term ("generic) is ased to indicate the subject independence of such competencies. Generic competencies are often called 'transversal'; indicating that they are not context-bound and can be applied to a range of areas and settings. Do we prepare graduates for a particular type of occupation, providing them with a comparative advantage in this occupation or do we prepare them to be active, Alexible, well-rounded and responsible academic agents? Like a pendulum, opinions have shifted between adwancing one or the other of the wo extremes. Recently, swings have been more strongly away from the narrow training of discipline-specific comperencies and have placed greater emphasis on generic competencies (see e.g. Bowden and Marton, 1998, Teichler, r999)"

\subsection{The stage of transition from higher education to work}

We will restrict this sudy to the transition from higher education to work. In this sense, we focus on a rather short working life period, namely the first three to fou: years. Although the inevitable result of this restriction is that certain relevant aspects are neglected, such as the obsolescence of competencies, the impact of dropping out of the labour market for a certin

4. According to Rey 4996 , the term "transwersal' does not tefer to elements common to different subject bascd comperencies, bet stricty to the addirional, subject-independent content of these competencics useable in other fields.

5. Athough the ewolvement of the knowledge economy may have restrengthened the discussion on the destgri of

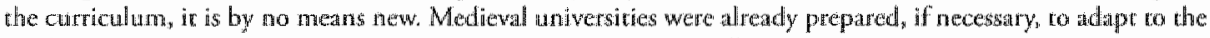
professional and business needs of the community, but without allowing their basic acadenic function to be compromized. Furthermore, rhe Arstorelian distinction berween intellectual ard mathal skils led to antuation in which rechnology, applied science and manual training - such as surgeons, arditects, farmers or bookkexpers - were excluded from the universiry curriculum for long time. Afrer teaching of rechnology had takern place at

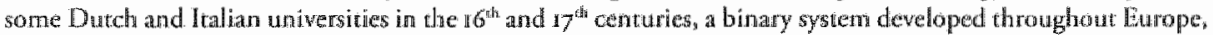
in which rechnology and raining for manual sklils were confined to spectallized school ar a non-university level (e.g. the school for surgery was established in Paris in 1698 and in Berlin in 724 ) In the $18^{\text {th }}$ century however, the infuence of the scientific revolurion and the revaluation of manual skills ty the Ealightmenc grew, together with the ambirions of engineers, surgeons and administrators, initiating proces of institutional upgrading that sooner or later resulted in the incorporation of engineering in the unversicy system. 
period of time, and factors infuencing the long-term employability of graduates, we believe that a concentration on the transition from higher education to the labour market in itself makes it possible to address particular aspects related to whe outcome of thigher education programmes more coherendy, Several fearures are crucial in this respect.

First, the period after graduation is the time when the link between competencies acquired in higher education and competencies required/used in the workplace is strongest. Due to a lack of extended labour marker experience employers rely heavily on information retrieved from the employee's educational career. With the accumulation of labour market experience, the weight attached to the initial educanonal career will fade out. By focusing on the transition stage, it is possible to examine coherently what education provides and what its role is in the labour market. It also avoids the danger of too much noise creeping in from the graduate's working experience.

Second; at that stage, the match between education and occupation is crucial. Both graduates and employers face crucial decisions. Graduates have to assess the occupational domain in which their competencies and personal characteristics are best urilized and must consider the additional efforts to be undertaken to achieve the required performance. Employers are forced to assess the extent to which warious personal and educational backgrounds of graduates match with the requirements of the vacancy and what adjustment costs in form of additional training will be incurred. Mismatches between what education taught and what the occupation requires might trigger costly adjustments in form of additional training to compensate for skill deficiencies (see e.g. Barron, Black and Lowenstein, 1989; van Smoorenburg and van der Velden, 2000; Wolbers, 2003), or provide incentives to change jobs (see e.g. Allen and van der Velden, 2001; Wollbers, 2003) as job mismatches form an important cause of job dissatisfaction (see e.g. Tsang and Levin, 1985 ; Burris, 1983 ). The match itself consists of two dimensions: a vertical one and a horizontal one. The former is related to the educational level attained at graduation and the educational level required by the occupation. The latrer relates generally to the field of study graduated from and the field of study required. Although the march of the education level is important, this study focuses in particular on the horizontal match. Considering the vertical march, common labour market theories assume that higher educated workers are preferted, either due to their higher direct productivity or because they are more easily trainable, if ic were not for their higher wage requests or their greater likelihood to resign from less challenging occupations (van de Werthorst, 2002). However, the same theories also lead to the expectation that the value of a field of study strongly depends on the congruence in competencies between the field of study and the occupation. Hence, whereas a higher level of education generates more productive power, the productive power of graduates from a particular field of study depends on the congruence between the field of study and the occupation.

Third, choices made at the beginning of a career may have long-term effects for the employee due to hysteresis. Suboptimal matches between occupation and graduates may not allow graduates to keep abreast of developments with respect to the core competencies in which they invested. Moreover to the extent that the principal of 'use it or loose it" applies for the graduares, we may expect such graduares to be more likely to be confronted with competence obsolescence. This will hold in particular for graduates from fields of study with a high turnover rate of discipline-specific competencies due to rapid technological progress. What is 
common to these situations, is that they may create negative signals to potential employers, making a move towards a matching occupation more difficult. Evidence for this point can be found in, for example, VSNU (2003): The labour market position of Dutch higher educa tion graduates seems to be strongly related to their situation immediately after graduation. In particular, initial unemployment, the level of the first occupation, and the math between the field of education graduated from and the field of education preferred by the first employer, are found to be determining factors for later career situations.

Lastly, making choices, as indicated above, would nor be very difficult if the labour market for graduates worked as a textbook example of a perfect competitive natket. But reality is different. Graduates and employers search in a labour market where information is costly, asymmerrically distributed and sometimes scarcely anallable. The heterogeneity and opacity on both sides make it difficult to achieve the perfect match between the characteristics of the graduates and the requirements of the job they need to perform. To avoid costly mismatches between desired and nealized performance, we can expect a growing importance of group membership of the graduates as a source of conveying information with respect to individual graduates.

Concluding, it can be stated that the restriction to the transition period from higher education to the labour market makes it possible to analyze a crucial period in the labour market careers of graduates, and to investigate more thoroughly the role and value of particular competencies acquired in higher education programmes.

\subsection{The place of this thesis in the literature, its ailm, and some subquestions}

This is unquestionably not the first study on the quality dimension of schooling and the understanding of the impact of quality differences in human capital (for a detailed overview of previous research, see Hanushek, 2002 and 2004 ). So far, two streams of research literature in particular have appeared.

The first concerns research that concentrated on identifying cognitive comperencies as a central dimension of educational quality. Generally, this research addresses the question whether a student's performance in standardized tests, as a proxy for cognirive competencies, is correlated with the individual's performance later on in the labour market. Examples of studies indicating substantial income advantages for graduates sconing higher on standard. "ized tests are Bishop (1989, 1991), O'Neill (1990). Grogger and Eide (1993), Blackburn and Neumark (1993, 1995), Murnane, Willet and Levy (1995), Neal and Johnson (1996), Murnane, Willet, Duhaldeborde and Tyler (2000), Altonji and Pierret (2001), Murnane, Willet, Braatz and Duhaldeborde (2001)6.

The second concerns research that analyzes the impact of the field of study on the labour market success of higher education graduates. This rype of research argues that the field of study plays a key role in mediating the link between participation in higher education and the educational ourcome (Muller, Steinmann and Ell, 1998), or that the field of study becomes

6. These studies analyze the impact of individual cognitive competencies based on standard Mincerian earnings functions. Most of them are based on surveys among American High School graduates. A good overview is given in Hanushek (2004). 
increasingly important as a selection criterion as the overall participarion in tertiary education grows (Kim and $\mathrm{Kim}_{2}$ 2003). Authors generally conclude that graduates from more professionally oriented disciplines (e.g. enginecring or business) tend to have higher than average wages; while those in disciplines such as arts and humanities tend to have lower than average earnings (see e.g. Rumberger and Thomas, 1993; Berger, 1988a, 1988b; James, Alsalam, Conaty and To, 1989, Finni and Frenerte, 2003).

Although both streamis of research generally do not deny the various components of competencies acquired in higher education, much of early and ongoing empirical work concentrates on unidimensional indicators of human capital, treating education largely as a black box. Research on the market value of particular types of competencies, allowing for differentiation in the returns to education, started only recently. Noteworthy studies include Green (1998), Heijke, Koeslag, and van der Velden (1998), Allen and van der Velden (2001), Green, Ashton and Felstead (2001), Mclntosh and Vignoles (200r), Shaughnessy, Levine and Cappelli (2001); Stasz (2001), ter Weel (2002), Lazaear (2003) and Heijke, Ramaekers and Ris (2005). In this thesis, we will follow this research and intend to address directly the heterogeneity of graduates and education programmes according to the competencies acquired by higher education students. More precisely, we will discuss the role given to discipline-specific and generic competencies in the transition from higher educarion to work. In doing so, we intend to contribute to the debate on what type of competencies should be emphasized in educational curricula. For that reason, the study addresses in particular the following subquestions:

I. How to define and measure the human capital acquired by higher education graduates?

2. To what extent are the level and the mix of competencies acquired in higher education determined by a student's time allocation and the learning environment?

3. What are the specific roles with respect to allocation, on-the-job training and productivity of discipline-specific competencies and generic competencies during the transition stage from higher education to the labour market?

4. To what extent can differences in the design of higher educarion programmes (e.g. specific versus generic competence orientation) explain the allocation and performance of graduates?

We believe that discussing these kinds of questions is of critical importance and answers to them will facilitate an efficient transformation of education, and higher education in particular, into the $2 \mathrm{r}^{\text {st }}$ century. Moreover, within the European context considered in this thesis, these questions may gain importance in the light of the Bologna Declaration that marks a turning point in the history of European higher education. Although not directly setting out a path towards a high degree of standardization or harmonization of European higher education, the aim of the Bologna Declaration to create an overall convergence by ironing out some of the least compatible characteristics of national higher education institutions will have a major impact. It will undoubredly succeed in achieving further convergence. However, it remains to be seen if adopting a similar Bachelor/Master system will have an impact on the differences in the underlying process of competency acquisition or whether it is merely a matter of using the same wrapping paper. In other words, if the results of the analyses in 
this study contribute to the discussion on a new struccute of higher education institutions, it is restricted to the question how to reshape the content of the ind vidual programmes concerned and not the Bachelor/Master structure as such.

\subsection{A guide through the thesis}

This section concludes the incroduction by providing a guide through this thesis. The sudy consists of 7 chapters. Chapters 2 and 3 are partially preparatory chapters for the empiricil studies and partially have a goal of their own. Chapters 4 until 6 present the empinical studies. Finally, Chapter 7 concludes the thesis. Figure I.I gives an overview over the setup of the study.

The left-hand side focuses on the competence transformation process in higher education. The process is assumed to be infuenced in particular by individual characteristics of the students, the students' pre-higher education schooling career, the students choice for a particular freld of study and type of higher education, and the students' cime allocation while studying. The latter factors may to some extent also be determined by particular student characteristics. Programme characteristics, such as the learning environment within which the study takes place, also infuence the transformation process.

The outcome of higher education is measured by the level of discipline-specific and generic competencies that graduates acquire during their studies. The competence outcome, both on an individual level and on an aggregated study programme level, together with other programme characteristics, such as the standardization of the programme with respect to the competencies taught, are expected to determine the labour market success of graduates. To analyze the labour market outcome and success, and thereby explicitly the role of the competencies in it, we have nor only measured the monetary returns bur also investigated the allocation over different occupational domains with different comparative advantages and the decision to follow further on-the-job training aimed at reducing any type of comperence lacks experienced during the transition stage.

The general content and main findings/insights of the chapters are as follows:

Chapter 2: Human Capital - Qualifications - Competencies: A conceptual approach. The aim of this chapter is rwofold. First, it provides the reader with a brief owerview of different theoretical approaches with respect to the impact of education on labour produccivity. We propose that particularly models based on the assignment theory provide useful insighes for this study.

However, we claim that the way in which education is measured in research is generally recognized as unsatisfactory. Following that, we will address subquestion (1) and introduce the competence concept, reveal its relevance in research on the transition from higher education to the labour market, and discuss different types of competencies. We will conclude the chapter by proposing a distinction between discipline-specific and academic (a particular type of generic) competencies, to be set at the centre for analyses on the transition from higher education to the labour market. The former type measures the cognivive prerequisites that enable a graduate to perform well in a given, bur mostly restricted, substantive area, whille the latrer type measures the abilities of a graduate to (re)learn, to adapt to changes and to deal with information. 
Figure 1.7

Setup of study

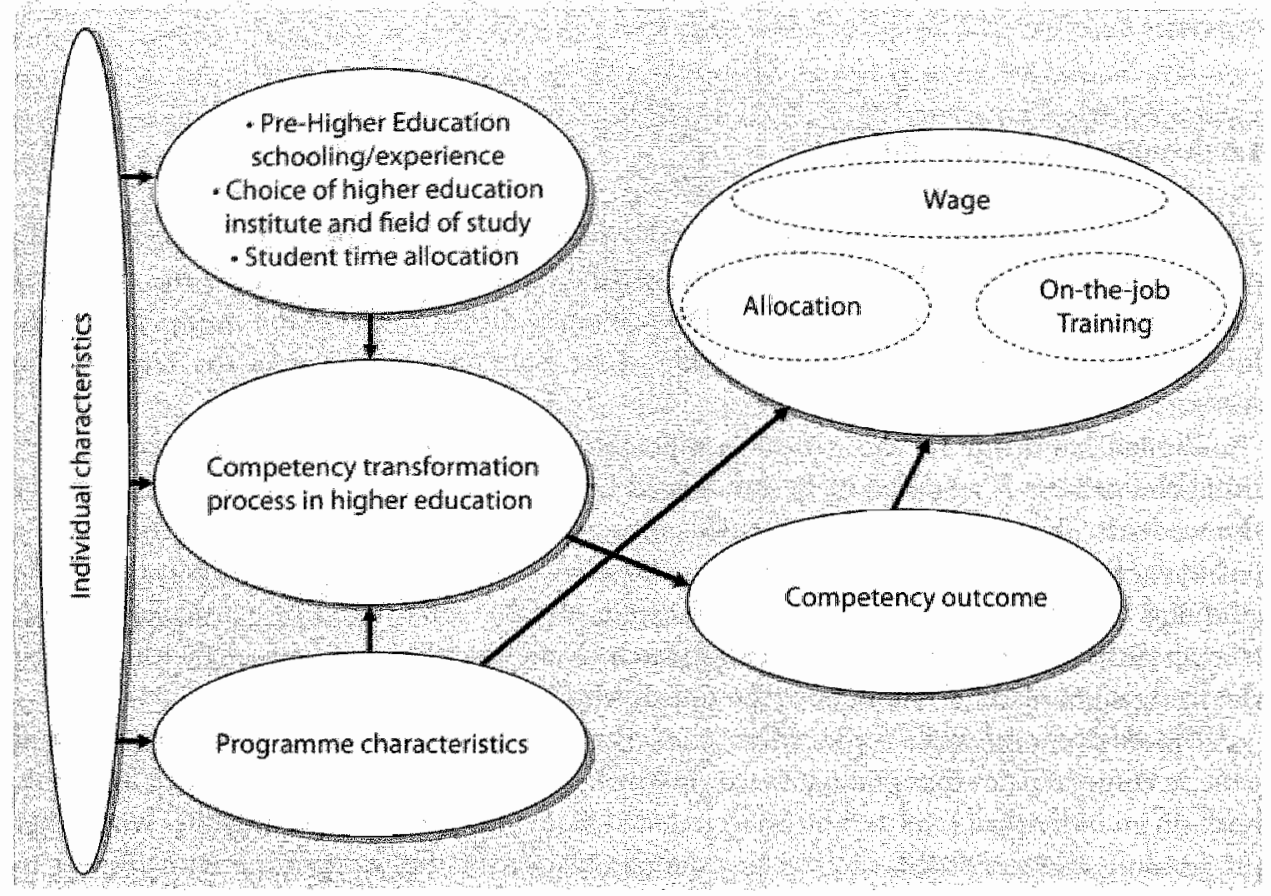

Chapter 3: CHEERS survey and measurement of academic and discipline-specific competencies. In this chapter, we will introduce the reader to the CHEERS data set (Careers after Higher Education: a European Research Study) used in the empirical studies of this thesis. The full English Questionnaire is included at the end of this thesis. Next, we will return to subquestion ( $\mathrm{r}$ ) and discuss a flexible way to measure the outpur of higher education in rerms of acquired academic and discipline-specific competencies. The measurement makes it possible to gain clear insight into the hererogeneity of graduates, given a particular study programme. Moreover, the measurement is flexible and is able to cope with changes in the competence mix taught in higher education and required in the labour market. Lastly, in addition to capturing the individual heterogeneity, the measurement provides an innovative way to characterize higher education programmes and higher education systems. More specifically, we will show that higher education systems in the Nerherlands, Germany and Austria, in line with their occupation-oriented labour market, are discipline-specifically oriented and that higher education systems in the United Kingdom, France, Finland and Spain are academically oriented, fitting well the expectations of an internal labour market. Tesring the measurement with respect to its validity shows that it is internally reliable and satisfactory with respect to its validity:

Chapter 4: Student time allocation, the leaming environment and the acquisition of competencies. In this chapter, we will address the question how academic and discipline- 
specific competencies are actually acquired in higher education in Europe (subquestion 2 ). In contrast to the vast majority of analyses addressing the link between financial resources and educational production outcomes, we will address in this chapter wo factors that form a central part of the core of the production process: the learning environment and student time allocation. With respect to the former characteristic, we will analyze in particullar the quescion to what extent new didactic methods, such as problem-based learning, are more effective in teaching competencies. With respect to the latter, we have analyzed the effects of such differences between as the numbers of hours spent in the classroom and hours spent on selfstudy, on the efficiency with which the two types of competencies are acquired. Key hindings of this study were that the learning environment is an important factor in determining both the level and the type of competencies that students acquire. Activating learning environments are clearly superior when it comes to teaching academic competencies. Moreover, they do not harm the effectiveness with which discipline-specific comperencies are acquired. For an optimal provision of borh types of competencies, however, an activating learning envinonment must be combined with a teacher transferring discipline-specific competencies to the students, when needed. With respect to the students" time allocation, this study shows chat discipline-specific competencies are mainly acquired inside the classroom, by self-study or by paid working experience which is related to the study. The latter two activities also enhance the acquisition of academic comperencies, whereas no impact was found from following formal education.

Chapter 5: Fitting to the job: the role of academic and discipline-specific competencies in adjustment and performance. Using the Netherlands as a case study, we investigated empirically the rolle and pay-off of discipline-specific and academic competencies during the transition period (subquestion 3). We will first deal with the literature that investigates the pay off of different human capital competencies acquired in education by introducing them directly in wage estimations. We will show that in this approach the rolle of competencies is difficult to reveal and, moreover, that it may bias the results towards discipline-specific competencies. Next, we will develop an empirical model in two steps, first analyzing sinultaneously the tole of competencies on the allocation and on-the-job training, and second, raking the first step into account, analyzing the monetary return to competencies. This makes it possible to reveal the different roles of academic and discipline-specific competencies and their distinctive values. The results indicate, first, thar the extent to which Dutch graduates are matched to an occupation in congruence with their field of study is influenced to a great extent by the level of discipline-specific competencies that they possess. As these occupations are better paid, being selected for them is important for the graduates from a monetary point of view. Second, we will show that academic competencies acquired in higher education play a major role in the question who is selected for further training and who is not. In othet words, training and the level of academic comperencies are established as complements. As a matter of fact, the results indicate that academic competencies are used to adjust the discipline-specific competencies of graduates to the requirements of the labour market.

Chapter 6: The effects of higher education programme characteristics on the allocation and performance of graduates. This chapter addresses the question to what extent characteristics of higher educarion programmes provide information and/or signals to potential employers with respect to the knowledge acquired in higher education (subquestion 4). 
Considering that the transition period is filled with asymmetric and private information and hence uncertainty, one can expect employers to rely on such group characteristics. For that reason, five characteristics of higher education programmes are discerned, which according to literature can be regarded as crucial: the competence orientation of a programme, the standardization of programmes with respect to the competencies distinguished, the intermational character of the programuie, the level of co-operation between working and studying which a programme provides, and the possibility that a programme provides exclusive access to particular occupations. Key findings of this study are that both the competence orientation of the programme and the standardization of the programme with respect to the two types of competencies are crucial determinants of the graduares' labour market outcomes. Whereas the competence orientation has a great influence on the allocation outcome of graduates, it was found that standardization of the competence outcome provides employers with better information on the true productive power of graduares, reducing selection and adjustment costs and allowing for a higher remuneration of the workers.

Chapter 7: Concluding remarks. This chapter concludes the thesis. Whe will return to the objectives that we tried to achieve, provide an overview over the main insights from this thesis, indicate their policy implications and discuss fruirful lines for future research. 


\section{Chapter 2 \\ Human capital - qualifications - competencies: A conceptual approach}

"How much trouble is spent in awarding people different clases of degrees in wniversities and polytechnics and yet for wost of them absolutely notbing depends on in in later life. As a society we take it wery seriously. But that is not what education is about, the difference betueen a Two One and a Two Two. Education is about we experience that went into that degree and the skills that were developed s.

C.J.E. Ball, MA, Warden, Keblle College, Oxford, 1987 Cited in Leckey and McGuigan, 1997 


\subsection{Introduction}

The last yo years have seen a clear change in the way in which education is considered. Whereas prior to the human capital revolution, which started in the 1960 s, education was generally considered a consumption good (see e.g. Alstadsaeter, 2003), it has now gained the status of an investment good with above-average expected returns. Even though research on the impact of education on labour market success has accumulated considerably over the past decades, economic liferature is still not unanimous with respect to the precise relevance of the school-to-work relationship and the processes involved in it.

In this chapter, we propose the idea that for further research on the transition from school-to-work it is necessary to drop the assumption that qualifications or graduation in a particular field of study imply a homogeneous standard of competencies across graduates. Accordingly, we daim that it is crucial to address directly the different types of competencies which graduates possess when leaving higher education. These competencies, forming a central part of the graduates" human capital, are seen as more accurate and reliable indicarors of individual labour market performance.

To do so, this chapter has the following structure. First, Section 2.2 briefly addresses the question of the impact of education on labour productivity in economic theories. More in particular, it discusses the central assumptions and implications of the human capital theory, the job competition model, and basic aspects of the assignment theory. Then, Sections 2.3 and 2.4 deal with the question how to define and measure the human capiral acquired by higher education graduates in terms of assets that are traded in the labour market. First (Section 2.3), we will introduce the competence concept, discuss the problems involved in using it and provide a working definition in line with the main objectives of this thesis. Second (Section 2.4), we will address the question what type of competencies can be regarded as core elements of higher education programmes. For this reason, we will discuss the literature on disciplinespecific and generic comperencies. Finally, Section 2.5 concludes the chapter.

\subsection{Impact of education on labour productivity: different approaches}

Schultz (196r) proposed that we should treat education as an invesment in man and to treat its results as a form of capial: "Since education becomes part of the person receiving it, I ball refer to it as bumatn apital". Accordingly, indiwiduals are assumed to choose the optimal amount of human capital improvement by investing into, for example, education up to the point where the marginal costs of further additions equalize the discounted value of the future marginal income to which it gives rise. Hence, the human capital theory assumes that education provides the student with capabilities of productive value in the labour market. To estimate the value of education, Mincer's model of earnings (Mincer, 1974) has played a key role in empirical economics (Willis, 1986, Heckman, Lochner and Todd, 2003). It specifies the natural logarithm of the wage rare as:

1. Such as ruition fees, costs of books as well as the indirect costs of forgone incone. 


$$
\ln [w(s, x)]=a+p s+\beta_{0} x+\beta_{1} x^{2}+\varepsilon
$$

where $\ln [w(s, x)]$ is the natural logarithm of the wage paid to a worker with educarion level $s$ and working experience $x, p$ is the rate of return to years of schooling assumed to be constant among different levels of schooling and $\varepsilon$ is an iid. error term. Mincer's framework implies a linear increase in wage rates due to prolonged education. However, the experience-earnings profile is assumed to be concave, reflecting that age - due to the decreasing time left to capture the rerurn - has a riegative effect on the probability of on-the-job training participation. This approach has been used widely as a basis for empirical estimations on the returns to schooling or the impact of experience on the wage gap between male and fenale workers ${ }^{2}$. In recent years, the original approach has been criticized for not allowing the incorporation of qualitative differences of one year of schooling according to, for example, the type of education followed (e.g. Wössmann, 2002).

The strong supply side orientation in determining labour productivity has also caused serious doubts. Implicitly, the wage competition model assumes that individuals holding a particular level of human capital, irrespective of the occuparion to which it is matched, provide a certain level of productivity (Green and McIntosh, 2002). Several economists (including Duncan and Hoffman, 1981, Rumberger, 1987, and Hartog and Oosterbeek, 1988) questioned whether firms were actually able to fully adapt their production technology to the supply of human capital. The substantial increase in the supply of higher education graduates in the last decades (see e.g. EC, 2002), institutional rigidities (see Green, McIntosh and Vignoles, 1999) or costly and asymmetrically distributed information can be named as factors scrutinizing this assumption. In all of these cases, productivity - and hence earnings - crucially depends on occupational characteristics (di Pietro and Urwin, 2002).

In this respect, a major competitor of the human capital theory is the job competition model (Thurow, 1975). In its most extreme case; productivity is explained entirely by occupational characteristics and not by individual characteristics. Thurow argues that, alchough school-leavers enter the labour market with a wariety of background characteristics, such as different levels of educational atrainment, these background characteristics do not constitute a group of skills with an immediate productive value. More likely, they determine the costs of the on-the-job training needed to acquire what is required in the occupation. Prolonged education results in more human capieal, implying better trainability, and allows the individual to advance in the labour queue. It has to be noted that "Thurow himself states that in reality there is a continum between the importance of occupational and individual characteristics and that the assumption to neglect supply side characteristics in the determination of productivity, is made to isolate the role of job comperition from supply side factors.

Both the Mincerian wage model and the job competition model in their original versions seem too restricted to one side of the market. Approaches that allow explicitly for an interaction between supply and demand side characteristics are generally known as assignment models'. Assignment models assume that the supply side consists of heterogeneous indi-

2. For a more elaborate discussion of Mincer's approach and empirical restults based on ic sea Hedoman, Lochner and Todd, 2003 .

3. For an overview of different assigninein models and the distinctive features with repect to matching models, as for instance proposed by Morrensen (1986), or search theorice (e.g. Jowanowic, 1970), see Duploy (2004). 
viduals wh knowledge and skills acquired in education or training. The demand side is given by occupations differing according ro the knowledge and skills they require. It is argued that education provides the student with productive capabilities but that it is the inceraction berween these capabilities and the ones required in the occupation thar determines productivity. The betrer the match, the higher productivity. Along this line of argumentation, diversification in the labour marke, given by the division of labour in society, and diversification in education come to play central roles. Considering higher education, diversification takes place along a vertical and a horizontal dimension. Vertical diversification relates to, often country-specific, differentiation in levels of higher education. Horizontal diversificaton relates in particular to different disciplines or fields of study offered in higher education. Allocation and productivity outcomes hinge therefore on vertical and horizontal sorting and henoe on the existence of comparative adwantages. Simple stated. "comparative advantage occurs if the productivity ratios between two different individuals are not constant, but depend on the activities (or jobs) where the comparion is made" (Hartog, 1992 p.107).

If it were not for their higher wage requests or their increased likelihood of resigning from less challenging occupations, employers, independently of the educational level best fitting to the vacancy; prefer highly educated workers. In case of the wage competition model this is because of their higher level of productive capabilities, and in case of the job competirion model because of their better trainability. Whereas different levels of higher educarion are ranked easily by employers, different fields of study are difficult to rank, as their ranking depends on the congruence between the type of knowledge and skills acquired in education and the type of knowledge and skills required in the occupation (see also van de Werfhorst, 2002). In this respect, different authors argue that the field of study deserves more atrention when it comes to analyzing the labour market success of higher education graduates. Müller, Steirimann and Ell (1998) argue that the field of study plays a key role in the link between participation in higher education and educational outcomes. Kim and Kim (2003) believed that the field of study would get increasingly importatit as a selection criterion for the future prospects of graduates, as overall participation in tertiary education grows. What is perhaps the most interesting point for our objectives is the fact that the field of study may provide information on the value of different types of human capital which the various disciplines represent. Studies on the American NLS72 and High School and Beyond darabases show firstly that there are statistically signifcanc and quantitatively large differences in earnings. levels by discipline, and secondly that particularly graduates from the more professionally oriented disciplines (such as engineering and business) tend to have higher than average wages, while dhose in disciplines such as arts and humanities tend to have lower than average earnings (see e.g. Rumberger and Thomas, 1993; Berger, $1988 \mathrm{a}, 1988 \mathrm{~b}$ or James, Alsalam, Conaty and To, 1989). Similar findings were presented by Finnie and Frenette (2003) for recenty graduated Canadian students. However, the study of Finnie and Frenette also provides evidence of a large remaining variation in earnings between graduates of a particular field of study. Even in the case of engineering and computer science graduates, presumably representing a relatively homogeneous group of graduates that faces similarly well-defined job

4. Vertical sortiog telates to the mach between the lewel of education graduated from and the level of education requited in the occupation. Horizontal sorting relates to the manch beween the rpe of competencies acquired in higher education and the type of competencies required in the occupation. 
apportunities in a well-structured job marker, the graduates actual earnings deviare from the regression-predicted values on average by $18 \%$. Hence, relying Just on the title of a qualification, neglects the fact that, like the name of a particular Indian curry, it only reveals its real variery of ingredients when consumed. Unless the qualificarion is focused on a single task (such as switching on the light when the sun goes down), it rather reflects a vector of a graduate's heterogeneous potential capacities to perform tasks corresponding ro activities along an array of jobs (Cedefop, 200I). As not all of these ingredients (capabilities) are easily axpressed, reading just the nenu denies us access to the whole stream of knowledge. In other words, neither the title of an educational qualification nor the title of the occupation held by the worker is an ideal measure of the capabilities actually acquired or used (see Ashton and Green (1996) for a detailed critique). Moreover, according to the Report of the Expert Panel on Skills (2000), the use of these rather static labels cannot do justice to the constantly evolving and expanding mix of technical, management and essential skills and attributes sought by employers and provided by education. In recent years, in particular Green and Mcintosh (2002), proposing a heterogeneous skills approach", and Lazaear (2003), postulating a skills weight approach, tried to tackle this problem. Common to both approaches is their explicit rejection of the assumption that qualifications or occupation titles represent a homogeneous standard of skills and abilities acquired/required across individuals/tasks ${ }^{6}$.

The objective of this study is to enhance the knowledge on this point. Rather than proposing a new and betrer economic theory on the impact of education on labour market success in general and productivity in particular, we propose a more detalled way of measuring education. In doing so, we intend first to allow explicitly for heterogeneiry berween graduates with the same qualification and second; to differentiate between the return to education according to this heterogeneity. To do so, we will introduce in the next section the competence concept and address particular types of competencies assumed to play a central rolle in higher education programmes.

\subsection{The competence concept}

Although nomenclature may not matter very much when everybody agrees on what is meant; we will follow Borghans, Green and Mayhew (2001) and argue that the question 'what is in a word' is pivotal to a discussion on competencies. This holds in particularly because the concept has undergone significant changes in meaning and there has been a tendency to widen the use of the term including personal attributes, which once would not have been thought in this manner (Payne, 2000). These changes in definition and meaning are partially the result of the fact that the term is being used as a relevant concept by a number of research fields, each with its own disciplinary roots, and partially the result of the usage of the concept inside a research field, as either interchangeable with terms stuch as 'skill' or as a separate concept.

5. The heterogeneous skills appiroach postulared by Green and Mclntosh (zoo2) is based on the argumentation of Allen and Van der Velden, 200 .

6. Similarly, Plamas, Giret, Sala and Vincences (2000) argued that it is of crucial impotance to fecognize and certify the assers behind a cercificate chat are actually exchanged in the labour market. 
Weinert (20on), contributing to the OECD project "Definition and Selection of Competencies' (short: $\mathrm{DeSeC}$ ), provides a comprehensive state of the art with respect to the comperence concept in the different research areas. He argues that ewen if one restricts the focus to the use of the word competence' in developmental sciences, psychology, linguistics, sociology, political seience and economics, this would still yield a wide variety of definitions. Nonetheless, the term 'competence' is used in all of these disciplines to indicate a specialized system of individual and/or collecrive abilities, proficiencies or skills necessary to reach a particular goal. Although Weinert concludes that a theoretically based definition of the concept 'competence' is a bridge too far at the momient, he provides deat indicarors as to what such a definition should take into account:

*. The term 'comperence' should refer to necessary prerequisites for successfull handling of complex tasks. Hence, it has to be a demand-oriented or functional approach (see also Rychen and Sallganik, 2003) and the primary focus must be on the results that the individual achieves given the demand.

》. The term must be used if successful handling requires cognitive factors as well as social components. Moreover, in most cases, motivational and ethical aspects form a further component of the action.

* The term implies that the task to be handled is above a critical level of complexity. Simple and to a large extent automated conditions must be classified as skills.

\$) Learning processes are necessary condition to acquire conditions required to handle the task successfully.

*. The term 'key competencies' has to be sharply distinguished from the term 'metacompetencies.' The former should be reserved for competencies that are useful in the handling of a diwersity of tasks, the latter for the declarative or procedural knowledge over one's own competencies.

The distinction between the terms 'skill' and "competence" was also adopted by Rychen and Salganik (2003). Although the latter authors admit that the term 'skill' is occasionally used in a way similar or even identical to the notion of 'competence', in most cases it carries at meaning that is, strictly speaking, different from the competence connotation. 'Skill' labels an ability to perform complex motor and/or cognitive acts with ease, precision, and adaptability to changing conditions. The term 'competence' is used to designate a complex action system encompassing cognitive skills, attitudes and other non-cognitive components. Along this holistic perspective, the term competence assumes that a range of mental prerequisites must be mobilized (Rychen and Salganik, 2003). Hence, the term includes more than just the skill of knowing how to typewrite but also the ability to bring the written words together in poetry".

Contrary to this, economic literature is generally more pragmatic, using the rwo terms 'skill" and 'competence' as synonyms. Levy and Murnane (2001), contributing from the

7. Similarly, Rainbird (1994) and Bijomavold and Tissot (2000) distinguish between 'skill' and 'competence'. In their view, the former is closely related to the performance of a specific ask whereas the latter is the prowen and indiwdual capacity to use know-how, skills, qualifications or knowledge in order to meet both farniliar and evolving situations. 
economic science perspective to the DeSECo project, therefore embraced a broad definition of skills, including not only cognitive skills but also non-cognitive skills such as perseverance. Similarly, Mertens (1999) argued that competencies and skills are interchangeable terms, relating both to certain aspects of knowledge and capacity, represented by a qualification needed to achieve results in a given situation. Considering the general use of the terms "skill" and "competence" in the English literature, this pragnatic approach is not surprising. Consulting the Collins English Language Dictionary (199o) reweals that 'skill' is the knowledge and abilicy that enable you to do something such as a job, game or sport very well, whereas "competence" is the ability to do something well or effecrively.

Despite the pragmatic approach taken in most of the economic literature, this thesis follow the approach of Weinert (2001) and Rychen and Salganik (2003) and distinguishes the term competency from the term skill. More specifically, the term 'comperency' is reserved for a group of skills, referring to a single underlying dimension and forming the condition to fulfil complex and varying tasks inside and outside the working sphere. In this sense, the ability to heat up the oven, the ability to cut the meat, and the ability to name different herbs are regarded as skills, whereas their combined knowledge is what makes a cook competent.

\subsection{Competence outcomes of higher education}

What does it mean to talk about comperencies in the light of a knowledge-intensive economy? And more precisely, what types of competencies are crucial for higher education students to acquire? Given that the term 'knowledge economy' is rather a widely used metaphor than a clear concept, it is not surprising to find different conceptions of what the knowledge requirements are for school-leavers in general and for higher education graduates in particular Lundvall and Johnson ( 1994 ), for example, distinguish four typer of knowledge that they regard as of key importance in a knowledge-based economy: know-what, know-why, knowhow and know-who. Know-what refers to factual knowledge that is easily stored and transferred. Know-why refers to scientific understanding and the impact of science on mankind. Know-how is the capability of performing certain tasks, while know-who tefers to knowing the people who possess the other three knows. Implicit in this classification is the often recurring distinction between "codified" and 'tacit' knowledge. The former can be expressed in language or symbols and is easily stored. The latter is linked directly to its bearer and is as such not readily transferable. It is the stock of knowledge that enables the person to select, interpret and dewelop the codified knowledge (Eurydice, 200za).

In terms of educational outcomes, codified knowledge very often reflects the disciplinespecific competencies of the study field graduated from, while tacit knowledge may also refer to generic competencies that are not content-bound. As the name suggest, the term 'discipline-specific competencies" refers to cognitive prerequisites that an individual requires in order to perform properly in a given substantive area (Weinert, 2001). The term generic is used as a label covering a diversity of concepts, of which some of the better-known are intelligence, information-processing models, metacompetencies and key competencies (Allen,

8. Throughout this thesis, the cerm 'discupline-specific' will be used as a symonym of "vocacional' 
Ramaekers and Van der Velden, forthcoming). In recent years, higher education faces to an ever larger degtee an increased demand for such generic competencies. Generic competencies provide graduates with abilities that are not only useful in addressing problems in a creative manner but can also be used to expand and adapt the potentialities of an existing job.

\subsubsection{Discipline-specific competencies}

If asked, students who enter higher education programmes prefer to indicate that their objective is to become an 'economist", 'lawyer' or 'engineer', than an 'academic' in general. This is not surprising; because higher education studies have been and generally continue to be organized around a particular scientific field or in some cases around a particular profession. Hence, reaching discipline-specific competencies has always been a central objecrive of higher education. Students at a faculy of economics learn the 'consumption theory', are given instruction about different models of exchange rate determination, and discuss what money is. Undoubtedly, high quality in methods and theories of a particular discipline continue to be of importance for the graduare's high level of performance on entering the labour marker, where advanced and often highly specialized knowledge is required.

Research intended to reveal the value of such discipline-specific competencies in higher education is relatiwely scarce. As discussed above, most research on this topic relies on differences in labour market outcomes according to the field of study. In spite of the fact that the field of study determines the type of discipline-specific competencies that constitute the core set of the study, the name of a field of study is an inappropriate indicator for the level of discipline-specific competencies and neglects the fact that students not only acquire discipline-specific competencies during their study. Research that explicitly looked at disciplinespecific comperencies so far mostly focused on pre-higher education. Bishop (1992, 1995), analyzing US high school graduates, provided perhaps the strongest evidence on the value of discipline-specific competencies in the labour market. According to him, occupational competencies are essential in achieving productivity in most jobs. On the basis of a survey among members of the National Federation of Independent Business in the United States, asked to rank abilities according to their infuence on hiring decisions, he showed that $54 \%$ ranked 'occupational/job skills' first or second, while only $41 \%$ did so with 'ability to learn new occupational and job skills" "The greatest rival for occupational skills is work habits, which were ranked within the top two places in $67 \%$ of the cases and only in $3 \%$ of the cases at the botrom. Bishop's findings seem to indicate that the best jobs tend to go to graduates who took vocational courses and/or worked part-time during the school year and hence, to graduates who already possessed occupational/job skills. Moreover, keeping demographics and employe evaluations of other traits constant, Bishop found that the workers thought to have "much better" occupational skills started with a $12 \%$ higher wage, were judged to be $10.7 \%$ more productive after holding the job for about I year, and were making $14 \%$ extra ar that moment of time. He concluded that productivity derives directly from social abilities,

9. Interestingly, prior knowledge in occupationaljob skills was also ranked by 20 of of the respondents as least important. According to Bishop (ng95), this was related to the fact that these jobs generally tend to hire less skilled service and clerical workers, operatiwes and sales clerks. In those lower level jobs, work habits were ranked ar the top. followed by the ability to learn new occupational and job skills. 
such as good work habits and people skills, as well as from cognitive skills that are specific to the job and occupation, and not from reading, writing and mathematics skills or the ability to learn new occuparion and job skills. In doing so, he departed from the premise that academic comperencies are mere tools for developing specific comperencies, rather than a good substitute for occupation-specific competencies. According to Bishop, "While learning a new skill is easier when the worker has good basic skills, a foundation of job knowledge and occupationat skills is usually even more essential."

The results found by Bishop (1991, 1995) are supported by other recent research literature (e.g. Campbell and Laughlin, 1991; Altonji, 1995; Mane, 1998), which also tends to find stronger positive effects of vocational course work on labour market outcomes. Even though this research focused mainly on high school graduates entering the labour market, and not on graduates of higher education as the present study does, the results are of interest as they indicate the role generally given to discipline-specific competencies acquired in education. More in particular, discipline-specific competencies are seen as a mediating factor in hiring decisions, allowing the school-leavers to be directly productive in the labour market. Even though discipline-specific competencies acquired in higher education may be more abstract than the ones acquired at lower education levels, and hence less directed towards a particular occupation, we may expect them to continue these roles.

\subsubsection{Generic competencies}

Employers undoubredly expect law graduates to have a solid knowledge of the law and medicine graduates of the anatomy of the human body. However, higher education has in recent years been facing increasing expectations of firms to provide more than just narrowly discipline-specifically educated graduates. Sternberg (2003) proposes that the furure needs a "generation of experts, whose expertise will extend well beyond technical knowledge." This is confirmed by the British Skills Survey zoor, which focused on an update and improvement of the knowledge on competencies used at the British workplace. Although the changes since the Skills Survey 1997 that are reported are small, the consistency of their direction of change is strongly suggestive of a steady ongoing transformation in the British labour marker (see Felstead, Gallie and Green, 2002). Occupations increasingly demand competencies that are not by definition applicable only in a small area but that are useful in a broad range of occupations. Along this line, recent reviews of education propose generic competencies that are applicable in a variety of occupations and across different life contexts, as desirable and key outcomes of education.

\section{"If you do not know what the future situation will be, then teach students some fundamental. skills which they can apply to any situation "(Bowden and Marton, 1998)}

Is this strong emphasis on generic competencies new? The answer is clearly No. As a matter of fact, it is far from correct to state that the interest in non-discipline-specific competencies acquired in higher education is new. Duncan (1968) in the 196os, and hence long before the 'knowledge economy' term conquered the political area, mentioned that "werbal and quatntitative skills are especially significant outcomes of higher education, not only because they are 
wathable in their oun right but also becatse they facilitate leaming of all kinds in college and throughout life." Similarly, Bowen (1977) found that "the important substantive aims of higher colucation do lie in the realm of residues... [and that]... the residues also consist of the skills and perspectiwes that enable students in later life to lean or relearn detailed knowledge in a variety of fields as occusion demands and to fot this knowledge into a fromework of larger principles and conceptos".

Table 2.1

Terms used in varlous countries to describe generic competencles.

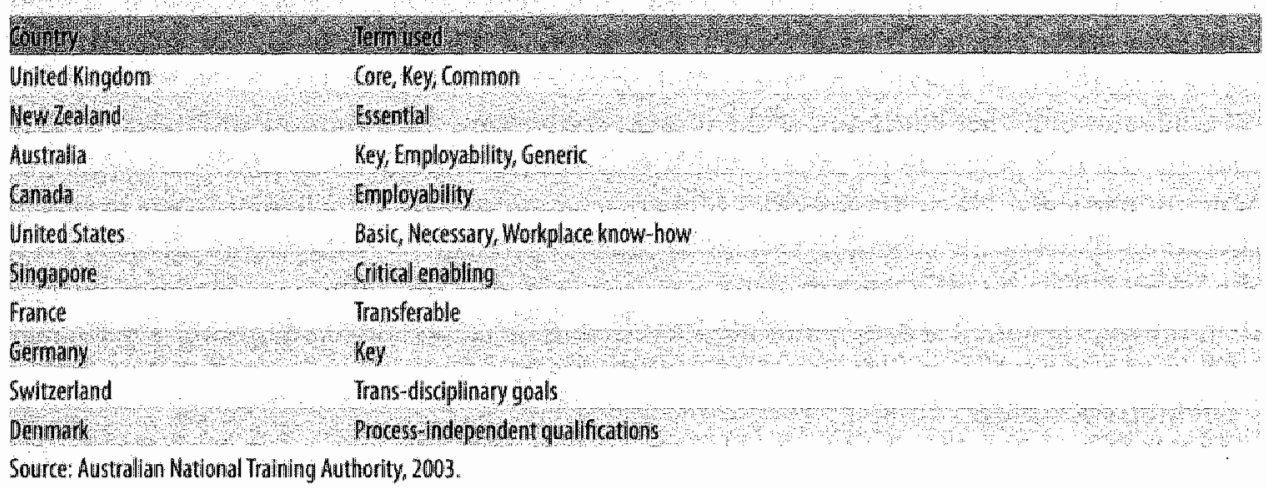

Reviewing the literature on generic competencies reveals that neither is there a definitive list of generic competencies, nor is the term 'generic used globally. Table 2.1 provides an overview of some of the terms used to indicare generic comperencies in warious countries ${ }^{k 3}$. Common to all these terms is that they are used to indicate the subject, discipline or occupation independence of the competencies considered. 'Generic competencies' are regarded as transversal. "The term 'transversal' does not refer to elements common to different subject-based competencies but strictly to the additional, subject-independent content of these competencies that is useable in other fields (Rey, 1996 ).

A variety of reports and surveys intending to establish a list of concrete generic competencies have been published in recent years. Generally, all addressed the question what are the relevant competencies to succeed in a modern economy?' Some of the better-known include the survey conducted by the Secretary's Commission on Achieving Necessary Skills

10. In line with theze ideas, Squires (1987) presented arguments for a broadening of higher education beyond specialized lknowledge. First, as graduates differ socially from non-graduares it terms of power, weald and opporturity, it would be desirable for them to be awate of these differences and to use them responsibly. Second, a special knowledge creates special intellectual limitations, it is wall uble to learn to see one's own expertise from wutside as well. "Third, knowledge about knowledge helps one become aware of the normis, vallues and assumpwons that underpin one's work and helps one relativize them and perceive altarnatives. Finally, learning can help graduates to reflect how theilr expertise is linked to their self-concept and identiry. Hence, recenr technological avolventent and, inherent to $\mathrm{it}_{\mathrm{r}}$ changes in the manging of organwations increased the emphasis rather than unvented it.

u. In some countries, genenic competencies are spectically emplowment-tellated, while in orher countries more emplhasis is placed on their social relewance. 
(SCANS) in the United States, the Employability Skills Profile of the Conference Board of Canada (CBOC), and the British Columbia Employability Skills survey". Table 2 2 provides an overview over six elements that are common to all aforementioned surveys.

We will briefy consider these six common elements to arrive at a more narrow definition of generic competencies that can be used for this study. Let us keep in mind that our focus is on higher education and hence on higher-order thinking skills rather than on lower-order ones, as discinguished in Bloom's taxonomy of educational objectives (Bloom, 1956). In this sense, we search for aspects that can be regarded as crucial elements of the generic competence package that higher education graduates take with them when they enter the labour market, by asking "are they specific to higher education?" and "can they be taught in higher education?"

\section{Table $\mathbf{2 . 2}$}

Common elements of various listings of generic competencies

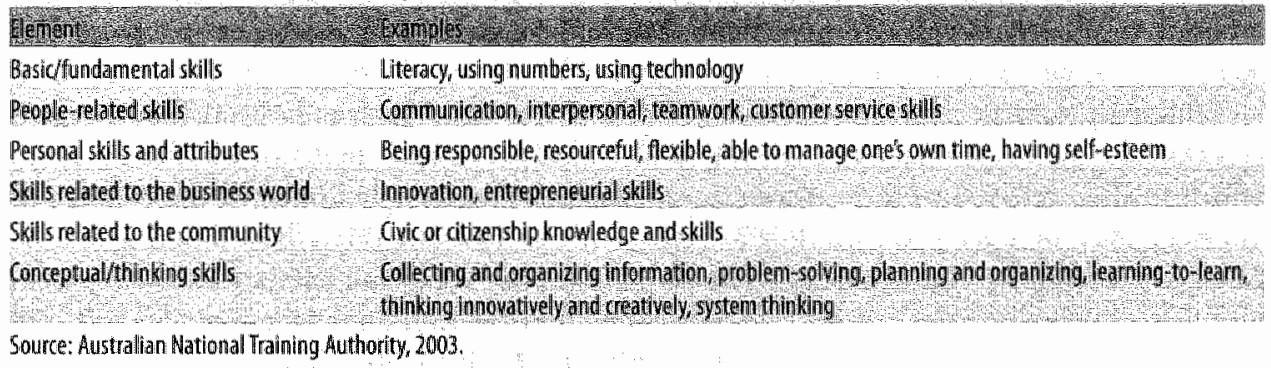

With perhaps the exception of the aspects labelled in Table 2.2 as skills related to the commu* nity' all of the elements include items that provide a direct value in the Jabour market.

A basic ${ }^{3}$ level in, for example, reading and mathematics (Basic/fundamental skills), the ability to communicate effectively both orally and in writing, as well as to interact with others, (People-related skills), is often named as central in decermining the long-term labour. marker outcomes (see e.g. Levy and Murnane, 20o1). However, considering our focus on higher education graduates, in particular with respect to the former element, the following side-note is noteworthy. The acquisition of an expertise level in mathematics, for example, is strongly inherent to a particular discipline at higher education levels and hence it is inconsistent with our functional approach on generic competencies.

The third element (personal skils and atmibutes) refers to human characteristics such as 'being responsible' or 'having self-esteem'. Although their relevance for the student's success in the labour market is undisputed, these aspects should be regarded as a by-product of education rather than its central objective. As a mater of fact, the level that students possess at the time of graduation is determined to a large extent by factors such as the childhood of

\footnotetext{
12. For a brive overview and discussion of these and other approaches, see Australian National Training Authority, 2003.

3. It is imporrant to note that the term "basic" does nor a priori refer to low level skils. Ir is aften used to indicate that these skills consriture a basis for other skills, rather than a particular level of complexity.
} 
the student, his past and current family situation, activities carried out outside education, and by the gemeral cultural context in which he or she lives.

'Innowation' or 'entrepreneurial skills', aspects included in the fourth element "skills related to the businiess world', relate to the growing need of graduates in general and higher education graduates in particular to be properly prepared for management positions in a post-industrial economy with global competition. Higher education responded to this need and started a variety of graduate, and in particular postgraduate, courses in management topics. The effectiveness of teaching such skills in classrooms is questionable. Milter and Stinson (1995) argued thar traditional management and busimess education falls short in educating leaders for the new competitive environment. McCall,. Lombardo and Morrison (1988) found that most of the development of management competencies takes place on the job, and not in seminars, classrooms or MBA programmes. A similar result was found by Heijke, Meng and Ramaekers (2003), who showed that rhe level of management competencies to be handled by higher education graduates entering the labour market was more strongly related to the amount of general academic competencies than to the amount of management competencies acquired in higher education.

The sixth element 'conceptuallithinking skills' includes items such as 'collecting and organizing information", "problem-solving' but also 'learning-to-learn'. Items inside this element, which is often referred to as 'academic competencies', are strongly linked to the concept of 'metacognitive competencies' on the one hand, and the literature on "critical thinking" on the other. Metacognitive competencies relate to the expertise about oneself as a knower, learner and actor (Weinert, 200r). Ennis (1987) defined 'critical thinking' as 'reasonable reflective thinking that is focused on deciding what to believe or do.' It involves 'formulating hypotheses, alternative ways of viewing a problem, questions, possible solutions, and plans for investigating something:' Accordingly, critical thinking is in particular associated with verbal-reasoning skills, argument-analysis skills, thinking skills such as hypothesis testing, thinking in terms of likelihood and uncertainty, decision-making and problem-solving skills (Halpern, 1988). Its distinction from lower-order thinking skills with their main focus on knowledge, comprehension and/or application, thus follows the aforementioned taxonomy of educational objectives as given by Bloom (1956). Items belonging to the element of critical thinking in this sense are inherent parts of higher education programme outcomes.

Reconsidering the objectives for discussing the six common elements found in surveys on generic competencies, we conclude that, in particular, aspects related to 'conceptual/thinking skills' are of great relevance to the narrow focus on higher education graduates. By this, we do not intend to make a nomative statement with respect to the relevance of particular skills or competencies that have not been selected. Rather, we want to argue that aspects of the selected element are most in line with the focus on the acquisition and use of competencies by higher education graduates. The relevance of these irems is also supported by their central role in the so-called 'Dublin descriptors', developed by the Joint Quality Initiative Network ${ }^{14}$ to indicate the required competencies of Bachelor and Master graduates in European higher education

4. The Joinc Quality lnithative wetwotk consists of representatiwes from ovelve European countries. Their general aim is to improve incernational co-operation in education. For more information, please refer to www. jointquathy org. 
and by findings of Harvey (1993) ${ }^{\text {i5 }}$. Harvey asked both a group of university academics and a group of potential employers of unversity graduates in the United Kingdom to rank different criteria according to their relevance by which the labour market assesses graduates. The rankings were quite comparable and in both groups, items such as problem-solving abilities and "analytical competencies" were placed among the top criteria". Accordingly, we conclude that a group of skills relating to further learning, solving problems and working with information and data, is best suited to the focus of this study. In the remainder of this thesis, this group of skills will be referred to as "academic competencies".

By restricting the focus to 'academic competencies', we also link the research directly to the concept of 'lifelong learning, currently placed at the centre stage by policy advisors. 'Lifelong learning' made its appearance in the early 1970s on the basis of two basic elements: the exrension of post-compulsory education to cover the entire lifespan and the idea of organizing the system in order to cover all aspects of life in recurring fashion (CEDEFOP, 2001). Its implementation was disrupred by the economic recession of the 1970 and the concept had more or less to be reinvented in the rg9os. This time, its appearance went hand in hand with another revival, that of the term key competencies ${ }^{17}$, and was inherently related to economical and demographical factors. Economically, the evolvements in information and communication technology (ICT) played a trigger role. The awareness that progress in ICT has made it possible to access and transfer codifed knowledge more and more rapidly and that at the same time the pace of technological progress may render it obsolete at an increasing rate (see e.g. Teichler, 1999), shifred the focus of attention towarts competencies that enable one to select, process and apply the knowledge store. This shift seems even mone pressing for European countries considering the ageing population, rising migration, increasingly complex career pachs, consistently high levels of unemployment, and the associated risk of social exclusion (Eurydice, 2002a).

Taking stock, we have argued that generic competencies in general and academic competencies in particular are relevant with respect to two features. First, they are a necessary condirion for graduates to react on changes taking place in the labour market as a result of technological changes, as well as the related changes in the way organizations are managed. They therefore determine the graduates adjustment potential. Second, but related to the same underlying factors, the increased uncertainty with which discipline-specific competencies can be applied in the bibour market, requires from graduates that they are able to continue learning and/or to acquire new or different types of competencies after graduating from

15. Other surveys are discussed in, for example, Harwey, Burrows and Green (1993), Burrows, Harvey and Green (1993), and Sasz et al. (1993).

16. In contrast to the findings of Bishop (1992, 1995), "specialist subject knowledge' is ranked at the bortom. Harvey (1993) noted that the low rating of special ist subject knowledge may be explained by employers taking a minimum level of specialist subject knowledge for granted or the respondents focusing on "specialist' rather than on 'subject' when giving their answers. The latter explanation indicates the potential danger inherent to the vagueness and/or ambiguity in survey questions. This kind of error is potentally very damaging, since it not only leads to an increase in random noise, but may lead to systemaric errors. We will return to this point in Chapter 3 , when discussing the data used for the empirical analyses and the way in which information on competencies was extracred.

17. Since Mertens (1974) in Germany and Prarziner (1978) in the USA used it, the term "key competencies" has been given a central place in the discussion on matching education and work. Mertens (1974) used the Geman word "Schlüssellqualifkationen". 
higher education. Investments in academic competencies during higher education therefore prowides a kind of option value to be cashed in in case the discipline-specific comperencies are of reduced value.

Considering the above argumentation with respect to the increased emphasis on generic competencies in general and academic competencies in particular, a legitimate question is if in the near futwe the role of discipline-specific competencies will become marginalized to the material needed to acquire generic competencies ${ }^{\text {in }}$. This is undoubtedly a too pessimistic view. First, discipline-specific competencies will continue to play an important rolle as competencies of direct value in the labour market. In this sense, basic anatomy will continue to be an important part of medicine curricula. Second, there are clear indications that the need for generic competencies revealed by surveys is endemically overestimated. Teichler (1999), for example, referred to the finding that "employers" statements or andyses of employers' expectations whderscoring the role of general competencies may wend to underestimate the weight specific skils have inter alia because general managers and the staff of personnel depanments are wore likely to be asked than the specialists in the various other departments, who bave constant diwect experience of the details of graduate work. Furthermore, general job requirements wend to be similar across a variey of job wasks and are therefore more likely to be mentioned frequently than are the specific skills needed for wariow professional areas. "Hence, we can expect discipline-specific comperencles to continue playing a central role in higher education as well as in the labour market. However, it may hawe to share its place with generic comperencies.

\subsection{Concluding remarks}

The objective of this chapter was to discuss different types of competencies acquired by higher education graduates and to propose them as an accurate way of describing the human capital assets that are traded in the labour market.

To do so, we briefly discussed the mainstream economic theories on the impact of education on the productivity of graduates in the labour marker. We stated that, in particular, models based on the assignment theory provide useful insights for this study. However, we daim that the way in which education is measured in research is generally recognized as unsatisfactory. More specifically, we propose that we should address a qualification as a summary of heterogeneous competencies. As a result, we introduced the competence concept.

Notwithstanding the pragmatic approach usually followed in economic theories, we propose that we treat the terms "skill' and 'competency" as distinct terms. We refer to 'skills" to indicate individual abilities such as the ability to switch on a computer, the ability to rypewrite, or the ability to save a document. The term "competency' is used to denote a group

11\%. Heviewing the literarume reweals that teaching generie competencies in general needs ro be rooted in teaching

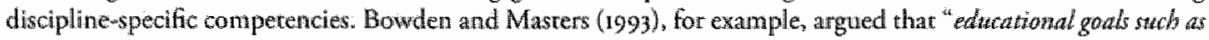

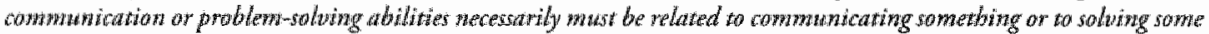

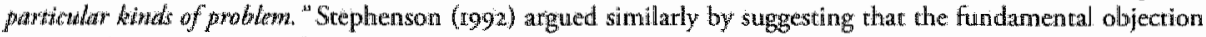
ro a stand-alone concept of generic competencies is that it denies "whe holustic nature of eqpatility. the essential

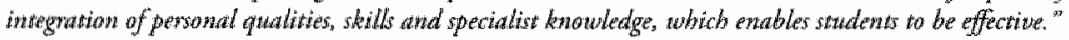


of skills that refers to one underlying dimension and forms the condition for handling a complex task. Hence, writing poetry on a conputer, using the above skills, is a competency. Lastly, we propose thar the distinction between discipline-specific and academic comperencies is a crucial one for research on the transition from higher education to work. The former measures the field-specific knowledge of the graduate, which is of direct productive value in the labour marker. The latter measures the graduate's higher thinking abilities and readiness to learn and to adapt to changing circumstances. In contrast to the applicability of disciplinespecific competencies which are restricted to occupations that are in congruence with the field of study graduated from, academic competencies are context-independent and hence useful across the entire range of occupations in which graduates might be employed. 
$\because \quad$

.

$\therefore \quad \because \cdots$

$\therefore$

$4 \div$

$\therefore \quad \cdots$

1 


\section{Chapter 3 \\ CHEERS survey and definition of academic and discipline-specific competencies}

" Frankly I find it bard to concive of a poorer measure of the maketable skils a person acquites in school that whe number of years he has been able to endure a classroom-environment. My only justification for such a crude measure th that I

can find nothing better

Welch, 1975, p. 67 


\subsection{Introduction}

Chapter 2 addressed the questions what it means to takk about competencies in the light of a knowledge-intensive economy and what types of competencies can be regarded as crucial for higher education graduates to possess. We argued that higher education has in recent years been confronted with a graduate labour market asking not only for a substantive level of discipline-specific competencies but also for an increasing level of generic competencies. With respect to the latter, in particular academic comperencies, such as "problem-solving abilities' or 'reflective thinking' are crucial. The focus on different types of competencies is based on the finding that static labels generally used to describe higher education output, such as the study field or the type of higher education (e.g. Fachhochschulen), cannor cope with the constantly evolving mix of competencies demanded in the labour market and taught in higher education programmes.

In this chapter, we will put the theory into practice. We will discuss and propose a Hexible way to measure the output of higher education in terms of the level of academic and discipline-specific competencies acquired by graduates. The measurement is derived directly from the actual level and type of competencies which students possess at the time of graduation. The measurement not only makes it possible to characterize programmes or higher education systems according to their competence orientation, but also to capture the heterogeneiry between graduates from a specific programme.

Classifying education systems in terms of their academic or discipline-specific (vocational) orientation is not new in itself. Germany, in line with its occupational labour market (see e.g. Gangl, 20or), has had a long tradition of occupationally orienced education, and hence is a representative of the latter type. At the tertiary level, in particular studies at Fachhochschulen, provide qualifications that are as closely related to vocational activities as are qualifications traditionally provided at the secondary level, for example through apprenticeships. Moreover, the general aim of the German higher education system is to prepare students for a field of professional activity (Eurydice, $2002 \mathrm{~b}$ ). Accordingly, studies at universities also comprise specialized scientific training for a profession, in addition to more general academic qualifications. In contrast, the higher education system in the United Kingdom is generally seen as highly academically oriented and matches well the expectations of an internal labour market. "The concept of an eduation that provided training in abstract wough wh that walued knowledge for its ow sake has alway bern present in bigher edvation in the United Kingdom" (Furydice, 2002b). In line with this, the Dearing Report (1997) considered the intellectual and cultural purpose of higher education in the United Kingdom as crucial and stated that the aim of higher education should be to 'sustain a learning sociery'.

So what is new about approach proposed here? It is not the tarminology per se (academic versus discipline-specific) but the intention to explicitly expose the competencies that hide behind this terminology and hence, to give the typology a clear content. Accordingly, the measurement used here will be capable of indicating more directly the outpur of a study at the tertiary level. Moreover, this measurement makes it possible to locate graduates, programmes or even encire higher education systems along a continuous scale from academic competen-

1. A similar situation exists in the Netherlands, with srudies at higher vocational educarion (HBO) instirures. 
cies orientation to discipline-specific competencies orientation instead of merely allocating them to either of the wo poles (academic or discipline-specific). In this sense, the measurement is able to capture directly any changes that take place within a programme or higher education system and provides the flexibility required to discuss the labour market success of higher education graduates.

The structure of the chapter is as follows. First, Section 3.2 provides general information on the CHEERS (Careers after Higher Education: a European Research Study) survey. The section also forms a preparatory part for the empirical studies presented in Chapters 4 to 6 and introduces the reader briefly to the data set used throughour this thesis. Section 3.3 then discusses the way in which the CHEERS survey was used to create the two constructs (academic and discipline-specific competencies) that were used to measure the higher education output. These constructs are submitted to different validicy tests. Section 3.4 addresses some possible sampling problems in relation to the data used. Section 3.5 concludes the chapter.

\subsection{The CHEERS survey ${ }^{2}$}

An essential element for a study that addresses the acquisition of competencies by higher education graduates and their value in the labour market is the availability of high quality data allowing derailed analyses. The empirical studies of this thesis make use of the CHEERS survey. This survey was partially financed by the European Commission's Targeted SocioEconomic Research programme ${ }^{3}$ and partially by the participating countries themselves. In total, I2 countries took part, ro of these being countries of the current European Union (Iraly, Spain, France, Austria, Germany, the Netherllands, United Kingdom, Finland, Sweden and the Czech Republic), one EFTA country (Norway) and Japan. Central co-ordination was done by the Centre for Research on Higher Education and Work of the University of Kassel. Professor Ulrich Teichler and Harald Schomburg were the co-ordinators of the project, both in terms of the administration of the project and the research process, notably the graduate survey. The survey (including the collection of addresses, mailing, and documentation of the coding) was carried out by the 2 national research teams ${ }^{4}$. In each of the 12 countries, a representative sample (according to field of study, type of degree and/or type of higher education institution and gender) was drawn from the cohort of graduates who graduated between the autumn of 1994 and the summer of 1995 from a course in higher education. The sample size was determined separately in each country, on the basis of an anticipared response rate, so as

2. Information provided in this section was partially retrieved from the CHEERS homepage: http:/www unikassel.de/wzr/tseregs.hrm.

3. The Targeted Socio-Economic Research programme is part of EU's $5^{\text {th }}$ Framework for research on social sciences and humanities.

4. For contact addresses of and further information on these local research teams, please refer to the abovementioned CHEERS homepage. 
to artive at ataset per country of approximately between 3,000 and 3,500 graduates. The graduates drawn were asked to respond on a standardized mail questionnaire in the autumn of 1998 . As a result, the survey was directed primarily at the situation of the graduates up to three to four years into the labou warket. The major themes addressed are given in List $3 . I^{\text {t: }}$

\section{List 3}

Thernes addressed in the CHEERS graduate questionnaire survey

* Socio-biographic and early education background wariables

* Enrolment and study conditions and provisions

* Sudy acliovenents

* Job search and transition period

* Employment during the first three years after graduation

3) Regional and international mobility

* Work content and use of qualifications

\$ Work motwation and job sacisfaction

* Further professional education/training

* Career prospects

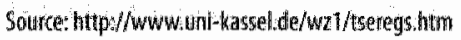

Although the study took place in 12 countries, the data of only nine countries was used. Sweden, the Crech Republic and Japan were left out. The Swedish case lacked data on competencies, which is the key issue in this thesis. The Czech Republic and Japan were left out because the specific situations in these countries did not allow a useful comparison with the other countries.

The data covers graduates from all types of higher education institutions in these nine countries. With respect to the countries under consideration, a simple classification can be made on the basis of the question whether a country provides a binary higher education system or a unitary higher education system.

Gemamy, the Nethertands and Noway have binary systems. Higher education courses in these countries can be divided between those taught in the relatively more scientifically oriented university sector and those in the more vocationally oriented non-university sector. In Germany, the latter consists of programmes taught at Fachhochschulen, in the Netherlands at higher vocational education institutes (HBO), and in Norway at university colleges. The Norwegian university colleges, established after a reorganization and merging of 98 former

5. The response rates of the questionaires were: Itally (tmknown), Spain (15\%), France (33\%), Austria (45\%), Ciermany (43\%), Netherlands $(47 \%)$. United Kingdom $(34 \%)$, Finland $(46 \%)$ and Norway $(50 \%)$. With the exception of Spain, the response rate can be seen as accepable to high, considering that this was an ro-page mail gnestionnaire with no incentives offered to the graduates for their response. According to the national repors of the field phase of the study the quality of the returned questionnanes sems to have been high. The profile of the respondents was compared with the profile of all $1994 / 995$ gracluares accorling to mational statistics in the courtrites. As it differed slightly, final weighing was performed co create a representative data base that is also usted in this thesis.

6. The English Master quest ounaire is induded at the end of this thesis.

7. Information whth respect to the Higher Education system in the differen countries is based on the Eurydice Database on Education (wwweurydice org). 
regional and vocational colleges, were until recenty known as 'stare colleges". The new tern "university college' reflects an academic upgrading of these institutes since 1994 . In contrast to Germany, where the majority of students enter universities, in Norway and the Netherlands; the non-university sector of higher education provides teaching for more than $50 \%$ of higher education students. In the case of Germany and the Netherlands, admission requirements for the non-university sector are generally lower than for the university sector. In particular, entrance to the university sector requires a higher and one year longer secondary education.

Even though France and the United Kingdom do not have a binary system in the above sense, their higher education system can be characterized by a distinction in the prestige of higher education institutes. In Frawce, a distinction can be made between higher education programmes at public universities and programmes at the "elitist" Grande Ecoles. The majority of French students follow courses at the universities. Universities in general provide open-access programmes. In contrast, instirutes of the Grande Fcoles institution, providing courses in selective fields, have stringent admission procedures (e.g. secondary school grades or numerus clausus exams) and require participation in preparatory classes. Until 1992, universities and polytechnics provided higher education in the Umited Kingdom. Polytechnics were originally set up by charitable endowment to enable working-class men and women to advance their general knowledge and industrial skills on a part-time or full-time basis. Their role changed with the 2966 White Chapter 'A plan for the Polytechnics and Other Colleges", describing the polytechnics as regional centres of higher education linking industry with business. Lastly, the 'Further and Higher Education Acr 1992' allowed all higher education institutions in England and Wales that satisfied prescribed criteria to apply for permission to include the word "uniwersity" in their names. All polytechnics were allowed to do so and only one (Anglia Polytechnic University) choose to retain the word 'polytechnic' in its name. Although these changes seem to render a distinction between education programmes taught at 'old universities' and 'new universities' (the former polytechnics) redundant, we differentiated between these two institutions when needed. The reasons were, first, that the respondents started their studies before 1992, and hence before the "Further and Higher Education Act' was implemented, and second, because old universities still differ with respect to their status and admission requirements, as reported by the Sunday Times League Table (Sunday Times, 2003).

Austria, Funland, Itaty and Spain make no distinction between different higher education institutions. In the latter two cases, no significant non-university higher education insticution exists. Austria and Finland have recenty implemented changes. Both countries reacted to labour market demands and introduced a more vocationally oriented non-university higher education sector (Fachhochschulen in Austria and Polytechnics in Finland) in the mid-1990s. However, the data used here do not yer cover graduates from these higher education institutions.

Summarizing, Figure 3.I gives an overview over the types of higher education and number of respondents per higher education institution covered by the data. 


\section{Figure 3:}

\section{Countries, Higher education institutions and number of respondents}

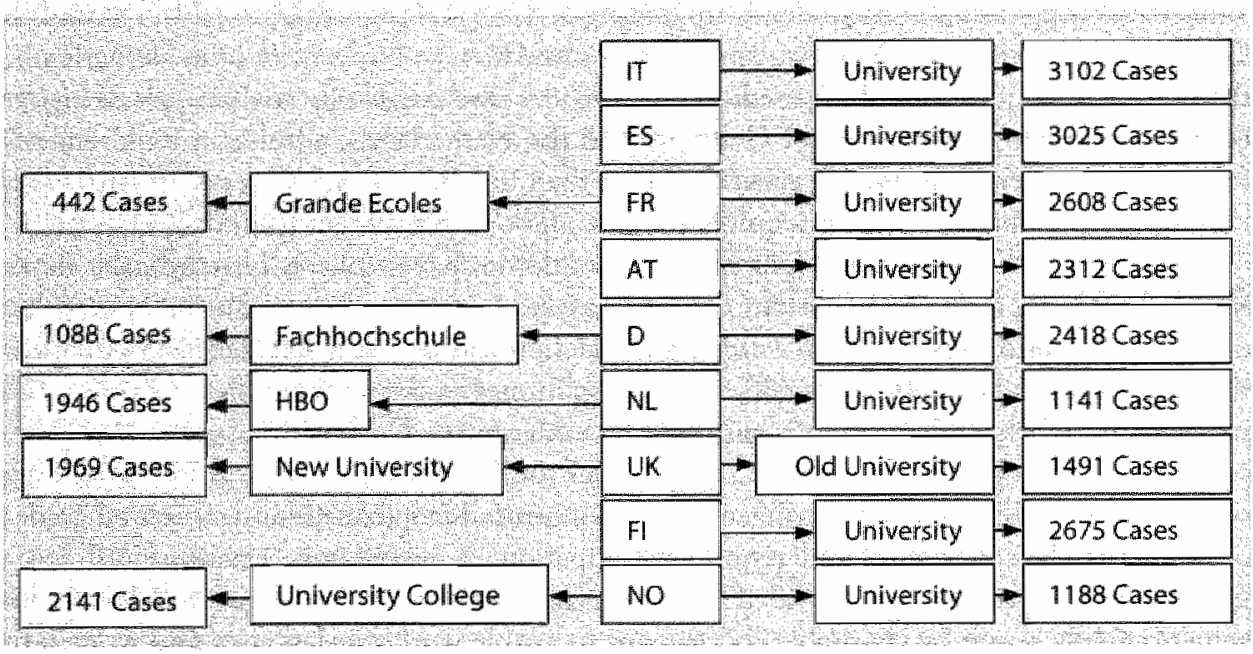

\subsection{Discipline-specific and academic competencies}

Chapter 2 addressed different types of competencies. Reviewing the literature, we proposed that in particular the acquisition of two types of competencies, namely discipline-specific and academic competencies, can be seen as central objectives of higher education programmes. In this section, we will analyze the CHEERS data to see to what extent the two concepts are visible in the answers given by the higher education graduates. Having established that two clusters of skills, reflecting well the theoretical construct, exist, we will then test their validity and address solutions to deal with potential measurement errors.

\subsubsection{Competence measurement}

The CHEERS survey used a direct and subjective approach to measure the knowledge and skills acquired by bigher education graduates and required in the labour marker. More precisely, the graduates were asked to indicate on a five-point Likent scale, ranging from I ("not at all') to 5 ("to a very high extent")", both the extent to which they possessed a particular item at the time of graduation and to what extent this item was required in their current work. In total, the questionnaire distinguished between 36 individual items (see Figure 3.2 belowis.

8. In the original questionnaire, the answers were coded from $x$ ("ro a very high extent') to 5 ('nor at: all'). To simplify the reading of the empirical analyses we recoded the answers to range from a (not at all') ro 5 ("ro a wery high extent').

9. Appendix 3 A of this chapter provides an excrace of the original questionnaire reporcing on the exact question and the comperency items in detail. 


\section{Box 3 :1}

Ward's hierarchical clustering method

Generally, the hierarchical clustering method starts from the finest partition possible (each skill item forms a cluster) and groups them. The agglomerative algorithm used is:

1. Construct the finest partition.

2. Compute the distance matrix $D$.

3. Find the two clusters with the closest distance

4. Put those two clusters into one cluster

5. Compute the distance berween the new groups and obtain a reduced distance inatrix Duntil all clusters have been agglomerated into s cluster:

More in detail, if wo irems, say $X$ and $Y$, are united, the distance berween this new dister $(X, Y)$ and a remaining item $Z$ is computed according to:

$$
d(X+Y, Z)=\delta_{1} d(X, Z)+\delta_{2} d(Y, Z)+\delta_{3} d(X, Y)
$$

where $\delta$, the weighting factors and $d$, the squared Euclidean Distance nieasure $\left(d(X, Y)=2,(X,-Y)^{2}\right.$. The weighring factors are given by

$$
\delta_{1}=\frac{\eta_{z}+\eta_{x}}{\eta_{x}+\eta_{x}+\eta_{z}}, \delta_{2}=\frac{\eta_{y}+\eta_{z}}{\eta_{x}+\eta_{z}+\eta_{z}} \text { and } \delta_{3}=-\frac{\eta_{z}}{\eta_{x}+\eta_{r}+\eta_{z}}
$$

where $n,=2,1(x, \in)$ the number of objects in group. $Y$. The values of $\eta 1$, and $n$, are defined analogously.

Handling all the individual items provided by the data set separately not only hampers a clear interpretation of results but also ignores the fact that individual items may be closely related and that their value as a group is larger than the sum of individual items. The latter argument is in line with the proposition made in Chapter 2 that the term 'competency' should be used to designate a complex action system and not an individual ability. Accordingly, we are interested in sets of skills that belong together and referee to one dimension, namely either the academic competencies dimension or the discipline-specific competencies dimension. To do so, we approached the individual skills measured in the CHEERS survey by means of cluster analyses (see Box 3.r). Cluster analysis allows the large group of items to be divided into smaller ones, whereby items within a group are similar in narure and observations in different groups are relative dissimilar in narure (see e.g. Latin, Carroll, Green, 2003).

The individual irems were clustered according to the extent to which they were required in the graduate's current occupation. Alternatively, one could use the extent to which the graduates possessed the aspect at the time of graduation as starting levels for the cluster analyses. We believe that our approach is justified in the sense that we intend to analyze the role of academic and discipline-specific competencies in the labour market. Hence, we will 
start with the question what combinations the labour market requires and then ask to what extent higher education produces them. For the purpose of this thesis, namely the distincrion between academic and discipline-specific competencies, both approaches would actually lead to highly comparable solutions. Figure 3.2 shows the dendogram output of Ward's hierarchical clustering method analyses which attempts to minimize the sariance within clusters. The algorithm begins with each item foming its own cluster (left part of figure) and then searches for objects that can be grouped together whle minimizing the increase in the sum of residuals squared, so wh minimum within-group variance (Latin, Carroll, Green; 2003). The distance between the items is measured by the squared Euclidean Distance, the most Gamliar distance measurement method for variables measured on an interval indicating theit close relationship.

Let us consider the dendogram output of the duster analyses, keeping in mind the discussion in Chapter 2 and the notions stated above. Starting at the left side of the dendogram, and hence where each skill forms its individual cluster, we find that at a first stage the two items "Field-specific theoretical knowledge" (in Figure 3.2 termed F-S theoretical knowledge) and 'Field-specific knowledge of methods' (F-S knowledge of methods) are brought together, indicating their close relationship. These two items undoubtedly constitute the centre of our" discipline-specific competencies dimension. A comparable grouping takes place with respect to two pairs of skills seen in Chapter 2 as highly relevant components of an academic competence construcr: 'learning abilities' and 'reflective thinking' on the one side, and problemsolving abilities' and 'analytical competencies" on the other. According to the cluster analysis; the two pairs a cluster of skills in a subsequent step, to which the item documenting ideas and information" also belongs. These five items so far seem to reflect well the idea of an academic competency constiruct.

What about the other skills considered? The cluster analysis reveals that other interesting sets of skills are formed. First of all, ar the top of the dendogram, a group of skills (initiative' until 'written communication') is starting to be brought together. This group of skills was labelled in Chapter 2 (see Table 2.3) as personal skills and atributes and people-related steills, all belonging to the group of generic competencies. At a later stage, these skills are brought together, first with a second group of generic skills (getring personally involved' until "tolerance) and later with the above-mentioned five trens, reflecting the idea of an academic competence construct, forming a large group of generic competencies.

At the bottom of the dendogram, a further cluster of skills is starting to emerge. It incorporates items such as 'braad greneral knowledge', 'cross-disciplinary knowwledge' but also 'creatwity', 'negotiating' and 'leadership'. All of these items seem to be highly relevant components of wanagerial or entreprenential competencies. Interestingly, this group of skills, even though best labelled as generic skills, are at a later stage brought together wh our discipline-specific skills before being added to the large group of generic skills discussed above.

Concluding so far, we may state that the cluster analyses show on a rather disaggregated level that we can form clusters of individual skills based on the answers of higher education graduates which are strongly comparable to the different types of competencies elements discussed in Chapter 2. According to the rather narrow focus on discipline-specific compe-

10. The usage of the term competencies in the latter case indicates that the terim "analytical competencies' already refers to a group of individual skills needed to act. 
tencies and academic competencies used here and to keep the clusters of skills as homogeneous as possible, two clusters are singled ouc (see List 3.2 ), reflecing best the idea of discipline-specific and academic comperencies.

\section{Figure 3.2}

Dendogram of competency items required in current occupation

\section{CASE}

Label

Intiative

Assertiveness

Taking responsiblities

Working independently

Working under pressure

Time management

Planning

Team work

Adaptalbility

Accuracy

Concentration

Oral communication

Mritten commulication

Getting personally involved

Loyalty

Critical thinikingz

Tolerance

Learning abilities

Reflective thinking

Problemi-solving

Analytical competencies

Docamenting ldeas and info.

F-S Theoretical knowledge

Fus lnowledge of methods

Understanding complex sit.

Economic thinking

Computer skills

Broad general knowledge

Cross-discipl. knowledge

Creativity

Negotiating

Leadership

Understanding rules

Fitness to work

Foreign language skills

Manual skilts

\section{Rescaled Distance Cluster Combine}

$\begin{array}{cccc}0 & 5 & 10 & 15\end{array} 20 \quad 25$

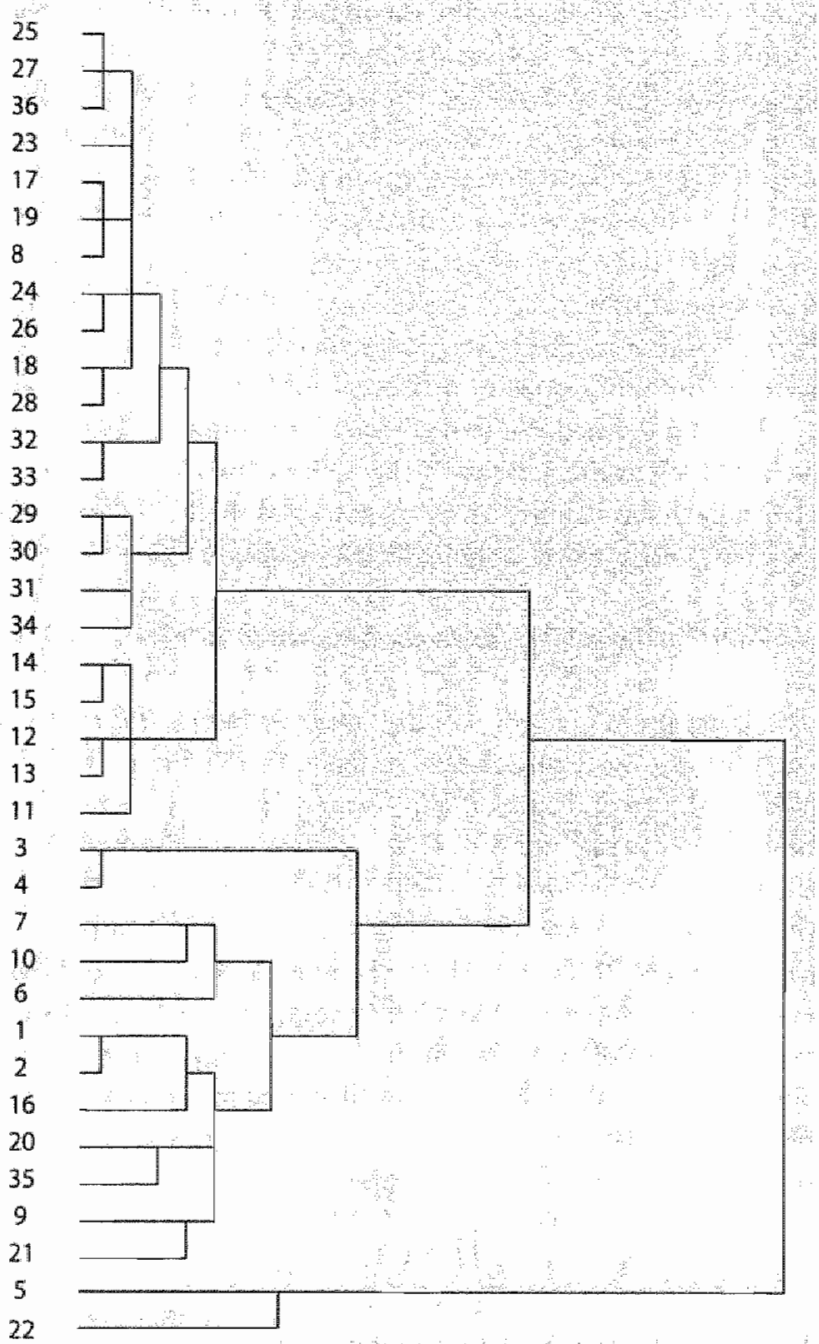


List 3.2

Individual skils nested in the competency clusters

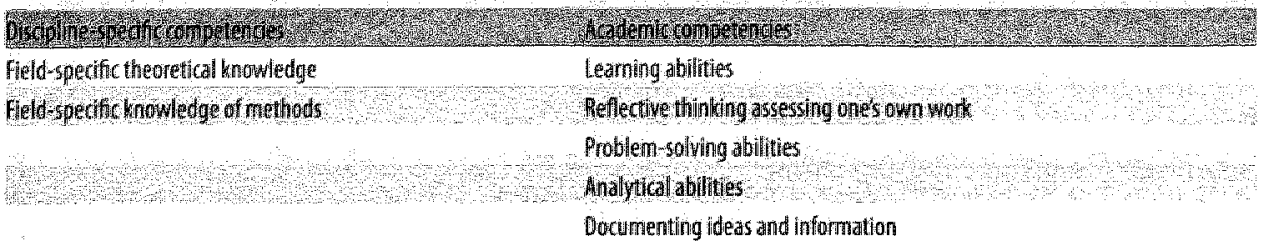

Consequently, when referring to discipline-specific competencies, we implicitly refer to the combination of field-specific theorevical knowledge and field-specific knowledge of methods. Similarly, the term academic competencies will be used to refer to a combination of learning abilities, reflective thinking and assessing one's own work, problem-solving abilities, analytical abilities and documenting ideas and information. We are aware that, in doing so, we are restricting the focus with respect to possible competencies very much. At the same time, we do not intend to make a normative statement with respect to the relevance of particular skills or comperencies not selected. However, the approach is in line with our argumentation in Chapter 2 with respect to the rellevance of different comperencies on a higher education level. Moreover, the focus allows a more detailed analysis with respect to the two selected competencies (discipline-specific and academic). Consequenty, we trade breadth for depth.

Having defined the two competence concepts that are central in this thesis, we will have a closer look at the validity of these two constructs. In particular, the subsequent section tests their internal reliability, their content and their construct validity. This addresses the question to what extent we actually measure what we believe to measure (Baker, 1988).

\subsubsection{Testing the validity of our competence constructs}

The most basic form of validity is the content validity. To address it, one needs to cricically examine the measure of the concept in the light of its intended meaning. Taking a first look at the two clusters distinguished above, we can state that they seem to represent to a high degree what was intended. There is no doubt that the combination of field-specific theoretical knowledge and field-specific knowledge of methods constitute the core of discipline-specific competencies. On the other hand, aspects such as problem-solving abilities or learning abilities, as well as the knowledge how to document ideas and information, are relevant components of academic competencies. A second check closely related to the first validity is to examine the internal consistency of the two data clusters. To test it, Cronbach alphas will be calculated. This indicates how well a set of items measures a single one-dimensional construct:

$$
\alpha=\frac{n \bar{r}}{[1+(n-1) \bar{r}]}
$$

where $n$ is the number of items used in the cluster and $\bar{r}$ is the average inter-item correlation among the $n$ items. The coefficient has a range from o to r. Generally spoken, alphas of 0.9 and larger are considered to indicate a very good level of scale reliability, but values of 0.7 or 
more are generally regarded as acceptable (Nunually, 1978). Table 3.1 reports on the alphas for the two clusters, both when measured as comperencies possessed by the students at the tinue of graduation and when measured as competencies required in the current occupation. In both cases, the internal consistency of the clusters is acceptable. Moreover, deleting individual items from the academic competencies cluster leads to a decrease in the internal consistency ${ }^{\text {in }}$. These findings reveal that the individual items forming the discipline-specific competency construct and the individual items that form the academic competency construct belong to each other and refer to one dimension.

Table 3**

Intemall consistency: Cronbach Alpha

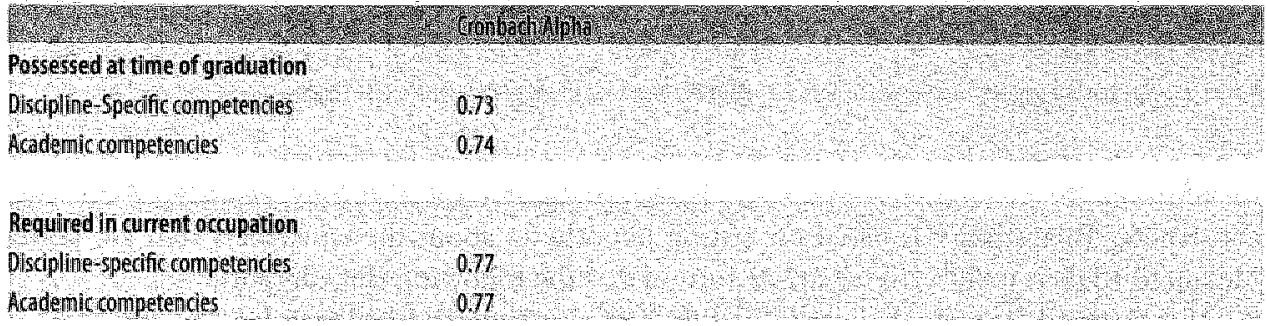

Table $3 \mathrm{~m}^{2}$

Internal consistency: Crombach Alpha - Strata: Country

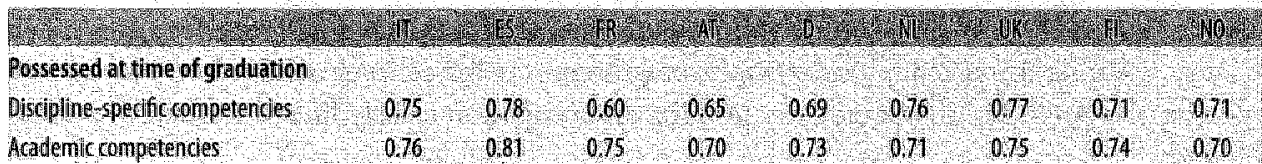

\section{Requiredin currentoccupation}

Discipline-specific conpletencies

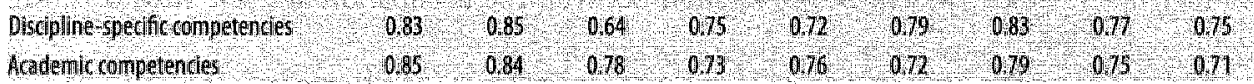

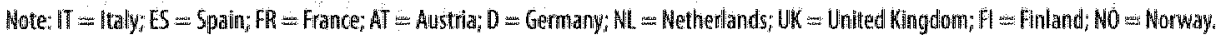

It is of crucial importance that the internal consistency of the two clusters not only holds on a European level but also within individual countries or individual education progranmes. Table 3.2 reports on the internal consistency coefficients calculated at the country lewel, while Table 3.3 does the same at the education programme level.

The reported coefficients show that on a country level, only four out of the 36 coefficients are slightly below the acceptable cut-off level. In the case of the education programme analyses, all coefficients are above the acceptable cut-off level.

Taking stock, we can state that first, the data reveals two competency clusters very much in line with the theoretical constructs. Second, the internal consistency indicates that the individual aspects forming a particular competency construct refer to one dimension, both

1. Data not shown. 
in higher education studies and as requirements of the labour market. Third, the internal consistency is comparable beween countries and berween fields of study.

\section{Table 3.3}

linternal consistency: Cronbach Alpha - Strata: Fielid of study

\begin{tabular}{|c|c|c|c|c|c|c|c|}
\hline \multicolumn{8}{|l|}{ Poscessedat lime of graduation } \\
\hline Disopplnesperoffectampetenicles & 071 & 075 & 072 & 80 & 074 & 012 & 074 \\
\hline Radenic conpetenges & 072 & 0,73 & 0.82 & 016 & 071 & 0,75 & 0.75 \\
\hline \multicolumn{8}{|l|}{ Required in current occupation } \\
\hline 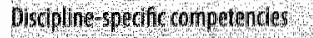 & 080 & 078 & 076 & 075 & 078 & 011 & 07 \\
\hline Aademla competendes: & 078 & 081 & 0,78 & 078 & 079 & 075 & 07 \\
\hline
\end{tabular}

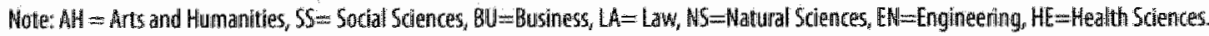

In addition to the content walidity, it is crucial to test the construt walidity of the two constructs. This validity is based on testing hypotheses about the constructs that are being measured (Baker, 1988$)^{12}$. To do so, we formulated the following three hypotheses:

(1) The reported average of the required level of competencies is dependent on the level of education that is required by the employer to fulfil the occuparion ${ }^{1 x_{*}}$ "The higher the educational level required, the higher the competence requirement.

(2) Controlling for the educational lewel required, graduates holding an occupation not closely related to the field of study from which they graduated (e.g. a graduate from a law faculty working as currency trader) on average report a lower level of required disciplinespecific competencies' than graduates holding an occupation closely linked to their own field of study.

(3) Controlliag for the educational level required, the reported required level of academic competencies is independent of the relation between the occupation and the field of study graduated from.

Table 3.4 treports on the average academic competence requirements according to the educational level assigned to the occupation and the relation between the field of study and the occupation in terms of match in the rype of discipline-specific competencies. Table 3.5

12. A relared and mone stringen vallidity test would be to address the predictive validity (see e.g. Allen and Van der Velden, 2005 ). Howewer, to do so, ane would need objective benchmark measures, stuch as competence measurements by job analyas or submission of graduates/workers to a serter of test (e.g. assessment centre method). To the extent that sitch external measuremen ane neither awallable nor easily applicable for a seft of more than 25,000 graduates, We are unable co test for the predicrive validity of these constructs.

13. We measued the level of education required in the occuparion by the following question dhat gradaates were asked: "What is the nost appropriate level of course of study/degre for your employment and work compared no that which you graduated from in 1994 or $1995^{3 "}$

14. We measured the relation berween the fied of seudy and the occupation by the following question that the graduates were asked: "How would you characterise the relarionship berween your field of study and your area of work?" We defined a strong relation as one in which the scudents answered that their own field of study or a related held of study best prepared for the areas of work. A wreak rellation was defined as a situation in which either another fetd of scudy would bave been more useful or in which the feld of study did nor nater very much. 
does the same for the average of the required discipline-specific competencies. The results presented in Table 3.4 confirm hypothesis I and hypothesis 3 with respect to academic competencies. Not only does the required academic comperencies level depend strongly on the level of education required in the current occupation, bur in three out of the four occuparion types, the level does not depend on the relation between the occupation and the field of study graduated from.

\section{Table 3.4}

Academic competencies: Mean requïred level (standard deviation in brackets)

\begin{tabular}{|c|c|c|c|c|}
\hline 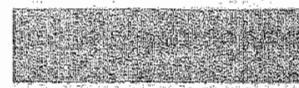 & 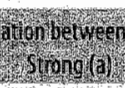 & What & Why & Writy \\
\hline Educationallevel reguired & & & & \\
\hline 1. Higher than graduated from & $4.22(0.55)^{*}$ & $424(0.59)^{+}$ & Not significant & $4.23(0.56)^{\circ}$ \\
\hline 2 Sameas graduated from & 401010,591 & $409(0.61)^{\text {t }}$ & Notsignificant & $4: 08(0,50):$ \\
\hline 2. Lower higher education llewell & $3.84(0.64)^{+}$ & $3.81(0.75)^{+}$ & Not significant: & $3.82(0.69)^{4}$ \\
\hline 3 No highther educationlewel & $36(1078)$ & $340(097)$ & 19: & $3,4(099)$ \\
\hline
\end{tabular}

Note: "iadicates that the average differs significantly on a 1 \%o level from the average ireported in a row abowe and below.

Turning to the required level of discipline-specific competencies (see Table 3.5), we can see that hypotheses $\mathrm{I}$ and 2 are confirmed. In line with the required level of academic competencies, the reported required level of discipline-specific competencies is dependent on the level of education required in the current occupation. Moreover, and this time in contrast to the results reported in Table 3.4, we can see that graduates holding an occupation with a weak link to their own field of study report a significantly lower level of required discipline-specific competencies.

\section{Table 3.5}

Discipline-specific competencies: Mean required level (standard deviation in brackets)

\begin{tabular}{|c|c|c|c|c|}
\hline \multicolumn{5}{|l|}{ Educational Level required } \\
\hline 1. Higher than graduated from & $421(0.83)^{-1}$ & $3.95[1.06)^{*}$ & $1 \%$ & $4.06(0,87)^{4}$ \\
\hline Sameas graduated from & 4.0910 .87 & 39941417 & $1 \%$ & $379(090)$ \\
\hline 2. Lowner higher education level & $3.75(0.95)$ & $3.14[1.76)^{*}$ & $1 \%$ & $3.240 .08)^{4}$ \\
\hline No: Whalaer education level & $3,55(099)^{\circ}$ & $270(120)$ & 10 & $275(1211$ \\
\hline
\end{tabular}

Whate: "indicates that the average differs significanthy an a 1 \% level fnom the average teported in a row abowe and lbelow.

So far, we have considered the validity of the output measurement on the individual graduate level. However, we proposed earlier that the measurement should also be capable of capturing differences between competence orientations (discipline-specific versus academic) of higher education programmes or even higher education systems. An interesting application of the latrer is illustrated in Figure 3.3. we contrasted the location of different higher education systems according to the measurement with the location of the countries allong the line of internal labour market (ILM) to occupational labour market (OLM). The distinction berween 
these two types of labour markers is generally seen in the institutional rules of access to skilled workers' positions, which are defined as positions requiring task-specific competencies. Educational credentials, such as the field of study, provide little guidance in the allocation of individuals to occupations in case of ILMs, as they lack occupational specificity. School-leavers start at entry porc occupations and are trained in firm-specific competencies; allowing mobility into higher positions. Accordingly, we expect higher education in these countries to be rather academically oriented, providing graduates with a strong basis for further learning. In contrast, in OLMs there is a strong linkage berween discipline-specific competencies acquired in education and the ones asked for by employers. As a result, we expect the acquisition of discipline-specific comperencies in higher education to play a key role in these countries. Even though occupational and internal labour markets may co-exist in a country, the relative weight between the two institutional arrangements varies strongly between courtries (see e.g. Eyraud, Marsden and Sylvestre, 1990). Along this line, Gangl (200r) used Marsden's criteria (see Marsden, 1990) to divide European countries into OLM and ILM countries. Of the countries included in this thesis, the United Kingdom, France, Finland and Spain are representatives of the ILM country group and Austria, Germany and the Netherlands of the OLM country group.

\section{Figure 3.3}

OLM versus ILM and the competence orientation of the higher education system

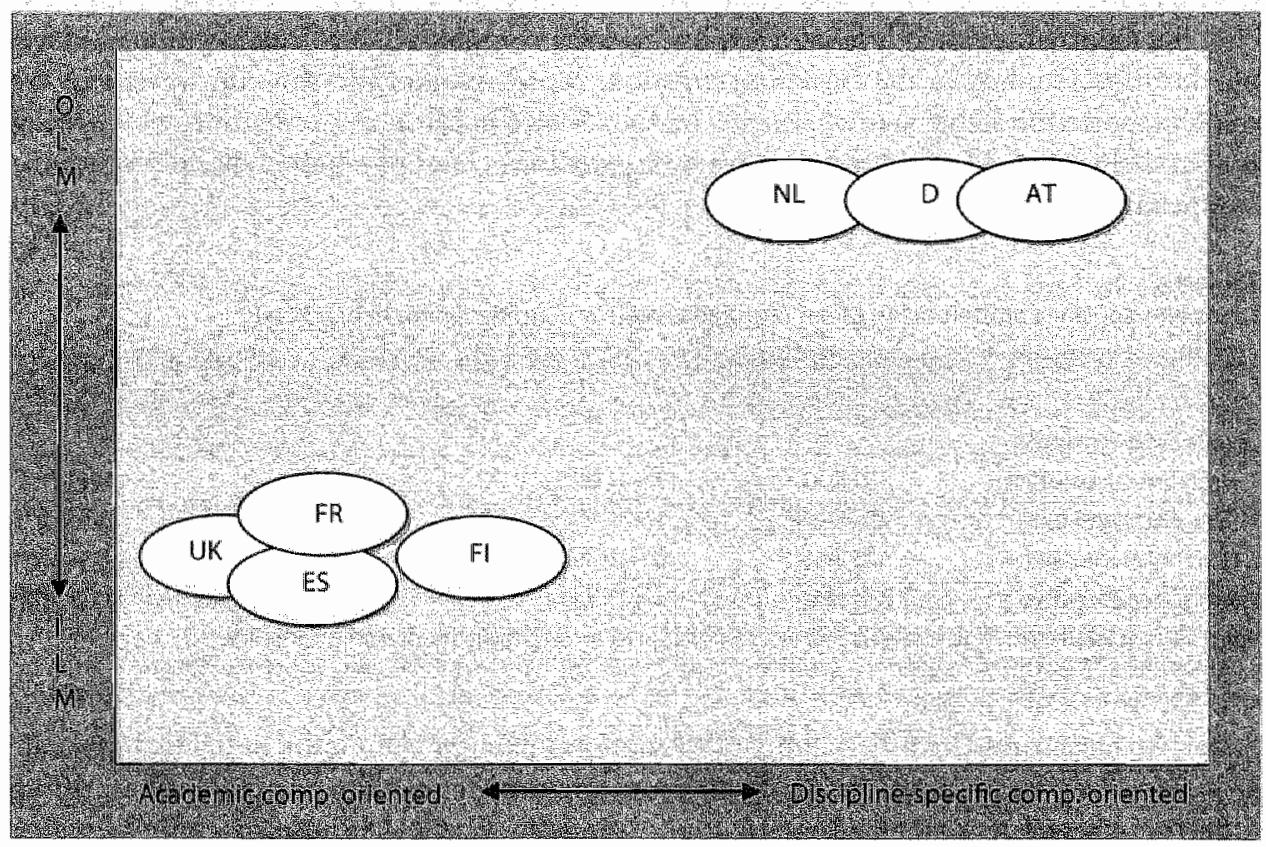

Note 1: Horlzontal axils competence orientation is megured as the average level of discipline-specific competendes acquired by students minus the average level of academic competencies acquired by studerits. Note 2 : The classification into LLM (Internal labour market) countries and OLM loccupatlonal laboui market) countinies is based on research by Gangl (2009). Hote 3: Italy and Norway were left out as they are not dassiffed according to the distinction between $L M$ and $0 \mathrm{LM}$. On the horizontal axis, Italy would be located dose to UK and Norway close to AT. Note 4: Distinguishing between countries on the basis of diffierent types of higher education (e.g. Fachhachschuthen versus Universities) does not change the pionure in a qualitatiwe sense. 
Contrasting this distinction with the output measurement for higher education, we found, as expected, that higher education in ILM countries on average produces graduates that are academically rather than discipline-specifically oriented. Comparably, higher education in OLM countries produces graduates with a discipline-specific orientation. As a result, the output of higher education according to our measurement fits in well with the central type of competencies graduates are expected to possess when entering the labour market. In later chapters, we will return to these two country groups when discussing the acquisition of competencies in higher education and the role and value of these comperencies in the labour market. For terminology reasons, we will then refer to the United Kingdom, Spain, France and Finland as academic countries and to the Netherlands, Germany and Austria as disciplinespeciffe countries.

Concluding this section, we can state that the two competence clusters forming the measurement for the higher education output are both satisfactory considering their internal reliability, content and construct validiry. Moreover, the measurement makes it possible to differentiate berween countries' higher education systems that fit in well with the institutional. setting of the labour market.

\subsubsection{Potential measurement errors and solutions used}

The main attractiveness of the self-assessment method used in this study to measure the level of acquired and required comperencies, lies in the fact thar graduates/workers may be the ones knowing best what they know and what they need to know to fulfil a particular task in a department/organization. The main disadvantage is related to the significant possibility of measurement errors's.

First, by asking graduates/workers to judge themselves, one risks getring answers biased towards pompousness or exaggerated modesty. Moreover; the answers may be influenced by other variables, such as working conditions. Second, one needs to deal with a potential error related to vagueness and/or ambiguities in the question. This may lead to systematic errors due to the fact that certain graduates interpret an item differently than others. The interpretation of a particular aspect may for instance be culturally influenced. Moreover, we have ro deal with the possibility that different graduates (i.e. graduates from different countries or different education programmes) use different "yardsticks" when answering the questions. In theory, some kind of reference point could be built into the question, in which graduates are asked to rate their competency levels. However, this would make the instrument much more cumbersome, and there would be no guarantee that the frame of reference provided corresponds to any clear-cur categories in the graduates' own cognition. "In fatt, it seems likely that answers given by graduates spontaneously and off-the-cuff will contain feuter errors that whose given to a more complex type of question with detailed explanations." (Allen, Ramaekers and Van der Velden, forthcoming, p.15).

15. A good overview ower these problems is given in Allen, Ramaekers and Van der Velden (forthcoming) and Allen and Van der Velden, 2005. 
Table 3.6

Acquired and Required level of competencies

\begin{tabular}{|c|c|c|c|c|c|}
\hline II & u & 360 & 334 & 399 & 3.51 \\
\hline 6 & U & 3.61 & 3.42 & 391 & 3.71 \\
\hline$F R$ & GE & 377 & 3,39 & 4,04 & 3.74 \\
\hline F & 11 & 3.60 & 3,38 & 391 & 358 \\
\hline AT & U & 3.71 & 3.80 & 4.03 & 3.54 \\
\hline 0 & FH & 3,44 & 358 & 380 & 3,70 \\
\hline 0 & $u$ & 364 & 3.75 & 396 & 3.61 \\
\hline NL & HBO & 354 & 3.63 & 3.83 & $3 n$ \\
\hline HL & U & 3.69 & 3.71 & 398 & 3.48 \\
\hline UK & NUI & 388 & 3.60 & (401 & 3,56 \\
\hline UK & OL & 3.83 & 3.47 & $4: 10$ & 3.61 \\
\hline $\mathrm{fl}$ & $\mathrm{U}$ & 3,66 & 3.62 & 417 & 374 \\
\hline NO & UC & 3.69 & 3.74 & 4.13 & 3.98 \\
\hline NO & U & 393 & 4.09 & 421 & 378 \\
\hline
\end{tabular}

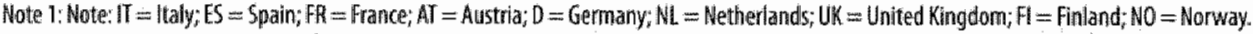
Note $2: \mathrm{U}=$ uniwersify, $\mathrm{GE}=\mathrm{Grande}$ Ecoles, $\mathrm{FH}=$ Fachhochschulen, $\mathrm{HBO}=$ Higher vocational ed ucation, $\mathrm{HU}=$ new university, $0 \mathrm{OU}=$ old uniwersity, $\mathrm{UC}=$ university college.

Considering the reported averages in Table 3.6, the potential errors restrict us in interpreting and comparing the absolute figures. As a matter of fact, the outcome that Italian university graduates score significantly lower on both types of competencies than graduates from Norwegian universities may be related to, first, the fact that the Italian universities are less efficient in teaching these competencies, second, that Italian respondents exaggerate less than Norwegian ones, or, third, that Italian graduates use a different yardstick. In the latter two cases, the true average score may be equal and not as reported in advantage of the Norwegian graduates.

To control as much as possible for the potential measurement errors indicate above, we will use some safery net approaches in the empirical studies, wherever appropriate. This holds in particular for Chapters 4 and 6, where we will make use of a pooled international data set. In Chapter 4 , when analyzing the acquisition of discipline-specific and academic competencies, we will normalize the competencies score with respect to the average score of the student's direct peer group and its distribution. In doing so ${ }_{n}$ we control as much as possible for the fact that there may be heterogeneity in the student's level of competencies (the dependent variable) that is relared to the country, the higher education institutions, insritures or programmes in which the respondent graduated. In Chapter 6, addressing the impact of programme characteristics on the labour market outcome, we will use the difference between the level of academic competencies and the level of discipline-specific competencies as independent variables. The applied safery net solutions are conservative, in the sense that they reduce differences in competencies rather than increase them. 


\subsection{Who works and who doesn't}

To conclude this chapter, we will address a potential problem that is inherent to the fact that the empirical analyses cover only a subgroup of the randomly drawn selection of thigher education graduares. In particular, the studies reported later on in this thesis intend ro relate higher education achievements to the labour market situation of gractuates. For that reason, we have selected respondents who worked at least 12 hours a week on their main assignnents ${ }^{16}$ and hence ignored not only graduates who did not work at all, but also graduares who had minor occasional jobs. Moreover, as we were interested in the performance of the graduates, non-response as to salary further reduced the research population. Table 3.7 reports on the overall number of respondents, the percentage of respondents working at least 12 hours and lastly, on the percentage of working respondents providing information on their satlaries.

Overall, $76 \%$ of the respondents worked at least 12 hours on their main assignments, while $70 \%$ also reported on their salaries. This figure is strikingly lower in Mediterranean countries, where berween $48 \%$ (Italy) and 63\% (France) worked at least 2 hours compared to Western and Northern European countries where between $80 \%$ (Norway) and 92\% (Netherlands) held an occupation for at least i2 hours.

If higher education graduates not having a job or not reporting on the issue of salaries differed in their higher education achievements, and in particular in the acquisition of academic and discipline-specific competencies, the empirical analyses in the later studies may be biased. To test for this, we analyzed the odds of having a job for at least 1.2 hours a wreek and reporting on the salary (the 'selected group') by logistic regressions, induding personal characteristics variables in addition to school-related ones. Table 3.8 reports on the countryindividual logistic regressions ${ }^{17}$.

Table 3.7

Research population and final selection

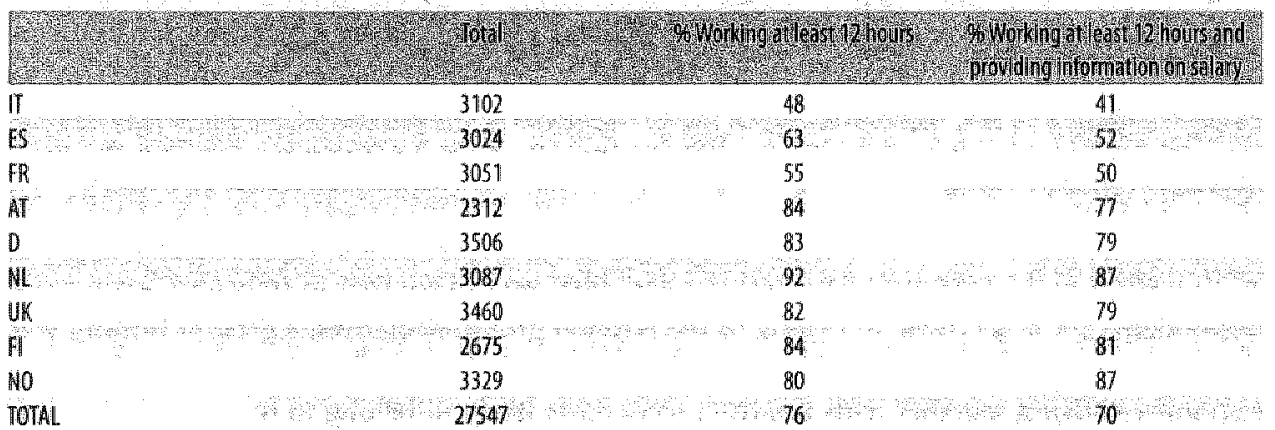

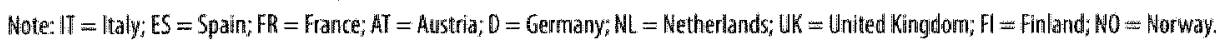

16. We Collowed the deffinion of Statistics Netherlands.

17. We also ran logistic regression amalyses within the group of respondenss working at least in hour: a week, to investiggte to what extent personal, educational and occupational chatacteristics could explain the decisun nor to answer the question regarding salary (data not shown bere). In none of the countries, this deciason seemed to be related to the level of discipline-specific or academic competencies possessed at the time of graduation. Moreower, the estimations also generally showed no significant impact from on her wariables. 
Table 3,8

Logistic regression on hawing a job for at least 12 hours a week and reporting on salary

\begin{tabular}{|c|c|c|c|c|c|c|c|c|c|}
\hline 4 & & & & & & & & & \\
\hline Hder malleresponde & 0,2496 & 0426 & 0010 & 0024 & 0007 & 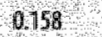 & 0004 & 0264 & 600 \\
\hline 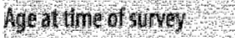 & 0011 & $0047=$ & $0065^{4}=$ & 00346 & $0002 \%$ & 0005 & $0.011 *$ & 0012 & 008 \\
\hline Whing chuluten & 0,011 & $0,410 \%$ & $03^{\circ}$ & 0240 & 00049 & 0313 & 0,047 & 001 & $0572 *$ \\
\hline Motulus & 0,6064 & $0,25, *$ & 10364 & $1980 \mathrm{k}$ & $4826 t+$ & $9709 *$ & $y_{181}$ - & $0.505:$ & $-1354^{\text {mif }}$ \\
\hline Wuingia partiner & $0361 * *$ & $0.597 \%$ & $0,234^{\text {than }}$ & 0.145 & $0,259 * 2$ & Oras & $0,452 \div$ & na. & $0.4966^{\text {tain }}$ \\
\hline & & & & & & & & & \\
\hline e. & & & & & & & & & \\
\hline duction & $+6,373 x$ & 0000 & 00,001 & $0,330 \%$ & 0,004 & $0,312^{* *}$ & 0,172 & 0,98 & 0052 \\
\hline Bedlum ginads & 0178 & $0369 \%$ & 0607 & 0,15 & 0181 & 0.117 & 00032 & 0,585 & 0608964 \\
\hline 6hordes & $0,406 \%$ & $0.651 \%$ & $0325+$ & 0003 & 0.43 & 0,082 & 0068 & 0,487 & $1095 s^{2}$ \\
\hline petornityot & & & & & & & & & \\
\hline nhersity & +4 & 4 & $0990 \%$ & & 0248 & 0339 & $0224^{\circ}$ & & 10014 \\
\hline 19 & & & & & & & & & \\
\hline ts andlumanitigs & nef & मnef: & Rel & Ref & $3 \quad$ Rel & Ret & Ref & Ref & Bet: \\
\hline dialsfences & 0268 & $09699 n$ & 07514 & 0779 & 0219 & $0,560^{2} *$ & 411 & $06686+4$ & $0613^{4+4}$ \\
\hline $165 \ln 5$ & $0,424 d^{x}$ & $0982 \times 1$ & $0602 \%$ & $0,705 \%$ & $0.623 \mathrm{kt}$ & $10.692 \%$ & $0,450^{x}$ & $0,43 \%$ & $1579 \%$ \\
\hline M & $1,00^{*} *$ & $0,533 * *$ & 0.378 & $0,182 x+4$ & 0,360 & 12916 & 0302 & 0376 & $0,67=$ \\
\hline 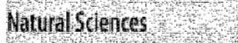 & $10849 \%$ & $0,867 \times$ & 0224 & 0124 & $0.45 \mathrm{~s}^{\mathrm{x}}$ & 1150 & 00009 & 029 & 0.504 \\
\hline frovereng & 0,147 & $10706 \%$ & $0521 \%$ & $0.381^{*}$ & $0,142^{* * *}$ & $0,750^{p+\alpha}$ & $-0,071$ & $0951 \%$ & $0,86^{*}$ \\
\hline edtuh Stiences & $0,549^{12 x}$ & $0,3894 \%$ & 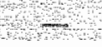 & 0,073 & 0,280 & $0677^{* *}$ & $01463^{*}$ & $0,546 *$ & $0,536 * \%$ \\
\hline & & & & & & & & & \\
\hline apon: & $01140 \% 1$ & 0.036 & $0165^{* x *}$ & 0038 & 0,014 & 0150 & 00,089 & a & 0,09 \\
\hline teemis & 0.020 & 0007 & 0.03 & 0.034 & 003307 & 0.128 & 0.019 & 0140 & 0,104 \\
\hline
\end{tabular}

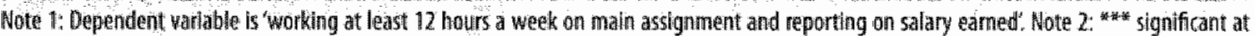

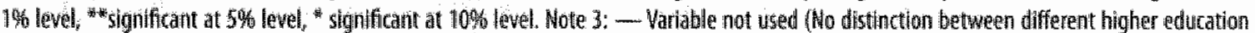

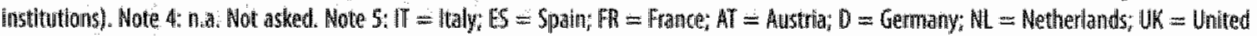
Kingdom; $f 1:$ Finland; $10=$ Norway.

With respect to the personal characteristics variables, we can see that in Italy and Spain male respondents are more likely to belong to the selected group. Moreover, a general finding was thar female respondents with children were less likely to belong to the selected group but that respondents living together with a partner were more likely to belong to it.

Of crucial interest were the findings with respect to the variables indicating the level of discipline-specific and academic comperencies. The coefficients indicate that with the exception of Italy and France (regarding the level of discipline-specific competencies) and with the exception of Germany (regarding the academic competencies), the level of competencies acquired in higher education did not influence the odds of belonging to the selected group. Moreover, if anything, the selecred group possessed at time of graduation a lower level of competencies than the graduates not selected. This finding may be related to the fact that 
graduates with higher levels of competencies were mone likely to proceed in further full-time studies and hence had not yet entered the labour market.

\subsection{Concluding remarks}

The objective of this Chapter was twofold. First, to introduce the reader to the CHEERS survey that provided the data for the empirical studies in this thesis. Second, to propose an output measurement for higher education, based on the competence concept introduced in Chapter 2.

The output measurement we proposed, consists of two competence constructs labelled as academic and discipline-specific. It is derived directly from the actual level of these competencies. Its originality lies mainly in cwo particular fearures. First, it allows getring a dear insight into the heterogeneity of graduates given a particular study programme. Second, it is Alexible and can cope with the constantly evolving mix of competencies taught at higher education and required in the labour market. Tests carried out show that it can be applied across Europe and that it is internally reliable and satisfactory with respect to content and construct validity.

In addition to capturing the individual heterogeneity in output achievements of graduates, measuring higher education output in terms of academic and discipline-specific competencies prowides an innovative way of characterize higher education programmes and higher education systems. Previous typologies located programmes or systems only on two extreme poles (academic or discipline-specific). The approach described here also locates dhem on the continuous scale between these two extreme poles. According to this measurement, in particularly Germany, Austria and the Netherlands come out as having discipline-specifically oriented higher education systems that fir well with their occupationally oriented labour market. "The United Kingdom, Spain, France, and to a lesser extent Finland, can be classified as countries with academically oriented higher education systems that are in line with the characterization of their labour markets as internal labour markets. 


\section{Appendix 3A: The competencies questions in the CHEERS survey}

\section{Competencles and Their Application}

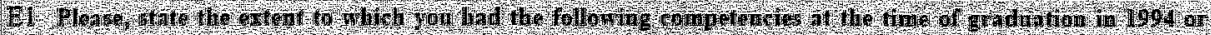

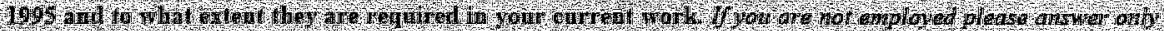
10

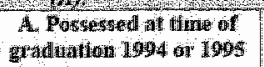

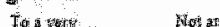

$\frac{1}{12}$

DOMOD.

पDLID

T[D०⿴囗十

$\square \square \square \square \square$

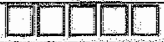

口П口冋口

\begin{tabular}{|c|}
\hline$\square \square \square \square \square$ \\
\hline$\square \square \square \square \square$ \\
\hline$\square \square \square \square \square$ \\
\hline$\square \square \square \square \square$ \\
\hline
\end{tabular}

$\mid$

a. Broad general laxiow ded

6. Crose-tisc iplinary thinking/knowledge

G. Field-speciffic theoretical knowledge

1. Field-speciffe knowilledige of nuethodis

- Foreigy language proficiency

1. Computier sikils

g. Understandnge compules surcial.

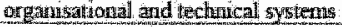

B. Work requithemenis

14. Planting co-ordinating and or gavising

1. Applying rules mid regularions

j. Exonomic reasoning:

k. Documenting idests and information

To a a very Nor

higatertery

$\square \square \square \square$

$\square \square \square \square \square$

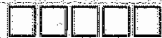

पव口QD

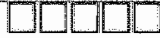

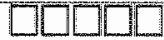

पD口OL

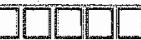

口TLLIL

\begin{tabular}{l|l} 
DIDLID &
\end{tabular}

07 a Problem-solwing aboling

b. Analytical competenctus

di. Leaning abilities

पIDOD

r... - .

2. Reflectrwe thinking assessing one's own watk

f. Cxeativity

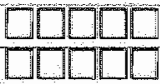

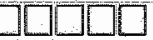

g. Working ander pressure

ti. Accuracy, attetution to detail

4.. Time anamagement

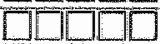

$\square \square \square \square \square$

i. Negotiatisng

k. Fitruess for worts

पLLTD

1. Manual stolls

$\square \square 000$

n. Working independeixty

Q $\square \square \square \square$

n. Working in a tean

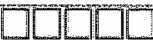

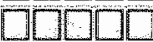

पDELIE

$\square \square \square[\square$

$\square \square \square \square \square$

1.

at. inirative

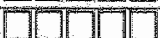

b. Adaptability

OUDLO

c. Assurtshentess, decisiveness, persistence

पDLDD

प0口T

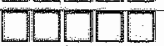

4. Power of concentration

*. Genting personatly involved

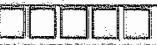

口0प0口0

प0口01

1. Loyaltge integrity

g. Critical thraling

th. Oral connumuneation skills

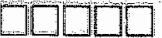

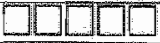

पㅁㅁㅁ

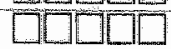

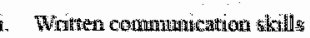

口ㄷㄷ

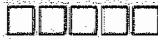

पODLC

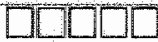

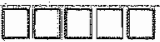

पDODO

$\square \square \square \square \square$

clecance, appreciating of different points of view

k. Leadership

1. Taking responsibilities, dectsions

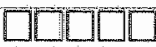

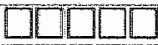

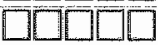

$\square \square \square \square \square$

$\square \square \square \square \square$

$\square \square \square \square \square$

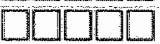

$\square \square \square \square \square$

$\square \square \square \square \square$

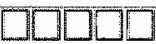

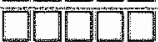

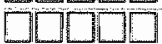




\title{
Chapter 4 \\ Student time allocation, the learning environment and the acquisition of competencies ${ }^{1}$
}

\author{
"The primary learning environment for undergraduate students, the fainly \\ passive lecture-discussion format where faculty alk and wost students listen, is \\ contrary to almost every principle of optimal setting for student learning "
}

Guskin (1994, cited in Barr and Tagg, 1995)

r. This chapter is an extended version of Meng and Heikke (2005). We would like to thank Lex Borghans, Wim Gijselaers, Jeannette Hommes, Ben Kriechel, Karl-Ulrich Mayer, Cees wan der Vleuten, the conference participants at TIY (2004, Nuremberg), ORD (2005, Gent), EALE/SOLE (2005, San Francisco), the participants at two Maastricht University seminars (2004) and a seminar at ZEW (2005, Mannheim) For their comments and discussions on earlier drafus of the paper version. 


\subsection{Introduction}

Successful labout market performance of higher education graduates is generally associated with the acquilition of the correct knowledge and competencies. High-quality education in a particular discipline is still sen as imporant for preparing graduates for a high level of performance on entering the labour market, where advanced and often highly specialized knowledge is required. However, higher education needls to be aware of the increased expectations of firms, who look for graduates resembling "active agents. Such actiwe agents not only address problems in a creative manner, but are able to expand and adapt the potentialities of an existing job. They look beyond the strict borders of their tasks and understand what is needed for a proper functioning of the organization of which they are part. Moreover, in a world in which subject knowledge is rendered obsolete at an increasing rate by the pace of technological progress (Teichler, 1999), active agents ane expected to be prepared for lifelong learning. In line with this, Albeda $(1998)$ argued that learning is no longer the privilege of the young, nor the monopoly of schools and that lifelong learning and permanent education are clear necessities for any rype of career. Hence, higher education is confronted with an increasing demand for graduates with a high level of generic competencies. This is also reflected in the statement by the Australian Government Department of Employment Education and Training (1987) that "the major function of education is $(.$.$) to increase the$ individuals capacity to learn, to provide them with a framework with which to analyze problems and to increase their capacity to deal with new information." In line with this, we argued in Chapter 2 that in particular academic competencies, as a subgroup of generic competencies, are central to higher education programmes. Accordingly, the question arises how curricula in higher education should be adapted to achieve this goal.

Giwen that time, manpower and capital used in higher education are available in limited quantities, the tension between the need for a high level of discipline-specific competencies and at the same time the need for a high level of academic competencies may force a tradeoff with respect to the curriculum serup in higher educarion. Shall higher education provide courses aimed at preparing graduates for a particular but narrow type of occupation or rather courses to prepare graduates as active, flexible and well-rounded academic professionals? Like a pendulum, opinions have swung between advancing either of the two extremes. In the I960s, Becker (1964) for instance concluded that the long pay-off period to education "increases whe advantage of an education that is useful in many kinds of economic environments" (p. 204). In contrast, Rosen, (1983) argued that specialization in education is beneficial in particular when the costs of comperence acquisition are separable. More recendy, the swings have been more strongly away from the narrow education of discipline-specific competencies towards an increased emphasis on generic competencies (see e.g. Bowden and Marton, 1998, Teichler, rggg).

The growing demand for generic comperencies in general and academic competencies in particular in the labour market, together with rising criticism on traditional teaching styles, has led to the widespread establishment of activating learning methods in the last decades. These activating leaming methods constitute the visible surface of a much deeper paradigm shift that is taking place in higher education. The change that we can observe is the shift from higher education institutes as places that exists to provide instruction, to higher education 
institutes that exists to produce learning. In the former case, the means is the end. In the latter case, the means and the end are separated and the end governs the means (Barr and Tagg, 1995). In line with that shift, the actor who plays the leading role in higher education studies is changing too. Whereas in the traditional style, the central figure was the teacher who controlled the learning process and delivered the knowledge in small pieces to passive receivers, activating learning methods expect the learner (student) to be an active discoverer. By stimulating the active discoverer in the student, activating learning environments are expected to promote the acquisition of generic competencies, such as "gathering information', 'interpersonal competencies', 'team working' or 'problem-solving abilities' (see e.g. de Corte, 1990; Everwijn, 1999; van Woerden, 1997).

Considering these newer didactic methods, the question arises if an implementation of them just trades the acquisition of discipline-specific competencies for the acquisition of academic competencies or provides a win-win siruation in which higher education graduares acquire both types of competencies at a higher level. To address this question, the students" time allocation over different types of study activities, which may partially be endogenous to the didactic method used by the higher education institute ${ }^{2}$ they attend, needs to be addressed as well. As a matter of fact, earlier findings (see e.g. Romer, 1993; Durden and Ellis, 1995; Dolton, Marcenaro and Navarro, 2001 ${ }^{3}$ ) that attending formal education is of crucial importance for the learning outcomes of higher education graduates question the implementation of activating learning methods, such as problem-based learning, where lectures are mostly traded-off for more self-learning time.

Analyzing explicitly the learning environment in combination with the students' time allocation will provide us with further insight on the competence acquisition in higher education. Moreover, we are able to confront the current setup of a country's higher education with our findings and see to what extent adaptations are required to address the challenges of a knowledge-driven society. Is further implementation of activating learning environments in discipline-specific oriented countries necessary to compete on the knowledge level with academically oriented countries? Should universities increase their pressure on students to atrend lecrures? Should universities worry in case students increase the number of hours they work for money alongside their studies to cope with higher study costs?

To address these features, we distinguish learning environments from each other according to (1) the emphasis placed on the teacher as the main source of information, and (2) the emphasis placed on activating learning methods such as problem-based learning, With respect to the time allocation of the students, we distinguish between time spent on (1) formal education, (2) self-study, (3) extra-curricular activities, and (4) paid work.

The remainder of this chapter is structured as follows. Section 4.2 discusses the competence transformation process that takes place in higher education. In particular, we will address the role of the learning environment and the role of student time allocation in the acquisition of academic and discipline-specific competencies. Section 4.3 introduces the data

2. We use the term "instirure" to refer to a particular university or school (c.g. University of Maastricht). In contrast to that, we use the term 'institution' to refer to a particular type of higher educarion (e.g. uniwersities or Fachhochschulen)

3. These studies are all restricted to a particular type of learning environment. For a brief discussion, sec Section 4.2 .3 
used for the analyses and provides a first descriptive overview over the different types of learning ervironment and the student time allocation. The empirical analyses are discussed in section 4.4. Finally, Section 4 s concludes the chapter and formulates, on the basis of the findings, policy advice for an adaptation of the higher education system.

\subsection{Competence transformation at Higher Education}

\subsubsection{The production process}

From an economic point of view education can be reganded as a production process in which a variecy of inputs are used to create a multidimensional output. The multidimensionality addressed here refers to the distincrion between academic and discipline-specific competencies, as defined in Chapter 3. Formally, the outcome of higher education in terms of competencies acquired $(C)$ by student $i$ written as a combination of discipline-specific competencies (DS) of type $s$ (e.g. law) and of academic competencies $(A)^{*}$

$$
\text { (4.1) } C_{i s}=C_{1}\left(D S_{i, s}, A_{i}\right)
$$

In order to analyze the educational performance of students on the two comperencies, we will consider a general multiple output production function:

$$
\text { (4.2) }\left(D S_{i, s}, A_{i}\right)=C_{2}(S, I, R, D, T, X)+\varepsilon
$$

where $S=$ students inputs (e.g. pre-higher education schooling achievements), $I=$ institutional/programme factors (e.g. exam formalities, nominal study time), $R=$ resource inputs (e.g. public money spent per student), $X=$ other inpurs (e.g. family inputs, peer inputs but also factors outside the classroom), and $\varepsilon=$ a stochastic term. Moreover, we will add explicitly the two factors that will play a key role in later analyses, namely $D=$ didactic techniques (e.g. activating learning methods) and $T^{*}=$ student time allocation (e.g. time spent on formal education or on self-study).

At the centre of this production process is the student himself. However, students entering a higher education programme are not empty boxes that can be filled with competencies. Rather, they have already passed through a long formation trajectory by parents, family, or in general terms - through their social enviromment and several years of pre-higher education schooling. Hence, the stock of discipline-specific and academic competencies already setted down constitures the basis on which additions and changes during the study at the higher education institute take place. Moreover, the initial tevel of competencies can have a major impact on the effectiveness with which additional competencies are acquired. This may hold in particular with respect to academic competencies to the extent that they reflect the initial

4. We have not added a subscript $(0)$ to $A$ to index the progtam in which academic competencies are acquired, indicating that ais does not matrer. In other words, we wse the term academic competencies not to refer to elements common to different subject-based comperencies but strictly to the additional, subject independent content of these competencies useals in orher helds (see also Chapters 2 and 3 ). 
learning ability level of the student. We will return to these points of concern when discussing the empirical results in Section 4.4. Next, student characteristics such as their motivation, learning style or locus of control influence the competence transformation process. However. it is questionable to what extent they can be seen independendy of the initial comperencies.

Most studies on educational performance (for an overwiew see Hanushek, 2002) focus on the resources available to the schooling system. More specifically, they intend to measure the effects of (i) real resources of the classroom (teacher education, teacher expentence, class size or teacher-student ratios), (2) financial resources (expenditure per student or teacher salaries) and, (3) measures of other resources in schools (specific teacher characteristics, administrative inputs or faciliries). We acknowledge the economic importance of these input factors, but believe that such studies underscore the importance of a crucial aspect of the production. process: the didactic technique. In contrast to the other aspects that constirtte the learning context, the didactic method used is at the heart of the production process. Of equal importance for the contribution to the higher education outcomes may be the student's individual. time allocation to different study activities. This aspect seems of particular interest at higher education level, as students at this lewel are generally given a large amount of freedom in this respect.

We agree that our shift of focus to the effects of didactic techniques and student time allocation relocates the window in the black box rather than creating a new one. Nevertheless, we believe that this helps us further on the journey towards an understanding of the crucial mechanisms inside the competence transformation process of higher education. In what follows, we will briefly address the role of the learning environment, and in particular the roles of activating learning methods and student time allocation. After that, we will present a simple theoretical framework to address the main questions involved.

\subsubsection{Learning environment}

Traditionally, higher education programmes are organized around lectures that intend to help the students to understand the literature. At the end of the study (course), an examination is held in which the students have to demonstrate their understanding of the content of the literature. This traditional style of teaching has met with a variety of criticism. Guskin (1994 cited in Barr and Tagg, 1995) argued that "The primary Ledming enwinoment for underghadwate students, the fairly passite lecture-discussion format where faculty talk and most studerts listen. is contraty to almost exery principle of optimal setting for sudent learning. "More specifically, Gerritsen (1999) argued that the traditional setting bears risks that students acquire knowledge that is meaningless to them and hence will soon be forgotten after the examination. Schmidt and Bouhuijs (1985) criticized this type of leaming environment because it divides the material up into distinct disciplines, whereas the reality that graduates encounter in their professional careers is organized around problems, which have to be addressed using knowl-

5. An important sidenote is that we do not address the possible impact of a change in the leaming environment on resources such as labour or infrastructure costs. As a mater of fact, activating learning mothods are more tabourintensive and need a large number of small rooms. To whar exrent an increase lin finatial costs of a reduchon in research ouptit teduces possible benefits of activating learning methods presenced in this chaper will be an interesting line of research for the future. 
dge from a range of disciplines. These critics have in the last decades given rise to the emergence of a growing number of applications of activating learning methods.

\section{Actwating learning envinonments}

An element that all types of activating learning environments share, is their student-centred approach, requining the sudent to be an active discoverer who is directly involved in the learning process rather than being fed passively by the teacher. Hence, actiwating learning environments include didactic styles that help and motivate students to learn and that promote an active engagement of students with the subject matter, their desire to understand it and their ability to actively apply it. The best-known examples of activating learning environments are project-based learning and problem-based learning learning approach started in medical teaching at the McMaster Uniwersity in Canadla. Its lkey characteristics can be described as follows: "Problem-based learning is the learning that results from the process of working toward the understanding or solution of a problem. The problents encowtered fint in the leaming process" (Barrows, Tamblyn, r980). Although problem-based learning was initiated in the 1970 , its roots can be traced back to the beginning of the $20^{\text {th }}$ century and in particular to the work of Dewey (1916). Dewey proposed that Methods which awe permanently successul in formal education... go back to the type of sitwation which cawes reflection out of school in ordinary life. They give pupils something to do, not something to learn. and the doing is of such a nature as to demand thinking; or the intentional noting of connections; learning naturally results" (Dewey, 1916 , p.r54). In line with this, and nearly roo years later, Vaatstra and de Vries (2003) conchuded on the basis of a literature review that the underlying theoretical point of view is that activating learning methods allow students to acquire the subject matter in an active way, resulting in a better recall of it. Moreover, as they are experienced to apply theoretical knowledge to solwe cases, these graduates are expected to be better able to apply this knowledge in practice. Finally, by stimulating the active discoverer in the student, activating learning environments should promote the acquisition of generic competencies, such as 'gathering information'; "interpersonal competencies', 'team working" or 'problem-solving abilities' (see e.g. de Corte, 1990; Everwijn, 1999; van Woerden, 1997). Comparable ideas are presented in three recent books on learning and teaching (Prosser and Trigwell, 1999; Biggs, 2003; Ramsden, 2003). The general conclusion of these auchors is that the reacher has to create an activating learning environment that stimulates the student to acquile knowledge in an active manner. This will enhance deep learning and a higher level of understanding.

The large majority of previous empirical research on the effectiveness of activating learning methods concentrated on the field of medicine (e.g. Dochy, Segers, van den Bossche and Gijbels, 2003; Norman and Schmidt, 2000). Some studies focused on different disciplines, such as the study by van den Bossche, Segers; Gijbels and Dochy (2001) who investigated

6. Acconding to van Woerden (1997), there are great similarities berween problem-based and project-based leatning. In both types of environments, situdents gain concreve experience with learning independently; working together in groups (education is generally orgainzed around small group meetings under guidance of a tutor , and approaching problems systematically.

7. Deway belonged to the progressive education mowement in America. This novement had irs sources in the phitosophies of Jean Jacques Rousseat, Johamn Pestalozzi, and Friedrich Froebel. 
the effects of problem-based learning environments on the results of economics students. What all of these studies generally conclude is that students who have worked in problembased learning enwironments are betrer at applying knowledge than students from a convenrional learning enwiromment. However, what is not clear is whether there are other differences in the acquired type and lewel of competencies between students from these two types of learning environment. Moreover, by focusing the analyses on a particular field of study or even a particular higher education institute, the possibility to generalize the results is greatly restricted. Finally, these studies mostly neglect the impact of time allocated by students to formal education, self-study and other study accivities and hence, the possible dose relationship between learning environment and time allocation. A broader approach, using daa on Dutch university graduates, was carried out by Vaatstra and de Vries (2003). Vaatstra and de Vries concluded that graduates who study in an activating learning environment during their university education, possessed more general and reflective competencies at time of graduation than graduates who completed a more traditional type of education. On the other hand, they could not establish a relationship between the type of learning environments and the amount of discipline-specific competencies.

Concluding this section, we can state that previous research established that activating learning methods seem in particular to stimulate competencies necessary to apply the knowledge acquired in higher education and competencies related to addressing problems and reflecting on one's own work.

\subsubsection{Time allocation}

Compared to secondary education, students at higher education institutes have a considerable amount of freedom in their decisions on how to allocate their time to different activities. The situation that students are obliged to spend strictly scheduled periods of time in class rooms together with a strict control of their attendance is the exception rather than the rule. The way in which the available time is best allocated between these different activities (e.g. self-study or attending lectures) is of crucial importance from the perspective of the individual student.

Surprisingly, in spite of the crucial impact of time allocation by students on the outcones of the educational production process, research on this topic is scarce. Moreover, most of due studies that control for the student time do so by measuring total time devoted to the course, a variable frequently found to be insignificant. Schmidt $(1983)$ argued that this finding could be explained by the fact that the intensity of study varies so much among students that the assumption of time homogeneity is strongly refuted or that such a time variable is overly aggregated, as students not only allocate scarce vime among courses and leisure but also ration time among alternative study modes within a couse.

The available previous research consists in particular of case studies carried out in the United States, such as Schmidt ( 1983 ), who used data from an experiment run in the aurumn of 1970 at the University of Wisconsin-Madison. The data included 216 students of the

8. Even in cases such as the economic programs at Mastricht Uriwersity, where students are officially requated to attend up to roow of all meetings, students have a backdoor opron and can trade the attendance for an additionall writren assignment. 
Macrocconomic Principles course. Using different econometrical approaches, he found that hours of classroom attention are more productive than hours of self-study. Romer (1993), using data from three U.S. schools (the full sample size was ros students), ran regressions of student performance on the fraction of lectures attended, both excluding and including proxies for motivation. He found in all estimations that the effect of classroom attendance was positive and significant, although the inclusion of proxies for motivation reduced the magnitude grearly. Durden and Ellis (1999), using a sample of 346 students in a Principle of Economics course, found that the typical student is not adversely affected by a few absences... but excessiwe absenteism is associated strowgly with poor academic performance (p. 345). Similar results were also found by Devadoss and Foltz $(1996)$, who found that motivation positively affected attendance and that attendance positiwely affected class performance, and by Chan, Shum and Wright (1997), who found a significant posivive relationship berween attendance and student performance in a Tobit model and an insignificant relationship using a Heckman selection procedure to control for the students' survival process in the course. What is common to these U.S. studies is their focus on the relationship berween classroom attention and student performance, omitring the question of time allocated to self-study.

Two studies that did look at time allocated to self-study in addition to the time allocated to the attendance of classes are Dolton, Marcenaro and Navarro (200r) and Bratti and Staffolani (2002). Dolton et al, (200r), analyzing a sample of 3,722 first- and final-year students from the University of Malaga, found that time allocated to lectures is between twice (using a stochastic production frontier approach) and four (using OLS) times as productive as time allocated to self-study. Bratti and Staffolani (2002) estimated an academic performance regression for frst-year undergraduate students of economics at the University of Ancona. They found evidence that, once they controlled for time allocated to self-study, the positive and significant effect of lecture attendance for some courses disappeared.

The scarce avialability of literature directly addressing the relationship between the allocation of time and student performance itself can be seen as a rationale for further empirical studies that atrempt to shed more light on this aspect. Moreover, what is generally omitted in the previous research is the impact that the learning environment may have on student time allocation and the different productivities of student time within a particular learning environment. In other words, studies investigating the impact of time allocation on educational outcomes without explicitly considering the didactic teaching methods used, ignore whe possible bink between time allocation and the learning environment.

\subsubsection{A simple theoretical approach}

"Those responsible for higher education, together with the students, try to maximize the competence outcome. Under the assumption that study length and monetary resources available are limited and that the marginal costs of producing academic and discipline-specific competencies are progressively related to the intended level, the production possibility frontiers receive a convex shape. Graphically, production possibility frontiers indicate the maximum level of one type of competencies that can be produced in higher education for every possible level of production of the other type of competencies. We have shown two possible production possibility frontiers $\left(P P F_{3}\right.$ and $\left.P P F_{z}\right)$ in Figure 4.r. The location of $P P F_{2}$ 
to the right of $P P F$ indicates a higher production possibility frontier, as a simular level of academic competencies can be produced with a higher level of discipline-specific competencies and vice wersa. A step from $P P F_{8}$ to $P P F_{z}$ requires an increased level of input resources available or, at a given level of inputs, the use of a better production method, such as a more effective learning enwironment.

\section{Fïgure 4.1}

The competence output of higher education programmes/graduates

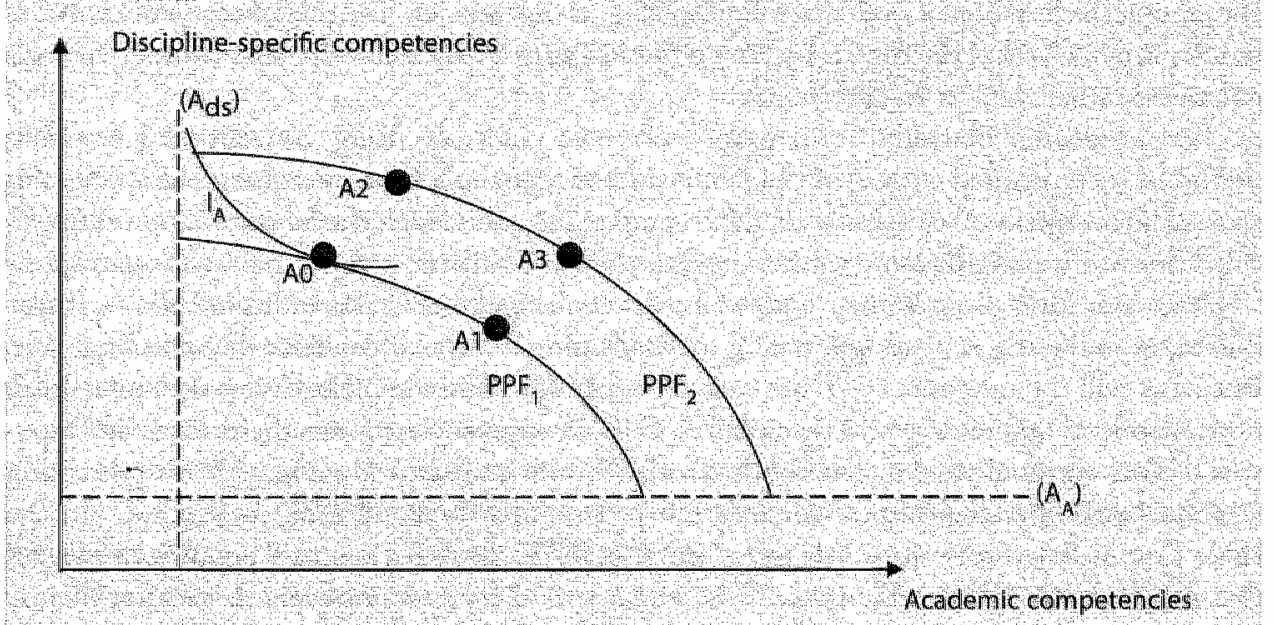

The two dotted lines $\left(A_{\mathrm{ds}}\right.$ and $\left.A_{\mathrm{A}}\right)$ restrict the possible outcomes to combinations with both a minimum level of academic competencies and a minimum level of discipline-specific competencies. Programmes that do not conform to these minimum standards are expected to be discontinued either by losing their accrediration, and hence their official status, or by market forces". Secondly, the location of the dotred lines is derermined by the facr that it is neither possible to acquire a high level of discipline-specific competencies without the acquisition of a minimum level of academic competencies ("without knowing how to learn, you can not learn') nor to acquire academic competencies without learning a discipline ${ }^{10}$.

Assuming that the demand for higher education graduates consists of firms that produce their goods using academic and discipline-specific competencies, we can expect education programmes at least partially to aim at the competencies mix asked by these firms. We have

9. The demand of studen for such programs will decerase ats a retr of continuous unstecesstulngs of the graduates in the labour market.

mo. That the acquistion of academic comperencies needs to be rooted in content, that is, what cducarional goals such as communication or problem-solving abilities necessatly must be relared ro communicating something or to solving some patticular hinds of problems, has been argued by Bowden and Masters (1993). Stephenson (1992) expressed similar ideas to those of Bowden and Masteris when he suggested that the fundarnental objection to a separate generic skill, which he referred to as "boliton capabiticy", is that it denies "the holistic nature of capability, the essential integration of personal qualities, skils and specialist knowledge which cnables students ro be effective' (Stephenson, 1992). 
Illustrated the demand of the firms in Figure $4 . I$ by the isoquant $I_{A}$, representing different combinations of academic and discipline-specific competencies yielding the same level of output. The concave shape assumed in Figure 4.I reflects the option of firms to substitute between the two comperencies. The substitution is assumed to become more difficult, and hence more expensive, the more of a particular type of competency the furm intends to use. Education programme $A o^{x}$ is assumed to respond to the labour market demand with respect to the competence mix that an average graduate acquires. Programme Ao, responding to a discipline-specific competencies-oriented mix asked by the production sector, directs its students at the learning of such discipline-specific competencies. The role of academic competencies is perceived as the means by which the learning of discipline-specific competencies is enhanced rather than as an end in itself.

Let us assume that education programme $A o$, currently using conventional teaching methods, is confronted with a shift in labour market demand. As a consequence of changes in the way firms operate, we assume that the competence mix which the labour market requires shifts drastically towards more value being attached to academic competencies. Those responsible for education programme Ao now face the challenge to teact. As indicated above, introducing or enforcing activating learning methods may be a possible route that can be taken. But what will the outcome be? Does such a change force a trade-off between the acquisition of academic competencies and discipline-specific competencies or are these methods superior to conventional teaching methods? In the former case, introclucing activating learning methods will move the output of education programme $A o$ along $P P F_{s}$ to (e.g.) Ar. In the latter case, it may move outwards to for instance $P P F_{2}$. In that case, two possible outcomes that can be achieved, are $A_{2}$ or $A_{3}$. If the new method increases only the level of academic comperencies that students passess at the time of graduation, programme $A o$ will reach $A 3$. If these methods not only increase the level of academic competencies but also the level of discipline-specific competencies, our programme may find its place in $A 2$. The question what the outcome will be of such a change in the learning environment and to what extent activating learning methods help higher education programmes to solve the dilemma that they are in, will be investigated empirically in Section 4.4 .

Although we argued above that the time allocation of students will be determined partly by the learning environment used, we may still expect to find some heterogeneity between students within a leaning environment with respect to time allocated to, for example, formal education or self-study. This relates back to the brief literature review, in which we stated that it is necessary to treat time allocated to different study activities separately rather than aggregated as overall time spent on studying. Considering the interest in the level and type of comperencies acquired by students at the time of graduation, which is a broader outcome

31. We ignore for the moment the fact that within an education program therc may be heterogeneity between graduates with respect to the acadernic and discipline-specific comperencies that they possess at the time of graduation. Hence, the ourcome may also be drawn as a larger area instead of the point that we have drawn. Illustrating it by an area would indicate that the educarion programme may try to achieve a particular point for the average student bur that betrer students are able to score higher, and vice wersa for the less inrelligent students. Moreover, the size of stch an area would at lewst partially reflect che standardization within a program with respect to the lewel of academic and discipline-specific competencies. In Chapter 6, we will discurs to what extent the standardization itself is an important factor in the transition from higher education to the labour market 
measurement than a particular grade achieved in a course, we have to include more types of study activities than simply the time spent in lecture halls or time spent reading books. As a matrer of fact, paid working time as well as time spent on extra-curricular activities may also be of importance.

Let us assume that each student is able to convert time spent on self study (STy), time spent on formal education (e.g. lectures, seminars) (F), time spent on extra-curricular activities (EC), and rime spent on paid work (W) into additional competencies $(C)^{13}$.

\section{(4.3) $C=C(F, S T, E C, W / S, I, R, D, X)$} subject to: $F+S T+E C+W=T$ (Time available)

Where $\mathrm{C}_{\mathrm{F}} \geq 0, \mathrm{C}_{\mathrm{ST}} \geq \mathrm{O}, \mathrm{C}_{\mathrm{BC}} \geq 0$ and $\mathrm{C}_{\mathrm{W}} \geq 0$. Furthermore, we assume diminishing returns to the rime devoted ro any type of activity and hence $C_{F F} \leq 0, C_{\text {STST }} \leq 0, C_{\text {ECEC }} \leq 0, C_{\text {Ww }} \leq 0$. The precise relation berween time dewoted to a particular type of activity and the competence outcome, as well as the degree to which diminishing returns occur, is conditional on $S$, the input of the student such as pre-higher education schooling achievements, $I$, instiutional or programme factors such as the exan formalities, $R$, resource inputs, $X$, other inputs (e.g. family inputs) and $D$, the learning environment.

This simple theoretical approach is sophisticated enough to explain why the competence outcomes of two graduates, investing the same total time in competence acquisition $(T)$, may differ as a result of the different allocation of the total time over the different ways of competence acquisition. Figure 4.2 illustrates this point.

Let us consider the case of an individual student atiending a higher education programme at an institure that uses a conventional teaching method. For simplicity reasons, we assume that the level of discipline-specific comperencies can only be infuenced by attending lectures and/or by self-study. $E$, represents the competence transformation line of time spent in lecture halls and $\mathrm{E}_{2}$ for time devoted to self-study. In both cases, more time allocated to the activity increases the final competence outcome but with dlecreasing marginal returns. The situation in Figure 4.2 was drawn according to the findings of previous research that we have reported on (e.g. Dolton et al, zoor), namely that spending a particulat anounc of time on attending lectures is more effective in acquiring discipline-specific competencies than spending the same amount of rime on self-study. Hence, our student can achieve a higher level of utility (reflected by a higher indifference curve $I^{1+1}$ ) by artending $n$ hours of lectures than by spending $n$ hours on self-study $\left(I_{2}\right)$.

12. We bave omirted the subscripe indicating the ind widual studen for simplictry reasons.

13. We have omined the decision of the student to enroll in thigher education instead of starting to work.

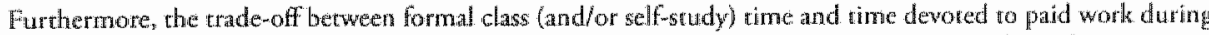
rhe sudy at higher education institute, is not wegarded as a trade-off decision buewern study performance and money in this paper, but rather as a tradeoff decision berween different activities influencing the competericies ortiptis.

I. The upward-sloping curvarure of the indiference curve indicanes the trade-aff betwen the 'good' of acquiriug comperencies and the "bad" of spending cime on studying instead of havirag leisure tine. 


\section{Figure 4.2}

Transformation of time into competencies

Level of discipline specific competencles

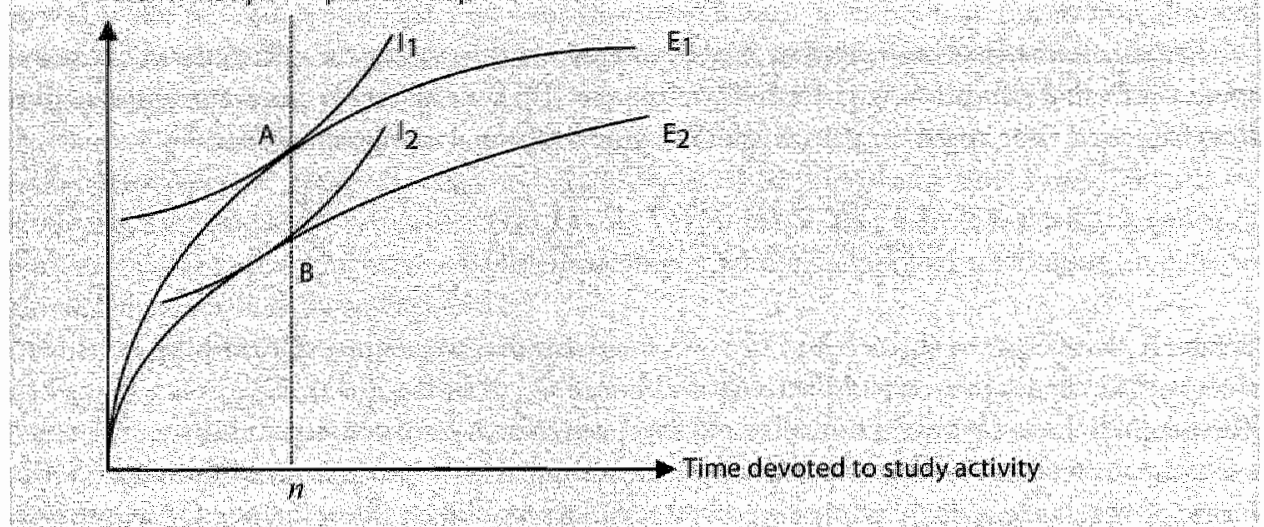

Note: The level of academic competencies to be acquired is set at the level possessed when entering higher education.

However, several questions arise. What does the picture look like when we consider the acquisition of academic comperencies instead of discipline-specific competencies? Might the return to formal education be related to the amount of self-study time to prepare for the class? Is time spent on working alongside the study time lost for the acquisition of competencies or not? These types of questions, together with the question of the effectiveness of learning environments addressed above, will form the focus in the empirical analyses that we turn to now.

\subsection{Data and a first descriptive view}

The research data for this chapter were obtained from the Europe-wide postal survey among $1994 / 1995$ higher education graduates carried out in 1998, introduced in Chapter 3 . The data provide, among a whole set of personal characteristics and the competencies possessed at the time of graduation, a rich set of information with respect to the study programme followed at a higher education institute. In particular, the data allows us to analyze the effects of learning environments and student time allocation for approximately 19,000 graduates in nine European countries (Austria, Finland, France, Germany, Italy, Norway, Spain, The Netherlands and United Kingdom) covering all rypes of higher education institutions"

In what follows, we will discuss and present the operationalization of, first, the competencies acquired by the graduates of higher education and secondly, the part of the data used to define the learning arvironment and the time allocation of the students.

15. Hence, the data not only cowers university graduates but atso graduates from HBO institutes (Netherlands), Fachoohschulen (Ausria), Grande Ecoles (France) and University colleges (Norway). 


\title{
4.3. Discipline-specific and academic competencies
}

The data contains information with respect to different competencies representing differen types of knowledge supplied by graduates. Graduates were asked to indicate on a five-point scale, ranging from $\mathbb{I}$ ("not at all') to 5 (to a very high extenc')", the exrent to which they had a given competency at rime of graduation (in 1994 or 1995). Using a herarchical clustering method, we retained two dusters of competencles representing best our dea of academic comperencies and discipline-specific competencies ${ }^{\text {it }}$. The two clusters consist of the following individual items:

\author{
Academic competencies \\ * Learning abilities \\ * Reflective thinking, assessing one"s own work \\ * Problem-solving abilities \\ * Analytical competencies \\ * Documenting lideas and information \\ Discipline-specific competencies \\ " Field-specific theoretical knowledge \\ Field-specific knowledge of methods
}

For our analyses, we then simply calculated an average of the competence clusters possessed at the rime of graduation. As the individual irems were measured on a fwe-point scale ranging from $x$ ("not possessed at all') to $s$ ('possessed to a very high extent') the graduates scores on a cluster is also bound to between $\mathbb{I}$ and 5 .

\subsubsection{Learning environment}

To define the learning environment, we relied on the respondents' self-report on the emphasis laid by the higher education institute on particular curriculum aspects. More precisely, we used information on the following two questions:

"If you look back to your cowrse of stwdy yow graduated from in 1904 or" 190 s, to what extent were the following modes of teaching and learning ewphosized by your institution of higher education and is teachers?"

a. Teacher as the main source of information and understanding?

b. Project-and problem-based learuing?

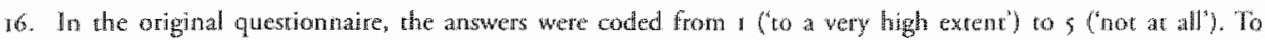
simplify the reading of the empirical analynes, we recoded the answers to range from I (not at all) $10 \mathrm{~s}$ ("to a very high externc).

17. For a more deailed discussion on the dustering method, some descriptives with respect to the conperencies clusters and validity tests of the nwo constructs, see Chaprer 3 . 
For both questions, the respondents could indicate their answers on a fwe-poin scale, ranging from I ("not at all') to ("ro a very high extent). On the basis of the answers by the graduates to these two questions, we distinguished four types of learning environments (see Matrix 4.1 ).

\section{Matrix 4.11}

Four different learining environments

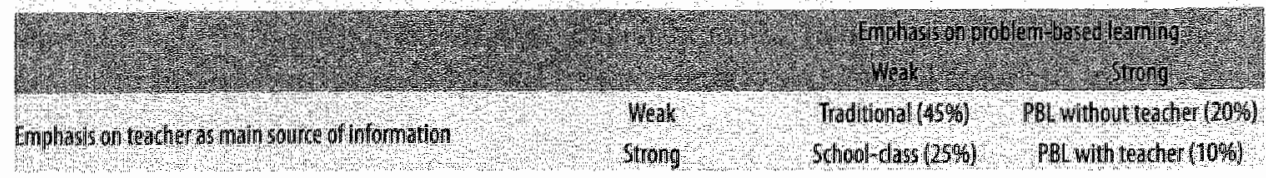

The first wo learning environments that we distinguished, do not use activating learning methods, at least not on a signuficant level (approximated by answer categories 4 and 5 ). The third and fourth learning environments distinguished apply activating learning methods to a significant extent.

\section{1) Traditional style (answer on Teacler: 1 -3; answer on PBL: $1-3$ )}

"This style is characterized by the fact that the higher education institute neither puts strong or very strong emphasis on 'teacher as main source of information' nor on 'problem-based learning. Roughly $45 \%$ of all graduates were taught according to this style.

\section{2) School-class style (answer on Teacber: 4-5; answer on PBL: $-3-3$ )}

In this case, the graduates indicated that the teacher played a strong or very strong rolle as central source of information, but that less emphasis was placed on "problem-based learning". This type of teaching resembles the situation to which students from pre-higher education are used, where the teacher talks and the siudents listen. Given the research population, $25 \%$ of the respondents indicated that this was the case in their higher educarion institute. In contrast to the traditional reaching style, we expect the school-class style to rely relatively more on classroom atrention and relatively less on self-study.

\section{3) PBL without teacher styl (awswer an Tedober: $1-3$; answer an PBL; 4-5)}

The third style that we distinguish, is a siruation in which 'problem-based learning' played a strong or very strong role, but where the teacher was not a major source of information. $20 \%$ of the respondents experienced such a learning environment. This style resembles most likely the original idea of problem- or project-based learning, in which the role of the teacher is seen as process- rather than content-oriented.

\section{4) PBL with wacher shle (anwwer on Teacher, 4-5; answer on PBL: 4-5)}

The final learning enviromment that we distinguish, mixes a strong or very strong role of the teacher as a central source of information with a strong or very strong emphasis on problembased learning. In contrast to the PBL withowt teacher style, this style gives the teacher a role beyond mere process monitoring. $10 \%$ of the respondents belonged to this group. 
Table 4 . reports the use of different learning enwironments in the countries and highter education institutions considered. In all countries providing two types of higher education institutions, the non-university nstitutions are mote likely to provide reaching according to activaning learning methods. However, in Norway, Germany and the Netherlands, the non university instirutions also score higher on teacher-centred learning environmens. Overal, the four learning enwironments are represented in all countries and higher education institutions available in comparable parterns.

\section{Tebllie 4,1}

\% of students in learning environment; Strata: Higher education institution

\begin{tabular}{|c|c|c|c|c|c|c|c|c|c|c|}
\hline \multicolumn{11}{|c|}{ Unwersity ype of higher education } \\
\hline Troflitional & 52 & 4 & 57 & 5 & 64 & 6 & 37 & 42 & 37 & 51 \\
\hline Schododass & 32 & 37 & 8 & 26 & 17 & 99 & 11 & 3 & 11 & 25 \\
\hline BLWIIhteacher & 1 & 10 & 10 & 1 & 4 & 3 & 14 & s & 6 & 7 \\
\hline ABI withoutterdher & & 12 & 15 & 13 & 15 & 16 & 91 & 2 & 20 & 16 \\
\hline (otall & 100 & 190 & 100 & 100 & 101 & 100 & 100 & 100 & 100 & 100 \\
\hline
\end{tabular}

\section{Othar type of higher educakion}

Traditional:

Shooldas

P86 withitediber

Betwothonteracher

Dotal

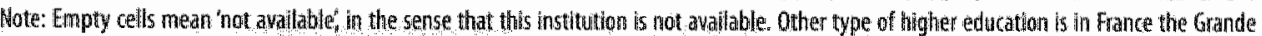

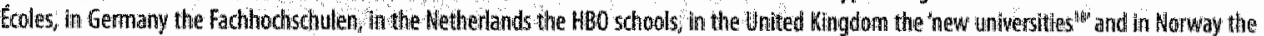
state colleges:

\subsubsection{Student time allocation}

The information on student time allocation was based on the question:

* During your study at the bigher edwcation institute. approximatrely bow many bours a week did you tiwe spend on the following activithes during term? "

The activities distinguished were 'attending formal education of the main subject', 'self-study on the main subject", 'following a second subjecr', 'extra-curricular activities (e.g. student association)' and 'employment'. Table 4.2 shows the average wekly time allocation. The findings show that on average students spend roughly 32 hours a week on their main study. Following a second study is the exception rather than the rule, as can be seen from the fact that the average student spent about $r$ hour and 30 minutes per week on this activity, which

18. "The reason why we rreat the new uniwersities (the former polytechnics) in the United Kingdom separately from the old whiversities was based on their striking differences in enurance requirements and starus as measured for instances by the Sunday Tomes League Tables (Surday Times, zooj). Moreover, the scudents in this study started their studies before the 1992 Higher Education Act was implemented in the United Kangdom. 
is only one third of the time spent on extra-curricular activities, such as working for a student organization. Finally, students spent roughly 2 days a week on paid work.

Dolton et al. (2001) addressed the difficuly of getting respondents to conrectly remember their time allocation. They referred to Juster and Stafford (rggr), who suggested that the best way to do this is by asking people to keep a diary'. However, Juster and Stafford (1997) also mentioned that the mistake was reduced by asking respondents to indicate daily work pattems. As the weekly time allocation is not expected to Auctuate sharply, we used this argument as some reassurance for the approach used here. Moreover, less than $1 \%$ of the respondents reported a weekly time that required them to spend more than 16 hours in total per weekday as students. Excluding extra-curricular activities which students might rather count as leisure time, the percentage of respondents reporting weekly time in line with a workload of 12 or more hours a weekday drops to below $1 \%$.

\section{Table 4.2}

Student time allocation

\begin{tabular}{|c|c|}
\hline Aiteniling formal educalion of fridns subjed & $17 / 35 \mathrm{~min}$ \\
\hline Self - study for main subjea & $14 \mathrm{~h} 49 \mathrm{~min}$ \\
\hline Suld ume of seconds otojet & $1635 \mathrm{~min}$ \\
\hline Extra curricular activities & $4 \mathrm{~h} 47 \mathrm{~min}$ \\
\hline Enploynent & $161220 \mathrm{~min}$ \\
\hline
\end{tabular}

\section{Table 4.3}

Time allocation: Strata: Higher education institution

\begin{tabular}{|c|c|c|c|c|c|c|c|c|c|}
\hline \multicolumn{10}{|l|}{ Universily type of highter education } \\
\hline Atten ding lectures of malnsubject & $17650 m$ & 20hosin: & $20140 m$ & Hh4m & 2010001 & $12 \mathrm{mam}$ & $160,00 \mathrm{~m}$ & $12600 m$ & Bhoom \\
\hline Sell sludy tormans subject & $24 \mathrm{G} 30 \mathrm{~m}$ & $16459 \mathrm{~m}$ & $12 h 08 \mathrm{~m}$ & $17105 \mathrm{~m}$ & 1209 . & $14435 \mathrm{~m}$ & $13 \mathrm{hom}$ & $12 h 29 m$ & $21140 \mathrm{~m}$ \\
\hline Study time of second sulloget & oolidoon & $02 n 20 \mathrm{~m}$ & $00149 \mathrm{~m}$ & $01745 \mathrm{~m}$ & $07 \mathrm{~h} 117$ & $03 h 30 \mathrm{~m}$ & $011 / 7 \mathrm{~m}$ & $05115 \mathrm{~m}$ & onhalm \\
\hline Extranqurloular activites: & 07600 m & $0.419 \mathrm{~m}$ & $03 h 37 \mathrm{~m}$ & OSHSOm & $05122 \pi$ & $03 \mathrm{hi} 6 \mathrm{~mm}$ & $05 \mathrm{hm}$ & $02103 \mathrm{~m}$ & $04440 \mathrm{~m}$ \\
\hline Enployment & 071490 & 03160m & $16137 \mathrm{~m}$ & 16hom & 15644 & 19hitim: & $2 \mathrm{~h} 24 \mathrm{~m}$ & $201607 \mathrm{~m}$ & $21 \mathrm{~s} 56 \mathrm{~m}$ \\
\hline \multicolumn{10}{|l|}{ Other type of bigher eduration } \\
\hline Arendenglectures of nain sobjed & & & $297100 \mathrm{~m}$ & & $20196 \mathrm{~m}$ & $181000 \mathrm{~m}$ & $77000 \mathrm{~m}$ & & $20120 m$ \\
\hline 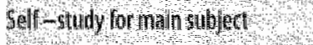 & & & $10 \mathrm{~h} 2 \mathrm{~mm}$ & & $1633 \mathrm{~m}$ & $2 \mathrm{hl} 1 \mathrm{~mm}$ & $15100 \mathrm{~m}$ & & $09102 \mathrm{~m}$ \\
\hline Suidy thme of sorond sillsulet & & & Q0h35m & & $00121 \mathrm{~m}$ & $03130 \mathrm{~m}$ & $011 h 03 \mathrm{~m}$ & & $00107 \mathrm{~m}$ \\
\hline Ertid curitcular actlvilies & & & $0479 \mathrm{~m}$ & & $05115 \mathrm{n}$ & Dothoom & $06 h 33 m$ & & $03 / 51 \mathrm{~m}$ \\
\hline Epiployment: & & & $07142 m$ & & toholn: & 3hint8m & $2 \ln 5 \mathrm{~m}$ & & $2672 \mathrm{~m}$ \\
\hline
\end{tabular}

Note: Other type of highter edtucation is in France the trande Ecolles, in Germany the Fachlochschulen, in the Wetherlands the HBO schools, 腈 the

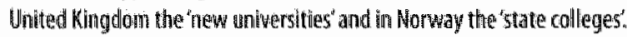

19. Dolton et al (200) mentioned that this approach also has a potential bias, referring to Mulligan, Schneider and Wolfe (2000), who suggested that time budget studies using diaries are subject to sampling biases as participatting in such projects does not take place randomly. 
When discussing the educational production process in Section 4.2 , we argued that time allocation may be influenced by the learning environment in which the study takes place.

Table 4.3 reports the weekly time allocation of students, separately for the nime coun tries considered and, if available, for the different higher education institutions. Students following their higher education study at a Grande Écoles institute in France on average spent more than 29 hours in the classroom, which is nearly three times more than their colleagues at Austrian universities (almost no hours). Although Austrian students compensated for this by allocating roughly seven hours more to self-study than the students at Grande Ecoles do, the large number of classroom attendance hours of the French students led to a great reduction in hours spent on employment/jobs. Students in the United Kingdom and the two Scandinavian countries allocated the highesit number of hours (between 21 and 23 hours) to paid work, whereas students in Spain allocated on average only three and a half hours to paid work. Considering extra-curricular actiwities, Italian and Dutch $\mathrm{HBO}$ students - with seven hours a week - spent most time on these activities. Finally, Finnish students used significantly more time on studying for a second subject than their colleagues in other countries.

Table 4.4 presents the weekly time schedule of our European graduates, according to the learning environment in which the study takes place. Students taught according to the 'problem-based learning with teacher' method, on average spent 20 hours and 40 minutes in the classroom, which is roughly 2 hours more than their colleagues in a 'school-class' or 'PBL. without teacher' learning enwironment did and more than 4 hours more than students in a "traditional' learning environment ${ }^{20}$. Partially, the increased attendance is traded-off against a reduced allocation of time to self-study.

\section{Table 4.4}

Time alllocation: 5trata: learning environment

\begin{tabular}{|c|c|c|c|c|}
\hline Attending formal edlucation of main subject & $16 \mathrm{~h} 20 \mathrm{~m}$ & 18 月 $20 \mathrm{~m}$ & $20 \mathrm{~h} 40 \mathrm{~m}$ & $18 \mathrm{hl} 05 \mathrm{~m}$ \\
\hline Self study formain subjed & $15 \mathrm{hl} 7 \mathrm{~m}$ & $41128 \mathrm{~m}$ & $13646 \mathrm{~m}$ & $14135 \mathrm{~m}$ \\
\hline Study time of second subject & $01 \mathrm{~h} 45 \mathrm{~mm}$ & $01 \mathrm{HB} 5 \mathrm{~m}$ & $01 \mathrm{~h} 38 \mathrm{~m}$ & 01 h $45 \mathrm{~m}$ \\
\hline Eotra arigular activites & $04 n 54 n$ & $04 \times 10 \mathrm{n}$ & 04hs $\mathrm{m}$ & $041154 \mathrm{~ns}$ \\
\hline Employrrentent & $16 \mathrm{~h} 16 \mathrm{~m}$ & $15 \mathrm{mln} 24 \mathrm{~mm}$ & $15.1159 \mathrm{~m}$ & $17 \mathrm{n} 58 \mathrm{~m}$ \\
\hline
\end{tabular}

\subsection{Empirical analyses}

The objective of this chapter is to relate information with respect to the leaming environment in which the study takes place and the time allocation of the student over difteren: study activities to the outcomes of the production process, namely the level of academic and discipline-specific competencies. In this section, we will first address the empirical method used for the analyses and secondly, discuss the results.

20. As expected, we found that students in the school-class method spent relatively more cime in the classroom and: relatively less cime on self-study than studenes in the traditional mednod. 


\subsubsection{The stochastic frontier model}

In the previous sections, we addressed the choice of the higher educarion instirute to apply a certain learning envitonment and the choice of students in allocating their time over the different possible activities to a firm that tries to obtain a particular output by the use of different input materials. If $y=f(x)$ defines such a relationship between inpurs, $x$, and the maximum potential output, $y$, then the textbook proposition that production function is a theoretical ideal implies that the observed value of $y$ must by definition be smaller than or equal to $f(x)$. For an empirical estimation model, this implies that in a formulation such as $y=f(x \mid \beta)+\mu$, with $\mu$ representing the error term, $\mu$ has to be negative and should be interpreted as inefficiency (see e.g: Greene, 2000). The stochastic production frontier function that makes it possible to address this problem, was proposed independently by Aigner, Lovell and Schmidt (1977), and Meeusen and van den Broeck (1977). The original specification involved a linear production function which had an error term with two components, one to account for tandom effects and another to account for technical inefficiency. Formally, such a model can be written as:

$$
\text { (4.4) } y_{i}=x_{i} \beta+v_{i}-\mu_{i}
$$

where $y_{i}$ is the output of the $i$-th student, $x_{\text {; }}$ a vector of input quantities, $\beta$ a vector of unknown parameters, $v$, a random variable assumed to be ind. $N\left(0, \sigma_{v}{ }^{2}\right)$ that is independent of $\mu_{i}$, a non-negative randon variable accounting for technical inefficiency. The model is a generalization of the standard regression model with $\mu_{i}$ as the distinguishing fearure.

The underlying idea of the model is that the student's attainment in academic and disciplinespecific competencies is affected by cwo types of random factors, which are unobservable for us:

The first type ( $v$ ) has a normal distribution. Dolton et al. (200r) referred to the assignment to an inspiring teacher, being a member of a good mutual or self-help study group, and finding the ideal textbook to study from, as examples for this type of random factor.

The second type of random factor $(\mu)$ relates to the inherent ability that restricts the student's achievement potential. With respect to the second type of random factors, it may be appropriate to expect it to have an asymmetric distribution. Considering the research population of higher education students, this asymmetric distribution can be related to the admism sion and selection requirements inherent to higher education. As a matter of fact, only the top 30-40\% of the population of pupils completing secondary education enters higher education. Even when the student, and the higher education institute he atrends, use the most effective mix of ingredients, the achieved outcome will be less than the maximum potential outcome, unless the student's innate ability is highest, allowing the most efficient conversion of input factors into the desired outcome. Aigner, Lovell and Schmidt (1977) suggested rwo possible distributions, namely the absolute value of a nomally distributed variable (the socalled half normal model) and an exponentially distributed variable. However, Battese and Coelli ( 1988 ) indicated that the half-normal specification is the most useful formulation for the kind of data considered here ${ }^{2 i}$.

21. Estimating the model, assuming an exponentially distributed variable, does not significandy change the findings that we will present in the next section. 
Two last problems need to be addressed. First, we have to consider the heterogeneiry of the graduate's level of competencies that is related to unobserved factors, such as higher education institutions, institutes' or programmes" selection and entry standards, assessment methods or resources avallable to them. If such factors differ significantly between education programmes, higher education institutions or countries, the level of competencies indicated by student A in programme I cannot be compared directly to the level of comperencies indicated by student $B$ in programme 2. Moreover, wave to consider that the level of competencies reported by graduates may be related to the amount of self-criticism of the student and to the cultural dimensions of a country. To consider that these aspects imply that a particular score may be strongly biased by the education programme, the higher educa tion institure, the higher education institution or the country the respondent graduated in, we used normallized scores as dependent variables. A frst best approach would be to distinguish between different institutes of higher education and berween highly disaggregared fields of study. Unfortunarely, the data does not allow us to follow such a first besit approach. We are forced to use a second best approach and aggregate the data over narrowly defined education programmes and individual institutes providing these programmes ${ }^{22}$. For the former, we made use of the information on the individuals' educational. fields provided by the International Standard Classification of Education (ISCED, 3 digits). We recoded the 3 -digit ISCED into 7 education fields, namely 'arts and humanities", "social sciences", "business", "law', 'natural sciences", 'engineering' and 'health'. In total, we distinguished 9 different education programmes, nested in 14 different higher education institutions that are nested in 9 different countries. Formally, this is written as:

$$
\text { (4.5) } A_{i, \text { horwalised }}=\left(A_{i}-A_{\text {shc }}\right) / A_{\text {shc }}^{\text {st dev }}
$$

where $A_{\text {, }}$ is the student's individual level of academic competencies, $A_{\text {sh }}$ the average level of academic competencies in study programme $s$ in higher education institution $b$ of country $c$ and $A_{s h c}^{\text {shdev }}$ the standard deviation of academic competencies within study programme s in institution b and country $c$ and, similarly,

$$
\text { (4.6) } D S_{i, \text { siormalised }}=\left(D S_{i}-D S_{s h c}\right) / D S_{s h c}^{s i d e q}
$$

where $D S_{i}$ is the student's indiviclual level of discipline-specific competencies, $D S_{\text {ste }}$ the average level of discipline-specific competencies in study programme $s$ in higher education institu-

2.2. Even though this makes it possible to control, for example for exaggeration of students becween countries, higher education instinutions or education programs, there is still the danger that studerits of a particuliar learning environment (e.g. PBL wichout teacher) exaggerate in weit answers. Logically, it is impossible to control for that directly in the analyses. We tested if similat parterns as repored hereater between the four learning environi ments were also visible for all other comperence types measured in the data (e.g. foreign-llanguge conpereticies). 'The resulus (datat not shown) of these tests show that there are no significant differences between the level of foreign-language competencles berween graduates of different learing enviromenth. At the same time, whe found the inturiwe logical results that female graduates possess a higher level of foreign-language comperencies and that graduates in Italy, Spain. France (with the exception of Grande Ecoles graduates) and in particular graduates from the United Kingdom score below average on foreigr language comperencits. We used these nesults as some reassurance that graduates from a particular learning environment do not a prioni exaggerate more than gractuates front a different learning environment. 
tion $b$ of country $c$, and $D S_{s h c}^{s y}$. the standard deviation of discipline-specific competencies within study programmes in institution b and country $c$.

Hence, we did do nor only normalize regarding the average score of the studenrs direct peers, but also took the standard deviation and thereby the distribution into account. Doing so, we assumed that scoring above (or bellow) average indicated something different in an education programme in which the final outcome varied more than in an education programme with a very harmonized outcome.

The second problem that we had to address, relates to the fact that the acquisition of one type of competencies may not take place independently of the other type of competencies. This holds in particular for the acquisition of discipline-specific competencies. The way we defined academic competencies, as a group of competencies providing a strong base for learning, indicates that these help to increase the effectiveness wich which discipline-specific competencies are learned. In other words, the level of academic competencies that students acquire may be a significant explanatory variable of the discipline-specific comperencies level that they acquire. For this reason, we will control for the acquisition of academic competencies in the discipline-specific competencies model.

To summarize, the model that we have estimated in the following secrion consises of the following two equations:

$$
\begin{aligned}
& \text { (4.7) } A_{i m}=\alpha_{A}+X_{i} \beta_{A}+Y_{i} \delta_{A}+W_{i} \chi_{A}+Z_{i} \gamma_{A}+v_{i A}-\mu_{i A} \\
& \text { (4.8) } D S_{i n}=\alpha_{D S}+X_{i} \beta_{D S}+W_{i} \chi_{D S}+Z_{i} \gamma_{D S}+A_{m} \zeta_{D S}+v_{i D S}-\mu_{i D S}
\end{aligned}
$$

where $A_{i n}$ and $D S_{i n}$ represent - respectively - the normalized score of academic and disciplinespecific competencies possessed by graduate $i$ at the time of graduation, $\alpha^{23}$ is a constant, $X_{j}$ a vector that comprises factors characterizing the student's pre-higher education school career and personal characteristics of the student, $Y_{i}$ an addicional vector of pre-higher education and personal characteristics of the student assumed only to influence the level of academic competencies, $W_{i}$ a vector that indicates the learning environment in which the student completed his study $Z_{i}$ a factor of variables indicating the student's time allocation $v_{i}$, a random variable assumed to be iid. $N\left(0_{x} \sigma_{r}{ }^{2}\right)$ that is independent of $\mu_{i}$, a non-negarive random variable assumed to be a half-nomal distributed vatuable. Moreover, we have added in (4.8) the predicted normalized level of academic competencies an an explanatory factor $\hat{A}_{\mathrm{m}}$. The predicted valued was extracted from applying ordinary least square regressions on equation 4.7 . We will return to this point in more detail after having discussed the results on the acquisition of academic competencies.

In what follows, we will diseuss the results of our empirical analyses in two parts. First, we will pool the data over all four learning environments to discuss the impact of the learning environment and student time allocation. Second, we will re-estimate the analyses per learning environment to anallyze in greater detail the impact of student time allocation in a learning envitonment.

23. The subscrips 'DS' and 'A' undicate that the paraneters belong to the discipline-specific competence model and the acadenic comperence model, respectively. 


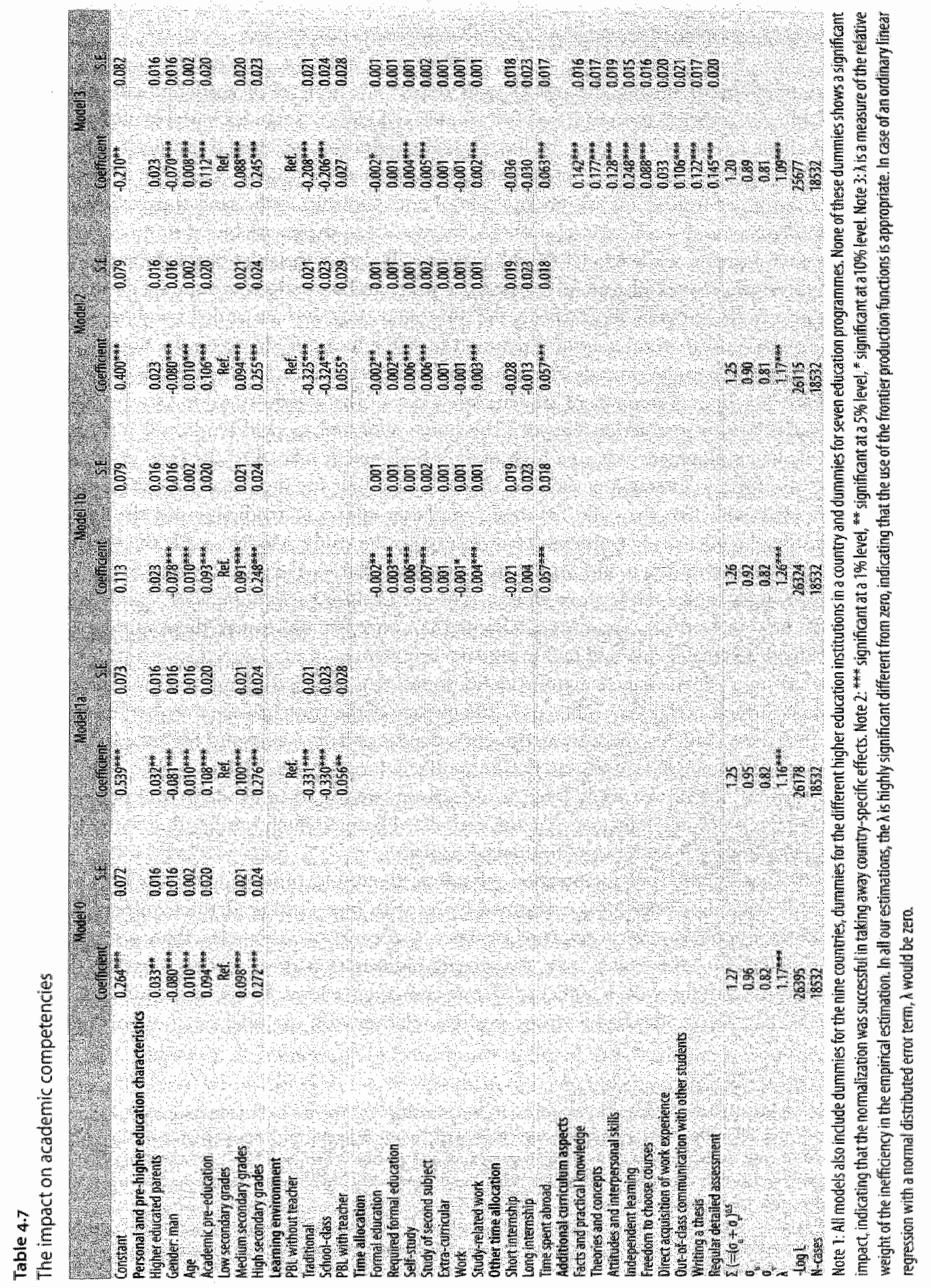




\subsubsection{Results l: Acquisition of academic and discipline-specific competencies}

Let us start off by discussing the results with respect to the level of academic competencles ${ }^{24}$. Table 4.7 presents the results of five models. Model $o^{25}$ indudes variables reflecting personal characteristics (a dummy for having higher educated parents dummies for being male and for age) and variables approximating the situdent's pre-higher education schooling career (a dummy for academic secondary school and dummies indicating the grades with which students passed secondary school). Model ra adds to these variables dummies for the learning environment, while Model $\mathrm{b}$ adds the time allocation variables plus information on possible internships/work placements during the study and on periods of time spent abroad. With respect to the varjables representing the time allocation, we have added two interaction terms. First, we added an interaction ('required formal educarion") between the hours spent in formal education and a dummy that is I if the higher education institute pur a great deal of emphasis on the requirement of student atcendance. The second wariable (study-related work) represents an interaction between the hours allocated to paid work and a dummy that is If if the employment was to a high or wery high extent related to the field of study ${ }^{26}$. Whereas the former interaction wariable allows controlling for if formal education hours are more effective when they are "required", the latter allows us to distinguish the impact of work related to the study from work not related to the study. Model 2 adds the variables on the learning environment and on the study time allocation. Finally, in Model 3, we have controlled for additional curriculum aspects. As some of these curriculum aspects may apply to one of the four learning environments more than once, we can expect them to take over some of the differences explained by learning environments.

Considering the personal characteristics, we found that female students and mote mature students performed better (see Table 4.7). The impact of the student's age may be related to the fact that these students spent some time between secondary school and higher education on activities (e.g. foreign experience) that more likely broaden one's horizon than focusing on the topic one intends to study later on. Moreover, we found in Model o and Model ra that students with higher educated parents performed better, which implies that some kind of knowledge transfer between genetrations takes place ${ }^{2 \gamma}$.

Considering the pre-higher education schooling, the resules indicated that students with an academic secondary education performed better with respect to academic competencies. As academic secondary education teaches more academic competencies than vocational secondary education, this result may also simply indicate that these students started their higher education studies with a higher academic competence level. Lastly, we found that the secondary education grades had a strong positive relation with the final outcome of higher

24. Appendix a defines the variables used.

25. All models also indude dummies for councries, higher education institutions and education programmes.

26. We thed the following question from the sturvey: "to what extent did your working experience tie up with the contemt of your sady? Respondents were given an answer scale from (nor at all) to 5 (to a wery high extenc). We combined answer caregories 4 (to a high extent) and 5 (ro a wery high extent) ro measure strong relation bewerer study and work.

27. To what cxtent such a transter is genetic or just the result of the fact that higher edtucated parenrs are more likely to be able to help their children by instrucring them how to leam or how to address a problem, is clearly beyond che scope of this analysis. 
education. With the exceprion of the dummy for higher educated parents, the impact of the personal and pre-higher education characteristics stayed robust when entering other variables in Model I through Model 3. The findings considering the personal and pre-higher education characteristics will later on be very helpful to instrument the level of academic competencies in the empirical analyses of the discipline-specific competencies.

After entering in Model ta the dummies indicating the type of learning enviroment in which the study took place, the results show the superiority of learning environments that include some type of activating learning method. In Model ra, the most effective learning environment is the 'PBL with teacher style'. However, its effect in relation to the 'PBL, withour teacher style' is lost in Model 2 (at least on a reasonable significance level) and Model 3. In Model $\mathrm{rb}$, we replaced the dummies for the learning environment by the rime allocated to different study activities. The first finding was that formal education (at leasr when nor required) actually reduced the effectiveness with which academic competencies were acquired. Hence, it seems that academic competencies were not most likely to be acquired in the classroom. Time spent on self-study and time spent on studying a second subject increased the performance of students with respect to academic competencies. Paid work, at least when it is related to the study followed, also added to the acquisition. Lastly, we found no significant impact of time allocated to extra-curricular activities ${ }^{28}$. With respect to time allocated to internships or time spent abroad, we found that graduates only benefited from staying abroad for some time. Generally, all results of the time allocation remained very robust when in Model 2 the dummies for the learning environments were addled, which indicates that time allocation is not a priori endogenous to the learning environment.

Lastly, considering the impact of other curricular aspects ${ }^{29}$, we observed that, although most have a significant and positive impact, it was in particular an increased emphasis on 'independent learning' that increased the student's effecriveness. Moreover, their inclusion sharply reduced the effects of our learning environment variables.

Let us continue the discussion with the results of the level of discipline-specific competencies (see Table 4.9). The setup of the models follows closely the setup discussed abowe. However, we added the predicted value of academic comperencies as an explanatory variable. The predicted valued was extracted by applying ordinary least square regressions on equation 4.7. As instrumental variables, we used the dummy for higher educared parents, the age of the students, the dummy for academic secondary schooling, and the two dummies indicating the grades with which the students passed their secondary education exams. Hence, these variables of the academic comperencies estimation do not turn up in the discipline-specific comperencies models. The selection of these five variables was based on the findings presentred in Table 4.7 and on preliminary results with respect to the level of discipline-specific competencies ${ }^{i 0}$. Moreover, different tests confirmed the validity of these variables as instruments (see Table 4.8). First, we provided an F-test statistic in order to test the correlation between these five variables and the level of academic competencies acquired. The resulting coefficients are strongly significant and provide a first validation of the instruments used. Second, we tested

28. We resred for diminishing returns to the time devoted to any type of activity" but were unable to establish such.

29. All of these variables are dummies which are if when the respondent indicated that the higher coducation instisure pur great or very great emphasis on this aspect and o otherwise.

30. Data not reported in this chapter. 
by means of a Hausman $\mathrm{t}$-test if OLS and IV coefficients were significantly different from each other. This rest was implemented by including the residuals obtained from the regression of academic competencies on the instruments as a regressor in the discipline-specific equation and testing its significance. If it was significant, the null hypotheses (OLS estimate = IV estimate) was rejected. With the exception of Model 3 , the t-statistic was significant on a $5 \%$ level validating again the instruments. Lastly, we rested if the instruments were orthogonal to the error term of the discipline-specific regression. In order to test this, the Sargan miss-specification was implemented. The null hypotheses for valid instruments clearly cannot be rejected. Hence, we may conclude that the instruments are highly valid for this purpose.

\section{Table 4,8}

Tests for the validity of instrument wariables

\begin{tabular}{|c|c|c|c|c|c|}
\hline J thes on exchuded warlables & $3764+4$ & $4044 \%$ & $1387^{*}$ & $3464=$ & $3395 \%$ \\
\hline dusman te test of erogenteity & $-2009 *$ & $-2069^{* * 6}$ & $-2.095^{*}$ & $-2,047$ & $-7.835 *$ \\
\hline igans ldentlicollon test & 7,87 & 8,04 & 79 & 167 & 875 \\
\hline
\end{tabular}

Note: All tests were based on 2515 regressions.

Let us first turn to the result with respect to the remaining personal characteristic. Similar to the finding with respect to academic competencies, we can see that male students performed less effectively in the acquisition of discipline-specific competencies than female students. However, the impact this time is clearly smaller and only significant at a ro\% level. Moreover, it loses its significance when orher aspects are entered (see Model I through Model 3).

Entering in Model ra the variables representing the different learning environments reveals that the 'PBL with teacher style' is clearly the most effective one. On the other hand, no significant differences are found between the 'PBL withour teacher style' and the 'traditional style' or between the 'PBL without teacher style' and the 'school class style'. However, the 'school class style' is slightly more efficient than the 'traditional style. These findings remain robust when entering in Model 2 the information on time allocation and in Model 3 the information on additional curriculum aspects ${ }^{31}$. In other words, the results scem to indicate that there is an important role in the acquisition of discipline-specific competencies for the teacher in transferring information to the students.

Turning to Model $\mathrm{sb}$, we can see that atrending formal education is an effective way of time allocation ${ }^{22}$ 33. Moreover, the coefficient for the 'required formal education' indicates that the effectiveness of class attention is strongly influenced by the question if the institure that one attends for one's study puts a great deal of emplasis on student artendance or not.

31. In Model 3, the school-class style becomes more efficient ar a ro\% significance level than the PBL without teacher style.

32. It is important wo note that we was unable to distinguish between the murnber of hours the student attended class and the number of class hours offered by the higher education institute. Hence, an alrernative explanation of this result is that higher education institures should increase the number of class hours offered.

33. We tested to what extent the return to formal education was dependent on the amount of self-study used as preparation time for the formal education. As an increased amount of formal education might reduce the average time available for preparation, one could expect the renurn to formal education per hour self-study to be diminishing. However, no such impact was found. 
More precisely, one hour of class attendance is approximately wice as effective when the instinute puts an emphasis on attendance than when the instirute does not. In addition, atrending required formal educarion is more effective than self-study. Neither time allocated to studying a second subject ${ }^{34}$ nor time allocated to extra-curricular activities show a significant impact. Lastly, we can see that rime allocated to paid work is not by definition time vaken away from the acquisition of discipline-specific comperencies, at least not as long as the work is closely related to the study followed. The findings with respect to the time allocation variables remained robust when entering in Model 2 the learning environment and in Model 3 additional curriculum aspects." No significant impact was found from variables indicating that the student participated in a short or long internship during his study, but a significant negarive impacr was found if the student spent some time abroad. In other words, and combining this result with the impact of staying abroad on academic competencies as presented above, we can see that even though students who spent some time abroad increased their level of academic competencies, which by itself helped increase the effectiveness in the acquisition of discipline-specific competencies, they ended up with a reduced level of discipline-specific competencies compared to students who stayed home. Hence, time spent abroad takes time away from the acquisition of discipline-specific comperencies.

Concluding our discussion on the findings of Table 4.9, let us have a short look at the adclitional curriculum aspects entered in Model 3. The results indicate that in particular attention to 'facts and practical knowledge' and attention to 'theories and concepts' had a great impact.

Before presenting some concluding remarks with respect to the first results, some important features will be discussed. First, we tested the extent to which the approach to normalize the dependent variables influences the story and compared the stochastic frontier appronch with simple OLS estimations (see Appendix 4 B). Moreover, we tested the robustness of the results by applying a Cobb-Douglas functional form instead of the linear functional form underlying the results presented. in Table 4.7 and Table 4.9 (see Appendix $4 \mathrm{C}$ ). All of these tests indicated that the main results are robust to changes in the functional form and the way the dependent variable is measured.

Second, we tested the robustness of the model with respect to two subtypes of higher educarion, namely university education and higher vocational education. For this reason, we re-estimated the analyses on the one hand for all respondencs who graduated from aniversity in the nine countries and on the other hand for graduates in Germany, the Netherlands and Norway who graduated from a higher vocational education institute (Appendix $4 . \mathrm{D}$ reports on the main resulis). With respect to the learning environment, the results for these wo subtypes of higher education are strongly comparable and in line with the overall findings presented above. However, some slight differences were found with respect to the time allocation coefficients. The fact that students at higher vocational education institutes generally possess less freedom

34. We would lite to remind the reader that we measured the discipline-specific comperencies of the nain subject. Hence, this result does not indicate that time allocared to a second subject is not useful in acquiring disciplinespecific competencies of the second subject.

35. We rested for diminishing returns to the unte devored to any type of activity, but could not astablish it.

36. In Germany, this consists of Fachhochschulen graduates, in the Netherlands of graxluaters from higher vocational education (HBO) and in Norway of graduates from state colleges. We did not inclucle in this group the french graduates from Grande Ecoles, as contrary to the other three countries, the Grande Ecales institutes form a higher and more elite type of higher education than university education (see also Chapter 3 ). 
Whacating their time to difererr study activities (c.g. formal educarion is to a larger part predetemined) yields that the cime coefficients are less significant for this group.

Thit, we tested the robustness of the results with respect to two subgroups of countries (countries with a more discipline-specific oriented higher education system (AT, D, NL, NO) and countres wh a more academically oriented higher education system (IT,ES, ER, UK) and with respect to subgroups of education programmes ( $\mathrm{e} g$ graduates from economics and business administation or graduates from health stadies). The results of these estimations do not differ qualitarively from the results presented above and confrem again the robustness of this nodel.

Fourth, the stochastic fronticr approach makes it possible to examine the decomposition of Whe vartance into its two parrs: $v_{i}$, the tandom variable assumed to be idd. $N\left(0, \sigma_{v}{ }^{2}\right)$ and $\mu_{i}$, the non-negative random variable accounting for technical inefficiency. According to Greene $(2000)$, the vartance of the composite error $\varepsilon_{i}$ is given by

$$
\text { (4i9) } \sigma_{E_{i}}^{2}=\left[(1-2 / \pi) * \sigma_{\mu_{i}}^{2}\right]+\sigma_{\psi_{i}}^{2}
$$

In case of the disciplinespecific competencies estimation (Model 3 ) around $57 \%$ and in case of the academic competencies estimation (Model 3 ) around $30 \%$ of the total varianice of $\varepsilon_{i}$ is accounted for by the variance of $\mu_{j}$, and can hence be atributed to technical inefficiency ${ }^{33^{3}}$. As in the case of academic competencies more than two thirds of the variance has to be atributed to unexplained, but normally distributed, variance, one may wonder if using a stochastic production frontier, in contrast to a simple linear regression, adds value to the empirical estimation. To address this, we had a look at the $\lambda$ reported in Table 4.7 and Table $4.9 . \lambda$ is a measure of the relative weight of the inefficiency in the empirical estimations:

$$
\text { (4.10) } \lambda=\sigma_{\mu i}^{2} / \sigma_{v_{i}}^{2}
$$

In all estimations, the $\lambda$ parameter is very significantly different from zero ${ }^{39}$, indicating that the use of the frontier production functions is appropriate.

Let us return to the initial dilemma between the acquisition of academic competencies and the acquisition of discipline-specific comperencies. We have reached a stage where we are able to address the question if a higher education programme confronted with a change in the relative weight attached to one of the two competencies in the labour market is able to react on it without having to accept a rrade-off between the two competencies types. To simplify the main conclusions, Table 4.ro summarizes in qualitative terms the change with which a sitandard studert will be confronted through a change in the learning environment.

The results summarized in Table 4 no show that for both conventional styles, namely the 'traditional style' and the 'school class style", more effective alternatives are available. In the former case, this will be the "PBL without teacher style' or the "PBL with teacher style" (although this would imply a change of both didacric instruments discussed here). In the latter case, implementing the 'PBL with reacher style' would provide a pareto improvement.

3\%. Duta not reported in this Chaprer

38. These figures differ nor significantly among the five models estimated.

39. In the case of an ondinary lineair regression with a normal discributed error term, $\lambda$ is zero. 


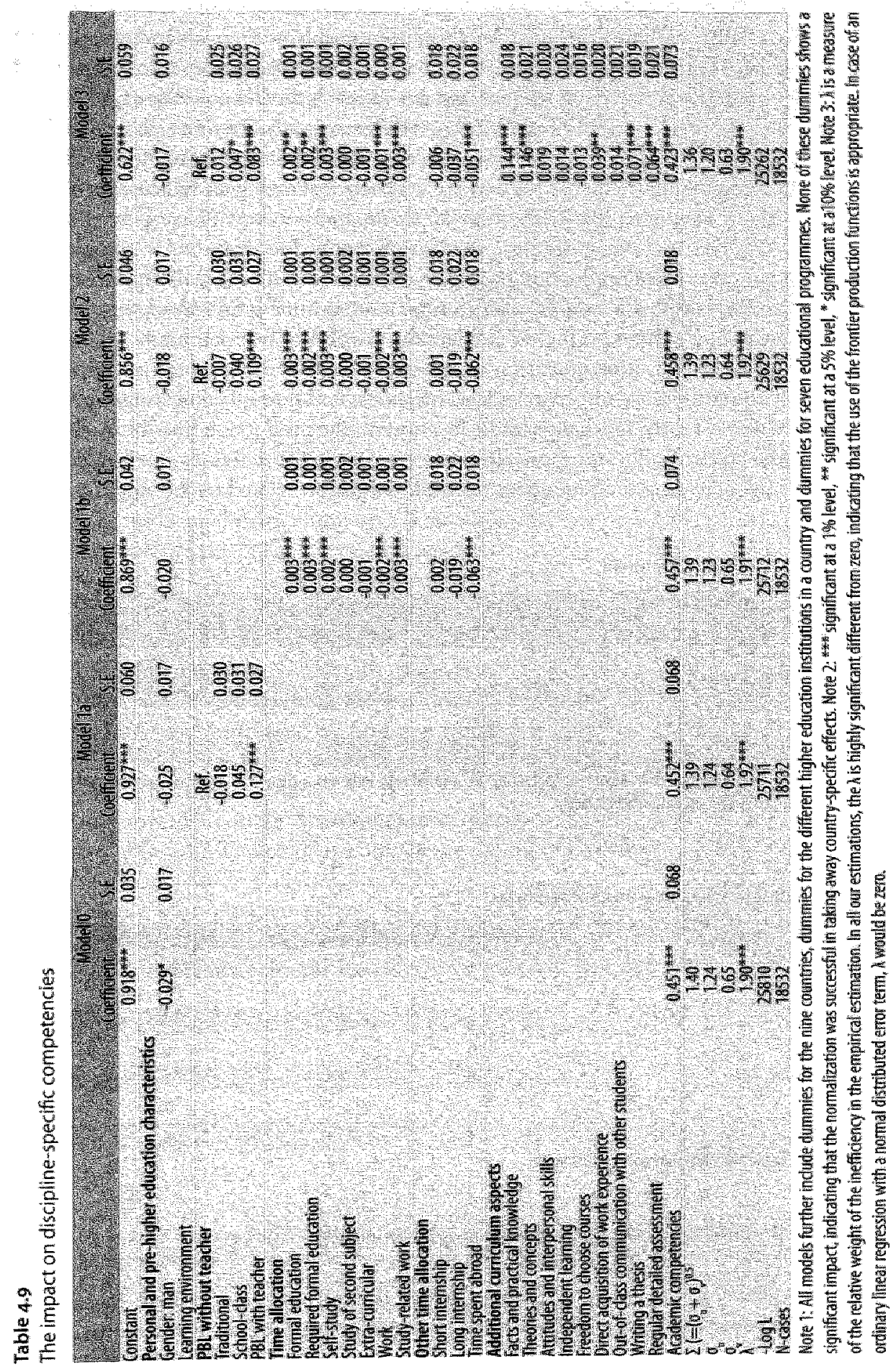


In the case of the PBL without teacher style", those responsible may consider strengthening the role of the teacher in transferring information to the students. However one has to be careful to keep the active discowering student and not to teach the 'school-class style'.

Considering the impact of time allocation across different study activities, Table 4.I gives a qualitative summary based on the resules of Model 3 . Considering only marginal changes in the time allocated to a particular study activity and hence allowing an increase in time in one activity without having to reduce the time spent on another activity, we may conclude the following: Whereas increasing the time spent on formal education that is not required yields a move along the initial production possibility frontier towards more discipline-specific competencies and less academic competencies, an increase in time spent on required formall education allows a move out to a higher producrion possibility frontier. Such an ourward move is also possible by allocating more time to self-study, study of a second subject (however, in this case only the academic competencies level increases) and through allocating more time to study-related work. Lastly, no change in the location on the production possibility frontier takes place if the student allocates more time to extra-curricular activities but the student moves inwards by increasing the time spent on work that is not related to the study.

\section{Thable 4.10}

A change in the leaming envilionment

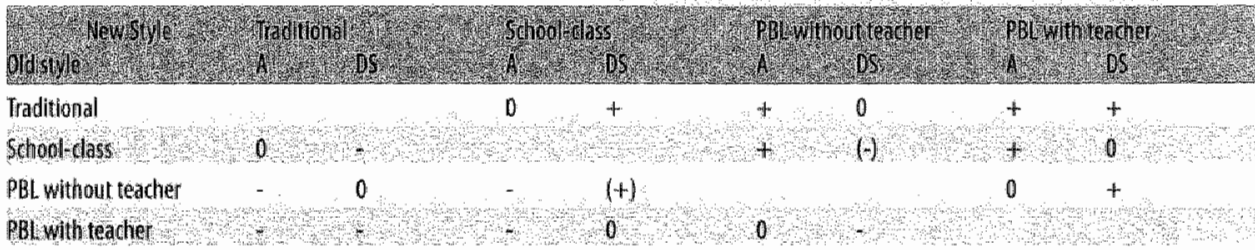

Note: The first sich indicates a change in academic competencies; the second sĭgn indicates a change in discipline-specific competencies. 0 indicates that a change is significant only at a $10 \%$ level.

\section{Table 4.717}

limpect of studentime allocation on competencies

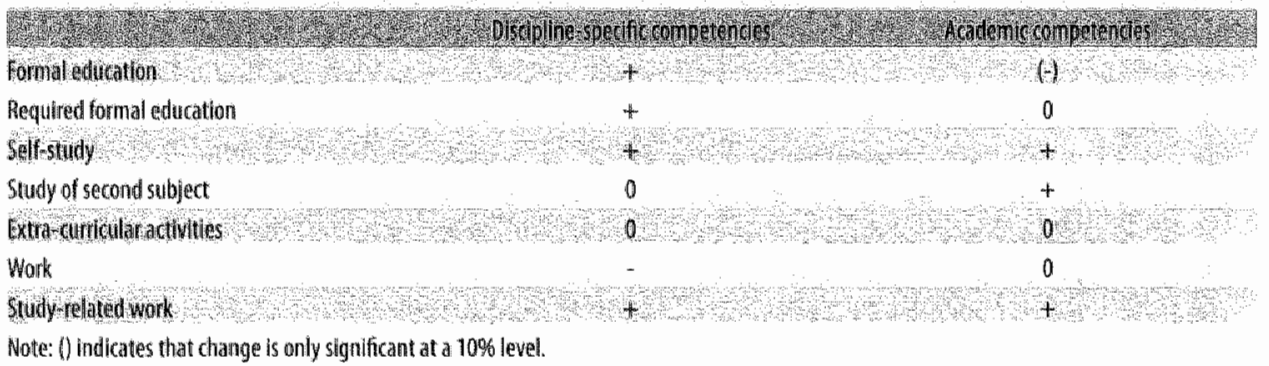

\subsubsection{Results II: Mechanisms working inside a learning environment}

In the section above, we discussed the impact which the learning environment has on the competency outcomes of higher education graduates. Moreover, we analyzed on an aggre- 
gated level the impact of student time allocation. Considering that a change in the learung environment involves a large set of decisions and hence a long time period, and that there may be differences between the impact of time allocated to a particular study activity, depending on the learning enwironment, two specific questions arise. First, given a specific learning environment, is the student himself able to influence the competence outcome once studying? In other words, is there enough freedom inside a learning environment to allocate time to different study acriviries in order to stimulate a particular type of comperenciesto Second, are lecturers in the higher education programme able to partly change the learning envitonment and influence the competencies outcome by, for example, increasing the emphasis put on independent learning withour having to change the learning environment as a whole? To address these questions, we wrill analyze in this section the acquisition of academic and discipline-specific competencies within a given learning environment.

Table 4.12 reports on two frontier models estimared to explain the acquisition of academic competencies within a specific learning environment, while Table 4.13 does the same with respect to the discipline-specific competencies. Model A includes the personal characteristics, the pre-higher education schooling variables, and the time allocation of the student. Model $B$ adds the additional curriculum aspects. Moreover, in line with the discussion in the section above, we will use the predicted value of academic competencies as an additional explanatory variable in the discipline-specific competencies equation.

Let us first have a brief look at the personal and pre-higher education schooling wariables. Alrhough most of them are in line with the general results presented above, some slight but interesting differences can be seen. In particular, male students seem not to perform less effectively than fernale students with respect to the acquisition of academic competencies in the 'school-class' style. Moreover, we find that age does nor play a role in the 'PBL with teacher' style and that the pre-higher education type of schooling does nor play a role in either type of activating learning method.

Let us now focus on the question to what extent students in a particular learning environment are able to influence their comperencies outcome by allocating their time differently over the distinct study activities. In particular, we will address the question if students in a conventional learming environment ("traditional" or "school-class' style) are able to increase their level of academic competencies without harming their acquisition of discipline-specific competencies and vice versa for students in an activating learning environment ${ }^{4 !}$.

40. It is important to note that all results can only be interpreted as a marginat shift and cannot be extrapolated ower the entire time avallable to the student, as we do not know what the minimum number of hours allocated to a particular activity (eyg artending formall education) is, so that the sedent passes the minimum exam requiremenes. The reader has to keep in tnind that all respondents passed the tir fonal exarrs.

41. We will focus on the results presented in Model $A$, allough in general terms the results reported in Modted IB are qualitatively comparable. 


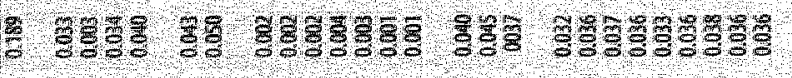

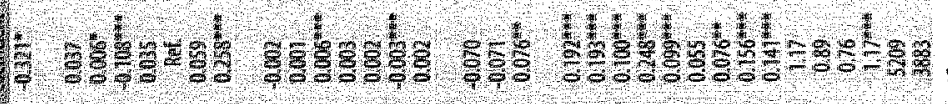

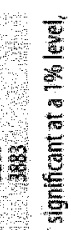

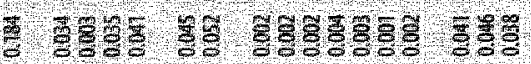

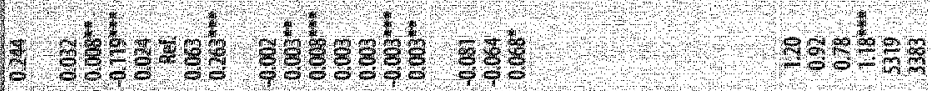

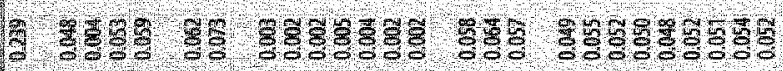

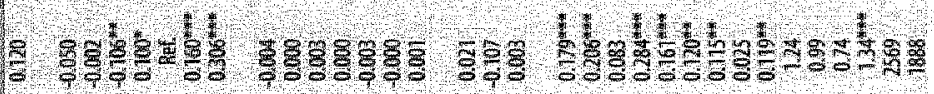

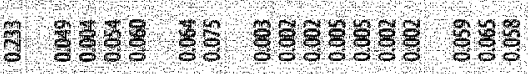

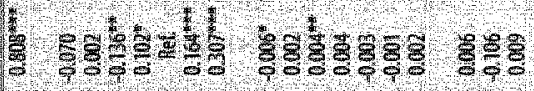

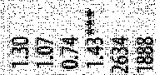

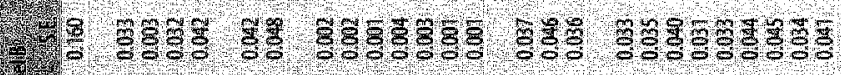

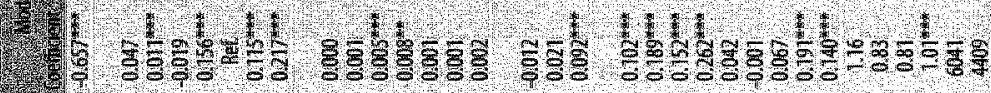

훙형형

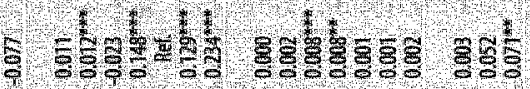

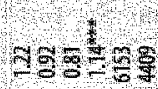

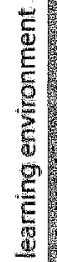

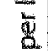

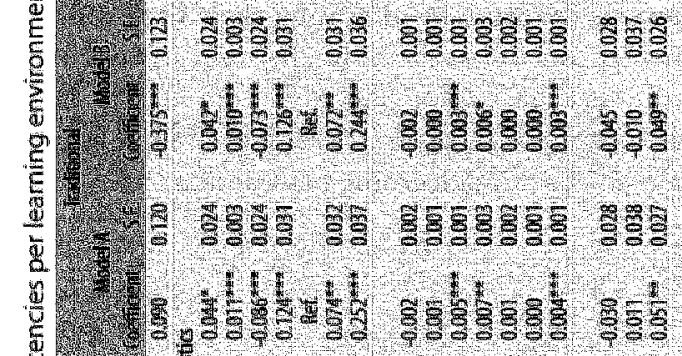

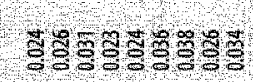

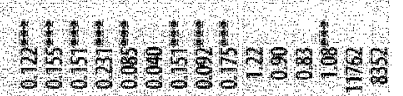

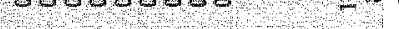

㩆
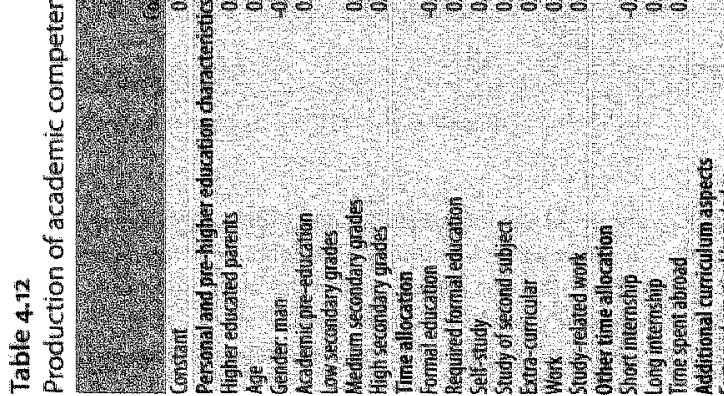

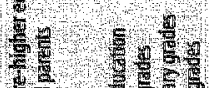




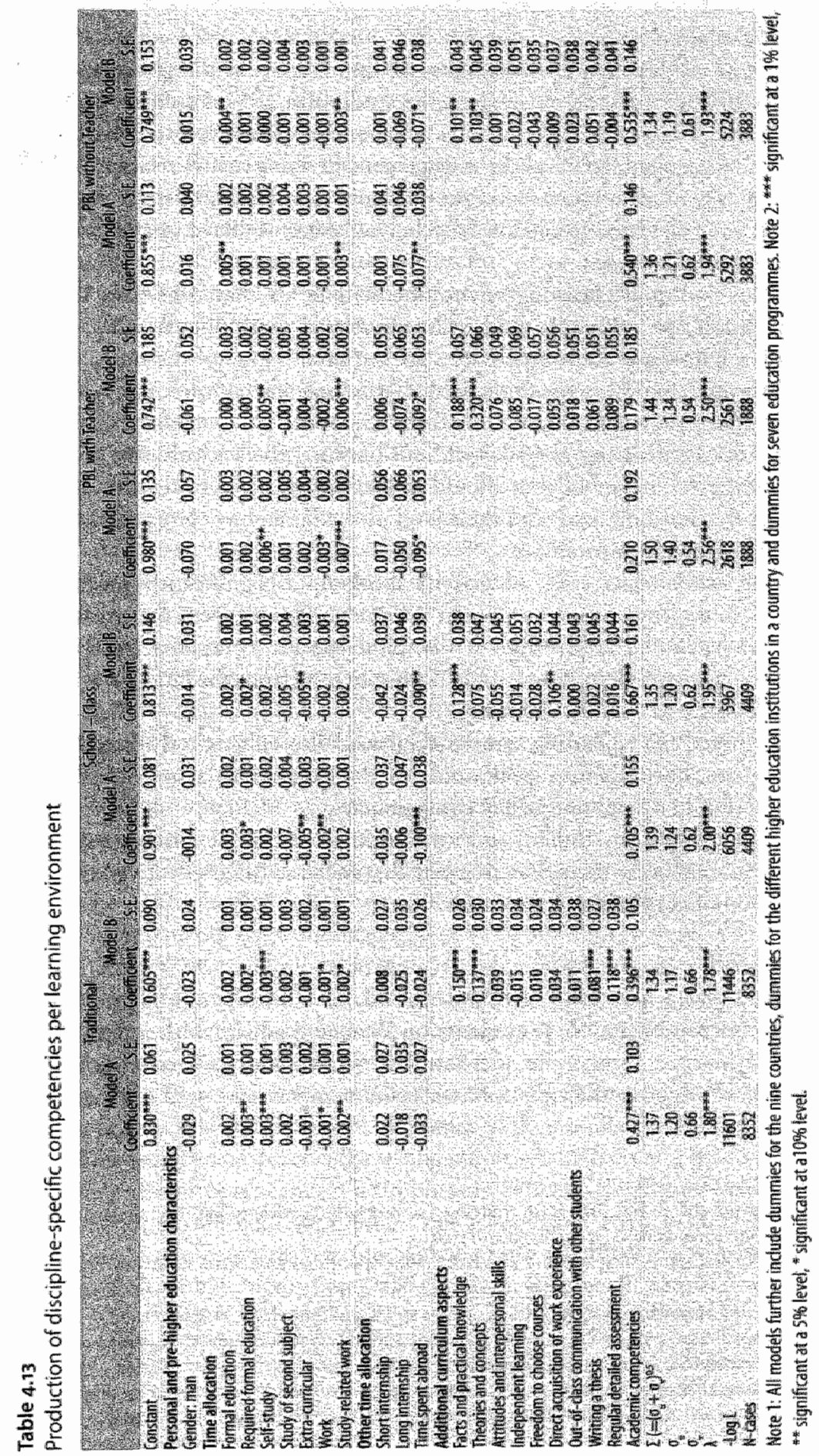




\section{Conventional learning enviroments}

In both types of conventional learning environments, we find that at the margin an increase in time allocated to self-study or rime devoted to the study of a second subject increases the effectiveness with which academic competencies are acquired. Moreover, students in the traditional style may achicve a similar result by enigagement in work that is related to their study. Considering that a significant increase in time allocated to one of these study activities implies a reduction in time allocated to one of the orher activities, we have to ask to which activity less time should be allocated.

For students in the traditional learning environment, it holds that time allocated to 'required formal education', to 'self-study' and to 'study-related work' increases the effectiveness with which discipline-specific competencies are acquired. None of the other activities have a significant impact on the acquisition of discipline-specific competencies. Hence, students in the traditional style can reallocate time from one of the larter activities to one of the academic competencies-enhancing activities without harming their acquisition of discipline-specific comperencies ${ }^{42}$. Preferably, they should reallocate time from non-study-related work ${ }^{43}$ to self-study as this not only increases their level of academic but competencies also their level of discipline-specific competencies.

For students in the 'school-class' style, no activity shows up as significantly positive in Table $4.13^{\text {t4 }}$. However, time spent on extra-curricular acrivities and time spent on non-studyrelated work seems to harm the acquisition of discipline-specific competencies. Hence, students in the 'school-class style' should preferably reallocate time from the larter two activities to self-study or the study of a second subjectss.

Finally, it must be stated that spending some time abroad also enhances the acquisition of academic competencies, but that this applies only in the case of the 'school-class' style combined with a reduction in discipline-specific competencies.

Summarizing, we can state that students in a conventional learning environment seem to have enough freedom to allocare their time in a way that increases their effectiveness with respect to the acquisition of academic competencies.

\section{Actituating Learning methods}

Let us turn to students in an activaring learning method. In contrast to students in the conventional learning environments, these students on average graduate with an academically oriented competence mix. Hence, the question that we will address is to what extent these students are able to increase their discipline-specific competencies without harming their academic competencies.

42. To what extert students are able to free time from studying a second subject without haming the acquistion of these disciptine-spectic competencies, is impossible to state.

43. Non-study-matad work reduces the effiency with which discipline-specific comperencies are acquired at a ron significnnce lexel.

44. "The finding that "required fornal education" only shows up on ao\% significance level, may be related ro the fact that sudens in the "school-class" style have less freedom in choosing the amount of time dhey intend to spend in the class room. The ssane holds with respece to students in the PBL, with teacher' scyle (see "Table 4.13)

45. We ignore that time spent on extra-curricular activities may add to the level of other competencies that are not measured in this study, on my help the sudenes ro build up a nerwork that will later prove beneficial in finding an ockupation. 
The results in Table 4.12 indicate that in both types of activating learning environments; time spent on self-study enthances the acquisition of academic competencies. Moreover, for students inside the 'PBL without teacher' style, the same holds for attendance in required formal education ${ }^{4 / 5}$ and for time spent on study-related employment. Finally, non-studyrelated work is harmful for the acquisition of academic comperencies. Hence, we see that students in both types of activating learning environment, but in particular in the "PBL, with teacher' learning environment, have ample possibilities to reallocate time without harming the acquisition of academic competencies. But where to reallocate to?

For a student in a 'PBL without teacher' learning environment, two attractive possibilities are attending more formal education or allocating more time to study-related employment. In the latter case, students will not only see their acquisition of discipline-specific competencies enhanced but also their acquisition of academic competencies. Higher education institutes may help by providing to students a network of employers offering closely related work, enabling students to trade their non-study-related employment for study-related employment.

According to Table 4.13, students in the 'PBL wich teacher' learning environment are able to enhance their acquisition of discipline-specific competencies either by self-study or by study-related employment. As the former also stimulates the acquisition of academic comperencies, students are able to achieve a win-win situation for example by reducing formal education and increasing self-study.

Finally, we can see that in both activating learning environments, in contrast to the discipline-specific oriented conventional learning environments, time spent abroad does not enthance the acquisition of academic competencies and that it harms the acquisition of discipline-specific competencies in particular in the case of a 'PBL without teacher' style. The former may be related to the fact that activating learning environments provide the most effective environment to acquire academic competencies and lience, there is no point in spending some time abroad.

So far, we have discussed the possible reallocation of time from a sudent's point of view; but some of the results indicate possibilities for higher education institute administrators. The findings reveal again the importance of "study-related work ${ }^{2}$ not only with respect to the acquisition of academic competencies (in 2 our of 4 cases) but also with respect to the acquisition of discipline-specific comperencies (in 3 our of 4 cases). Hence, stimulating, but also helping, students to obtain such jobs may be of crucial self-interest for higher education institures.

Let us finally turn to the question if teachers, given a particular learning environment, are able to fine-tune the competence ourcomes of their students. We can see that in the case of discipline-specific competencies a strong emphasis on 'facts and practical knowledge' and on 'theories and concepts' seems to be important. Whereas the former holds for all learning environments, the latrer does not hold for the 'school-class' style. With respect to the acquisition of academic competencies, we found that nearly all additional curriculum aspects turn up positive and strongly significant. This may indicate that the acquisition of academic compe-

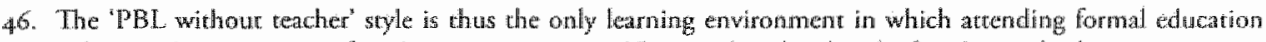
enhances the acquisition of academic comperencies. This may be ratated to the fact that in this learning environ. ment formal ed weanion implies discussing topics with other studens and thence enables one to acquare academic comperencies easily during dass rime. 
tencies is in particular stimulated by good teaching. However, clearly the greatest influence comes from enhancing "independent learning".

\subsection{Concluding remarks}

The objective of this chapter was to analyze the impact of the learning environment and the student's time allocation on the acquisition of academic and discipline-specific competencies. This poses the question whether higher education institutes should implement activaring learning environments, such as problem-based or project-based learning, and what would be an effective use of time for students in higher education studies.

To conclude this chapter, we will consider the European situation and use the results presented in this study to indicate how the higher education system in various countries can be adapted to address the challenges of a knowledge-intensive economy and maintain its competitive level. More specifically, we will compare the situation in the two country groups defined in Chapter 3. The first group consists of the Unired Kingdom, Spain, France and Finland and was labelled academic comtries, the second group consists of the Netherlands; Germany and Austria and. was labelled disciplone-spectfic countries. We will focus on three outstanding features of the large variety of results presented in this paper, namely the use of activating learning environments, the emplasis placed on class attention , and the relation between paid employment alongside the study and the study itselfiz.

A first clear result is that to prepare graduates for the tequirements of a knowledgeintensive economy more activating learning environments are needed to provide not only a substantive level of discipline-specific competencies, but also a high level of academic competencies. The percentage of students taught in the discipline-specifically oriented countries according to activating styles is $25 \%$ in the Netherlands (universities: $21 \%$, HBO institutes: $31 \%$ ), $21 \%$ in Germany (universities: $19 \%$, Fachhochschulen: $23 \%$ ) and $20 \%$ in Austria. This is low; compared to countries such as the Unired Kingdom ( $55 \%$ ), France (32\%) or Finland $(27 \%)$, all of which are representatives of the academically oriented countries. The relatively limited use of activating learning environments in the discipline-specifically oriented countries fits the requirements of their traditionally ocoupation-oriented labour market. However, if one wishes to adjust to a gradual change in the weight attached to academic competencies in the labour market, the implementation of activating learning environments in these countries needs to be stimulated. Interestingly, both in Germany and in the Netherlands, institures (Fachhochschulen and $\mathrm{HBO}$ institutes, respectively) that formally provide more occupationally oriented programmes than universities are in a better starting position than universities in these countries. Unless universiries catch up, graduates from $\mathrm{HBO}$ and Fachhochschulen institutes may become serious comperitors to university graduates for academic-competenceoriented occupations that form a central part in a knowledge-intensive conomy.

47. Two remarks need to be inade. First, the reader needs to keep in mind that we are unable to analyze the cost side of, for example, an implenentation of an activating learning environment. The cost side inducles both financial costs and a reduction in the research output of the higher eduction institute. Accordingly, our conclusions were based on costuneutral changes. Second ${ }_{i}$ the analyses were restricted to extracting impacts on the level of academic and discipline-specific comperencies only. 
Another result of these analyses is that attendance in formal education is particularly effective for acquiring discipline-specific competencies when universities place a strong emphasis on class attendance (measured as time spent on "required formal education"). A similar resule can be observed for academic competencies when "problem-based learning without teacher" is used. It was interesting to see again that the situation at Dutch, German and Austrian universities is less than optimal. In contrast to the United Kingdom, where 60\% of all class attendance takes place at institutes placing a strong emphasis on it or in Spain with $48 \%$, the score of $30 \%$ is only half the percentage for universities in the Netherlands, Germany or Austria. This is particularly surprising as the latter countries provide on average a discipline-specifcally oriented type of higher education. Regardless of the fact whecher the change towards activating learning environments is made or not, universities in the Netherlands, Germany and Austria need to increase the pressure on students to attend classes frequently. If no activating learning environments are implemented, it increases the effectiveness with which discipline-specific competencies are acquired. If 'problem-based learning withour teacher' is implemented, it increases the effectiveness with which academic competencies are acquired.

In contrast to the wwo features discussed above, the situation with respect to paid employment activities alongside the main study is much better in the discipline-specifically oriented countries. The resulss show that study-related paid employment is not only an effective way of acquiring academic competencies but also discipline-specific ones. $35 \%$ of paid work done by Durch higher education students matches well their field of study. Slightly lower bur still relatively high ratios were found for the other discipline-specifically oriented countries German and. Austria (both 25\%). In contrast, the ratio in academically oriented countries is significantly lower: $x 4 \%$ in the United Kingdom, $12 \%$ in France and only $7 \%$ in Spain. It is clearly important for the outcome of higher educarion in the discipline-specific countries to keep this preferred situation and for academic countries to work on their situation. If stucly costs in the Netherlands, Germany or Austria are increased (e.g. through higher tuition fees or lower/shorter grants), the students'. need to react with an increased number of hours working for money will put pressure on the ratio. This holds as the supply of matching occupations may be restricted or finding such occupations needs an additional effort on the part of the students. In that case, higher education institures should react and facilitate the matching of their students with these occupations. In doing so, higher education institutes may prevent the negarive impact of higher study costs on the discipline-specific competence outcome.

To conclude, with respect to two our of the three features singled out (weak on activating learning environments and strong on study-related paid work activities) the serup of higher education in the Netherlands, Germany and Austria fits well with its discipline-specifically oriented aim and the occupational labour market for which graduates have been prepared. Similarly, the setup of higher education in the United Kingdom, France and Spain (strong on activating learning environments combined with being strong on class attendance requirements and weak on study-related paid work activities) fits its academic ain and the internal labour market that graduates enter. However, if the labour market in the first group of countries gradually starts to resemble the labour marker in the second group, adaptations are necessary and in specific further implementations of activating learning environments are required. 


\section{Appendix 4A: Definitions of variables used}

\section{Dependent Variables}

Wrotnespeofic competendes

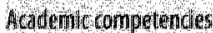

\section{Independent variates} Mgler od oucted pairents

Gendersment

19.

Aoromicore adoution

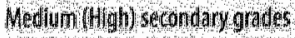

QDL withoulteroror

Tudinonal

Sd oololaso

BDl with reacher

gomal eductow

Dequiredromalsoducation

Seftostify

Study of serond subjert

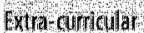

Work:

Study related word

Bats and pratugillnowledge

Theorles and concepts

Attludes znd Interpetsonalskils

Independent terming

reedon to choose ow onses

Directacquistlonof workerperience

Dul-o/las commun cation withother students

Whingulanes?

Meoular denaledociscosment
Nornalized average of items

Normalized average of thens
Dimmy if mother and or lorther thas higher education diploma

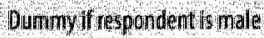

Age in years ar the thine of lhe surwey

Dumny if tesponden conplete an acadenic secondary education befone hingher education

Dunny if respondent graduated fom secondary school with med bum (hingh) awerage grades

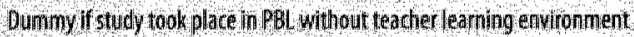

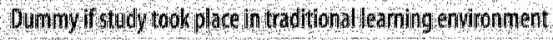

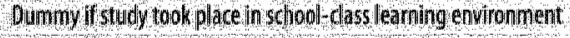

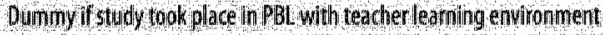
Houts per weekspent on antending dasses/ectures/meetings Hoirs,per weets spent on attending dasses/lectures/meetings f atlendlance was required Wours wer weeks pent on selfstudy Hours per week spent on studying a second sibjed Hoursper week spent on ex tra curricular activilies Hours ger week spent on paid employment fours per week spent on paid enployment if work was related to study

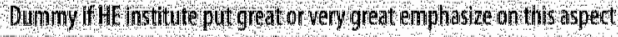

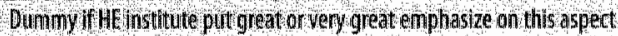

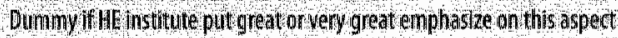
Dummy iff iE inst titure put great or very great emphas ze on thits aspect Dumumy If 1 E Institule put grea or very great emphas ize on this aspect Dummy df LE Institule put great or very great emphasize on this asped Dummy if IH Institute put great or very great emplias ize on this aspect

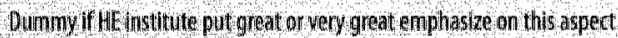
Dumnu if LC institute put great or very great empliasize on this alspect 


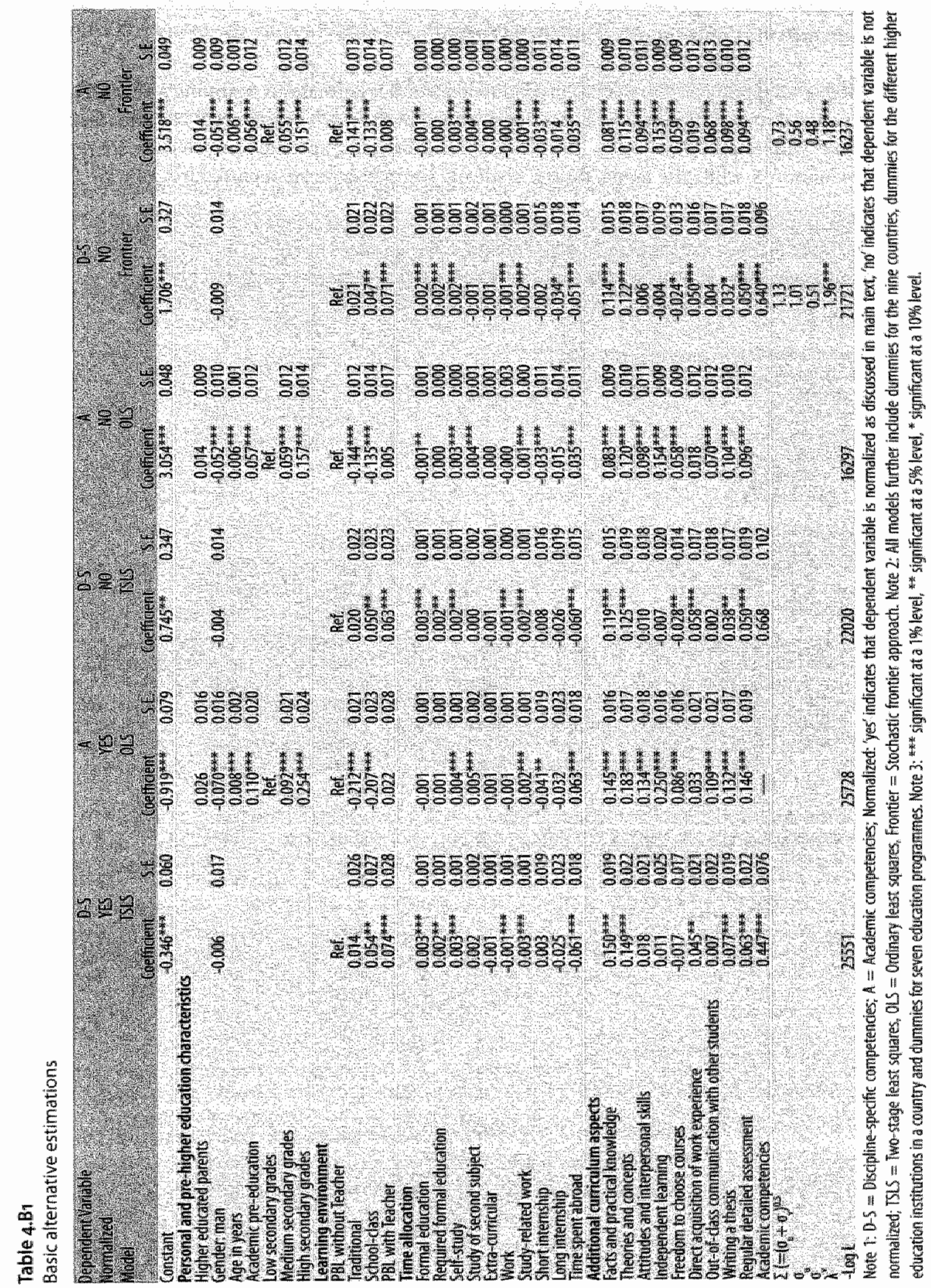




\section{Appendix 4C: Cobb-Douglas Functional Form}

Table 4 . Ci reports on the stochastic production frontier estimations assuming a Cobb-Douglas functional form instcad of the linear one assumed in the main texc we will concentrate on the results with respect to Model 3 . The results for the discipline-specific competencies are reported in Column 2, while the results for the academic competencies are reported in Column 3 .

Table 4.C.

Stochastic production frontier assuming a Cobb-Douglas Functional Form

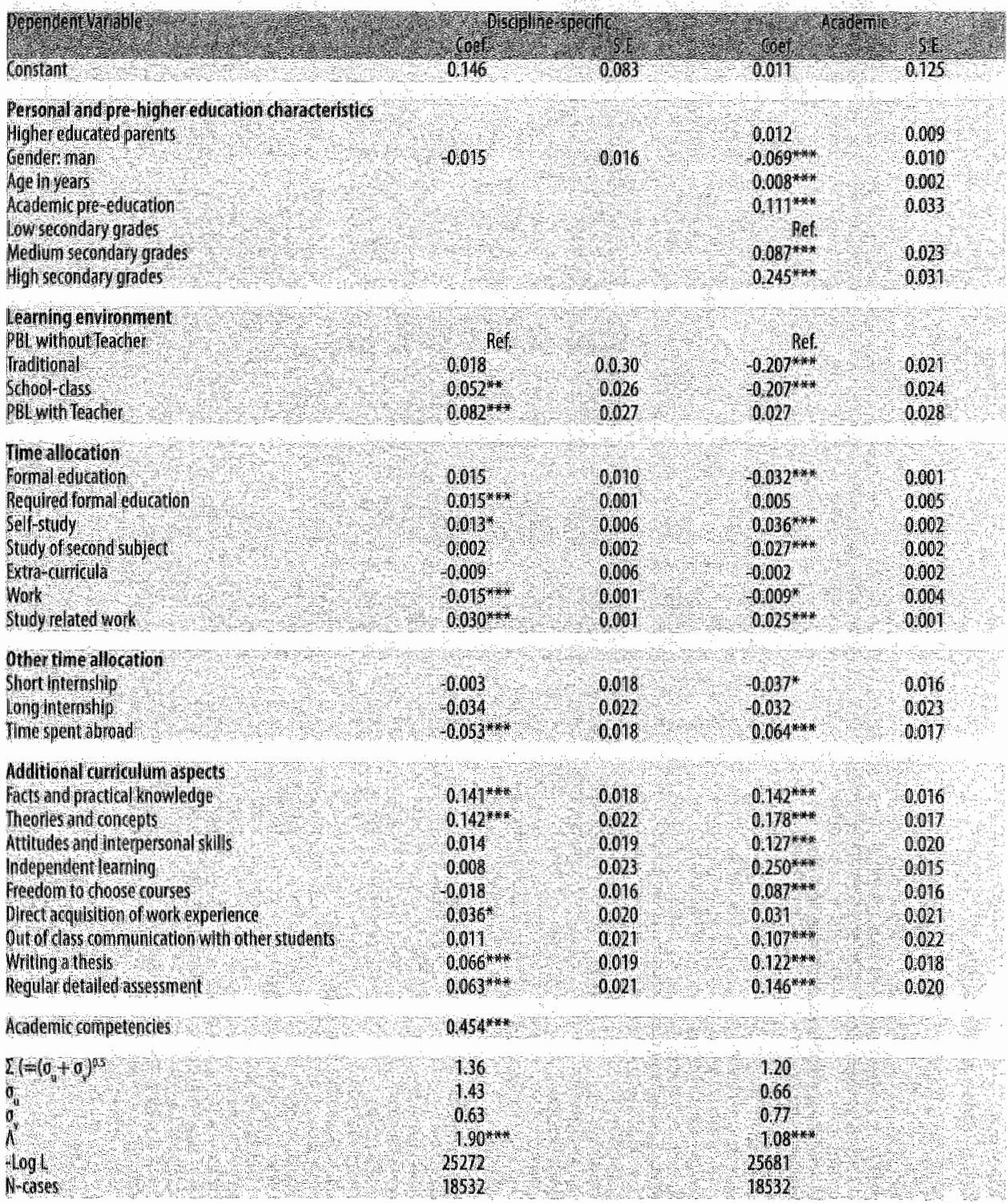

Note 1: All modes further indude duminies for the nine countries, dammies for the different higher education institutions inside a country and

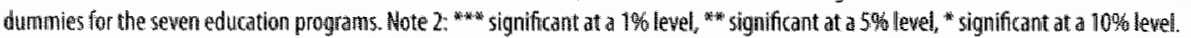




\section{Appendix 4D: University versus higher wocational education}

This appendix reports on the results of Model 2 for two separate types of higher education graduates: university graduates and higher wocarional education graduates.

\section{Table $4 \mathrm{D}$. 1}

The impact on competencies: Uniwersity versus Higher wocational education

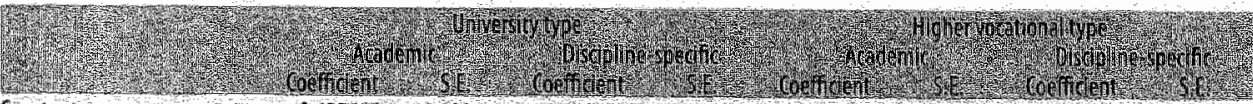

$0,43.60008$

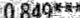

0.050

$0.442:$

0.17

$0340 \div \div 0.09$

Bersonal and pre-higher education characteristics

Hogher ed arated parents $\quad 003 \%$ ? 0048

Gender man $\quad 3 \quad 0.092 \times 0 \quad 0.018$

Afe

$0.010^{*}+0002$

Acodemic pre education

Lovi secondan grades

Mestum secondary grades

$0,110 * * 0,025$

High secondary grades

Rê.

$0.081+240.002$

$0.240 * 0.026$

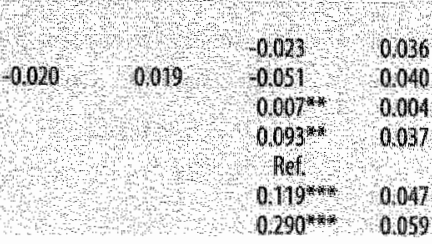

\section{Leaming environment}

Pol without teacher

Waridititonal

Sothool-tlass

PAB with teacher

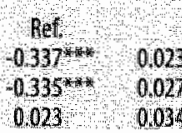

\begin{tabular}{|c|c|}
\hline Re! & \\
\hline 0005 & 0,035 \\
\hline his & 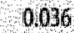 \\
\hline $0178^{* \%}$ & \\
\hline
\end{tabular}

per
$0,22^{* *}$
$01283^{*}$
$0132^{*}$

+
0.045
0.050
0.055

0,001

0039

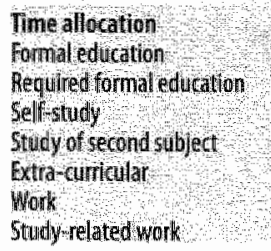

\begin{tabular}{|c|c|}
\hline $0.002 \%$ & \\
\hline $0002^{-4}$ & \\
\hline $0.006 \%$ & \\
\hline $0005 \times$ & \\
\hline 0001 & \\
\hline 0017 & \\
\hline
\end{tabular}

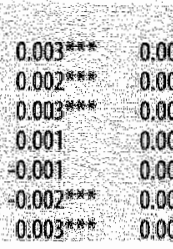

40,000
0.002
$0.007 \%+1$
0.0019
0.002
0.002
0.002

\section{3}

\section{0,002}

0,0012

0,002

0,002

0.001

0,005

0000

0.004

0.004

0,001

?) 009

$0001 \% \bigcirc 0001$

0001

0.9n:

- 0600

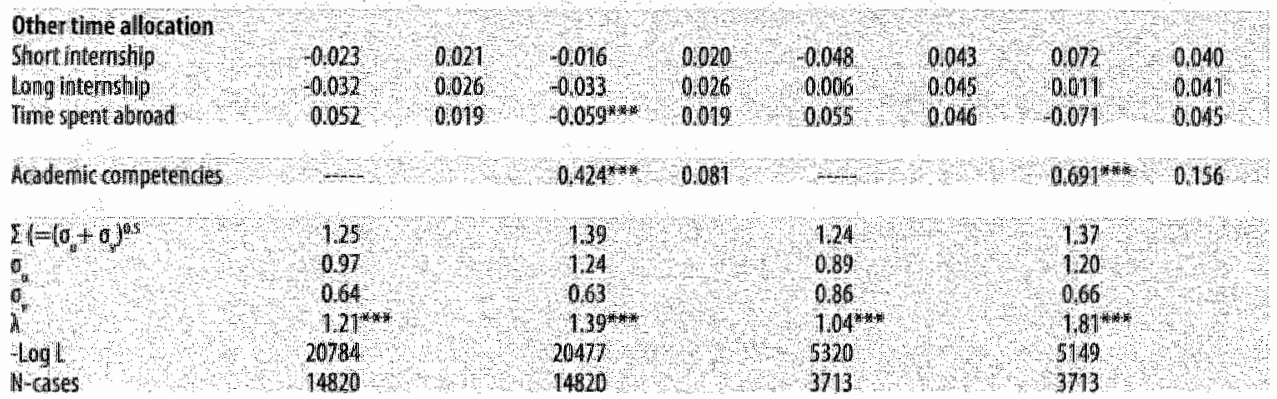

Note: Unwersity type: this estimation inciudes the wiversity graduates in all nime countries: higher vocationd type: this estimation includes.

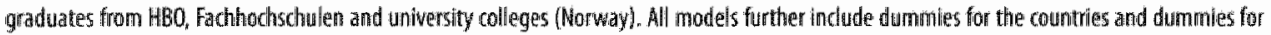

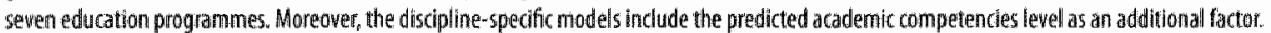

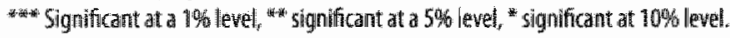

Considering the learning environment, we can see that the results are very similar for the wo types of higher education. Considering the rime allocation, we found that for graduates of higher wocational education the significance of the coefficienus is clearly smaller. This finding is related to the fact that higher vocational education students generally have less freedom in allocating their time than university students. 
$\begin{array}{lll}8 & \vdots \\ \vdots & \vdots\end{array}$ 


\title{
Chapter 5 \\ Fitting to the job: the role of academic and discipline-specific competencies in adjustment and performance'
}

\author{
"The divertion in which education starts a mat \\ will determine bis futwe life o \\ Plato
}

1. This chapter is a combined and extended version of rwo papers: Heijke, Meng and Ramaekers (2003) and Heijke, Meng and Ris (2003). We would like to thank Lex Borghanas, Bart Golsteyn "Harald Schomburg, Maartem Vendrik. Bruce Weinberg, Gerard Pfann, wo referees of Labour Economics and rwo referces of the Intermational Journal of Manpower for their commen is on earlier versions of these two papers. Furthermore, We benefited a great deal from discussions with participants ar ROA seminars (2002), at the ROASKOPE conference (200r. Maustrichr), at the ILM (2002, Aberdeen), at the g $^{\text {th }}$ IZA summer school (2002, Munich), the EALE conference (2002, Paris) and TTY conference (2002, Florence). 


\subsection{Introduction}

In the transition period from education to the labour market, graduates from different educatonal backgrounds apply for jobs in which they can use the competencies acquired at school. The process that matches heterogeneous graduates to heterogeneous jobs within this transition period has recewed much attention in the literature (e.g. Jovanovic, 1979, 1984; Barron and Loewenstein, 1985 ; Topel, 1986 ). If this match is not perfect, additional learming by training and/or job experience is needed to improve or adjust the initial competencies acquired in education. Indeed, the importance of on-the-job training for improving competencies has long been emphasized (Becker, 1964; Mincer, 1974), and there have been many debates on its impact on productivity and wages (Brown, 1989; Lynch, 1992, Acemoglu and Pischke, 1998* Pischke, 2000). In addition to a less than perfect match, there are other well-known reasons for transferring the generation of competencies partially from the initial schooling phase to later working life. One of these is the uncertain future application possibilities of specific competencies obtained during the educational career. Another reason is that some rypes of competencies can be generated more efficiently in a context combining working and learning or, in generall terms, when one has more life experience. ${ }^{2}$. Two features with respect to this postponed learning process are of crucial importance.

First, the effectiveness with which graduates are able to adjust or improve their competencies according to the labour market requirements is determined by the level and type of competencies acquired in initial education. The importance of initial education can be found in the discussion on whether on-the-job training and initial education are complements or substitutes. Analyses provide evidence of complementarity berween education and on-thejob training (Barron et al., 1989; Brunello, 2001). Indeed an implication of the human capital theory is that individuals who learn quickly, that is the ones with the highest level of education, are more likely to take part in training since they are associated with lower costs for learning (see e.g. wan Smoorenburg and van der Velden, 2000).

Second, the actual adjustments to be made depend on the outcome of the graduate-job match. Considering the allocation of higher education graduates over jobs, in particular the match between the field of study required and the field of study graduated from (congruence in type of competencies) infuences the required adjuscment and the costs involved with these adjustments. Whereas graduates matched to an occupation closely linked to their field of study may need to adjust their level of competencies (vertical sorting), graduates matched to

2. The pase few decades have been characterized by a growing ned for unversiry graduates who are propcrly prepared for management positions in a postinduserial economy with global competicton. Universicties responded to the need for graduates by starting a waticty of graduate and postgaduate courses in management ropics. The actions, which acoordiriyg to Wheren and Cameron (ng95) are of crical importance for effective mangement, weter to personal contipetencies (e.g. creative problem-solving), to interpersonal competencics (e.j. mothating others or manging conflics) and to group competemcies (e.g. empowering and delegating). The effectiveness with which management competencies can be acquired in classrooms is disputable Milrer and Situson (1995) argued that tradinonal mangement and business education falls short in educating leaters for the new competitive enwiromment. In line with this, McCall, Lombardo and Morrison (1988) found that most of the dewelopment of management competencies takes place on the job, and not in seminars, dessrooms or MBA programs and Heike; Meng and. Ramaekers (2003) showed that the lewel of management competencies required in occupations is dosely related to the amount of general academic competencies rather than to the amounc of management comperencies acquired in higher education. 
an occupation nor linked to their field of study also have to adjust the type of competeneies (horizontal sorting).

Having established in Chapter 4 what the most efficient ways are to acquire disciplinespecific and academic comperencies, this chapter focuses on the role and pay-off of these competencies during the transicion from higher education to the labour market.

In the current debate on occupation-specific versus general education and training; Bishop (1995) strongly advocates that education should focus on occupation-specific competencies rather than on general academic competencies. According to Bishop, "reseawh shows what productivity derives directly from social abilities (such as good work habits and people skills) and cognitive skills that are specific to the job and orcuparion, not from reading writug. and mathematics skills." In doing so, Bishop departs from the premise that academic competencies are mere tools for developing specific competencies but not a good substitute for occupationspecific competencies. "While bearning a wew skill is eusier when the worker has good basic skills, a foundation of job knowledge and occupational skills is aswally even more essential" according to Bishop. In an earlier article, Bishop and Kang ( 1989 ) argued that for high-school gradu* ates who enter the labour market discipline-specific and academic education in high school are complements thather than substitutes. The more recent research literature (e.g. Campbell and Laughlin, 1997; Alton $i_{1}$ 1995; Mane, 1998) also rends to find stronger positive effects of discipline-specific course work on labour market outcomes.

Whille these authors stress the importance of occupation-specific competencies, other authors underline the importance of generic competencies". Stasi et al. (1993) stated "Employess and workers note the need for generic competencies, such as problem solving, communication and the ability to work in teams." Furthermore, Duncan (1968) already mentioned that "Verbaland quantitative skills are especially significant outcomes of bigher edaction, not only because they are valuable in their own right but also becatse they facilitate learning of all kinds in college and throughout life." In line with this, Bowen (1977) believed that "the important substantive aims of bigher education do lie in the realm of residues... [and that] ... the residues also consist of the skills and perspectives that enable students in later life to leam or relearn detaited knowledge in at wariety of frelds as occasion demands and to fit this knowledge into a framework of lavger principles and concepts."

In deriving competencies to be taught in initial education from the competencies required in the work place, important points are often neglected. Firstly, the notion that some competetucies are more likely to be acquired in combination with work than in a purely educational context. In this respect, Becker (1962) already argued in the early sixties that some types of knowledge can be mastered better if simultaneously relared to a practical problem; others require prolonged specialization. This argument is further supported by studies of Ducatel (1998), Green, Ashton and Felstead (2001) and Heijke, Ramaekers and Ris (2005).

The second point of neglect is the notion that education is the best place to generate competencies needed to improve the efficiency with which additional competencies can be generated later. In general, more educated workers train more because the available human capital is an input in the production of new human capital or because individuals who are betrer 'learners' will invest more in both schooling and training, (Bartel and Sicherman, 1998).

3. Bishop used US datlat on high-school graduares in the 1980 os.

4. For an extensive discussion on the differenr rypes of generic competencies, please refer back to Chapter 2. 
Similar argumentation was found in Johnson (1979), van Smoorenburg and wan der Velden (2000), and Stalsz (2001).

The third point relates to the avallability of data. Educational indicators (such as tenure, grades or courses) are often used as proxies for a worker's avallable competencies. Howewer in today's knowledge econony with its emphasis on continuous learning, these kinds of indicators are no longer sufficient for measuring or predicting career successs. For instance, Green (1998), Heijke, Koeslag, and Van der Velden (1998), Allen and Van der Velden (200I), Stasz (2001), Green, Ashton and Felstead (2001), McIntosh and Vignoles (200r), Shaughnessy, Levine and Cappelli (200r), ter Weel (2002) and Lazaear (2003) have all done research into the labour market value of particular work competencies, which can be seen as a more accurare and reliable way for estimating individual labour market capacities.

The objective of this chapter is to contribute to these discussions. More specifically, we will analyze the role of academic and discipline-specific competencies in the allocation process, with respect to the required adjustment to job requirements and the monetary return of these competencies. We will focus on the Netherlands. Hence, we need to keep in mind that the pievious chapters have characterized the Netherlands as a country similar to Austria and Germany; which on average prowide relatively discipline-specifically oriented higher education systems preparing graduates for an occuparionally oriented labour market. Where necessary, we will point out differences that can be expected when analyzing the role and value of academic and discipline-specific competencies in relatively academically oriented countries such as the United Kingdom or France.

The structure of the chapter is as follows. To start with, Section 5.2 presents the data used and then provides a brief overview of some stylized facts with respect to the acquisition of discipline-specific and academic competencies by Dutch higher education graduates and their use in the labour market. Section 5.3 describes the literature thar investigates the pay-off of different human capital competencies acquired in education by introducing them directly into wage estimations. Having established that by this approach the role of competencies acquired in higher education is difficult to reveal and may yield biased results, we will develop in Section 5:4 a model in different steps, first investigating simultaneously the role of the discipline-specific and academic competencies on allocation and on-the-job training and then, taking the first step into account, we will investigate again the wage rates paid to the graduates. Section 5.5 reports on the empirical analyses, while Section 5.6 concludes the chapter:

\subsection{The data ${ }^{6}$}

This chapter concentrates on the Dutch part of the international CHEERS survey discussed in Chapter 3 . Since the survey was held some three to four years after graduation (in 1998), the study observed graduates at the beginning of their professional careers. In the Netherlands,

5. See atso the discussion in Chapter 2 ,

6. For a more deated discussion of the data set used throughout this thesis, the way the rwo chasters of competerncies ate cowstruct through hierachical dustering methods, and the validicy of the constructs please refer to Chapters. 
a division can be made between university education (WO) and higher vocational education (HBO). Universities provide academic education and intend to provide their graduates with scientific knowledge in a particular field or discipline. Higher vocationall education instirutes, on the other hand, provide higher professional education and intend to prowide their graduates with knowledge that is directly linked to a parcicular occupation. All respondents covered in this chapter completed degree courses from one of the two types of higher education institution.

The data also contains information with respect to different competencies representing demands for and supplies of knowledge. Graduates were asked to indicate on a five-point scale, ranging from I ("not at all") to 5 ("to a wery high extent")", the extent to which they had a given competency at the time of graduation (in 1994 or 1995) (the acquired level of competency) and the extent to which this given competency was required in their current work (we required level of competency). Using a hierarchical dustering method, we retained wwo clusters representing best the idea of academic competencies and discipline-specific competencies. The two clusters include the following individual items:

\section{List 5,1}

Clusters of competencies

\section{Academic competencies}

* Learning abilities

* Reflective thinking, assessing one's own work

3) Problem-solving abilities

* Analytical competencies

* Documenting ideas and information

2. Discipline-specific competencies

\% Field-specific theoretical knowledge

* Field-specific knowledge of methods

The internal consistency of the discipline-specific competencies (academic) cluster is supported by Cronbach's alpha of $0.79(0.72)$ when measured as required items and 0.76 (0.7) when measured as acquired items.

For this analysis, an average was calculated for each individual of the competence clusters possessed at the time of graduation and of the competence clusters required in the current occupation. In addition to the acrual level of competencies possessed at the time of graduacion, the analysis will also focus on the distance between the required and the acquired level or rype of competencies. With respect to the discipline-specific competencies, we distinguish berween a pertical mismatch (mismatch of the level) and a horizontal mismatch (mismarch in cype). The former is simply calculated by subtracting the acquired level of discipline-specific comperencies from the required one. The latter is based on the relationship between the graduate's field of study and his or her area of work. More precisely, a horizontal mismatch occurs if the graduate reported that neither "the own freld of study' nor "a related freld of study"

7 . In the original guestionnatre, due answers were coded from 1 (to a very high extent") ro s ( not ar all"). To simplify the reading of the enpirical analyses, we recoded the answers to range from i (not at all.) 105 ('to a very high extent'). 
would have been the best preparation. Finally, we also measured the difference between the level of academic competencies required in the occupation and the level of academic competencies acquired in higher education (mismatch of the level). As academic comperencies are assumed to be context-independent, a horizontal mismatch in academic competencies is not possible.

\subsubsection{A descriptive look at two types of competencies.}

To what extent does the acquisition of competencies by higher education graduates in the Netherlands match the labour market requirements? To address this question, we will present a descriptive look in this section at academic and discipline-specific competencies. In particular, we will focus on the level of comperencies built up during the tertiary education study and on the level of competencies that is required in the current working situarion (see Table 5.1.).

Table 5.1

Academic and discipline-specific competencies

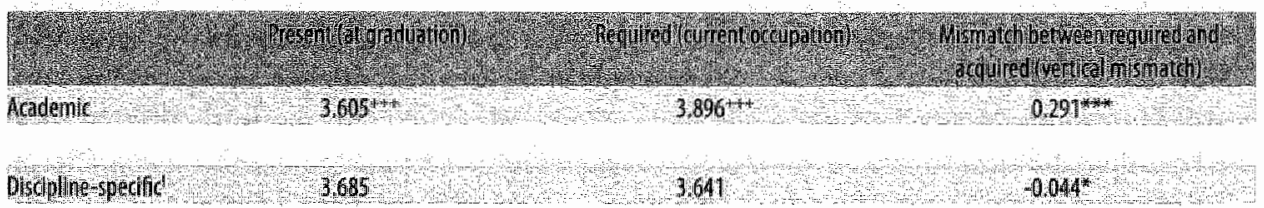

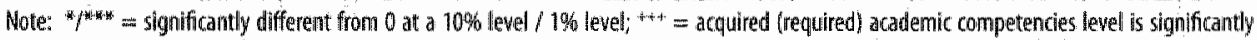
different from acquired (required) discipline-specific competencies level an a 1 \% significance level. ${ }^{\text {" }}=$ both the arcuired and the required level of discipline-specific competenties is measured in terms of the type of discipline-specific competencies acquined in higher education.

On average, Durch higher education gradwates have a slightly, but significantly, higher level of discipline-specific competencies than academic competencies. In contrast, the labour market seems to ask for a competence mix that is more directed towards academic competencies, resulting in a situation where on average the level of discipline-specific competencies acquired by Dutch higher education graduates is more in line with the requirements than their acquired level of academic competencies. To what extent this is a twist of the data by not allowing ts to measure any other type of discipline-specific competencies than the one that was acquired in higher education, is the question that we will turn to now. In Table 5.2, we distingutshed between two different types of occupations. First of all, occupations for which the own field of study or a related field of study prepares best (from now on called an occupation "inside one's own educational domain"), and second, occuparions for which a different field of study than the one graduated from prepares best or for which the feld of study does nor matter (from now on called occupation "outside own educational domain").

8. Unfortunaty. the datu do not allow us to measure directy any other type of disciplinewspecific competencies required in the current ocupution next ro the rype of discipline-specific comperencies acqured in the higher oducation theld of smdy. Hence, measuring the horizontal mismatch in this manner can only be seen as a crude proxy of the actual mismatch.

9. Appendix 5 A gives a descriptive owerwew of other characteristice of the graduares, the ed ucation they followed and the occupation they are allocated 0 . 
If the graduate is matched to an occupation in the latrer domain, one expects the level of the acquired type of discipline-specific comperencies that is required to be significantly lower than if the graduate works inside the own educational domain.

\section{Table 5.2}

Academic and Discipline-specific competencies: Strata: Working inside own educational domain

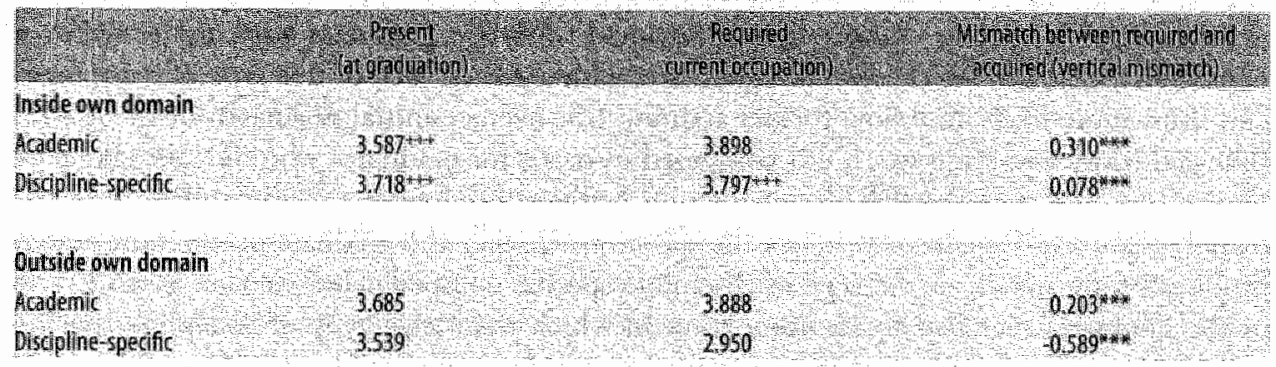

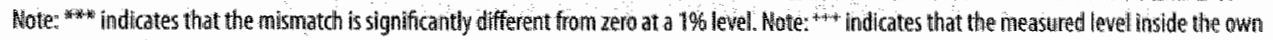

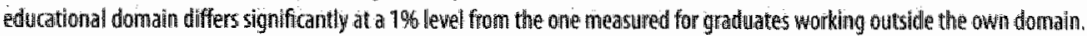

Considering first the required level of competencies in the current accupation, we can see that the required level of academic competencies is independent of the occupational domain in which the graduate works but that graduates matched to an occupation not closely resembling the field of study from which they graduated, have to accept that for the type of discipline-specific competencies they acquired there is a relatively smaller demand ${ }^{\circ}$. To the extent that the principal of "use it or loose it applies for these graduates, we may expect these gradu. ates to be more likely to be confronted with competencies obsolescence. This will hold in particular for graduates from fields of study with a high turnover rate of discipline-specific competencies due to rapid technological progress. Hence, the figures in Table 5.2 confirm the approach used in Chapter 2, where we argued that academic competencies, as a subgroup of generic competencies, are context-independent whereas discipline-specific competencies have a restricted range of applicability. Comparing the required levels with the competence levels which the graduares acquired in higher education (vertical mismatch), we can see that for graduates matched to an occupation in their own educational domain both the initial level of academic competencies and the initial level of discipline-specific comperencies are merely a starting level, and that they have to continue learning. A similar siruation exists for graduates matched to an occupation outside their own educational domain, although the lack of the type of discipline-specific competencies required in the occupation is not immediately visible. Moreover, their higher initial level of academic competencies implies that these graduates are confronted with a smaller lack of academic competencies than the average fellow graduate working in the own educational domain. So far, the figures reported seem to indicate that graduates are allocared at least partially according to the type and level of competencies and their applicability/usefulness for the task of a particular occupation.

10. The finding that graduates marched to an occuparion outside their own educational domain ate still required to use some of their discipline-specific competencies indicates that our distinction in to rwo different occupational domains is an artificial one and only approximates realicy. 
Given their level of academic and discipline-specific competencies, the initial competence level of Dutch graduates falls shiort compared to what the labour market requires them to possess approximately three years after graduation. To what extent does this trigger further on-the-job training? Table 5.3 splits the data according to the question whether or not graduates participated in on-the-job training in the first three years on the labour market. Overall; approximately two out of every three graduates participated in further training. With respect to the discipline-specific competencies (measured solely for graduates working in the own educational domain) we can see that graduates with a grearer lack of this type of competencies seem more likely to follow further training (the average initial mismatch of those who followed further training was 0.081 compared to 0.065 for graduates who did noc take part in any training). Considering the distinction between occupations inside and ourside the own educational domain, and hence the question whether the graduate-occupation match produced a mismatch in the type of discipline-specific competencies, we can see that $71 \%$ of the graduates matched to an occupation in which their own type of discipline-specific competencies was not asked, took part in further training compared to only $65 \%$ of the graduates marched to an occupation inside the own educational domain. Turning to the second type of competencies , we can see that a mismarch in academic competencies seems to be no major reason for taking further training. However, graduates who were selected for further training seem to have had a slightly higher initial level of academic competencies.

Table 5:3

Competencies, mismatches and training followed

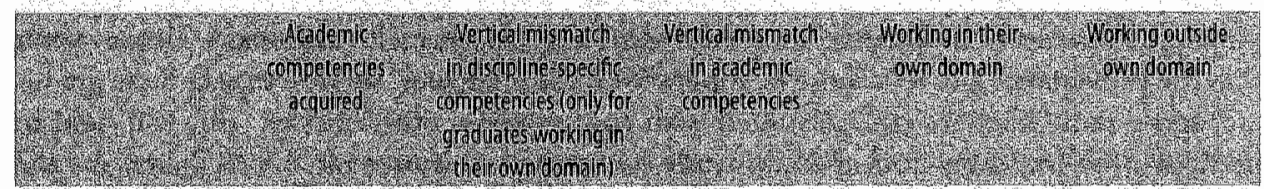

Tookno further rraining ? 3.59 ? 0.065

0.28

35\%

$20 \%$

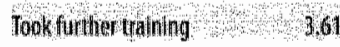

0.081

0.28

65\%

$71 \%$

Wote: Gitaduates working outside their awn domain differed significant (5\% level) from graduates working inside their own domain with respect to the percentage taking part in further training. Neither the initial level of academic competencies nor the wertical mismatch in discipline-specific of acadenic competentiejes differed siggificontly between gradeates who took further training and graduates who did not.

Concluding, the descriptive view seems to indicate that both the acquired levels of disciplinespecific and the acquired level of academic competencies are determinants of allocation, and that mismatches in the type and the level of discipline-specific competencies, as well as the acquired level of academic competencies, are determinants of on-the-job training selection decisions. We will return to these points later.

11. See also Appendix 5 A. 


\subsection{The return to academic and discipline-specific competencies}

\subsubsection{Theoretical notion I}

Let us assume that the income that a graduate may obtain in articular occupation is given by the set of discipline-specific competencies and academic comperencies he or she offers to the employer.

$$
\text { (5.1) } y_{i j}=C_{i}\left(D S_{i s}, A_{i}\right)
$$

where $y_{j}$ is the income received by graduate in occupation, $C_{i}$ the competence set offered by graduate $i, D S_{i s}$ the offered level of discipline-specific competencies of type $s$, and $A_{i}$ the level of academic competencies offered. Assuming that the set offered is a linear combination of the different types of competencies and taking into account the difierent types of discipline-specific competencies which graduates may have acquired, we can write:

(5.2) $y_{i j}=\eta_{j} *\left[\sum_{s=1}^{n}\left(\mu_{s} * D S_{i s}\right)\right]+\left(1-\eta_{j}\right) * A_{i}$

where

$$
\text { (s.3) } \sum_{i=1}^{n} \mu_{s}=1 \text { and } 0 \leq \eta_{j}, \mu_{s} \leq 1
$$

Equation (5.2) indicates that the income is a function of the mix of competencies offered, given by the sum of discipline-specific comperencies (DS) of the different types $s$ and the level of academic competencies $(A)$. The term $\mu$, measures the weight given to a particular type of discipline-specific competencies inside the package of required discipline-specific competencies, while the term $\eta_{i}$ measures the weight given to the whole package of discipline-specific comperencies.

For simplicity, we will assume the horizontal difference between a particular type of discipline-specific competencies and all other types of discipline-specific competencies to be a constant ${ }^{33}$.

$$
\text { (5.4) } \overline{D S_{s=m} D S_{s \neq m}}=c_{s}
$$

In other words, we assume that the step to be taken made from discipline-specific competencies in business administration to the discipline-specific competencies in law to be the same as the one to be taken from discipline-specific competencies in business administration to the discipline-specific competencies in medicine. In this sense, $c_{s}$ is determined by the closeness of a particular education programme to the others and hence by the broadness of disciplinespecific competencies that a graduate alcquires. From the viewpoint of graduates from education programme $m$, we can then write:

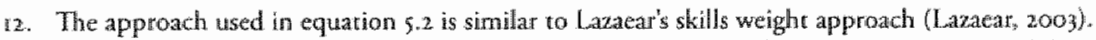

13. This assumption allows us to add up the evel of discipline-specific comperencies required, but nor acquired in the study program graduated from, ignoring the fact that whey are of different types. 
(5.s) $\left.y_{i j}=\eta_{j} *\left[\mu_{s: m m} * D S_{i, s=m}+\left(1-\mu_{s=m}\right) \sum_{s=1}^{m} D S_{i, s \neq m}\right)\right]+\left(1-\eta_{j}\right) * A_{i}$

Considering that graduates may lack particular competencies and that such a mismatch between the required level/rype of comperencies and the acquired level/type may have a distinct impact on the income received, we extend and rearrange equation 5.5 as followst:

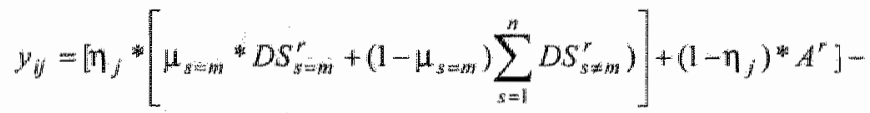

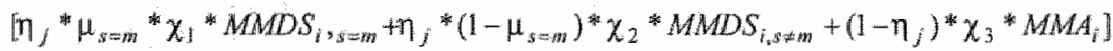

where $M M D S_{\text {tis } m}$ is the mismatch in the type of discipline-specific competencies acquired in higher education, $M M O S_{\text {, stw }}$ the mismatch in any other type of discipline-specific competencies and $M M A_{i j}$ the mismatch in academic competencies. Moreover, we replaced the acquired level of competencies by the required one ( $D S^{r}{ }_{j=m} D S^{r}$, and $A^{\prime}$ ). Lastly, we have introduced $\chi_{1}, \chi_{2}$ and $\chi_{3}$ as parameters that allow the weight that a particular competence mismatch (e.g. $M M D S_{i, x D y}$ ) has in the income determination to differ from the weigh of the competency (e.g. $\left.0 S^{r}{ }^{m}\right)$ it $)$ itself.

\subsubsection{Results 1: Wage rate}

To investigate whether the acquisition of academic and discipline-specific competencies in higher education pays off in the labour market, we will consider in this secrion three simple linear models based on equations 5.5 and 5.6 which try to explain the wage rate paid to graduates approximately three years after graduation:

$$
\begin{aligned}
& \text { (5.7) In }\left(y_{i j}\right)=\alpha_{1}+\alpha_{2} D S_{i, 5}+\alpha_{3} A_{i}+\alpha_{4} X_{i}+\varepsilon_{i j} \\
& \text { (5.8) In }\left(y_{i j}\right)=\alpha_{j}+\alpha_{i} D_{i, s}+\alpha_{i j} A_{i}+\alpha_{10} X_{i}+\alpha_{11} Z_{i}+\sigma_{i j}
\end{aligned}
$$

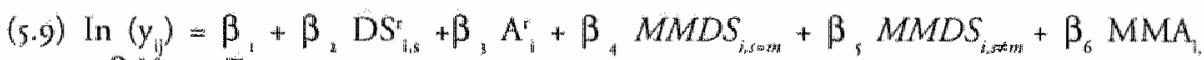

$$
\begin{aligned}
& +\beta X_{i}+\alpha_{z} Z_{i}+\mu_{i}
\end{aligned}
$$

In Model $\mathrm{r}$ (equation 5.7 ), we have explained the logarithm of the gross hourly wage rate in particular by DS $_{i, s}$ the acquired level of discipline-specific comperencies and $A_{i}$ che acquired. level of academic competencies. Moreover, we controlled for several school experience features $X_{i}$ (e.g. field of study). In Model 2 (equation 5.8), we lave added aspects related to the occupation Z (e.g. type of contract, rraining raken). In Model 3 (equation 5.9), we have replaced the acquired level of competencies by the required ones and added the discipline-specific competence mismatch of the type of discipline-specific competencies acquired in higher education $M M D S_{i, s e m}$ the mismarch in the type of discipline-specific competencies $M M D S_{i, n \rightarrow s}$

14. Note that $M M C=C-C$ 
(approximated by a dummy indicating that the graduate worked in an occupation not dosely related to the freld of study graduated from), and the mismatch in academic competencies MMA, as additional explanatory variables. To control for the fact that a mismarch in the own ype of discipline-specific competencies may be particullarly harmful when the occupation purs great weight on this type of competencies, we included $M M D S_{\text {, smm }}$ interacting with a dummy indicating the educational domain in which the graduates worked. We expected $\alpha_{3} \alpha_{3}, \beta_{3}$ and $\beta_{3}$ to be positive and $\beta_{4}, \beta_{5}$ and $\beta_{6}$ to be negative. Table 5.4 reports on the results found.

Table 5.4

Linear Regression analyses of the gross hourly wages (In)

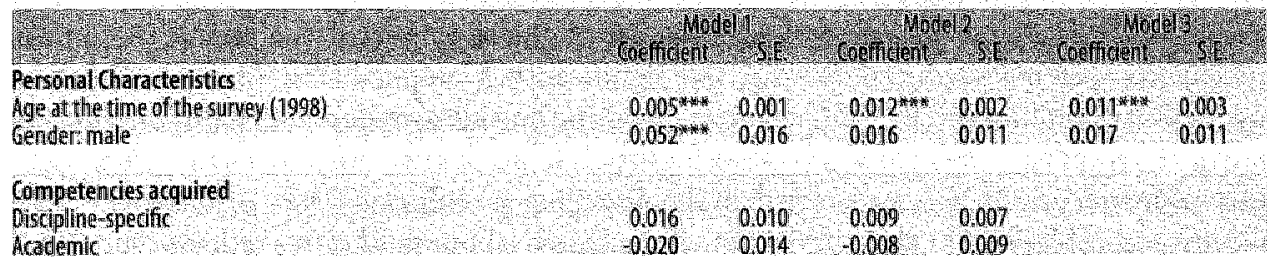

\section{Competencies required}

Oiscipline spectic

0000100,010

Arademic

0018.00013

\section{Comperencemismatch}

Gisciplene soedifo working in own domaln

Dixcpil ne spectic wo king outside own domain

Acaidemic:

Working outs de own donalin

\section{Education level}

HBC

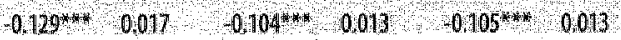

\section{Job Characteristies}

Pantume contrad

Permanent contract

Educationallevel required same

Educational Hevel requined higher

Eidurationd level tequiled fower

$\begin{array}{lllll} & \\ 3\end{array}$

\section{Wokling experience}

Tenuma (minaonths)

Travere (inmonthi) * workng outside own domain

Interminip lot ween and 6 months during study

forternstion loniger than 6 months during study:

Enployment achated te study between 1 and 6 months during study

Enploynent related to study longer than 6 months during study.

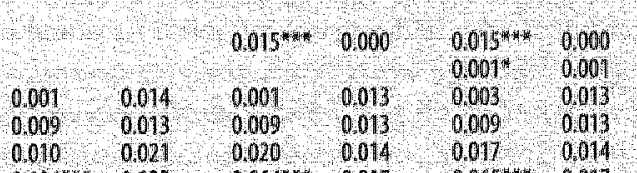

\section{Iraining}

Parthipated won the job training

Parcucpated in on the job training wolling outside own donaln

Organization tharacteristics:

Privale sactor:

Dimsine (190000)

Constiant

$0.104 * 0022$

$0,064 * 0 * 00$

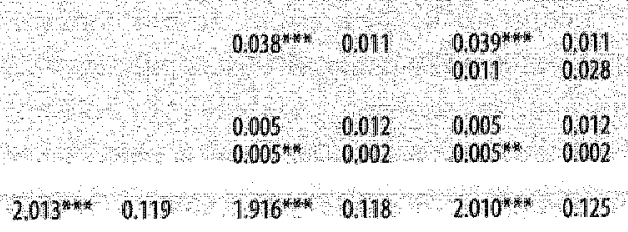

Feld of sndy dummies noluded

Buontmical sector dumanles inithod

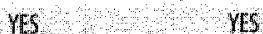

Yiss

No

46

Yes

Add $n$ squared

012

0,28

028

Nurimber of observations

1751

1751

1751

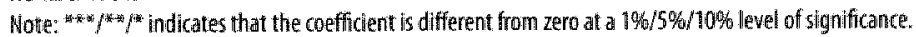


Controlling for the usual covariates"s, the reported resultis indicate that neither the acquired (required) levell of academic competencies nor the acquired (required) level of disciplinespecific competencies seems to be rewarded directly in the labour market. This holds in all. three Models. However, we can see that the inclusion of control variables relating to the occupation which the graduates holds, or his or her labour market experience, greatly reduces the impact of both the initial level of academic competencies and the initial level of discipline-specific competencies (see Model $\mathrm{r}$ and Model 2). Turning to the question whether gradtates lacking the required competencies had to accept a lower wage rate, the results of Model 3 show that this was the case with respect to discipline-specific competencies. For graduares working in their own educational domain, and hence in occupations in which the acquired discipline-specific competencies are of crucial importance, a lack of disciplinespecific competencies reduced the wage rate significantly. Comparable to this, a mismatch in the type of discipline-specific competencies ('working outside own domain') reduced the wage rate too. No penalty seemed to be given for a lack of academic competencies, even though this mismatch was on average larger than the discipline-specific one. These results seem to be intuitive, considering our characterization of the Dutch labour market as a rather occupationally, and hence discipline-specifically, oriented one. Running comparable analyses for other countries's, we found that the findings for the Netherlands were qualitative similar to those for Germany and Austria. However, no impact of the vertical discipline-specific competence mismatch on the wage was found in academic countries (e.g. the United Kingdom, Spain or France). Moreower, in the United Kingdom we found that a lack of academic competencies reduced the wage rate significantly. Interestingly, the results confirm again the distinction made in Chapter 3 berween discipline-specific countries with an occupational labour market (Austria, Germany and the Netherlands) and academic countries with an internal labour market (France, United Kingdom and Spain).

We also evaluared the impact of an educational level mismatch on wages. Following previous studies (Sicherman, 1991; Cohn and Kahn, 1995; Hartog, 2000), we found that wages were not only determined by individual characteristics but also by job level. Overeducared graduates received lower returns than similar graduates who had a job that matched their educational level. On the other hand, undereducated graduates received more than similar graduates who had a matching job'. As noted by Allen and van der Velden (2001), 'although higher education matses productivity in general, the actual level of productivity realized is also determined by the match between educational tevel and job leve?. As, for example, working in a job below one's own level imposes a limitation on the utilization of skills, the lower level of the job imposes a ceiling on the worker's productivity, resulting in lower wages.

Taking stock, these results do not confirm that in tecent years the increasing emphasis on the acquisition of academic competencies yields a significant positive return for higher

15. We also tested for decreasing renurns of tenure. The fact that no evidence with respecr to decreasing returns to renure was found, is probably related to the face that the survey only enables us to observe a naximum of 3 years of renure.

16. Data not shown.

17. These results are close to those reported by Cohn and Kahn (1995) for overeducted graduates, who earned no less than simila: graduates who worked in an occupation for which they were adequarely educated. However, for undereducated graduates, the results here are lower than chose from Cohn and Kahn (1995) (3.8\% compared to $10-14 \%$, 
educarion graduates. As a matter of fact, the results rather inclicate that for graduwtes working in their own educational domain, and hence for roughly four out of five Dutch higher gradum ates, an increased acquisition of discipline-specific competencies would thave been preferable. Does this mean, at least in a traditionally discipline-specifically oriented country such as the Netherlands, that the role of academic comperencies in the transition period from school to work is nil and that the role of discipline-specific competencies drops to zero if the graduate is allocated to an oceupation not closely linked to his own feld of study? Can we conclude that higher education should concentrate on teaching discipline-specific comperencies? This would clearly be premature. Rather, we have to change our focus from the possibility that competencies provide a direct return in the sense of a higher wage rate to the possibility that competencies influence crucial decisions during the transition period and hence influence the wage rate indirectly. With respect to this, we alleady mentioned in section 5.2 .1 that the level of discipline-specific competencies and academic competencies may influence the allocation of graduates over different occupational domains. Moreover, as training is needed to adjust the acquired comperencies to the required ones, the comperencies acquired, and in particular a lack of them, may be a crucial determinant for on-the-job training. Lastly, considering our definition of academic competencies, we can expect them to be decisive in on-the-job raining selection, which, as reported in Table 5.4, increases the wage rate.

\subsection{Allacation to on-the-job training and the return to competencies}

\subsubsection{Theoretical notions II}

In the previous section, we established that neither academic nor discipline-specific competencies seem to have a direct impact on the wages paid to higher education graduates in the Necherlands. However, we found that graduates matched to an occupation that was closely linked to the field of study from which they graduated earned significantly higher wages. In rerms of equation 5.10 (a copy of equation 5.6), these graduates worked in occupations in which $\eta_{j}^{*} \mu_{\text {sen }}$ was close or equal to one. Hence, the question arises who is selected for such accupations?

$$
\begin{aligned}
& \left.(5,10) y_{j}=\left[\eta, *\left[\mu_{s=m} * D S_{s=m}^{r}+\left(1-\mu_{s=m}\right) \sum_{s=1}^{n} D S_{s \neq m}^{*}\right)\right]+\left(1-\eta_{j}\right)^{*} A^{r}\right]-
\end{aligned}
$$

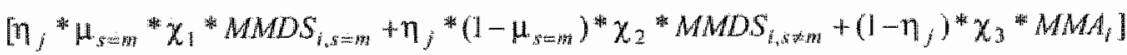

Morcover, in Model 3, we found that a lack of discipline-specific competencies when working

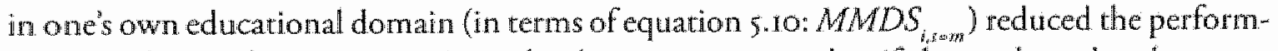
ance and hence the wage rate. Accordingly, we can expect that if the graduates endowment with respect to the level and/or type of comperencies does not match perfectly the requirements of the occupation, employees need to invest more in the acquisition of these competencies, and that the amount of additional leaming (e.g. on-the-job training but also informal learning-by-doing) is positively related to the actual mismatch in competencies. Moreover, we expect the return to on-the-job training and to learning-by-doing, measured in terms of 
an increase in competencies ( $C$ ), to be determined by the quality of the graduate as a learner, and hence in particular by the graduates lewel of academic competencies.

$$
\text { (5. In }) \frac{d\left(C_{n, t=1}-C_{1, m=0}\right)}{d t}=\theta_{c}\left(A_{i}\right) \text { with } \frac{d \theta}{d A} \geq 0
$$

Where treflects the the spent in on-the-job training or used for learning-by-doing. Assuming that employers intend to reduce an initial competence mismatch of their employees step by step over time, we can write the mismatch in competencies $(M M C)$ at time $t$ as a function of the inicial mismatch $\left(M M C_{a}\right)$, the rime period passed $t$ and the factor $\theta_{c}\left(A_{i}\right)$, reflecting the percentage by which the inithal mismatch is reduced per time unit.

$$
\text { (5.12) } M M C_{i, t}=M M C_{i, r=o}-\theta_{c}\left(A_{i}\right)^{*} t * M M C_{i, t=0}
$$

Inserting 5.12 into 5.10 , we obtain an extended version of the basic competence weighr approach:

$$
\begin{aligned}
& \left.y_{i j, t}=\left[\eta_{j} *\left[\mu_{s=m} * D S_{s=m}^{\prime \prime}+\left(1-\mu_{s=m}\right) \sum_{s=1}^{n} D S_{s \neq m}^{m}\right)\right]+\left(1-\eta_{j}\right)^{*} A^{r}\right]- \\
& \text { (5.13) }\left[\eta, * \mu_{s=m} * \chi_{i} *\left(M M D S_{i, s=m, l=0}-\theta_{s=m}\left(A_{i}\right) * t * M M D S_{i, s=m, t=0}\right)\right]-
\end{aligned}
$$

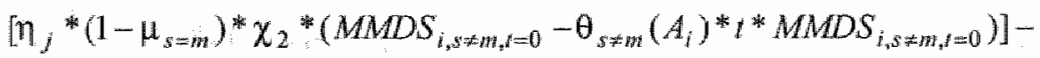

$$
\begin{aligned}
& {\left[\left(1-\eta_{j}\right) * \chi_{3} *\left(M M A_{i, t=0}-\theta_{A}\left(A_{i}\right) * t * M M A_{i, t=0}\right)\right]}
\end{aligned}
$$

Considering that both employers and graduates, when hiring/applying a graduate for an occupation, intend to maximize the return to the competencies acquired in higher education, we can write the partial first derivatives of 5.13 with respect to the acquired level of disciplinespecific and academic competencies ${ }^{\text {th: }}$ :

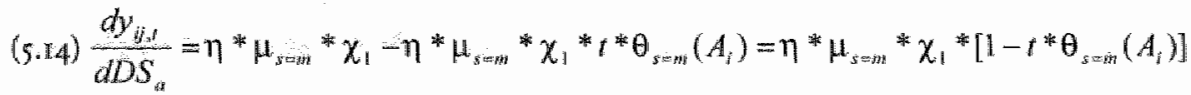

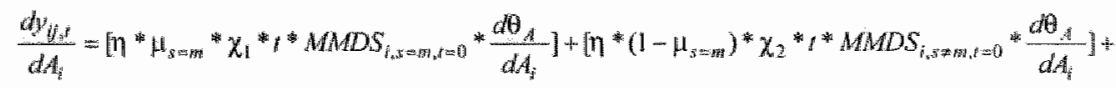

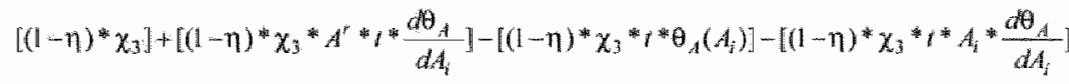

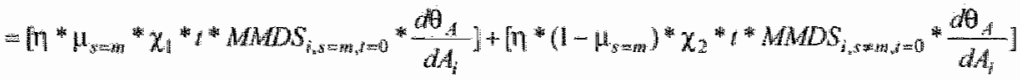

$$
\begin{aligned}
& +\left[(1-\eta)^{*} \chi_{3} * \frac{d \theta_{4}}{d A_{i}} * M M A_{1, s=0}\right]+\left[(1-\eta)^{* *} \chi_{3}^{*}\left(1-r * \theta_{A}\left(A_{i}\right)\right]\right.
\end{aligned}
$$

88. Nore that $M M C=C-C$ 
The implications of equation s.14 for the value of discipline-specific competencies are quite staightforward. Ceteris paribus, the value of discipline-spectic comperencies acquired in thigher education increases as more weighr is attached to them by the occupation $\eta * \mu_{s=m} * \chi_{1}$ increases). However, the marginal value decreases with an increased level of academic comperencies, which determines the speed with which any possible competence mismatches are reduced. The same holds for the length of the time period aken into consideration. The longer it is, the more the initial level of discipline-specific comperencies is in line with the required one. The importance of the academic competencies for the value of discipline-specific competencies is illustrated in Figure 5.ra and 5.rb. Figure 5. ta assumes a lower level of academic competencies than Figure 5.Ib, which is rellected in a steeper income line in Figure 5.Ib (The slope of the income-rime line is given by $\theta_{s=m}$ (A). The gain from an increased initial level can be read as the area between the two income-rime lines. It is immediately visible that the gain is larger in the case of lower academic competencies.

\section{Figure 5.1a}

The income gain of an increased level of disciplinespecific competencies with low academic competencies

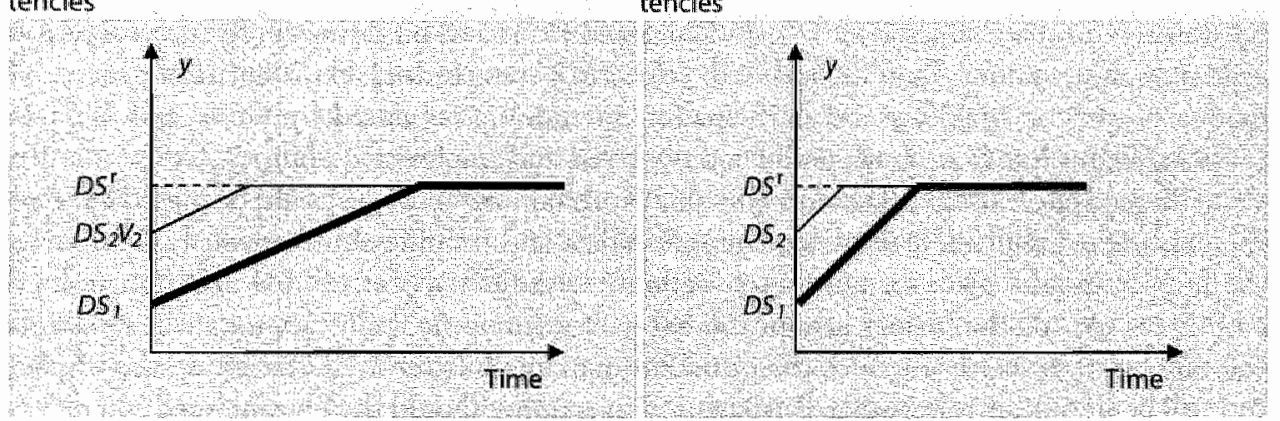

\section{Figure 5.1b}

The income gain of an increased level of disciplinespecific competencies with high academic competencies

As expected, the value of academic competencies is not restricted to a particular type of occupation. The first two terms of equation 5.15 show the value of academic competencies in helping to reduce a possible discipline-specific competence mismatch. The third term remains the same for a mismarch in acadenic competencies. Whereas the first two are positively related to $\eta$, the latter is negarively related to it. Lastly, the fourth term indicates that the marginal value of academic competenciles increases with the weight attached to it by the firm, but, comparable to the marginal value of discipline-specific competencies, the marginal value decreases with an increased initial level of academic comperencies.

Concluding this section, the following expectations with respect to the rolle of academic and discipline-specific competencies during the transition period can be established. First, given a certain level of required competencies, we expect the graduate's level of disciplinespecific comperencies at the time of graduation to be positively related with the graduate's probability to be matched to an occupation closely linked to the freld of study from whicli he or she graduated. The reason is that a higher level of discipline-specific competencies increases: the direc productivity of the graduate in this type of occupations and reduces the need for further costly training. Second, both a mismatch in the type and a mismatch in the level of 
discipline-specific comperencer are expected to increase the likelihood of the graduate having to complete further on the job training. Third, the impact of the academic competencies on whe allocation outcomes seems at first sight to be neutral. However, given that the empirical analyses will solely distinguish occupations for which $\eta * \mu_{s=m}$ is close ro I or close to $o_{*}$ and hence distinguish occupations closely linked to the own field of study versus orher accupaunons, equation 5.15 implies that we can expect, ceteris paribus, graduates with an increased level of academic competencies to be more likely to be matched to an occupation outside the own educational domain. In this type of occupations, academic competencies have botla a direct productive and indirect supportive value. Lasty, we expect to find a clear-cut direction of the impact of academic competencies on training participation. A high level of academic competencies is equivalent to be a good leamer and hence should increase the probabiliry of taking part in further training, independently of the occupation to which one is allocated.

\subsubsection{Empirical specification}

To evaluate both the impact of having an occupation not closely linked to ones own educational domain and the impact of raining, running a simple OLS regression, as presented in Section 5.3, on the characteristics of graduates and firms and on dummies for the allocation outcomes and training, cannot deal with selection issues. Indeed, the allocation process of graduates over occupations and participarion in training, as noted by Goux and Maurin (2000), obviously rely on both graduates' observed and unobserved abilities. Consequently, the estimated effect of the allocation outcomes and training on wages could be biased because the unobserved abilities determine wage, allocation and training simultaneously. Moreover, the impact of allocation on training is undoubtedly different for trained and non-trained employees. As for the former group, the effect of a suboptimal allocation can be small, as training has been used to reduce the initial mismatch, while for the latter group the impact can still be significantly negative. Participation in training should then be analyzed as a determimant of the allocation impact on wages. To take this into account, not only the training variable but also the allocation-training interaction must be analyzed as a wage determinant. If graduates are also likely to be selected for training depending on their allocation, we may further expect to find a correlation berween training and allocation. In order to deal with these two selectivity criteria, we have developed a wage model with two selection functions, one for the allocation and one for training. This will make it possible not only to identify the allocation process of graduates and the training selection mechanism, but also the impact of competencies on wages.

Let $M M D S_{;}$, s,ij be the dummy that denotes that graduate $i$ is assigned to a job $j$ which does not thath his type of discipline-specific competencies (and hence to an occupation outside the own educational domain), $T R_{\text {if }}$ is the dummy that denotes that graduate $i$ takes part in further training while holding job $j$, and $l n y_{j j}$ is the logarithm of wages. Let us then consider the following system of simultaneous equations

(5.16) $\operatorname{MMDS}_{s \neq m, i j}^{*}=\gamma_{1} W_{i j}+\varepsilon_{1 j j}$

(5.17) $M M D S_{s: m, i j}=1$ if $M M D S_{s \neq m, i j}^{*}>0$ and 0 otherwise 
(5:18) $T R^{*}{ }_{i j}=\delta_{1} Z_{i j}+\varepsilon_{2 i j}$

(5.19) $T R_{i j}=1$ if $T R_{i j}>0$ and o orherwise

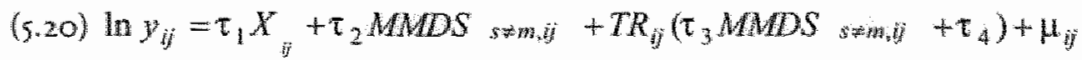

where $W_{i j}$ is a vector of independent variables that influence the allocarion over jobs, such as individual and educational characteristics, and $Z_{i j}$ is a vector of independent variables that infuence participation in raining. As discussed abowe, determinants of training may inchule measures of competence mismatches, the competence sex acquired in higher education and other individual characteristics. $X_{\text {ij }}$ is a vecror of ind vidual, educational, occupational and organizational characteristics that determine the wage rate. Coefficient $\tau$ makes it possible to identify the impact of allocation on wages. $\tau$ captures the difference between the impact of allocation for traned and non-trained graduates.

To take endogeneiry with respect to the allocation and the training process into account, we assume $\varepsilon_{i j i}, \varepsilon_{x i j}$ and $\mu_{i j}$ to be correlated and normally distributed. Consequently, we have used an extension of the two-step treatment effect method discussed by Barnow, Cain \& Goldberger (1981), derived from Heckman (1976) and Maddala and Lee (1976). First, we estimated the allocation process and rraining participation using a bivariate probit model. Second, we estimated the wage equation and added $\lambda_{1: 3}=E\left(\varepsilon_{1 i,} / M M D S_{s \sin , 4} T R_{i j}\right)$ and

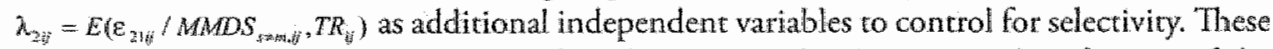
ratios were provided by the estimate of the bivariate probit. To assure identification of the parameters, we needed variables that could be expected to be correlated with allocation and training but not with the unobserved determinants of the wage rate. First, in both the allocation and the training function, we used the level of academic competencies as possessed at the time of graduation and the level of disciplne-specific competencies as possessed at the time of graduation. The assumption here is that graduates undoubtedly increase their level of competencies through additional training or work experience during the first years in the labour market. Hence, the possessed levels of competencies at the time of graduation characterize the graduares knowledge three years before the wage rate is reported. It is therefore assumed that these levels have changed since graduation, and we may obviously expect that the increase differs between graduates ${ }^{\text {is }}$. The initial levels of competencies are therefore expected to determine the allocation process and training participation ${ }_{\text {b }}$ both of which determine the way in which competencies will change.

Furthermore, we included wariables that described the graduates bowo situation at the vime of graduation as specific determinants of allocation and training. Living with a partiner or one's parents at the time of graduation may relax the graduate's financial constraints and allow him or her to search longer for an occupation that matches closely the type of education. taken. On the other hand, hawing children (in parcicular for female graduates) may restrict graduates with respect to the time available for investment in furcher training. Moreover, as regressors for the allocation function, we used a vector of variables that influences $M M D S_{s \neq m \text { is }}$ but not $T R$, such as the importance given to the possibility of using knowledge and skills acquired

19. This is also supported by the fundings in section 5.3.2, where we did not fund a significant imapack on the wage rate of the possessed level of comperencies at the time of graduation. 
in bigher education, and the extent to which graduates reported that they possessed adapt ability as a competence at the rime of graduation ${ }^{20}$. Whereas the former provides information over the graduate's unwillingness to accept an occupation outside the own educational domain, the latter gives information on the ease with which such a switch could take place: Lasty, to identify the training effect, we also used the number of firms offering traing cowries for firms in the region in which the graduate wrorked. An increased stuply of training courses in the region may increase the training opportumities for firms and hence enable on average more employees to actually participate in training.

\subsubsection{Empinical results it: Allocation and Training}

We will start by discussing the results of the bivariate probit model, simultaneously estimating the allocation outcome and the training participation. Table 5.5 presents the results ${ }^{21}$. Turning first to the allocation estimation part, we can see that the results clearly indicate the importance of the two distinct types of competencies for the probability of being matched to an occupation outside the own educational domain. A higher level of discipline-specific competencies decreases the probability of being matched to an occupation ourside one's own educational domain, which confirms the field-limited usefulness of discipline-specific competencies. In contrast to this finding, a higher level of academic competencies increases the chance of obtaining such a job, indicaring first of all that academic competencies are not context-bound. Second, as academic competencies are defined as a combination of learning abilities, analytical abilities and problem-solving abilities, they provide competencies for dealing with new problems in wide range of domains and are needed in particular outside the domain to learn the newly required competencies. Quallitatively comparable results were again found for other discipline-specifically oriented countries (e.g. Austria and Germany). However, the impact of the acquired level of discipline-specific competencies on the allocation outcome is significandy smaller in academic countries, such as the United Kingdom, Spain or France ${ }^{x x}$. Hence, the results are in line writh our theoretical expectations as illustrated in Figures 5.1a and 5.Ib. Furthermote, we can see that graduates with study related working experience during their study time have a higher probability of finding an occupation marching closely their type of discipline-specific competencies. Investing in contact with potential employers during one's study seems to help during the job search stage. With respect to the field of study, graduates from law, natural sciences and health have an higher probability of finding an occupation inside the own educational domain compared to the reference group (graduates from arts and humaniry faculties). As discussed above, we also included as instrumental variables the home situation, the importance attached to the use of the acquired comperencies and the acquired level of adaptability comperency. In particular the latrer two seem to be important factors. Whereas the importance given to the use of the competencies acquired in higher education positively influences the probability of getting matched to an occupation inside one's own educational domain, a high level of adaptability,

20. tho the last wo wartables, graduates were asked to give their answers on a five-point scale, ranging trom a ("not at all") to 5 ("to a very high extent").

21. Appendix $\$$ B provides some insight into robustness tests for the allocation-training estimation.

22. Data not shown. 
on the other hand, positively influences the probabiliry of being matched to an occupation outside ones own educational domain.

\section{Table 5.5}

Bivariate probit analysis for training and allocation

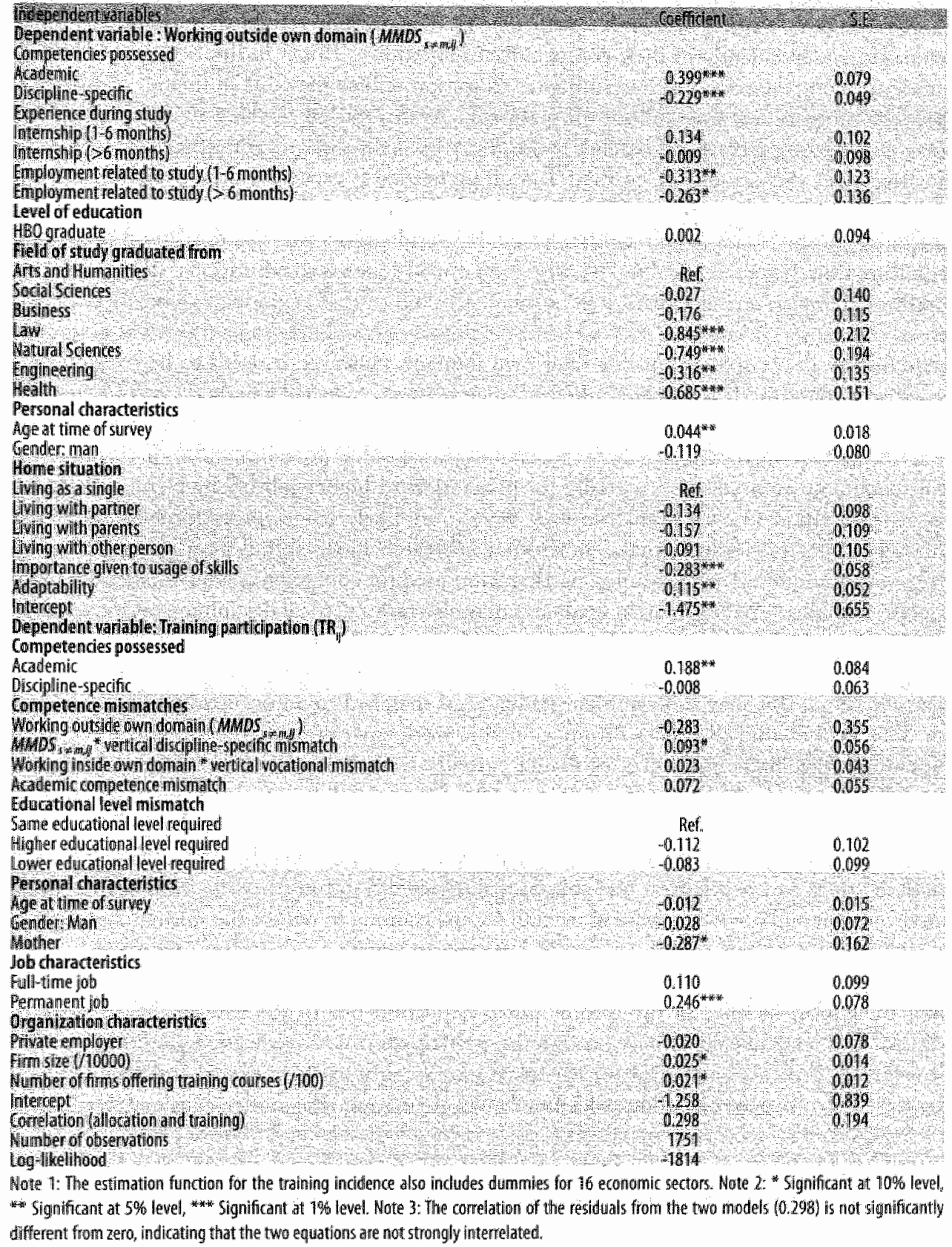


Let ws now turn to the results on training incidence. We can see that the level of academic competencies, as possessed at the time of graduation, thas a significant and posinive infuence on training participation. On the orher hand, the level of discipline-specific competencies seems to have no impacr on training incidence. Hence, complementarity between initial education and on the job training can be established, but only for a certain kind of educa tional outcome, nanely academic competencies. Companable resulus were found for other countries independenty of their comperence orientation ${ }^{23}$. This is in line with the idea that academic competencies acquired in higher education reduce the costs of further learning by providing higher learning abilities to graduates. As introduced in the previous section, we may expect competence mismatches to be costly because of the resulting producrivity loss. In this serise, the amount of on-the-job training needed is expected to be positively related. to the actual discipline-specific comperence mismarches, as training is needed to adjust the acquired competencies to the required ones. The results show that the horizontal mismatch resulting from being matched to an occupation outside one's own educational domain has no additional impact on participarion in training. This indicates that graduates who are matched to an occupation inside their own educational domain are as likely to be trained as graduates marched to an occupation outside their own domain. Howewer, it needs to be recalled that graduates who experienced a horizontal mismatch, on average had a higher level of academic competencies which had a positive effect on overall participation in training. Moreover, it was impossible to distinguish between training used solely for eliminating a competence mismatch and training used partially for promotion to higher job levels. Hence, if graduates inside the own educational domain were more likely to get promotion training, the finding could still indicate that a horizontal mismatch in discipline-specific competencies triggered an higher level of training participation used for competency adjustments. In addition to this horizontal mismatch, graduates may also face a vertical discipline-specific competence mismatch. The results indicate that an increase in the level of this vertical mismatch for graduates inside their own educational domain did nor significantly increase training participation. This may indicate that graduates, if matched to an occupation closely linked tho their field of study, benefited from a suitable work environment to eliminate an existing disciplines-specific competence mismatch partially by learning-by-doing. Contrary to this finding, we can see that for graduates matched to an occuparion outside the own educational domain, an increasing vertical discipline-specific comperence mismarch had a positive influence on raining participation (on a $10 \%$ significance level). Hence, when the match berween field of study and occupation was suboptimal, graduates did not benefit from such a work environment and obviously were in need of formal training to reduce the mismatch. Lasty, a mismatch in academic competencies did not seem to trigger on-the-job training ${ }^{24}$.

We also introduced a measurement for the educational lewel match between graduates and their jobs. Neither in the case of under-education nor in the case of over-education did we find a significant impact on training participation. Over-educated graduates, whose learning capacities are already explicitly taken into account by their level of academic competencies, did not need to follow additional formal training. For under-educated graduates,

13. Datrat not sown.

24. Testing for differential impacts of an acadenic competence mismatch between ohe two occuparional domains did hot reveral qualitarively different results. 
additional training did not seem to be prowided by firms to substitute any lacking educational level. Lastly, female graduates with children were less likely to participate in training (on a $10 \%$ significance level) and the number of frrms offering training courses in the province in which the graduate worked had a positive inthuence on the chance of actually participaring (at a 10\% significance level).

\section{Table 5.6}

The wage equation (revisited)

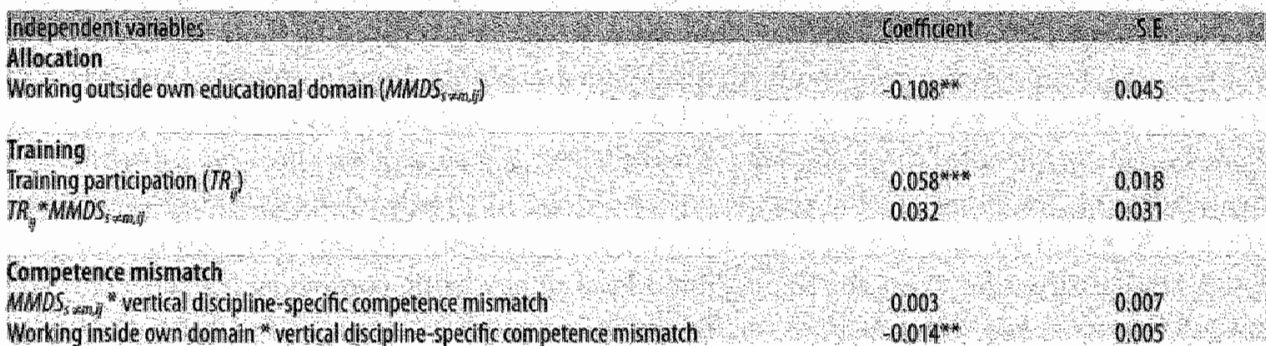

\section{Educational level mismatch}

Same educational le wel required

Mloher edicationalleveliequired

Ref:

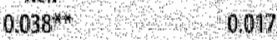

lower educational level renuired

0168

0016

\section{Expentence during study}

Hitem hip during study (6) 6 months)

Hotemship oluing tudy $(>6$ months

Simployment related to study $(16$ month $s$ )

Employment related to study ( $>$ months)

\section{Personal charactersitics}

Hae al time of surwey

Gernder Man

\section{Sold chanarteristics \\ Rillone jo \\ Memanent $10 \mathrm{~b}$ \\ Wow 1 re (th months) \\ Mos, menume \\ Priwale emplower: \\ Din sixe (10000) \\ (timisallocation) \\ (training) \\ linterespt}

\begin{tabular}{llll}
\hline \\
\hline
\end{tabular}

0,002

0008

0,018

$0065^{* *}$

0,017

0,013

0011

0,017

Digfanjation thanacteristic

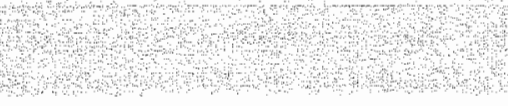

$0071^{1 / 2}$

0.003

0,016

0.0111

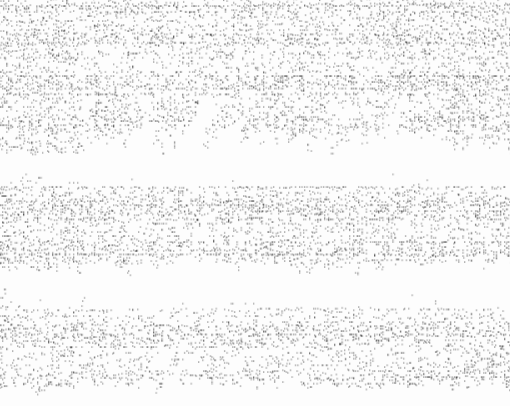

0,015

0013

00001

0.001
0002

0019

0.009

0.024

0018

0.027

0.049:

$1905^{\text {int }}$

0116

Humber of obsewattions

Fstatistics

1426

Notie 1: Dependent variable: log hourly wages measured on the thasis of the reported gross monthly wage ratle and the reporthe number of working hours as stated in the contract The estimation also includes 9 dummies for degrees achteved, 6 dummles for job titles and 16 dummies for economic sectors. To estimate $k_{1}$ and $h_{2}$, we used the probit model presented in Table S.4; standard enrors have been adjusted using the Murphy and Jopd (1985) correction (the selection model estimation was conducted under LMMOEP 7.0; see Greene, 2000). Note 2 : "Significant at 10\% level,

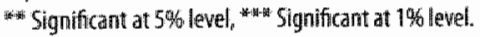




\subsubsection{Results ill: The wage rate rewisited}

Let us now return to the discussion on wage rates, this wime controlling explicitly for the results found in the estitination of the allocation-training model. The results are shown in Table 9.6. Although the findings presented do not differ strongly from the results of the starting wage estimation (see Table 5.4 ) in the sense that both the coefficient for training ${ }^{2 x}$ and the coefficient for working outside the own educational domain are still significant at a r\% level and the size is comparable, we are now in a situation in which we can relate these findings to the different types of competencies acquired in higher education.

First, we found that working outside the own educational domain reduced the wage rate by approximately rr\%. Moreover, the level of discipline-specific competencies is a primary determinant of the allocation outcome. Hence, there is a significant, positive return to the acquisition of discipline-specific competencies. As the impact is relatively indirect, through the allocation outcome, the basic wage estimation in Section 5.3.2 was wnable to reveal it.

A similar situation exists for the acquired level of academic competencies although the overall impact is less clear-cut than for the discipline-specific competencies. First, graduates with a high level of academic competencies (cereris paribus) were more likely to be selected for further on-the-job training, yielding a positive monetary return. Second, graduates with a high level of academic competencies were more likely to be matched to an occupation outside their own educational domatin that paid, on awerage, lower wages. Third, graduates working outside the own educational domain had a higher return on learning-by-doing (measured by tenure) due to their higher level of academic competencies (at a $10 \%$ significance level). To what extent the overall impact of a high level of academic competencies acquired in higher education is beneficial is therefore unclear.

Ewen though the analyses rewealed several interesting results with respect to the role and value of academic and discipline-specific competencies acquired in higher education, further research will be necessary, in particular on the following two features. First, the group of occupations called 'outside own educational domain' may be very heterogeneous. As a matter of fact, they consist of both occupations for which the discipline-specific competencies of another higher education programme are required and occupations for which no particular discipline-specific competencies are required. We will return to this point in Chapter 6. Second, the value of academic competencies may be strongly related to the time period under consideration. As changes in the technology of the production process are more likely to occur in the longer run, and hence increased training and adaptability becomes of more importance over time, we may expect the return to academic competencies to increase over cime. Hence, it would be of great interest to analyze longer time periods than the three to four years that could be considered here.

25. Note that the significant and positive sign of $\lambda_{2}$ indiates that there are whobserved factors positively influencing the ratining incidence and wage rare. 


\subsection{Concluding remarks}

The objecrive of this chapter was to analyze the role and value of academic and discipline specific competencies acquired in higher education. We focused on the situation in the Netherlands, keeping in mind that the Necherlands have a relative discipline-specifically oriented higher education system (comparable to Austria and Germany) and a traditionally racher occupationally oriented labour market.

To start with, we examined a possible direct link between the competencies level possessed at the time of graduation and the gross hourly wages paid three years after graduation. Neither for the level of discipline-specific nor for the level of academic competencies was it possible to establish such a link. However, we found that a mismatch in either the level or the type of discipline-specific competencies harmed productivity and hence the wage rate. Comparing these results with analyses in other countries, we can see that it is a typical situation for countries with a relatively discipline-specifically oriented higher edication system (e.g. Germany or Austria), but does not hold for relatively academically oriented countries (e.g. Unired Kingdom, France or Spain). In other words, the first results indicate that at that moment in time, discipline-specific comperencies seemed to be what mattered for higher education graduates in the Netherlands, Austria and Germany, racher chan academic competencies, as is often claimed. This is the good news for these countries as it fits in well with the findings of Chapter 4 in the sense that the setup of higher education in these countries stimulates discipline-specific rather than academic competencies.

In the second part of the chapter, we analyzed other important roles for the two types of competencies considered. We found in particular that they are important criteria for allocation and further on-the-job decisions made in the labour market.

First, the extent to which Dutch graduates are matched to an occupation in congruence with their field of study is strongly influenced by the level of discipline-specific competencies the graduates possess. As these occupations are better paid, being selected for them is of importance for graduates from a financial point of view. Again, the situation is comparable in discipline-specifically oriented European countries. However, in academically oriented countries, we found that discipline-specilic competencies play a significantly lesser role in allocation decisions.

Second, we showed that academic competencies acquired in higher education played a major supportive role in the Netherlands for the acquisition of further competencies. Hence, academic competencies had an indirect monetary value rather than a direct one. In contrast to the two findings discussed above, this result seems to be independent of the comperence orientation of the country's higher educarion system or the country's labour market. "This is the bad news for discipline-specifically oriented countries such as the Netherlinds, Getmany or Austria, in the sense that their traditional setup of higher education prepares graduates (compared to e.g. the United Kingdom) relative less well for this feature of the labour market.

The finding that academic competencies influenced the selection for on-the-job training contribures to the empirical literature on the question whether training and education are complements or substitutes. We found that training and the level of academic comperencies acquired in higher education are complements, but no significant relationship was estab- 
lished between the level of discipline-specific comperencies and training. Actually, on-the-job training seemed to use academic competencies to adjust the discipline-specific competencies to the requirements of the labour market.

Lastly, the fact that a high level of academic competencies influenced the probability of the graduate getting/accepting an occupation outside his or her own educational donain again confirmed that academic competencies are not context-bound and hence can be applied in a wide range of occupations. 


\section{Appendix 5A: Characteristics of Dutch graduates}

\section{Tablie 5:A1}

Characteristics of the Dutch graduates

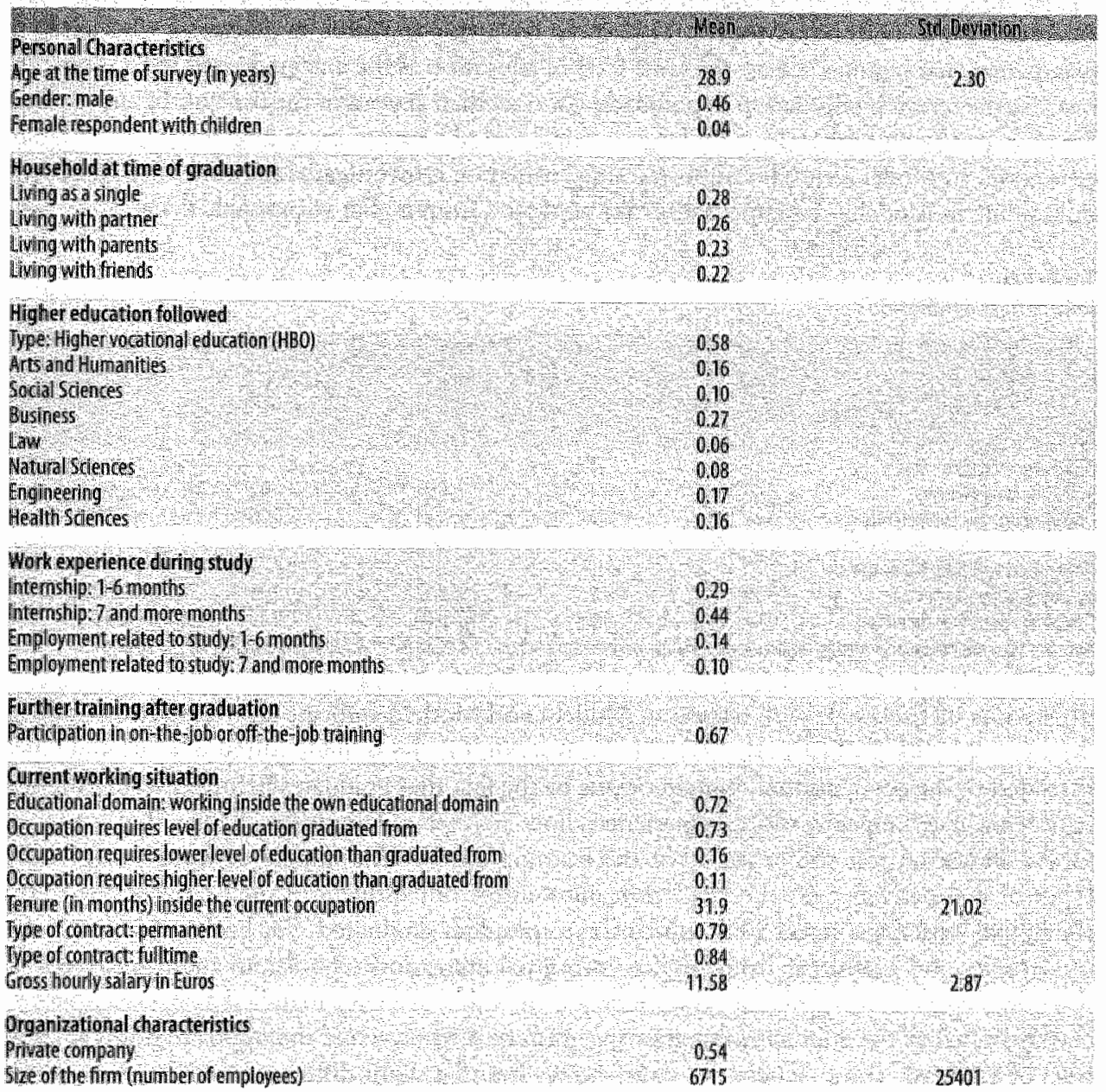

\section{Appendix 5B: Robustness of allocation-training model?}

In this section, we will briefy investigate the robustness of the allocation and raining model with respect to several assumptions made in the analyses. In particular, we will test the extent to which the impact of the two types of competencies on the allocation outcome is influenced by ignoring different levels of occuparions in the estimation above and by ignoring the fact that the data consists both of graduates who entered the higher education system immediately after secondary school and graduates who spent some time working between 
secondary school and entering the higher education system. Lastly, we will analyze to what extent differences can be found between graduates from the university sector and graduates from the higher vocational education sector. Table 5 . Bi presents an extraction of results from frve different model estimations. For reasons of simplicity, Model o is the original estimation as discussed in the main teat. Model 1 restricts the research population to graduates who have an occupation that requires at least the same level of education as the one graduated from. Model 2 restricts the research population to graduates younger than $3 \mathrm{r}$ years at the time of the survey and hence to graduates with at least no long working period between secondary school and higher educarion. In Model 3, the allocation-training estimation is investigated for university graduates only, while in Model 4 the same is done for graduares from higher vocarional education.

\section{Table 5.B1}

Riobustness estimations

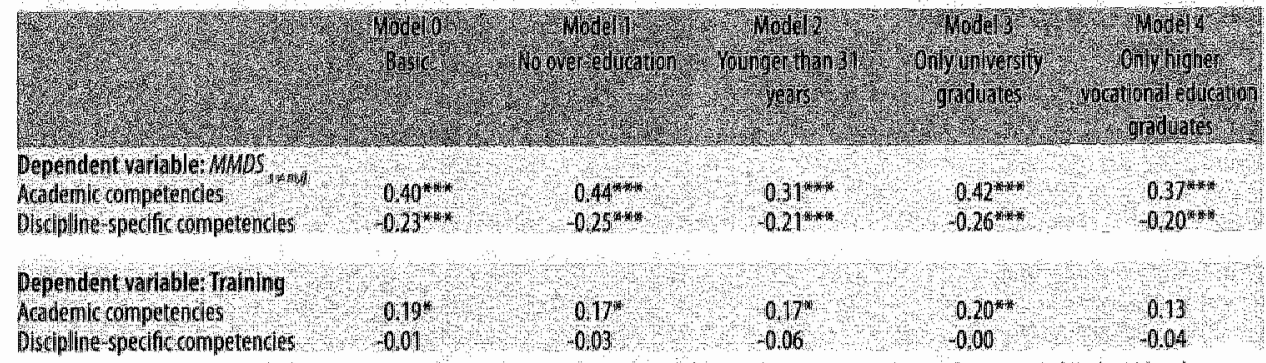

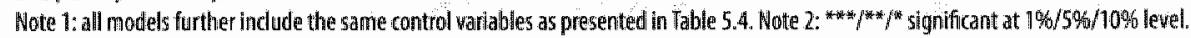

The results in Table 5. Bi with respect to Model $\mathrm{I}$ and Model 2 indicate clearly that controlling for a possible bias/influence due to either a situation in which the required educational level is related to the occupational domain or due to the fact that graduates before entering higher education had longer working experience, does neither qualitatively change the outcome of the allocation nor the outcome of the training model. The impact of the two different cypes of competencies on the allocation outcome is not infuenced qualitatively either by the higher education sector from which the respondent graduated. For both graduates from universities and graduates from higher vocational education schools, an increased level of discipline-specific comperencies does increase the odds of being marched to an occuparion closely linked to the education programme graduated from, while the opposite holds for the level of academic competencies. In contrast, we found a slight difference with respect to the impact of academic comperencies on training participation. Whereas for university graduates the level of academic competencies was found to be a primary determinant of training participacion this did not hold for graduates from higher vocational education. To what extent this is related to the more discipline-specific orientation of programmes in the higher vocational education sector compared to the university sector, will be a quescion that furcher research needs to answer. Summarizing this section, it can be stated that our investigation with respect to the allocation and training participation outcome seems to be robust against some critical factors neglected in our basic estimation. 


\section{Chapter 6 \\ The effects of higher education programme characteristics on the allocation and performance of the graduates ${ }^{1}$}

1. This chapter is an extended version of Heike and Meng (forthcoming). We would like to thank participants at the Transition in Youth Network. Conference in Madeira (2003), at the EEA conference in Madrid (2004), ant the EAIE conference in Lisbon (2004) and participants at seminars at the University of Barcelona (September, 2003). Mastricht Uniwersicy (October, 2003 and December, 2003). EIM (Zaetermeer, 2004). LAB (Nuremberg 2004) and Bamberg Uniwersity (2004) for their comments on earlier drafts of the paper. Fturthermone, We benefited a great deal from comments by Jim Alen, Hans-Peter Blossfeld, Lex Borghans, Josep M. Masjuan Codina, Ben Kriechel, Ferrane Mane, Jondi Planas, Inge Sieben, Alexandra Spirz and Roy Thurik. 


\subsection{Introduction}

The transition from education to the labour market is crucial. Graduates search in a labour marker about which they are relatively badly informed and whete jobs may be scarce. Employers try to find the most suitable higher educared candidaces for their available vacancies. In addition to the applicants educational backgrounds and performances, employers know relative little about their specific productive capacities. Mismatches between desired and realized allocation over jobs and between expected and realized performance in these jobs may occur easily ${ }^{2}$. Given this context, employers may be expected to rely not only on individual characteristics of the applicant, but also on characteristics of the education programme, and hence on group features, to retrieve relevant information for hiring and/or salary decisions. To increase the knowledge on this point, we will address in this chapter the extent to which typical characteristics of higher education programmes are valued, as they either seveal the productive capacities taught to the students or as they reduce the uncertainty with respect to the type and level of competencies which the graduates possess. In both cases, the risk of high adjustment costs is reduced.

Most of the existing comparative research on the impace of educarional characteristics on labour market outcomes focuses on secondary education level systems. In particular, authors considered the extent to which vocational training at this educational level is provided and the extent to which secondary education programmes within a country are standardized and stratified. Allmendinger ( 1988 ), studying career mobility patterns in the United States, Norway and Germany, proposed a typology of education systems based on the two dimensions of "standardization" and "stratification". Standardization is defined as "the degree to which the quality of education meets the same standard nationwide" (Allmendinger, 1988, p.35). The term "stratification" is used to reflect "the proportion of a cohort that attains the maximum number of school years provided by the educational system and by the degree of differentiation within a given educational level" (Allmendinger, 1988 , p.35). On the basis of these definitions, Allmendinger argued that stratified and standardized systems provide clear signals on the real educational achievements of school-leavers and allow employment decisions to be based on educarional credentials. Müller and Shavit (1998), analyzing school-to-work transitions in thirtern countries, added the vocational specificity of secondary education and the proportion of school-leavers with post-secondary education as additional dimensions. Other typologies have been introduced for instance by Maurice, Sellier and Sylvestre (1982), who made a distinction between "qualificational space" and 'occupational space", or by Hannan, Raffe and Smych (1996), who introduced the strength of the linkages between educational and labour marker systems as a further dimension.

Notwithstanding their relevance for the school-to-work transition, the general focus on secondary education and their analyses on system level restricted these earlier approaches greatly. With an increasing proportion of the young Western population continuing their education into terwary level, we are in need for indicators extending the range into rertiary education programmes and encompassing signals that these programmes provide to the labour market. Accordingly, a first line of research looked at the impact of the field of study

2. See also the discussion on this topic in Chapter s. 
on labour market success. Generally, this research argued that the field of study mediates the link between higher education participation and educational outcome (see e.g. Muller, Steinmann and $\mathrm{Ell}, 1998$ ). However, we argued in Chapter 2 that the simple use of the higher education qualification (or field of study name) is a far from ideal indicator of the competencies actually acquired in higher education or used in the labour market. Consequently, whe will consider in this chapter five chanacteristics of education programmes that nomally remain hidden in the black box of the field of study. The objective is to reveal the effectiveness with which higher education programmes allocare their graduates over various occupational domains in the labour market and how these graduates perform in the occupation obtained.

In line with the main objective of this thesis; the first three characteristics to be investigared consider the type and level of competencies taught to the students. The fourth and fifth characteriscic deal with experience outside the regular teaching process and competenctes acquired in this context. More specifically, the first characteristic is the competence oniewation (discipline-specific versus academic) of the higher education programme. This chatracteristic is comparable to the approach by Müller and Shavit (1998) on the vocational specificity in secondary educarion. The second characteristic concerns the level of standardization of the programme with respect to the competence level acquired by graduates, measuring the homogeneity of the graduates. In line with the fundings of Allmendinger (1988) at the system. level, we expected highly standardized programmes to offer clearer signals of the capacities of their graduates, reducing the uncertainty on the actual level of discipline-specific and academic competencies possessed by graduates. The third characteristic deals with the fact chat certain education programmes provide exclusiwe entrance to particular occupations in the labour market. The reason for this exclusive entrance lies mainly in the fact that tasks in these occupations are considered high-risk tasks and failure produces high costs to society. Hence, employers and their customers may rely on this characteristic as a guarantee that the graduate possesses an acceptable minimum level of required discipline-specific competerncies. Well-known examples are the health care and law sectors. The integration of working and Learning, and hence the extent to which the work term is a vital part of the academic anriculum, constitutes the fourth characteristic discerned. Lastly, we investigated the impact. of the degree of internationalization of the programme. In doing so, we incorporated in the analysis the fact that the labour market for graduates has become increasingly international due ro the globalization process and the integration of markets (e.g. the European Union).

In order to trace the effects of these programme characteristics, we can look at the labour market from the perspective of a particular education programme. More precisely, three occupational domains ate distinguished: A domain in which optimal fulfilling of the tasks reguires graduation, and hence the discipline-specific competencies, of a particular programme, a domain in which discipline-specific competencies of another education programme offer a comparative advantage, and a domain in which graduation from a particular higher education programme is not a direct requirement and hence academic competencies are demanded".

The structure of the chapter is as follows. Section 6.2 discusses first the labour market framework assumed and second the five characteristics of the education programmes discerned. Section 6.3 presents the data used in this chapter. The econometric model is devel-

3. For an exrended discussion on this rype of liverature sec Chapter 2.

4. Ir Chaperer 5, the later two domains were combined in ro one domain. 
oped in Section 6.4. First, we will evaluate the impact of the education programme characteristics on allocation. Second, the infuence of the education programme characteristics on the wage will be inwestigated. Section 6.5 concludes the chapter and relates the findings back to the earlie distinction beween discipline-specifically oriented countries and academically oriented countries.

\subsection{Theoretical framework}

\subsubsection{Labour market characterization: Three occupational domains}

The main objective of this chapter is to relate wariations in the initial labour marker outcomes of graduates to characteristics of the higher education programme they completed. In line with Chapter $\xi$, we will characterize occupations according to the level and set of disciplinespecific and academic comperencies which they require for optimal fulfilment of the tasks:

$$
\text { (6.I) } C^{\mu^{\prime \prime}}=C^{r}\left(D S_{s}^{r}, A^{r}\right)
$$

where $C^{r}$ is the required competencies set in occupation $j, D S_{s}^{*}$ the required discipline-specific competencies of type $s$, and $A^{r}$ the required level of academic competencies". Assuming for reasons of simplicity that the required set of competencies consists of a linear combination of a package of discipline-specific competencies and of academic competencies, we can write:

$$
C_{1}^{r}=\eta_{j} *\left[\sum_{s=1}^{n}\left(\mu_{s}^{*} D S_{s}^{r}\right)\right]+\left(1-\eta_{j}\right) * A^{r} \text { with } \sum_{i=1}^{n} \mu_{s}=1 \text { and } 0 \leq \eta_{j}, \mu_{s} \leq 1
$$

Equation 6.2 implies that the required mix of competencies in a particular occupation $j$ is given by the sum of discipline-specific competencies (DS) of the different types $s$ and the levell of academic comperencies $(A)$. The term $\mu_{s}$ measures the weight given to a particular type of cliscipline-specific competencies in the package of required discipline-specific competen-

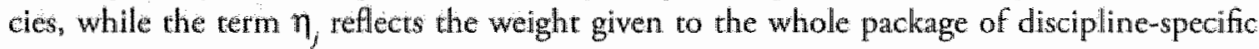
comperencies.

The horizontal difference between a particular type of discipline-specific competencies (acquired in programme $s=m$ ) and all other types of discipline-specific competencies $(s \neq n)$ is assumed to be constant

$$
D S_{s=m} D S_{s \neq m}=
$$

5. We will not add an index (n) to term A reflecting the fueld of study in which they are acquired, as we assume academic competencies to be transwersal. Hence, the cerm "academic" does not refer to eliements common ro differen discipline-spectfic comperencies but to the additional subject-independent content of these competencies (for a more detailed discussion on this poin', see Chapter 2 ).

6. This assumprion makes it possible to add up the level of discipline specific competencies required but not acquired in the study program giaduated from, ignoring the fact that they are of different types. 
Hence, we assume that the step to be taken from, for example, discipline-specific competencies in business administration to the discipline-specific competencies in law to be the same as from discipline-specific competencies in business administration to the discipline-specific competencies in medicine. In this sense, $c_{s}$ is determined by the closeness of a particular education programme to the others and hence by the broadness of the discipline-specific competencies that a graduate acquires. Combining $(6.2)$ and $(6.3)$, we get:

$$
\text { (6.4) } \left.C_{j}^{r}=\eta_{j} *\left[\mu_{s=m} * D S_{s=m}^{r}+\left(1-\mu_{s=m}\right) \sum_{s=1}^{n} D S_{s * m}^{r}\right)\right]+\left(1-\eta_{j}\right)^{*} A^{*}
$$

Restricting the overlap in an occuparion berween different types of discipline-specific competencies to $\mu_{s a m}=1$ or $\mu_{s \mathrm{~s} m}=0$ and/or between discipline-specific competencies and academic competencies to $\eta_{j}=$ or $\eta_{j}=0$, we can classify the occupations from the perspective of education programme $m$ into three domains:

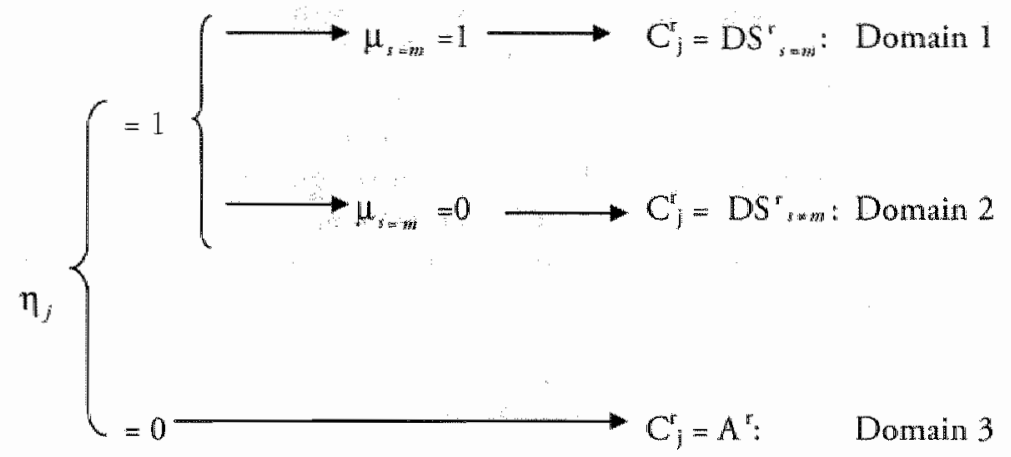

Domains 1 and 2 include occupations in which importance is given to discipline-specific comperencies. From the point of view of graduates from education programme $\mathrm{m}$, Domain $\mathrm{X}$ is the group of occupations closely related to their own education programme (the oun discipline-specific competencies domatin), while Domain 2 is the group of occupations that require the discipline-specific comperencies of another education programme (the disciplinespeciffe competencies domain of another education programme). Domain 3 consists of occupations in a market segment that is characterized by a less strong link between occupations and a particular education programme. The focus of atrention in this market segment is on academic competencies rather than on a particullar type of discipline-specific competencies (the academic competences domain). However, these occupations still require a higher education diploma. This does not a priori imply that discipline-specific comperencies are not important in this domain, but rarher that either the discipline-specific competencies required in this domain are less likely to be acquired in higher education or that they are so new that they have nor yet been incorporated in the higher education programmes. 


\subsubsection{Education programme characteristics}

This section discusses the five indicators discerned to characterize the education programmes. It also formulates the expected telation bewween these indicators and the labour market siruation, in terms of allocation and performance, of graduates.

\section{a) Discipline-specific versus academic competencies}

Higher education programmes are generally organized around a particular discipline or higher professional fidd and hence around the learning of discipline-specific competencies. However, in higher education, students acquire not only discipline-specific competencies but also academic competencies. In line with the characterization of accupations, we will write the outcome of higher education $\left(C_{i}\right)^{g}$ of student $i$ graduating from programme $s$ as a mix of these two types of competencies:

$$
\text { (6.6) } C^{a, j i}=C_{i, s}^{a}\left(D S_{i, s}, A_{i}\right)
$$

In spite of a possible symbiotic process between the acquisition of discipline-specific and academic competencies (see Chapter 4) that might take place in higher education, educarion programmes differ with respect to the weight of discipline-specific competencies and academic competencies as major or minor outcomes of the programme. In this sense, the particular mix of competencies which a representative student acquires during the study, is restricted by the placement of the education programme on the spectrum from disciplinespecific to academic competence orientation. Assuming the competence mix ourcome to be a linear combination, we can write:

$$
\text { (6.7) } C_{i_{s, s}}^{*}=\lambda_{i}^{*} D S_{i, s}+\left(1-\lambda_{i}\right) * A_{i}
$$

where $\lambda_{i}$ is the weight given by the education programme completed by the graduate to the acquisition of discipline-specific competencies as a major learning outcome.

Structuring the education programme towards a planned leaming outcome of disciplinespecifo compertich ( $\lambda$, close to 1$)$, and hence perceiving the role of academic competencies solely as the means by which the learning of discipline-specific competencies is enhanced rather than an end in itself, provides the graduates on average with a relatively greater share of discipline-specific competencies". To the extent that these competencies have a direct productive application value in occupations closely linked to the education programme completed $\left(\mu_{s=58}\right.$ and $\eta_{j}$ in equation 6.4 are close or equal to 1 ), we may expect these graduates to have ari greater probability of finding their way into the own discipline-specific competencies domain (see also Chapter 5). Furthermore, we may expect these graduates to have a relatively greater comparative advantage when mathed to an occupation in the own discipline-specific domain but a relative greater loss in the application of their discipline-specific competencies in other cases. In other words, whereas these graduates an be expected to find relatively

7. We use at to indicate the acquired level of comperencies, as distinct from ${ }^{2}$ ind icating the required level.

8. Acoording to the findings in Chaper 4 , these types of edtuational programmes may use nather tradicional teaching scyles and reguite from the scudents to atrend a great deal of formal exducation. 
higher wages inside the own discipline-specific domain, their wages are expected to be lower in other cases, and particularly to drop considerably when matched to an ocoupation in the discipline-specific domain of another education programme.

Structuring the edwcation programme towards a plawned leaming outcome of acalowic competencies $(\lambda$, close to 0 ) provides the graduates on average with a relatively greater share of academic competencies: These programmes use the acquisition of discipline-specific competencies as the material needed to enhance the acquisition of academic competencies. The non-context-bound characteristics of academic competencies can be applied in a wide range of occupations and hence it is expected to find a more dispersed allocation of these graduates across the different occupational domains distinguished, with a tendency rowards the academic competencies domain. Moreover, the allocation dependence of the wages is expected to be less.

\section{b) Standardiation of the competencies provided}

In a world of complete and freely awailable information, employers can be expected to search for graduates who offer a mix of competencies resembling as closely as possible the mix of competencies required to optimize performance of their tasks. Conversely, graduates search for these occupations to maximize their wage rates. Unfortunately, the matching of higher education graduates to vacancies in the labour market dow not take place in such a perfect world. In spite of an accurate perception of their competencies, characteristics and possibilities, graduates have only a vague notion of the exact working requirements. Similarly. employers, knowing what the working requirements are, are relative badly informed as to what extent the characteristics of the graduates match the requimements. Given this asymmetric distribution of informarion and its private character, employers face a time-consuming and costly evaluation of an applicant's productivity. In this sense, the standardization of education programmes with respect to the competencies taught can be an important costderermining factor.

Let us assume that both the graduates' level of discipline-specific competencies and the level of academic competencies acquired in higher education are not perfectly measurable during the application procedure. More precisely, we can write:

(6.8) $D S_{i, s}=D S_{i, s}^{e}+\delta_{D S s}$

(6.9) $A_{i}=A_{i}^{e}+\delta_{A s}$

where $D S_{i, s}^{e}$ and $A_{i}^{e}$ are the revealed level of discipline-specific competencies of type $s$ (indicating the higher education programme graduated. Fom) and academic competencies of applicant (i), respectively, $D S_{i, s}$ and $A_{i}$ are the real level of discipline-specific and academic competencies acquired by the graduate, respectively, and $\delta_{D S S}$ and $\delta_{A, S}$ the measurement error unknown to the employer, assumed to be normally distributed around zero.

Inserting 6.8 and 6.9 into 6.7 , the competencies mix offered by a graduave, from the employer's point of view looks as:

9. Chapter 4 showed that these types of educational programmes are more likely to provide actiwaing leaming envitonmerrs in which self-study and addressing problems in group metrings play a central role. 
(6.ro) $C_{i, s}^{a}=\lambda_{i} *\left(D S_{i, s}^{e}+\delta_{D S i}\right)+\left(1-\lambda_{i}\right) *\left(A_{i}^{e}+\delta_{A s}\right)$

Equation (6.10) implies that graduates, afrer having been selected for an occupacion, may reweal productive capabilities above or below the level initially measured. Both situations, a productivity lower of a productivity higher than the targeted one, may be regarded as undesirable by the employer as they involve further costs at least partially to be born by him. If actual productivity is lower than targeted, the employer faces the decision berween continuing the work contract and ending it. In the first case, the employer needs to inwest in employee training. In the second case, he needs to restart the costly search process for a more sutable candidate. If actual productivity is higher than targeted, the employer may first profit from the situation. But he will be confronted to an increasing extent with an unsatisfied employee; who either demands higher wages or quits the job and forces the employer to restart the costly search for a new candidate.

A reduction in the measurement error is beneficial both for the employer, as it reduces the expected costs inwolved in hiring a graduate, and for the graduate, as it increases the wages offered. To address this problem, employers may prolong the applicarion procedure and run more tests, or rely on information gathered through experience or accessed externally. In the latter case, the importance attached to the group membership of the graduate, as a source of conveying infornation with respect to the individual graduate, increases. The more homogeneous the group of students grailuating from a particular education programme, the more information their group membership reveals about the individual graduate. In our case, a strong index ${ }^{\star 0}$ for this homogeneity is the standardization of an education programme with respect to the level of discipline-specific competencies or the lewel of academic competencies. The more standardized an education programme, the less variation between graduates' levels of competencies and hence the smaller the expected measurement error.

Conduding, it was found that the higher the degree of standardization of the education programme with respect to the competencies taught, the lower the expected transaction costs involved in hiring a particular graduate and hence the higher the wage rates offered to such graduates. The question arises if employers/graduates profit more from a standardization of discipline-specific competencies on from the standardization of academic competencies. The answer is related to the importance atached to one of the two comperencies in the accupation to which the graduate is matehed (see equation 6.4 ). If the vacancy offered matches the type of discipline-specific competencies which the graduate acquired in higher education, the standardization of the discipline-specific competencies will be of interest. If the graduate applies for an occupation outside the own discipline-specific competencies domain, and hence will have to acquire new types of competencies, the standardization of academic competencies, providing information with respect to the graduate's learning ability, plays a more important role.

\section{a) Frachisive enswince}

Our third characteristic concerns the fact that certain education programmes provide an exclusive possibility to enter certain labour market occupations. This holds in particular for

10. We follow spence (1973) and refer to observable atributes (which cinnot be altered by the graduate) as indices, reserwing the term stgmals for obserwable characteristics attached to the individual that are subject to manipulation by him. 
law and health science studies. To be employed as a lawyer, one has to graduate in law and to be employed as surgeon, a medical study is a prerequisite. This guarantees employers and potential customers that the job holder has the necessary competencies to fulfil the tasks. Considering our intention to analyze the allocation of graduates over different occupational domains, this characteristic can undoubtedly be regarded as important.

\section{d) Integration of learing and working}

The increasing umportance of knowledge in society and economy, and the implied shift from the importance of a classical scientific knowledge structure in disciplines towards specific contextualized knowledge (Hövells, 2003) stimulate لlarger interactions between learning in the classroom and economic life. In an economy in which knowledge capital adds more value than classical factors, such as physical capital, taw materials and physical labour, it seems less and less useful to distinguish berween exclusive classroom education and learning that takes part outside the classroom (see e.g. Kessels, 1998). Higher education cannot afford to take a passive stand, but should initiate possibilities for co-operative education, providing opportunities for connecting the traditional higher university campus to the work environment. This helps students to acquire competencies "that are difficult to acquine in the traditional wniversity Lecturing room, such as communication skills, the ability to work together in a team and being comfortable in work environment" (Kessels and Van Wingaarde, 2003).

Strengthening the link berween classroom teaching and direct acquisition of working experience imposes a trade-off between time spent on classical teaching of competencies and time spent on generating work habits and out-of-classroom competencies, contributing to a smooth integration of graduates into their first occupation. Co-op education not only enables graduates to apply their theoretical knowledge to real working situations, but also to take the new information and extended knowledge back to the classroom. Moreover, contacts established between employers and students and the information transfer taking place may help solve the information asymmetry during the transition period.

The strongest positive effects of comop education can be expected for graduates who have actively participated in work placements or internships. However, the set-up of a co-op education programme can produce positive spillover effects for non-participating peers. First of all, stimulating and providing students with possibilities of internships or work placements outside the campus, generally goes hand in hand wirh structuring the curticulum itself in a more practically oriented way, allowing the two-way transfer of knowledge by graduates to be maximized. Second, non-participants may benefit at the time of graduation from the non-exclusive nerwork with employers established by the educational institute they attended. Firms may contact lecturing staff with information on wacancies or firms may generally prefer students from a particular programme due to good experience with interns of this programme. Concluding, co-op education programmes may be expected to give graduates an increased probability of finding an occupation closely linked to the discipline taught and hence an occupation in which their central competencies are required.

\section{e) Internationalization}

"Internationalization" and "Globalization" are widespread terms in economic textbooks of the past 15 years. Mergers and acquisitions are no longer restricted by the frontier of a country or 
continent. Contacts with foreign partners or customers have become the daily wotk of a large number of employes. Not surprisingly, we can see in the labour market a growing demand for graduates with knowledge of unternational affairs, international economics, international law or more generally, with the knowledge of foreign languages and cultures. In recent years, the internationalization of economic life is being reflected more and more in the internationalization of education. An increasing number of higher education students complete part of their studies in a foreign cotnntr. Moreover, education at home gets more and more internationalized by, for example, teaching part of the courses in a foreign language. The confrontation of graduates with this internationalization of education programmes may have its impact on the level of competencies of all graduates of the programme. However, it may be of even more imporance that it browdens the horizon with which graduates enter the labour market. As the labour market increasingly asks for "international" graduates, we expect the return to this asset to be positive.

\subsection{Data}

We make use in this chapter of the pooled international data set described in Chapter 3. To control for differences berween programmes of different higher education institutions in a country, we distinguish in France between university and Grande Ecoles programmes, in Germany between university and Fachhochschulen programmes, in the Netherlands between university and higher vocational education programmes, in the United Kingdom berween old and new universities, and in Norway between university and university colleges programmes. In Spain, Italy, Austria and Finland, no distinction "Is made. Although in Austria and Finland Fachhochschulen and Polytechnics, respectiwely; were introduced in the mid-199os, the data used here do not cover graduates from these higher education institutions.

Considering our focus on education programmes and their characteristics, a first best approach would be to analyze narrowly defined education programmes (e.g. econometrics, business administration, economics, etc.), and to distinguish between the institutes offering these programnes (e.g. Econometrics at the University of Maastricht, Econometrics at the Uniwersity of Amsterdam). Unfortunately, the data does not allow for such a first best approach and forces us to use a second best approach. We therefore aggregared over institutes in articulat higher education instirution (e.g. university type higher educarion in the Netherlands) and over narrowly defined study programmes. For the latter, we made use of the information on the individuals' educational field provided by the International Standard Classification of Education (ISCED 3 digits). We recoded the 3 -digit ISCED into 7 educa* tion fields, namely 'arts and humanities', 'social sciences', "business', 'law', "natural sciences", 'engineering" and 'health sciences'. Aggregating individual instivutes could weaken the relevance of the results if individual. institutes attracted/selected different types of students and such differences were not reflected in differences between the fields of study. Concluding, the data allows us to distinguish between a total of 9 different higher education programmes nested in 14 higher education institutions and nine countries (see Figure 6.1).

Ir. In Chapter 4, we showed that higher education students spending some time abroad during their studies have a bigher lavel of academic competencies at the time of gracluation, but at the same time a lower level of disciplinespecific compirtencies. 


\section{Figure 6.1}

Countries, Higher education institutions and programmes.

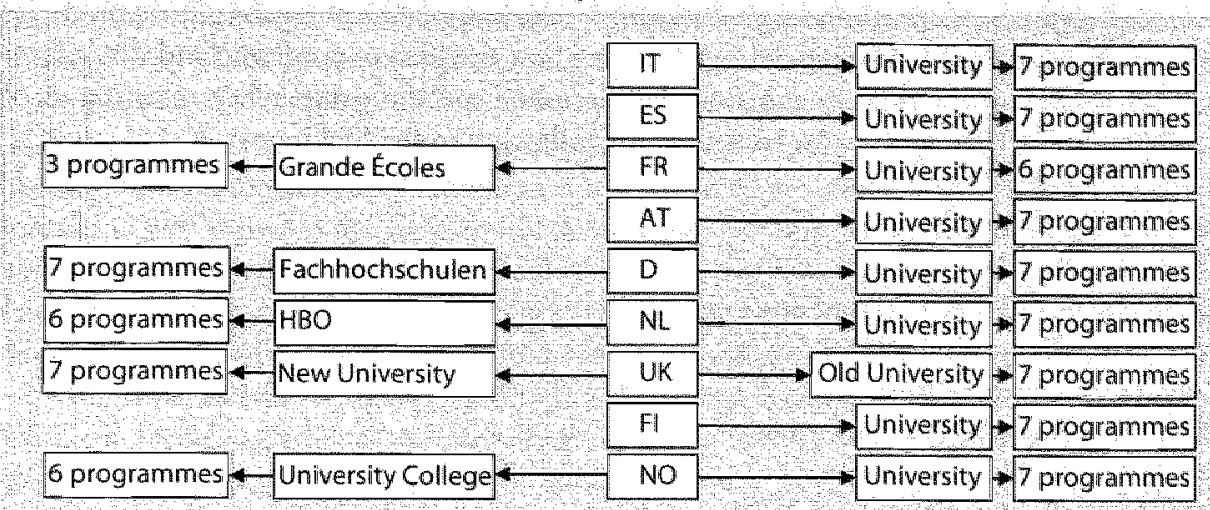

Wote: The Datch HBO and the Norweglan Lnivers ty College institution do not provide a solid law programme. The French Grande Eroles institutition teaches in particular business, natural sciences and engineering programmes. The number of respondents from french uniwersity health programmes is tom small to be taken into account.

\subsection{The measurement of the occupational domain}

In Section 6.2, we proposed a division of occupations into three occupational domains, namely a domain in which optimal fulfilling of tasks requires graduation, and hence discipline-specific competencies of a particulat programme, a domain in which discipline-specific competencies of another education programme offer a comparative advantage, and a domain in which in particular academic comperencies are demanded. To group the graduates occuparions, we relied on the following question in the survey: "How would you chamoterize the relationship between your fueld of sudy and your area of work?" We assumed that the graduate worked in the own discipline-specific competencies domain if he answered that either "ny oun field of study is the only'best preparation" or "a related field could as well prepare. "Graduates were assumed to work in the discipline-specific competencies domain of another programme if they answered that "another field wowld batwe been mowe weful." Lastly, graduates were assigned to the academic competencies domain if they indicated that "the field of sudy does not mater very much." Overall, a dear majority of graduates worked in their own discipline specific competencies domain $(75 \%)$, approximately ro\% work in the domain of another education programme, and $15 \%$ in the acadenic comperencies domain.

\subsubsection{The measurement of the education programme characteristics $5^{\text {i. }}$}

\section{a) Competence oricutation of the programne}

To measure the discipline-specific competence orientation of the education programme, we have used the information in the data set with respect to different competencies, representing. demands for and supplies of knowledge. Graduates were asked to indicate on a fwe-point

12. The figures for the fveducational programme characteristics are presented in Appendix.6A. 
scale, ranging from $x$ ('not at all') to $s$ ('to a very high extent")", the exrent to which they had a given competency at the rime of graduation. Using a hierarchical clustering method, we retained two clusters of competencies representing best the idea of academic and disciplinespecific comperencies needed to measure the discipline-specific competence orientation of the programme $e^{\text {s. }}$. The two clusters consist of the following individual items:

\author{
1. Academic competencies \\ * Learning abilities \\ n. Reflective thinking, assessing one's own work \\ b. Problem-solving abilities \\ *. Analytical competencies \\ "Documenting ideas and information \\ 2. Discipline-specific competencies \\ "Field-specific theoretical knowledge \\ $n$ Field-specific knowledge of methods
}

For the analyses, we first calculated an average of the competence clusters possessed at the time of graduation per education programme. Second, we calculated the difference between the level of discipline-specific competencies and the level of academic competencies that an education programme provides to its graduates ${ }^{\text {th }}$. Hence, the competence orientation of a particular programme carn range from -4 (extremely academically oriented) to 4 (extremely discipline-specifically oriented). On average, the education programmes scored slightly academically oriented (average score over all programmes is -0.05 ), ranging from -0.70 (law programme in the Old University institurion of the United Kingdom) to 0.38 (health science programme at Austrian Universities). Moreover, the figures presented in Table 6.AI of Appendix 6A indicate a strong country effect with respect to the competence orientation of programmes. As a matter of fact, programmes in Austria, Germany, the Netherlands and Norway scored strikingly more discipline-specifically oriented than programmes in other countries. Lastly, there were also some differences between higher education institutions inside a country. In particular, non-university higher education institutions on average scored slightly more discipline-specifically oriented. However, the relative ranking of an education programme is quite similar across the fourteen higher educarion instrtutions.

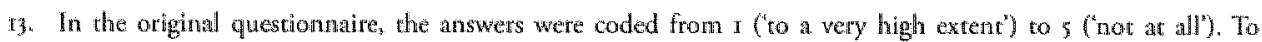
simplify the reating of the empirical analyses, we recoded the answers to range from 1 ("not at all') wo (to a very hight oxtent').

14t- For a dealled discussion on the clustering method used, an overwiew of some descriptives wim nespect to the lavel of actemic and discaplinespecific competencies acquired by higher education graduates and required in the labour manker, as well as for a discussion on the validicy of the mo construcrs, please see Chapter 3.

15. The reatson for not just simply raking the average level of discipline-specific comperencies and the average level of academic comperencies separately in the analyses, is that graduares in particular countries or in particular higher education institutions can be expected to score high (low) on both dusters depending on the extent of self-criticism. Using the difference berwern the rwo scores was a possible way to circumvent dhe problem of possible bias in the level of reported competencies. 


\section{b) Sirandardization}

The standardization of an educarion programme was introduced as a measurement for the homogeneiry of the graduates with respect ro the competencies obtained during their studies. A simple way of measuring this was given by the variance of the disciplune-specific comperen. cies acquired by the graduates of a particular education programme and by the variance of the academic competencies. Being unaware of the institute concerned, it was necessary to be careful not to measure the variation between instirutes but, as far as possible, the variation related to the heterogeneiry between graduates. For this reason, we used the within wartance estimator extracted from an ANOVA analysis. To simplify the reading of the tesults, we then used the inverse of this as measurement for the standardization of a programme.

The standardization figures reported in Appendix 6A (Table 6A.2a and 6A.2b) indicate that, on average, graduates are more homogeneous with respect to academic competencies than with respect to discipline-specific competencies.

\section{c) Exclusive entrince}

The third characteristic is based on the fact that certain education programmes exclusively offer entrance to certain labour market occupations. This holds in particular for studies in 'law" and 'health sciences'. To control for this in the empirical analyses, we explicidy used a dummy indicating whether the respondent graduated from either of these two fields of study. In total, 2 r\% of the respondents graduated from these two fields of study, namely $8 \%$ from a law faculty and $13 \%$ from a health science faculty.

\section{d) Work-learning relation}

The data contains different questions with respect to the work-learning relation of the programme. Graduates were asked to indicate if they have completed an internship/work placement during their study as part of their degree course and were also asked to rank their programme with respect to the importance given to the direct acquisition of working experience. To circumvent the problem of cultural bias with respect to the second question and the problem that graduates might rank their programme depending on the extent to which their expectarions were fulfilled, we used the percentage of graduates that took part in an internship/work placement as a measure for the extent of co-op education.

On average, $41 \%$ of the graduates completed an internship/work placement as part of their degree course. The lowest percentage was found for respondents that graduated from law faculties in Italy (only $\mathrm{r} \%$ followed an internship/work placement) and the highest percentage for engineering graduares of the French Grande Ecoles institutions (92\%).

\section{e) Internationalization}

The final education programme characteristic was the international orientation of the educarilon programme. The only possible indicator provided by the data was the percentage of graduates that completed part of their study programme abroad. On average, $23 \%$ of the graduates spent some time abroad during their studies. The highest percentage was found for health sciences in the Dutch Universiry institutions ( $56 \%$ ), the lowest percentage for natural sciences in the Norwegian College institutions ( $4 \%$ ). 
Concluding this section, Table 6.1 reports on the corratation between the fwe programme characteristics. The results show that there are, in particular, positive relations between the discipline specific competence orientation, the standardization of discipline-specific competencies, the standardization of academic competencies and the work-leaming relation.

\section{Table 6.1}

Correlation between programme characteristics

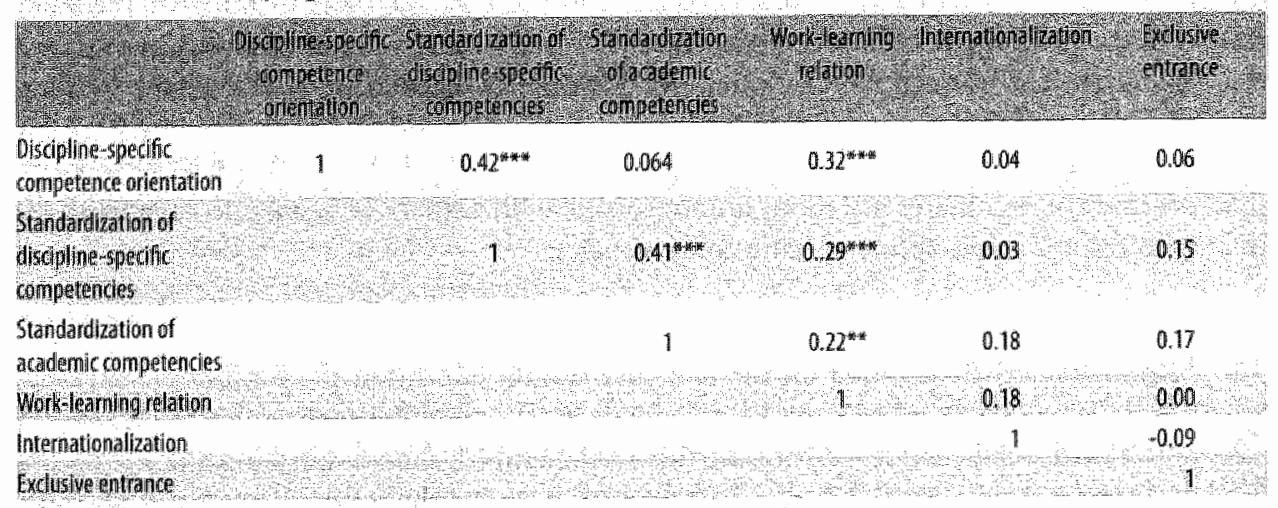

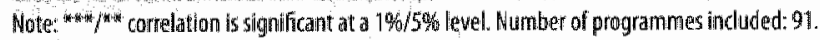

\subsection{Empirical Analyses}

\subsubsection{The empirical model}

Our objective was to relate differences with respect to the allocation outcome of graduates across the three occupational domains and with respect to the wage rates paid to higher education programme characteristics. As these characteristics vary across the education programmes, but are by construction constant among the graduates belonging to the same programme, including them joindy in an estimation with individual characreristics ignores the possible stochastic properties of the parameters at the educarion programme level and is likely to bias the estimation results and the error term (see Mouton 1986). To address this problem, we followed Card and Krueger (1992), Heckman, Layne-Farrar and Todd (1996) and Case and Yogo (1999) and applied a two-srage procedure ${ }^{\text {th }}$. In the first stage, we estimated differences in the allocation outcome and wage rate between graduates from different: education programmes. We estimated chese effects with a fixed-effects model, and hence did not allow the individual covariates to differ according to the country or the higher education institutions from which the respondent graduated. We will return to this assumption. in Appendix 6C when the model is tested for robustness. In the second stage, we regressed

16. According to Card and Krueger (s992), this approach provides a convenient reduction of the data and facilitates highly geneal models of, for example, the earnings funcrion. Moreover, Heckman, Layne-Farta and Todd (1996) stated that this model has the 'beaucy' of being deriwable from a 'richly inteppretable economic model of how quality aftects earnings (p.599). 
these 'frxed effects' on the programme characteristic indicators. In more detail the empirical approach for allocation and income looks as follows.

\section{a) Allation}

As there is, a priori, no explicit order between the three labour market domains discerned, we used in the first stage a multinomial logit model, which provided fixed effects for the education programmes comparing the probabilities of being allocated to an occupation inside a particular domain (the domain of another programme" or the "academic competencies domain") with the probabilities of being allocated to an occupation in the reference domain ("the own discipline-specific competencies domain"). Formally, the model makes it possible to compute the log-odds ratios as follows:

$$
\text { (6.15) } \ln \left[\frac{P_{i d}}{P_{i(d=0)}}\right]=\alpha_{d}+S_{n t} * \gamma_{m u d}+X_{i} * \beta_{d}+\varepsilon_{i d}
$$

where $d=0, I, 2$ indicates the own discipline-specific domain, the domain of another education programme and the academic competencies domain, $P_{i, i}$ is the probability that individual $i$ is allocated to an occupation inside domain $d, P_{i, d=0}$ is the probability that individual $i$ is allocated to an occupation in the reference domain, $\alpha$ a constant, $S_{m}$ are the dummies for the education programmes $m, X$, is a matrix of variables characterizing individual $i$, and $\beta_{s}$ and $\gamma_{\text {sud }}$ are row vectors of coefficients for category $d$. To control the programme effects from influences on the individual level, we included as covariates the age of the respondent, gender, dummies for the pre-higher education grades, the socio-economic background of the student, the level of academic competencies, the level of discipline-specific competencies, dummies for internships and work placements, a dummy for spending part of the study in a foreign country, the self-reported level of adaptability, the importance given to the use of the competencies acquired in higher education and the family situation at the time of graduacion. In the second stage, we regressed the fixed effects $\left(\gamma_{\text {md }}\right)$ on the indicators discerned ${ }^{17}$ :

$$
\text { (6.16) } \gamma_{n a d}=\delta_{d}+M_{m} * \phi_{d}+H_{u} * \eta_{d}+\psi_{d n s}
$$

where $\gamma_{m d}$ is the fixed-effects log-odds ratios of the first stage, $M_{m}$ a vector comprising the five education programme characteristics, $H_{a}$ a vector with dummies identifying the higher education institutions graduated from (e.g. Dutch university) and $\Psi_{\text {diw }}$ an i.i.d. error term.

\section{b) Wage}

The serup of the wage analyses is analogous to the allocation model approach. First, we estimated the education programmes' fixed-effects on wage rates, and second, we related these findings to the educarion programme characteristics. To take into consideration that the individual, as well as the education programme characteristics, might have different impacts,

17. Because the fxed effect that we tried to explain in the second stage regression were estimated coefficients, we: weighred the least square regressions in the second stage by the inwerse sampling variance of the furst sage to take the preciseness of the first stage estimation into account. 
depending on the occupational clomain in which the graduate worked, we estimated the wage analyses for each of the three occupational domains separatel $y^{\text {si }}$.

$$
\text { (6.17) } Y_{i d}=\omega_{d}+S_{m} * v_{i a d}+Z_{i d} * \kappa_{d}+\zeta_{i d}
$$

where $Y_{j d}$, is the $\log$ hourly wage rate paid to graduates in occupational domain $0,1,2, \omega_{d}$ a constant, $S_{\mathrm{m}}$ are the dummies for the education programmes, $Z_{i}$ is a marrix of vartables characterizing individual $i$ and of his job and $\zeta_{\text {id }}$ an i.i.d, error term. As covariates on an indwidual/occupational level, we included the age of the respondents, gender, dummies for the pre-higher education grades, the socio-economic background of the student, a dummy for having children, dummies for internships and work placements, a dummy for spending part of the study in a foreign country, the comperence mismatch between the required and the acquired level, dummies for educational level mismatches, the tenure inside the occupa tion, dummies indicating part-time and permanent jobs, a dummy for private employers, a dummy indicating whether the graduate completed additional on-the-job training, the size of the firm and dummies for 16 different economic sectors.

Since we are interested in the way in which the discerned programme characteristics influence the wage of graduates in a particular domain, we rewrote in the second stage $\mathrm{v}_{\text {mad }}$ as an equation in which these characteristics were included:

$$
\text { (6.18) } v_{m d}=\chi_{d}+M_{m} * \theta_{d}+H_{u} * \xi_{d}+\tau_{m d}
$$

where $v_{\text {mid }}$ represents the domain-specific fixed effects of the education programmes on the wage rate, $M_{m}$ a vector comprising the education programme characteristics, $H_{u}$ a vector with dummies identifying the higher education institutions graduated from (e.g. Dutch university) and $\tau_{m d}$ an i.i.d. error rerm"s.

\subsubsection{Results}

\subsubsection{Allocation 20}

The first-stage estimation yiedds the fixed effects of the education programmes that we intend to analyze in this section. Table 6.BI in Appendix $6 \mathrm{~B}$ reports on the first-stage estimation findings, while Tables $6 . \mathrm{B}_{2}$ and $6 . \mathrm{B}_{3}$ do the same on the fixed effects found in it. We will first discuss the findings on the probability of working in the domain of another education

18. Although there is substant all amount of literature on possible unobserved selection bias through variables influencing both allocaton and wages (see Chaprer 5), we assumed that unobserved variables in che allocation. motel were not contated with the rate of return conditional on the orher wariables in the equarion. We nade whis assumprion to keep the estimation tractable, and becuse we focussed on edncarional program characterisncs, which are unobservables in most studias of the return to aduation.

19. Comparably to equation 6.16, we used weighted least square to estimate 6.18. See also footnote 17.

20. We testred to what extent the results for the allocacion model were infuenced by nor being able to control for the Ger that graduates not working inside wheir own educational domain might also be more likely ro work below their educational level. Restricting the andysis to grad ax res working at least on a higher education level did not gualitariyelly drange the results presented in this chaprer (dara nor shown). 
programme relative to the probability of working inside the own educational domain. Next, we will address the relative probability of working in the academic competencies domain versus the own educational domain. Lastly, we will provide a combined discussion.

\section{Table 6.2}

Impact on the relative probability to work in domain of another educational programme versus own discipline specific domain (standard errors in brackets)

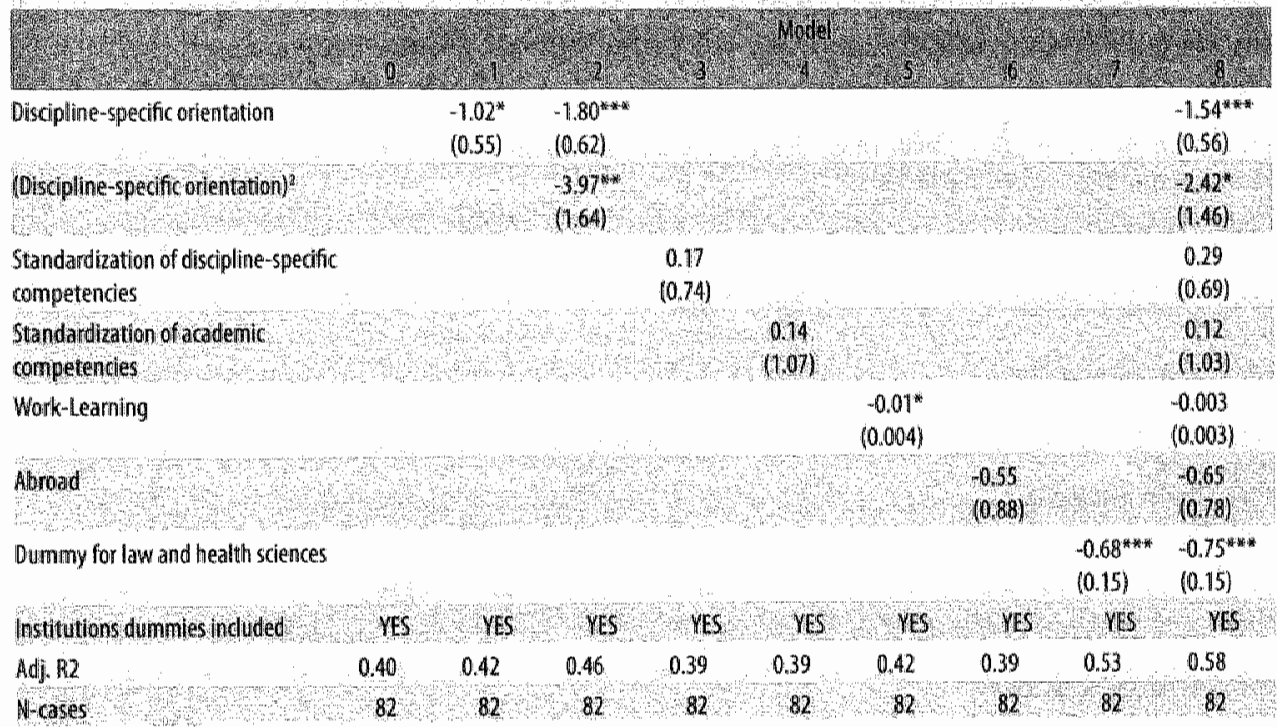

Note 1: All models further indude an unrestricted constant and were estimated using WHS with the inverse sampling warance as weightht Note $2 *$ significant at $1 \%$ level, ${ }^{*}$ singificant at $5 \%$ level ${ }_{*}^{*}$ significant at $10 \%$ level.

Table 6.2 presents findings of a series of regression models fitted to the estimated differences in the odds ratios comparing the probability of being matched to an occupation inside the domain of another education programme with the probabilities of being matched to an occupation inside the own discipline-specific domain. All models include not only the education programme characteristics, but also unrestricted dummies for the 4 higher education institutions distinguished, and a constant. Model o, the baseline model, only includes dummies for the higher education institutions. Thereafter, the education programme characteristics are first introduced individually in Models $\mathrm{I}$ through 7 , and second, jointly in Model 8. Ters with respect to the linearity in the estimated relation established that only for the disciplinespecific orientation, the inclusion of the square measurement increased the fit. To keep all the following models comparable, we included the square of the discipline-specific orientation as an additional explanatory factor independent of being significant or not.

Entering the variables individually, we found that three characteristics, namely the discipline-specific orientation (and its square), the work-learning relation and the dummy fort the 'special' programmes of law and health science showed a significant correlation with the dependent variable. When entered jointly, the discipline-specific orientation and the dummy for the 'special' programmes keep their significance while the work-learning relation loses 
it. Whereas the latier effect simply proves the existence of borders around occupations in the health and law sectors ${ }^{23}$, the impact of the competence orientation is of more interest. Graduates from both extreme types of course design, either highly academic or highly discipline-specifically oriented, have a decreased probability of working inside the domain of another education programme. We will return to this finding when discussing the results with respect to fixed effects of the probability of working in the academic competencies domain relative to working in the own educational domain. No impact was found for the internationalization indicator and the standardization indicators.

\section{Table 6.3}

Impact on the relative probability of working in academic competencies domain versus own discipline-specific domain (standard errors in brackets)

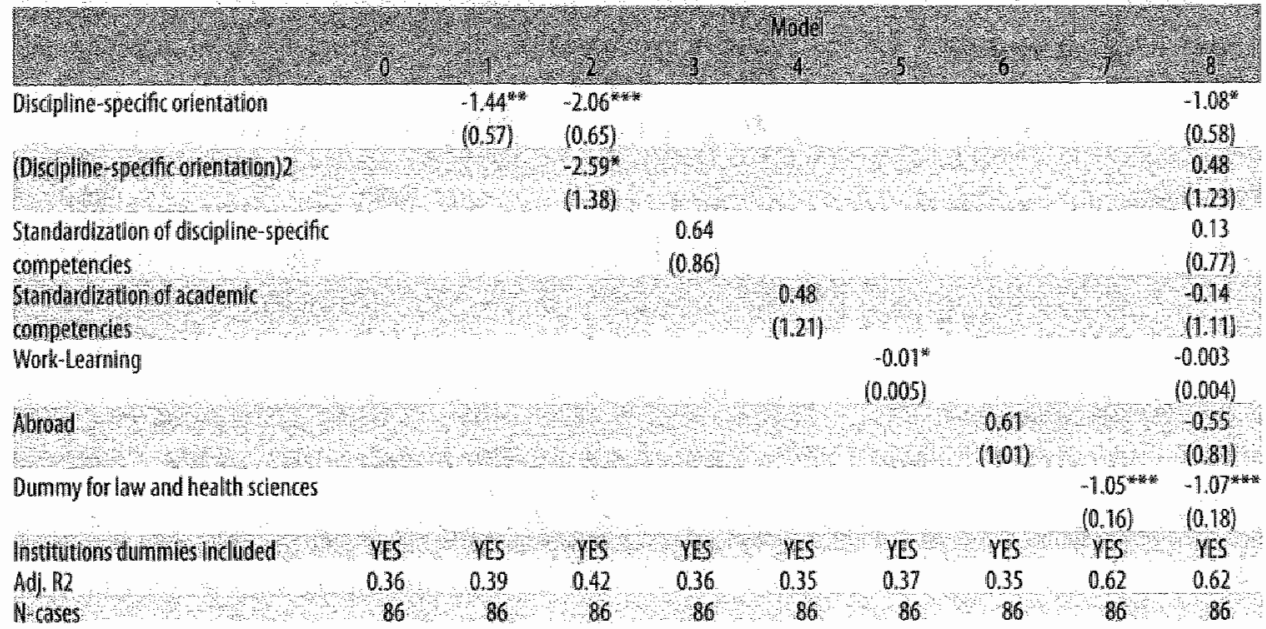

Nate 1: All modets further include an unrestricted constant and were estimated using wh with the Inwerse sampling variance as weight.

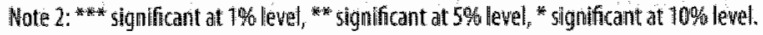

Let us turn now to the fixed effects of the probability of working in the academic competencies domain relative to working in the own educational domain. Table 6.3 reports on the second-stage results.

Entering the indicators individually, the competence orientation of the programme, the work-learning interaction and the dummy for the law and health sectors had a significant impact on the relative probability. Considering the work-learning co-operation, we can see that the results confirm the expectation that co-op education provides a closer link to occupations inside the own discipline-specific competencies domain. However, when entered jointly, the work-learning indicator loses its significance. Moreover, Model 8 reveals that, in contrast to the results presented in Table 6.2, the relation between the competence orientation and the outcome is purely linear. Hence, graduates from academic-competencies-oriented

2r. Distinguishing in the models between the health and the law sectors does not qualiarively change the findings. 
programmes have an increased probability of being matched to an occupation inside the academic competencles domain where their central competencies are of high walue.

Combining the result presented in Table 6.2 and Table 6.3 , we may conclude the following (see Figure 6.2). Graduates from highly academically oriented programmes are most likely to be matched to an occupation inside the academic competencies domain. Moving from the left to the centre, and hence towards programmes providing a balanced competencies approach, the probability of being matched inside the academic competencies domain relarive to the own discipline-specific competencies domain is reduced. At the same time, the relative probability of being matched to an occupation in the domain of another education programme increases. Hence, graduates from balanced education programmes most likely have to accept an occupation in the domain in which neither their discipline-specifie compevencies nor their academic competencies are regarded as central. Lastly, moving further to highly discipline-specifically oriented programmes, we can see that both the relative probability of being marched to an occupation in the academic competencies domain and the relative probability of being matched to an occupation in the domain of another education programme is reduced. Hence, the allocation outcome seems to be very much in line with the implications of a comparative advantage approach. Graduates are matched when possible, to activities that make use of the acquired comperencies on a large scale. Moreover, the results indicate that if the labour market, as is often argued, is shifting towards academic competencies, programmes offering a highly discipline-specific competencies education need ro change their programmes considerably, in order to avoid that their graduates have to accept occupations in which neither their type of discipline-specific competencies nor their academic competencies are valued highest.

\section{Figure 6.2}

Change in probability of being matched to... relative to being matched to own education domain

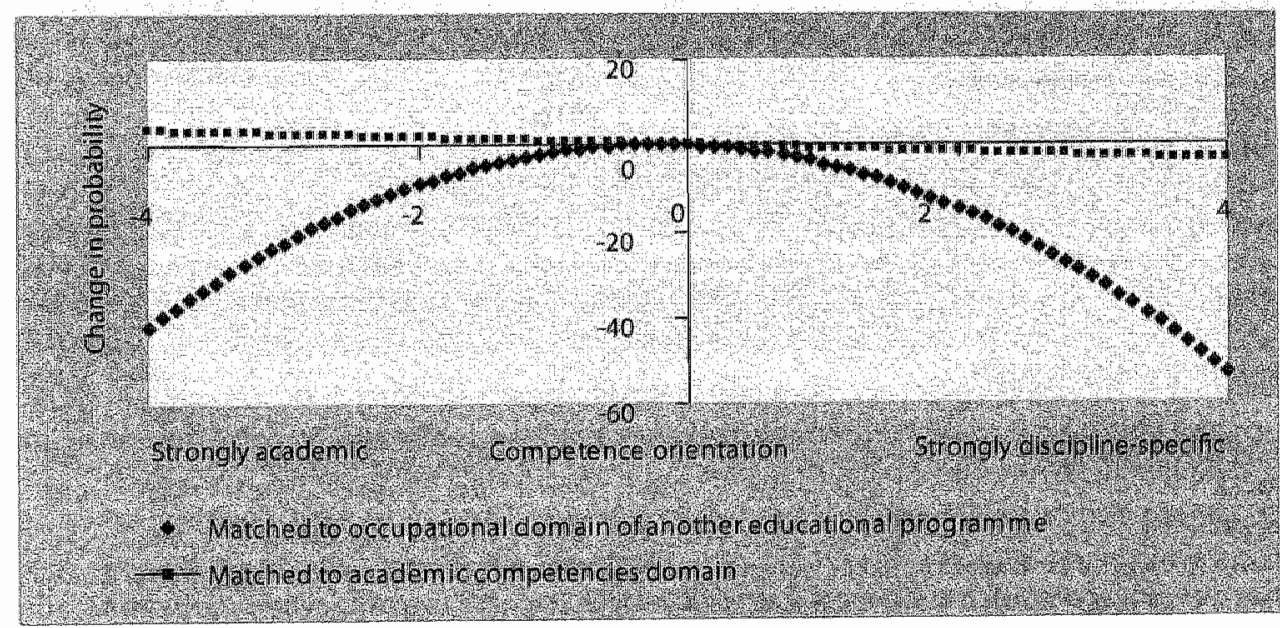

Wote: The figures were drawn for the full possible tange of competence arlentation ( -4 to +4$)$. The reader should bear in mind that the programmes under consitteration have a range from -0.70 to 10.38 . 
Taking stock at the end of our first result section, we may conclude the following. The only two indicators of real relevance for the allocation outcome of the graduates, are the boundaries around the health and law sectors and the competence orientation of the education programme they followed. However; we would like to remind the reader that the first-stage resultes presented ir Appendix $6 \mathrm{~B}$ indicate that both participation in an internship or work placentent and spending some time abroad during one's study infuence the allocation outcome of an individual graduate. In other words, the non-significance of these indicators in the second stage indicates that there are no spillover effects on the non-participating peers.

\subsubsection{Wages}

Analogously to the discussion on the allocation ourcome, we will present the results of the second-stage wage analyses step by step ${ }^{\text {in }}$. We will start with the wages paid to graduates working inside the own discipline-specific domain, followed by a discussion of the findings for graduates working in the discipline-specific domain of another education programme and lastly, we will have a closer look at the wages paid to graduares working in the academic competencies domain. A point to be taken into account during the discussion of the results is the fact that graduates working inside the discipline-specific competencies domain of another education programme (the academic competencies domain) on average earn approximately $11 \%(4 \%)$ less than graduates working inside the own discipline-specific competencies domain.

\section{Table 6.4}

Impact on wages when working inside one's own domain (standard errors in brackets)

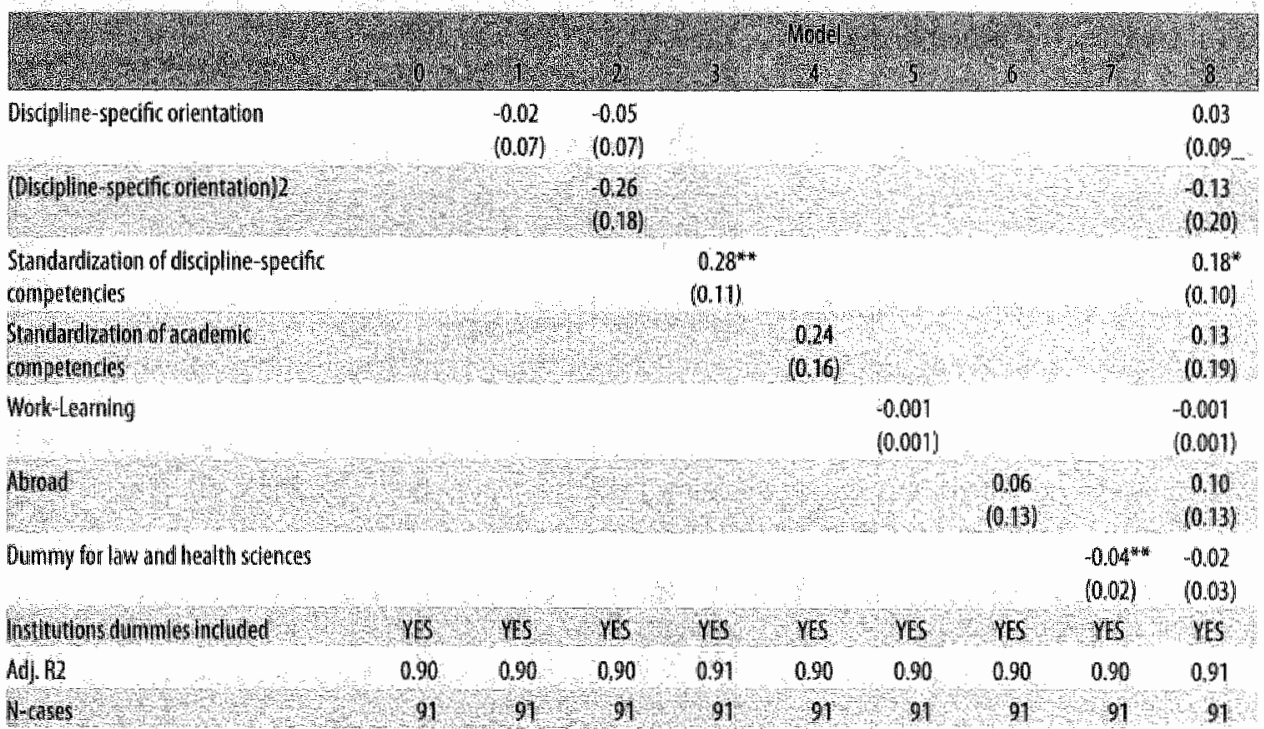

Wote I: Mll models further ind ude an unrestricted constant and were extimated using WS with the inverse sampling wariance as weight.

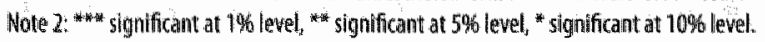

22. "lablat $6 . \mathrm{B}_{4}$, in Appendix $6 \mathrm{~B}$ reports on the first-stage estmation findings, while Tables $6 . \mathrm{B} 5,6 . \mathrm{B} 6$ and $6 . \mathrm{B} 7$ report on the fixed efferts extacted. 
We will start by discussing a number of estimation models (Table 6.4) fitted to the esrimated wage differentials between graduates of different education programmes, all working inside their own discipline-specific domain. Induding the characteristics individually first (Models i chrough 7) results in the ourcome that two characteristics reveal a significant influence on the wage rate. First, and in line with the expectations, we found that graduates from more standardized discipline-specific programmes on average receive higher wages. Second, we found that graduates from law and health faculties on average start with lower wages. No significant impact was found for the other characreristics, namely the discipline-specific orientation, the standardization of academic competencies, the work-learning relation and internationalization. Entered jointly, the negative impact of the dummy for law and health graduates is no longer significant, whereas the result with respect to the standardization of the disciplinespecific competencies does not change qualitatively.

\section{Table 6.5}

Impact on wages when working in the domain of another educational programme (standard errops in brackets)

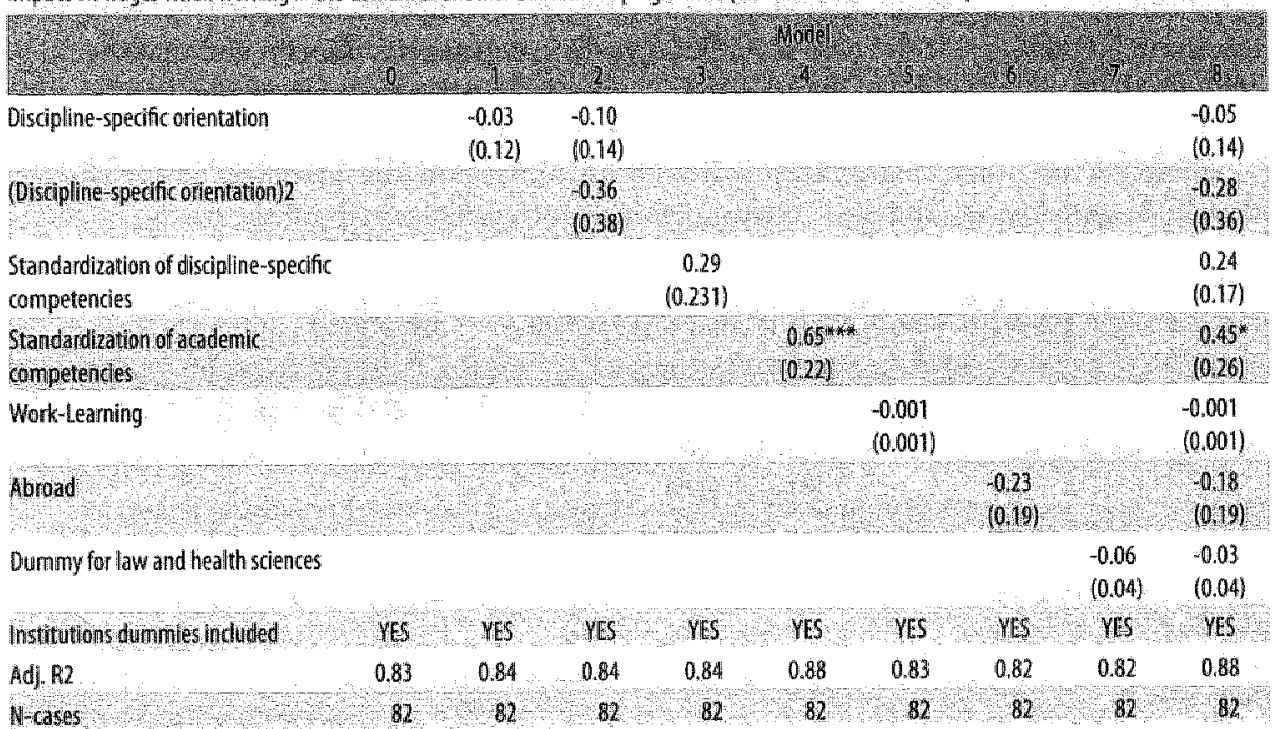

Note 1: Al models further indude an unrestricted constant and were estimated using WLS with the inwerse sampling waranca as westht. Mote 2* * significant at $1 \%$ level, "* significant at $5 \%$ lewel * significant at $10 \%$ level.

Table 6.5 reports on a series of models fitted to the estimated wage differentials between graduates of different education programmes, all, working in the domain of another education programme. Entering the characteristics in a first step individually reveals the significant importance of one characteristic. We found that the standardization of academic competencies now takes over the role of the standardization of discipline-specific competencies in the estimations above. Hence, employers accepting graduates from education programmes nor directly linked to the discipline-specific competencies of the occupation, profit from an increased standardization of academic competencies, which they at least partially transfer to the employee in the form of higher wages. No significant impact was found for the discipline- 
specific competence oruentation of the programme, work-leaming interrelation, the internationalization of the programme, or the dummy for the studies of law and health sciences. When entered jointly, the individual impact of the standardization with respect to academic competencies did not change qualitatively.

Lastly, ruming to a series of models (Table 6.6) frted to the estimated wage differentials for graduates working in the academic domain, we found that the standardization of the academic competencies, as in the case above, again played a significant role in the determination of wage rates. Furthermore, when entered individually, the standardization of discipline-specific competencies also showed a significant impact. However, the individual impact of the academic competencies standardization was roughly twice as large as the impact of the standardization with respect ro discipline-specific competencies. When entered jointly, the correlation between the two standardization mearsures, together with the fact that they both individually showed a slightly positive correlation with the wage rate, resulted in a loss of significance for both characteristics ${ }^{23}$. Comparing the results of Table 6.6 with the findings in Tables 6.4 and 6.5, we can sec that the impact of the standardization of discipline-specific competencies, when taken individually, is smaller than inside the own discipline-specific comperencies domain and that the same holds for the standardization of the academic competencies when compared to the results inside the discipline-specific competencies domain of another educational domain.

None of the other characteristics showed an impact on the graduates' wages in the academic competencies domain, either individually or when entered jointly.

\section{Table 6.6}

Impact on wages when working in academic domain (standard enors in brackets)

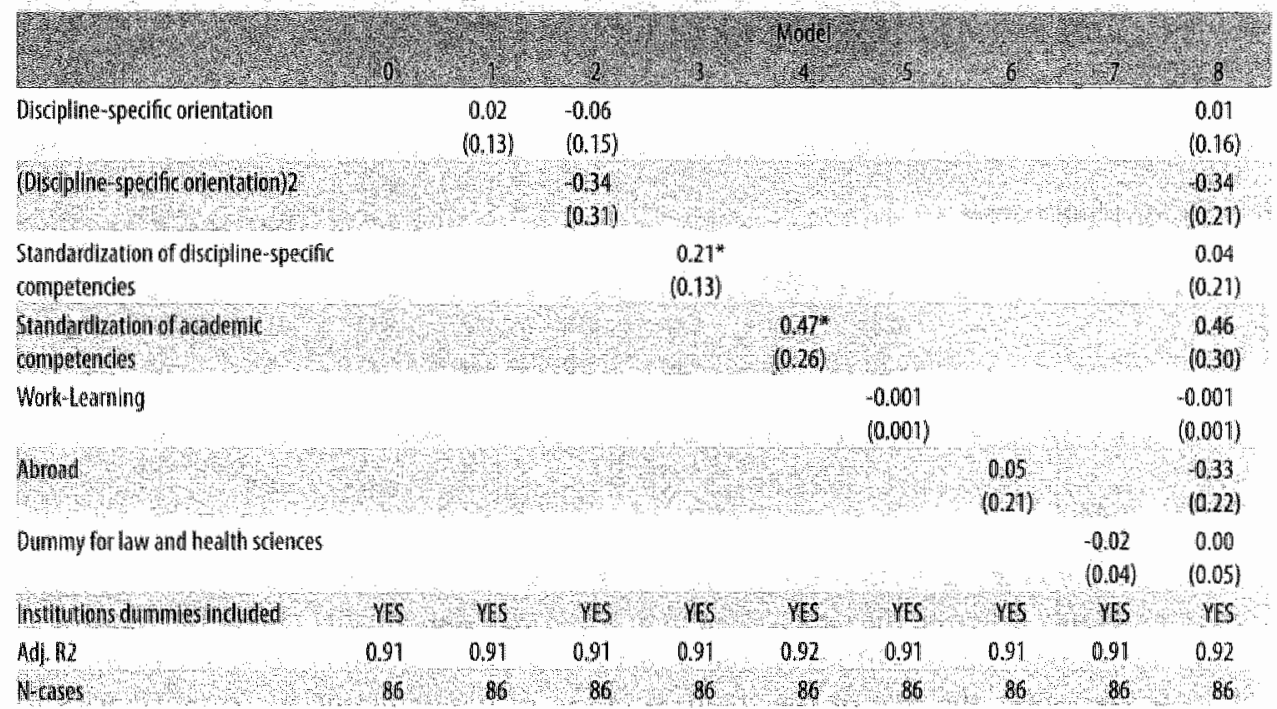

Wote 1; All models also :foctude an unrestricted constant and higher education institution dummies and were estimated using WLS with inverse sampling variance as weight. Note 2 : significant at $1 \%$ lewel, * significant at $5 \%$ lewe, significant at $10 \%$ level.

23. Inserting in Model s bork the other characteristics and only one of the standardization measures, does nor qualitatively change the results presented in Models 3 and 4. 
Taking stock at the end of this discussion on wage results, the following picture emerges. We proposed that standardizing the competencies outcome of students is tway in which an education programme may help improve the information provided to potential employers. These results clearly confirm this. More in derail, and considering the findings with respect to the allocation ourcome, the results show that for graduates from an education programme that provides rather narrowly oriented discipline-specific competencies education, a high degree of standardization in discipline-specific competencies is profitable, and that for graduates from academically oriented programmes a comparable finding holds with respect to academic competencies. However, in the latter case this only applies when the characteristics are taken as the exch usive explanatory variable.

Considering the comperence orientation of the programme, we expected graduates from discipline-specifically oriented programmes to lose considerably in terms of competencies applicability when not matched to an occupation inside the own discipline-specific competencies domain. The findings did not confirm this hypothesis. Howewer, as these programmes are generally also more standardized with respect to discipline-specific competencies, their graduates do not benefit from it in contrast to their fellow-graduates working inside the own discipline-specific competencies domain. Moreover, the reader should bear in mind that competence orientation played a significant role in the allocation process and that the allocation outcome influences the average wages. Graduates working inside the own educational domain on average were paid highest, followed by graduates working in the academic competencies domain and graduates in the domain of another education programme.

With respect to the characteristics that measure how internarional an education programme is or how strongly it combines learning with working, we could not establish any positive spillower effects. However, we need to bear in mind that in two out of the three domains, spending some time abroad during the study period increases the wage rate on an individual level (see results presented in Appendix 6B, Table 4). Lastly, we did not find any evidence that graduates from the two special studies of law and health sciences were penalised extra when matched outside their highly regulated own educational domain. However, these graduates were more likely to find an occupation inside their own educational domain.

\subsection{Concluding remarks}

The objective of this chapter was to investigate to what extent specific characteristics of thigher education programmes influenced the transition of graduates to working life. Key elements were the effecriveness of programmes in allocating graduates across various occupational domains and how graduates performed in the occupations they obtained.

We showed that programmes providing a highly discipline-specifically oriented outcome were most likely to place their graduates in the occupational domain with a related type of competencies. Similarly, programmes providing a highly academically oriented outcome placed their graduates in the academic comperence domain. Independently of the country concerned, the results confirmed the strong reflecrion of the competence requirements on the labour market in the outcome of higher education programmes. Moreover, as shown in Chapter 3 , programmes in discipline-specifically oriented countries (є.g. the Netherlands, 
Austria, Germany) are on average more discipline-specifically oriented and programmes in acaclemically oriented countries (e.g. the United Kingdom, France, Spain or Finland) are on average more academically otiented. This observation reasserts that higher education programmes target their output in line with the general institurional setup of the labour manket, that is internal or occupational. So far so good. But the analyses also showed that graduates from programmes artempting a balanced mix in the competence ourcome, were most likely to have to accept a lower-paying occupation, neither waluing their type of discipline-specific nor their academic competencies properly. This result indicates in particalar a clear danger for programme designers in tradicional discipline-specifically oriented countries. If the labour markets in these countries, as is often claimed, are changing gradually to a more academic-competence-oriented one, creating upwatd pressure for the demand and wages of higher education graduates in the academic competence domain, higher education. programmes need to make a drastic adjustment with regard to the central competencies in their programmes.

The second result is that it is not enough for a programme to focus on a particular type of competence (academic or discipline-specific), but programmes must also produce a group of graduares that is highly harmonized with respect to this type of competence. Standardization of the competence outcome provides employers with better information on the actual productive capabilities of the graduates, reducing selection and adjustment costs and allowing higher remuneration of workers. Hence, in occuparional labour marker countries (e.g. Austria, Germany and the Netherlands) the preparation of graduates for the discipline-specific labour market has to go hand in hand with a standardized outcome in discipline-specific competencies. In countries with a strong internal labour marker (e.g. the United Kingdom, France, Spain or Finland), it seems that preparing graduates for the academic orientation of this labour market type needs to go hand in hand with a standardized outcome in academic competencies. 


\section{Appendix $6 \mathrm{~A}:$ Education programme characteristics}

\section{Table 6.A.1}

Discipline-specific competence orientation

\begin{tabular}{|c|c|c|c|c|c|c|c|}
\hline & & 8 & 47 & 4 & 13 & & \\
\hline 170 & -21 & $-0,38$ & -0.30 & -0.46 & 016 & -0.22 & 0.40 \\
\hline ESU & $-0,09$ & 034 & 012 & 034 & 0,05 & 0.30 & 0.07 \\
\hline FRU & -0.15 & -0.24 & -0.23 & $-0,22$ & -0.18 & 0.29 & N.A \\
\hline FRGE & $\mathrm{NA}$ & NAA & 9054 & MA & 0,30 & 0.58 & Wh \\
\hline ATU & 0.02 & -0.10 & 011 & 0.04 & 0.15 & 0.19 & 0.38 \\
\hline DU: & 0.14 & 014 & 010 & 016 & 0.15 & 0.10 & 002 \\
\hline DFH & 0.09 & N.A. & 0.27 & 0.23 & -0.11 & 0.07 & 0.14 \\
\hline Wut & 0,06 & $0: 15$ & 0.07 & 021 & 0,06 & 0.15 & 011 \\
\hline MLLBBO & 0.17 & 0.16 & 0,04 & MA & 0.15 & 0.05 & 0.13 \\
\hline U1KU & 084 & 0.41 & -0.46 & 070 & 020 & 000 & 022 \\
\hline Hormu & -0.25 & -0.39 & -0.38 & -0.54 & -0.34 & -0.24 & 0.13 \\
\hline WI & 006 & 0,10 & 9017 & 023 & 0,00 & 0.07 & 020 \\
\hline$M 0 U$ & 0.10 & 0.10 & -0.32 & 0.38 & 0.19 & 0.04 & 0.34 \\
\hline Moc & 0,23 & 0.37 & 0.03 & & 0.00 & 0.069 & 0.10 \\
\hline
\end{tabular}

Mote: Measured as (average of discipline-specific competencies) - (average ol academic competencies) H.A.rnot available; ITU =italian univers ities,

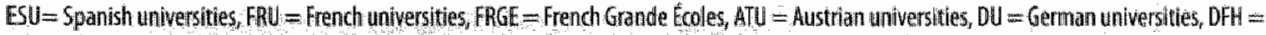
German Fachlochschulen, NLU = Dutch uniwersities, NLHBO = Dutch higher vocational institutes, UKU = United Kingdom old universities, UKNWU = United Kingdom new universities, FU = Finish universities, $N \mathrm{NOU}=$ Norweglan universities, $\mathrm{NOC}=$ Norwegian university colleges.

\section{Table 6.Aza}

Standardization of discipline-specific competencies

\begin{tabular}{|c|c|c|c|c|c|c|c|}
\hline ITU & 105 & 0.66 & 0.67 & 1.11 & 0.76 & 0.66 & 0.85 \\
\hline ESU & 077 & 0.67 & 0.66 & 0.66 & 0.68 & 0.74 & 072 \\
\hline $\mathbb{F R A}$ & 0.79 & 0.66 & 0.54 & 0.90 & 0.70 & 0.78 & N.A \\
\hline FRGE & HA & NA & 0.60 & NA & 052 & 059 & HA: \\
\hline AIU & 0.65 & 0.64 & 0.51 & 0.70 & 0.57 & 0.48 & 0.64 \\
\hline DU & 0.55 & 0.59 & 0.63 & 0.63 & 0.57 & 0.53 & 074 \\
\hline DEH & 0.64 & N.A. & 0.62 & 0.80 & 0.76 & 0.48 & 0.51 \\
\hline WLI & 0,54 & 070 & 0.60 & 0,46 & 0,53 & 0.41 & 066 \\
\hline NLLHBO & 0.61 & 0.58 & 0.65 & NA & 0.60 & 0.49 & 0.56 \\
\hline UkJ & 145 & 092 & 0,94 & 0.97 & 095 & 1.07 & 099 \\
\hline 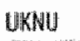 & 0.99 & 0.79 & 0.85 & 0.90 & 0.97 & 0.75 & 0.79 \\
\hline Fu: & 060 & 056 & 0.52 & 054 & 066 & 0.60 & 0,59 \\
\hline HOU & 0.64 & 0.49 & 0.40 & 0.64 & 0.52 & 0.60 & 0.49 \\
\hline NOC: & 0,53 & $0 s 1$ & 0.49 & $\mathbb{N} / \mathrm{A}$ & 132 & 0.59 & 0,54 \\
\hline
\end{tabular}

Wote- Measured as within varlance of discipline-specific competencies; N. A.. not avallable. 


\section{Table 6.A2b}

Standardization of academic competencies

\begin{tabular}{|c|c|c|c|c|c|c|c|}
\hline ITH: & 036 & 0.40 & 036 & 0.48 & 0.40 & 0.40 & 0.44 \\
\hline ESU & 019 & 040 & 048 & 049 & 044 & 0,2 & 048 \\
\hline EPU & 0.4 & 0.45 & 032 & 0.45 & 0.41 & 0.41 & N.A \\
\hline $\mathrm{FBQP}$ & $\mathrm{NA}$ & HA & 032 & $\mathrm{NA}$ & 030 & 026 & $\mathrm{NA}$ \\
\hline ATU & 0,40 & 036 & 0.40 & 0,44 & 0.29 & 0.35 & 0.45 \\
\hline DU & 040 & 038 & 032 & 033 & 0,3 & 02 & 0.47 \\
\hline $\mathrm{DFH}$ & 0.56 & MA & 038 & 0.34 & 0.14 & 035 & 0.27 \\
\hline Mus & 0.37 & 1032 & 0.25 & 0.27 & 003 & 026 & 034 \\
\hline HLHBO & 039 & 0.42 & 028 & NA. & 0.39 & 0.26 & 0.29 \\
\hline 6rol & 046 & 0,37 & 0,31 & 0,35 & 035 & 0,38 & 0.48 \\
\hline UKNU & 0,50 & 0.29 & 0,32 & 0,32 & 0.45 & 0.47 & 0.47 \\
\hline 80 & 037 & 0,39 & 035 & 034 & 038 & 034 & 039 \\
\hline MOU & 0.35 & 0.30 & 0.28 & 0.30 & 0.33 & 0.35 & 0.38 \\
\hline $\mathrm{NOC}$ & 1042 & 033 & 0226 & & 022 & 034 & 037 \\
\hline
\end{tabular}

Note: Measured as within warlance of acedemic competencies, N. A.: not available.

\section{Table 6.A3}

Work-learning relation

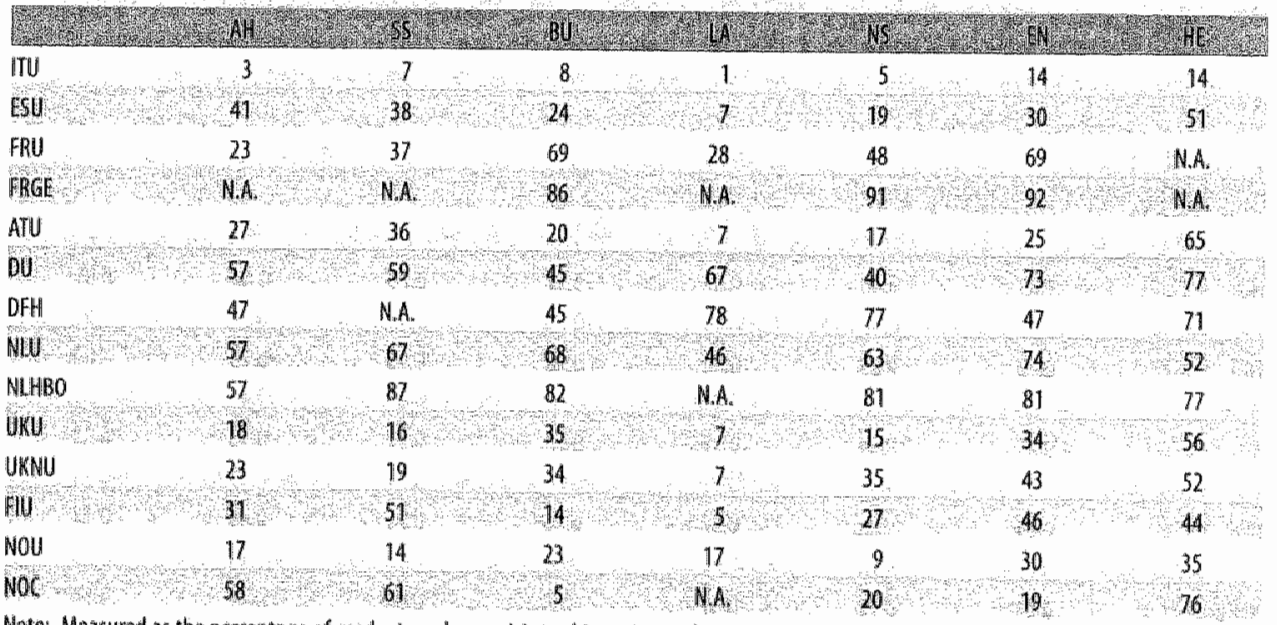

Note: Measurad as the percentage of gridutuates who participated in an interinghiph for work placement) as part of their degree courses. N.A.: not avallable. 


\section{Table 6.A4}

\section{Intermationalization}

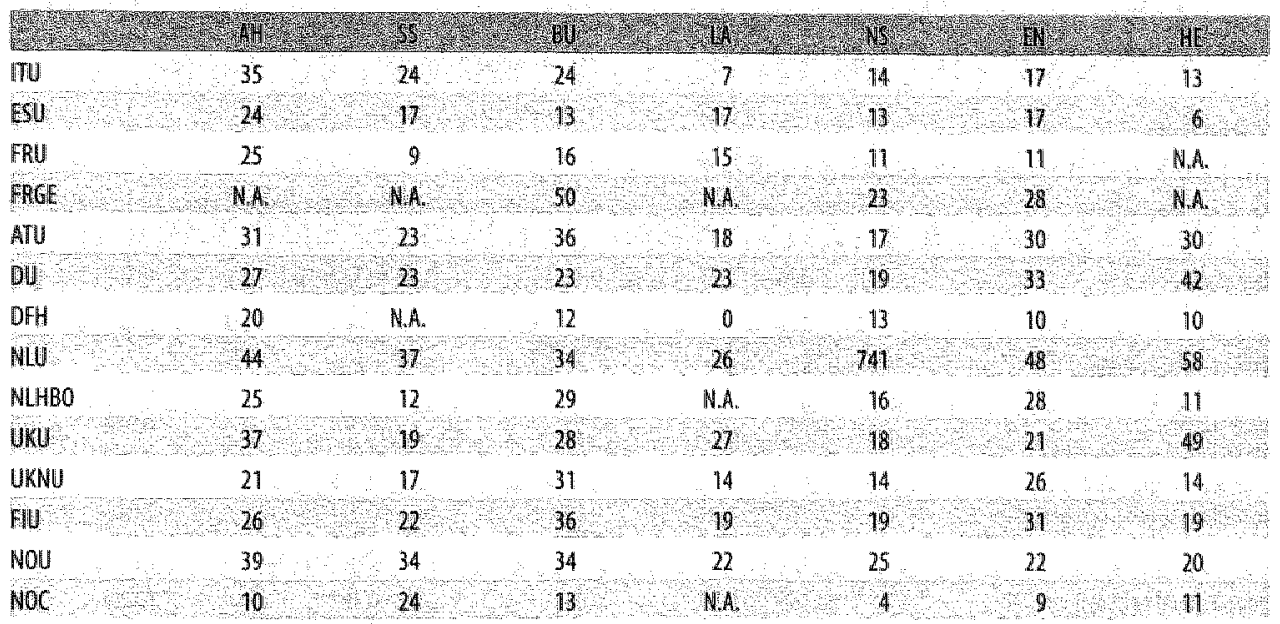

Note 1 : Measured as the percentage of graduates who completed part of their study programmes abroad. Note 2: N.A.: not available.

\section{Table 6.A5}

\section{Exclusive entitance}

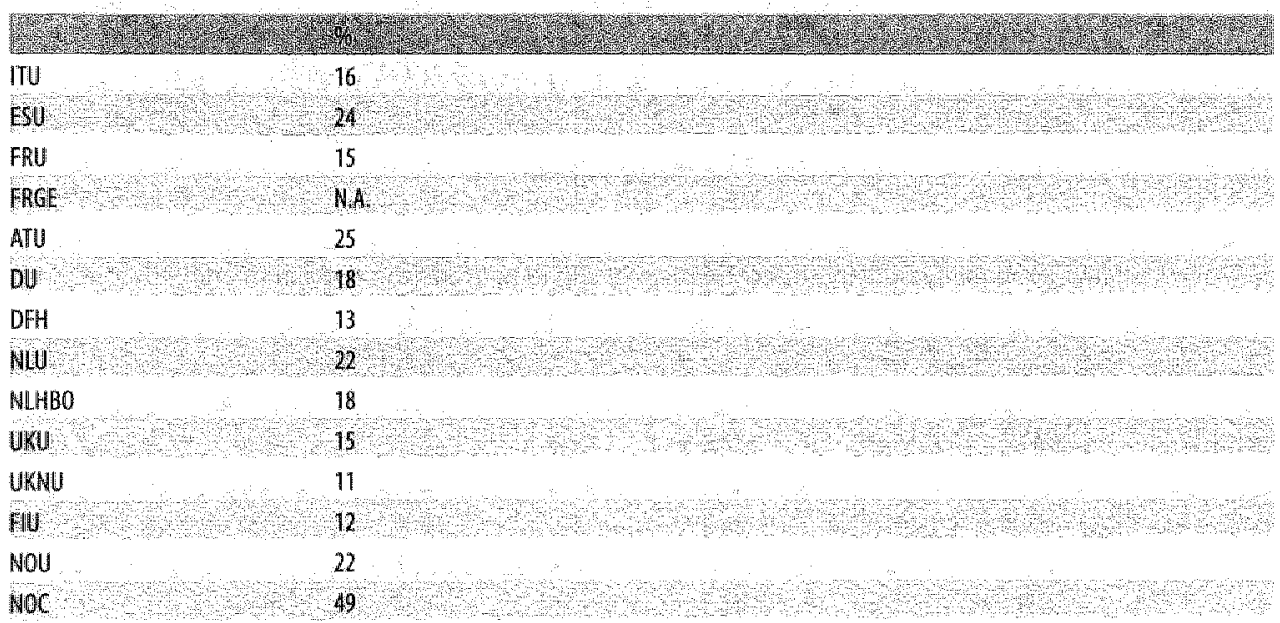

Note 1: Measired as the percentage of gitaduates who studied law or health sciences. Note 2: N A.: not awailable. 


\section{Appendix 6B: First-stage model}

a) First-stage estimation of allocation model

\section{Table 6.8 .}

Multinomial logit analyses on allocation outcome

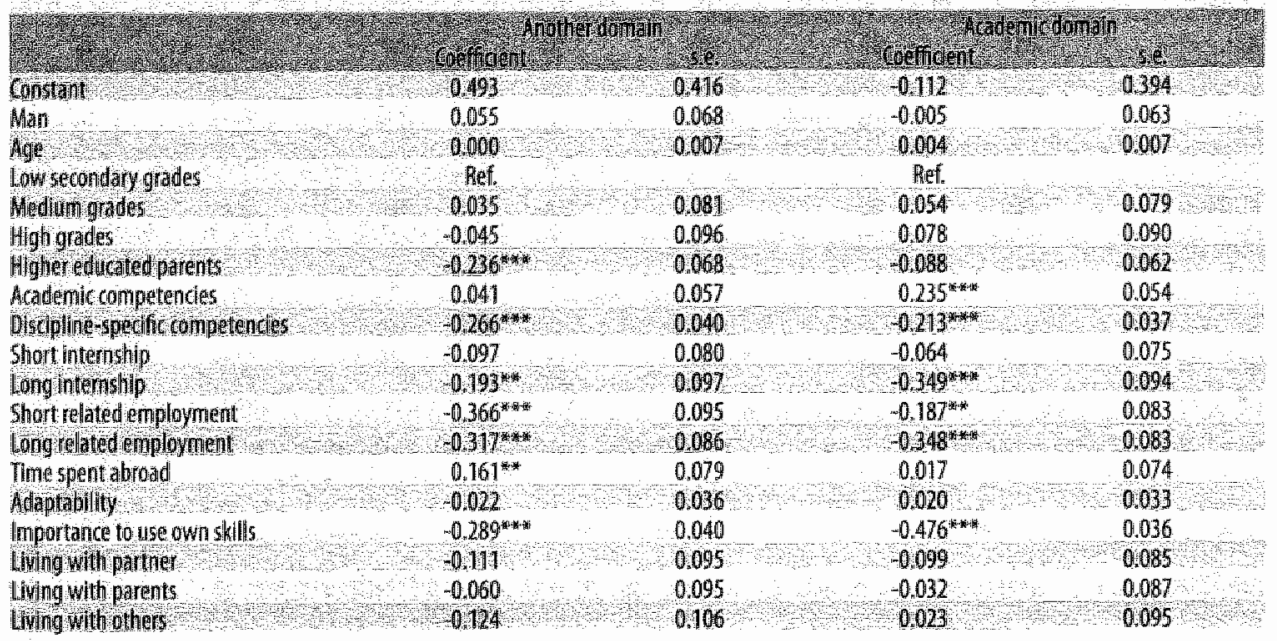

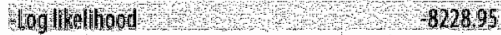

Note" Neference domain; own educational womain. Note: The model also includes 92 dummies for the different education programmes.

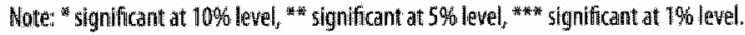

\section{Table 6.B2}

Log odds: relative probability of being matched to an occupation inside the domalin of another education programme to being matched to an occupation inside the own discipline-specific domain

\begin{tabular}{|c|c|c|c|c|c|c|c|}
\hline IIII & Ret. & -0.16 & 2.15 & -1.11 & 0.22 & -1.54 & nee. \\
\hline 150 & 0.44 & 0.5 & 086 & 011 & 030 & 9.18 & 0,68 \\
\hline $\mathrm{BU}$ & -0.144 & 0.04 & 0,51 & -0.53 & 0.12 & 0.47 & n. \\
\hline nete & 196 & nal & 096 & ma & 0,33 & 9037 & nia \\
\hline til & -0.64 & $-0,02$ & -1.07 & -0.98 & -0.64 & $-0,63$ & -2.75 \\
\hline & 4050 & 070 & 0.57 & 086 & 016 & 0.52 & 146 \\
\hline $6 \%$ & -1.49 & net. & -0.96 & -2.01 & 0.44 & 0.00 & $-1,88$ \\
\hline 11 & 060 & 022 & 114 & -10 & 087 & 977 & -206 \\
\hline VULHBO & -0.40 & -1.67 & -0.36 & M.a. & -1.80 & -0.53 & -0.87 \\
\hline Wu & 0,38 & 016 & 140 & nes & 024 & 022 & $\mathrm{ne}_{\mathrm{e}}$ \\
\hline UKMU & -0.54 & 0,07 & -0.44 & -1.60 & -0.25 & $-0,47$ & $-1,42$ \\
\hline 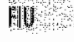 & 0.61 & 058 & 1,10 & 100 & 0,37 & 90,49 & 2,10 \\
\hline NOU & -0.68 & -1.33 & n.e. & me. & -0.82 & $-0,39$ & ne. \\
\hline 100 & 313 & nIse & 122 & na. & nee & 118 & 240 \\
\hline
\end{tabular}

Note: N.A.: not avallable; W.E.: not estimated as no graduates worked in the domain of another programme. 


\section{Table 6.B3.}

Log odds: relative probability of being matched to an occupation inside the academic competencles domain to being matched to an occupation inside the own discipline-specific domain

\begin{tabular}{|c|c|c|c|c|c|c|c|}
\hline & 84 & 8 & 10 & W & 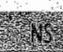 & r & 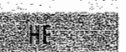 \\
\hline mu & Ref & 0.05 & 074 & 021 & 0.39 & -1.02 & n.e \\
\hline Sul & 0.09 & 0,66 & 029 & 0.64 & 0.49 & 0.79 & $1: 14$ \\
\hline FRU & 0.24 & 0.63 & 0.04 & -0.31 & -0.12 & -0.17 & n. \\
\hline FRGE & na & na. & 002 & na & 0.59 & 082 & nata \\
\hline ATU & 0.38 & 0.46 & 0.75 & -1.03 & 0.09 & 0.47 & 1.62 \\
\hline DU & 0.67 & 0.48 & 011 & -119 & 032 & 0.46 & 181 \\
\hline DFH & 0.24 & me & -0.09 & -1.47 & ne. & -0.37 & 034 \\
\hline AU & 130 & 0.72 & 0.28 & 0.43 & 0.38 & 0.39 & 169 \\
\hline NLHBO & -0.19 & 0.90 & 0.48 & n.a. & 2.000 & -0.58 & -1.10 \\
\hline UKu & 150 & 158 & 092 & 012 & 0.83 & 0,4 & 0.96 \\
\hline UKKU & 0.30 & 1.42 & 1.11 & -0.63 & -0.02 & -0.18 & -0.68 \\
\hline Fi: & 183 & 0.12 & 0,26 & 4198 & 0.85 & 078 & 3.08 \\
\hline $\mathbb{N O U}$ & -0.50 & -0.49 & ne. & -1.07 & $-0,84$ & -0.58 & -1.71 \\
\hline 106 & 168 & ne & 0.65 & nas & 1.14 & 0.96 & 192 \\
\hline
\end{tabular}

Hote: N.A.: not awailable; N.E.: not estimated as no graduates worked in academic competencies domaün

\section{Table 6.B4}

First-stage wage analyses (OLS)

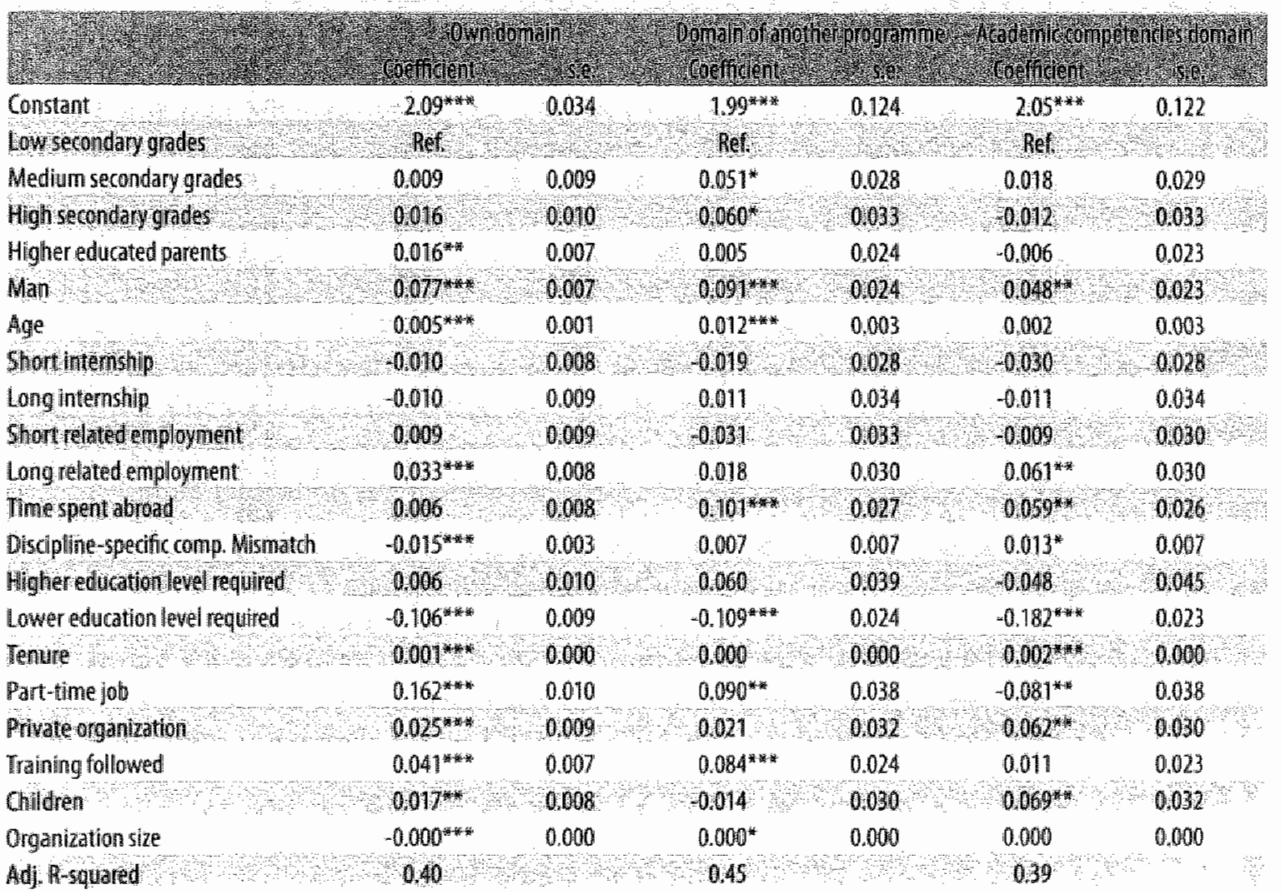

Wote: All models also indude dummies for the education programmes alyd dummies for 16 different economic sectors. Note: "significant at 10\%" lewel, significant at $5 \%$ level, **** signifificant at in 
Table 6.8s

Fixed-effects rate of retums for graduates working inside the own discipline-specific domain

\begin{tabular}{|c|c|c|c|c|c|c|c|}
\hline 110 & Ref & 014 & 0,2 & 010 & 0.05 & 0.19 & -0.10 \\
\hline su & 0016 & 000 & 0.25 & 013 & 006 & 0.04 & 0017 \\
\hline FU: & 038 & 030 & 032 & 0.26 & 0.44 & 039 & n.a. \\
\hline $\mathrm{Ftef}$ & 9. & nes & 056 & ntr & 065 & 05 & n,a \\
\hline MIS: & 0,83 & 0,48 & 066 & 0.36 & 0.52 & 0.52 & 0.33 \\
\hline DI & 076 & 07 & 087 & 0.62 & 0,78 & 080 & 0,75 \\
\hline DFH & 068 & na. & 0,68 & 0.49 & 0.83 & 0.80 & 0.57 \\
\hline MU & 007 & 0,19 & 058 & 05 & 0.46 & 0,3 & 0,54 \\
\hline NLEBO & 032 & 028 & 0.32 & n. & 0,42 & 0.36 & 0.33 \\
\hline HKU & 047 & 063 & $0 \mathrm{~s}$ & 0,6 & 0.54 & 0.68 & 0,61 \\
\hline UKMU & 0.43 & 0.28 & 0.54 & 0,49 & 0.63 & 0.59 & 0.69 \\
\hline$\triangle 4$ & 0.59 & 0,47 & 0.63 & 0,63 & 0,5 & 061 & 0,63 \\
\hline 110u & 0,78 & 079 & 0.90 & 0.85 & 0.79 & 0.85 & 0.88 \\
\hline$M 0$ & 062 & 064 & 086 & nat & 0.81 & 074 & 0,68 \\
\hline
\end{tabular}

Wote Nu not avallable.

\section{Table 6.B6}

Fixed-effects rate of returns for graduates working inside the domain of another education programme

\begin{tabular}{|c|c|c|c|c|c|c|c|}
\hline TU & Bef & 0.24 & 0.28 & 0.07 & 0.36 & 0.06 & me. \\
\hline SSG & 0.21 & 0,15 & 0.09 & 0.6 & 0008 & 0.00 & 022 \\
\hline FPU & 0.16 & 0,21 & 0.38 & 0.28 & 0.42 & 0.27 & $n$ a. \\
\hline RRGE & nod & nid & 0,5 & nat & 0.69 & 0,6 & Ma: \\
\hline ATU & 0.53 & 0.65 & 0,61 & 0.51 & 0.59 & 0.80 & 0.72 \\
\hline D. & 070 & 087 & 093 & 0.68 & 090 & 085 & 0,59 \\
\hline $\mathrm{DFH}$ & 0.93 & a. & 0.72 & 0.31 & 0.88 & 0.90 & 0.52 \\
\hline $\mathrm{WU}$ & 04 & 04 & 037 & 072 & 0,41 & 0,4 & 0,37 \\
\hline NLHBO & 0,27 & $0.3 \pi$ & 032 & Ma. & 0,41 & 0.25 & 0.18 \\
\hline$W$ & 0.61 & 0,4 & 0,6 & nue. & 0,61 & 0.64 & ne: \\
\hline UKWU & 0.37 & 0,49 & 0.67 & 0.76 & 0.38 & 0.58 & 0,63 \\
\hline Mu & 040 & 05 & 0,5 & 0,67 & 0,45 & 056 & 071 \\
\hline Mou & 0.73 & 0.85 & nis. & mie. & 0.88 & 0.92 & nue. \\
\hline$M 0$ & 0,42 & ति & 008 & na & $\mathrm{Bre}$ & 015 & 061 \\
\hline
\end{tabular}

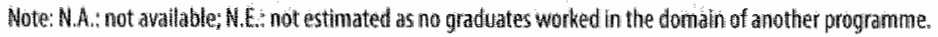




\section{Table $6 . \mathrm{B} 7$}

Fixed-ffects rate of returns for grad wates working inside the academic competencies domain

\begin{tabular}{|c|c|c|c|c|c|c|c|}
\hline III & Ref, & 0.04 & 037 & 0,58 & 0.11 & 0.44 & ne. \\
\hline ESU & 0016 & 0,12 & 0.02 & 008 & 007 & 026 & 0,02 \\
\hline FND & 0.89 & 0.57 & $0.5 \pi$ & 0.57 & 0,57 & 0.65 & nsà. \\
\hline FNAL & nd & na & 0.76 & nad & 099 & 0.81 & nia: \\
\hline ATU & (1).66 & $a, 66$ & 0.85 & 0.78 & 0.55 & 0.96 & 0.36 \\
\hline Qu. & 1,13 & 0,94 & 112 & 1,15 & 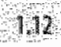 & 113 & 0,62 \\
\hline DFH & 0.65 & na & 1.02 & 0.71 & ne. & $1 . \| 1$ & 0.79 \\
\hline WLU & 065 & 011 & 179 & 099 & 0.77 & 0,86 & $0, n$ \\
\hline NLHBO & 0.45 & 0.55 & 0,49 & na. & 1.19 & 0.61 & 0.53 \\
\hline War & 080 & 0,79 & 0.84 & 0.36 & 018 & 0,73 & 669 \\
\hline WKKU & 0.62 & 0.67 & 0.74 & 0.89 & 0.81 & 0.68 & 0.96 \\
\hline Fu & 0,52 & 0175 & 086 & 0.46 & 087 & 0,80 & 078 \\
\hline HOU & 1.05 & 1.08 & ne. & 1.17 & 1.02 & 1.17 & 1.19 \\
\hline MOC & 097 & $\mathrm{ne}$ & 104 & $n_{n}$ & 1,56 & 100 & 091 \\
\hline
\end{tabular}

Wote: N.A; not availate; N.E. not estimated as no graduates worked in acadenic competencies dilomain.

\section{Appendix 6C: Robustness Tests}

A critical assumption in the first-stage estimations, in which we tried to explain the allocation outcome and wage rate by individual/occuparional chatacteristics and by the dummies for the different education programmes, is the use of fixed-effects models. In this way, we force the covariares to have a homogeneous impact for graduates from differenc education programmes. This assumption may harm the analyses in cases in which an oxisting differential impact is at least partially taken over by the education programme dummies that we try to explain in the second stage. To test to what extent the extracted fixed ellects of the education programmes are biased by this restriction, we re-estimated the allocation function and wage analyses separately for each of the higher education institutions and then extracted from these analyses the fixed effects for the education programmes. Logically the first best approach would have been to estimate the allocation function for each education programme in each higher education institution separately. Unfortunately, this appronch is not possible, as the number of respondents per education programme is too small, considering they are also allocated over three labour market domains.

Table 6.Cr presents the correlation coefficients beween the fixed effects of an education programme when extracted from a pooled estimation with all higher education institutions included ("Extraction r"), and the fixed effects of an education programme when extracted from estimations separately for each higher education instutution ('Extraction 2). 
Table 6.C. 3

Correlations:

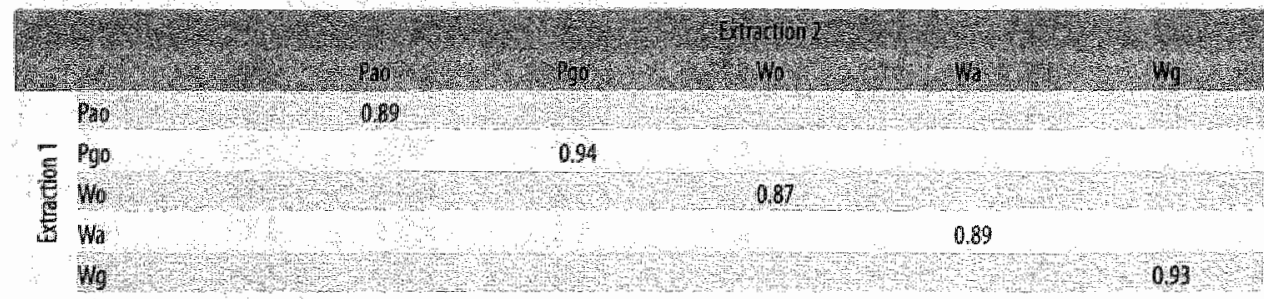

Note: All correlations are signficamt at a 1o level

Wote $P_{\text {us: }}$ Probability of working inside the domain of another edlucation programme versuss

Probabiliky of workting inside the own domain

$\mathbb{P}_{\text {sow }}$. Probability of warking inside the academic competencies domain versus

Probabillty of working inside the own domiain

W: Wage rate paid to graduates working inside the own domain

$W_{3^{*}} \quad$ Wage rate paid to graduates working inside the domain of another educational programme

$W_{1:} \quad$ Wage rate paidd to graduates working inside the academic competenties domain

In all cases, we can see that the correlations between the fixed effects, as used in this chapter, (Extraction I) and the fixed effects extracted from first-stage analyses carried out for each higher education institution individually are on a very high level. In other words, al though using a fixed-effect model forces the covariates to behave in a homogeneous way over all higher education institutions, this has no real impact on the fixed effects that were extracted and used in the second stage as dependent variables. 
Chapter 7

Concluding remarks 
The acquisition and maintenance of competencies valued in the labour marker is crucial for school-leavers in general and for higher educarion graduares in paricular. Changes in the modern wokplace have intensified the debare concerning the kind of competencies that are required in a knowledge-driven economy and the kind of competencies that are best acquired in education. As a result, political and analytical interest have started to focus on the quality dimension of schooling and the impact of quality differences in human capital on the labour market success of graduates (e.g. Hanushek, 2002, 2004).

The objective of this thesis is to add to the ongoung discussion on the measurement of human capital. More specifically, we propose a human capital output measurement of higher education that explicitly distinguishes two specific types of competencies that are acquired by students. On the one hand, there are the discipline-specific competencies based on the cognitive knowledge of the graduate that allow him to perform productively in a restricted labour market area. On the other hand, there are the academic comperencies that cover the ability of knowing how to (re)learn, how to address problems and how to deal with information and ideas. In contrast to discipline-specific competencies, academic competencies enable the graduate to adapt easily and fexibly to changes in the labour market and to acquire, where necessary, new competencies. Accordingly, this measurement covers competencies that are crucial for higher education graduates in order to succed in a knowledge-driven economy. Moreover, they are of strong relevance during the transition period from higher education to the labour market, as discussed in this thesis. In the case of discipline-specific competencies because they provide direct productive knowledge, and in the case of academic competencies because they support a graduate in closing any remaining gaps between what the labour market currently asks and what the graduate has acquired in higher education. Lastly, the relevance of these two types of competencies has long historical roots, as indicated by the following quotation from a speech by Condorcer before the French Nationall Assembly in 1792 :

"Education has to be universal, i.e. it has to reach every citizen. In different Levels education should embrace the evtire realm of human knowledge and provide humans at every stage of their life with the ability of conserving their knowledge and acquine new comperencies. We awll teach the people new laws, observations in agriculture, economic methodology ane should not ignove: we will show them the art of leaming by themseltes

(Cited in Werquin, 2002)

The proposed measurement makes it possible furst to address in more detail the production. process in higher education. In particular, we have analyzed the way in which higher education may stimulate the acquisition of discipline-specific and academic competencies and to what extent the stimulation of one type of comperencies induces a reduced effectiveness in the acquisition of the other type. Second, the measurement makes it possible to investigate the relevance of the two key types of competencies for a successful transition from higher education to the labour market. In this light, we related findings from our research to the often stated claim that the weight which the labour market attaches to academic competencies is increasing, and we have asked what responses are needed to enable higher education 
graduares to be well-prepared for a knowledge-intensive economy. The four main insights from this study are as follows:

The first man finding (Chapter 3) shows an original way to measure higher education output in terms of discipline-spectic and academic competencies on the basis of self-reported competence levels. The measurement provides clear insights into the comperencies acquired by graduates and is flexible enough to cope with changes in the set of both acquired and required competencies. Furthermore, irs Europe-wide applicability provides an innovative way of characterizing higher education programmes and higher education systems along a continuous scale, ranging from academically to discipline-specifically oriented. We have shown that higher education systems in the Netherlands, Germany and Austria, in line with their occupationally oriented labour markets, are discipline-specifically oriented and that higher education systems in the United Kingdom, France, Finland and Spain are acadenically oriented, matching well the expectations of an internal labour market. Our approach also makes it possible to spot differences in the relative competence orientation of Bachelor and Master programmes in the future. Future research may provide more decailed insight into the outcomes of the two higher education phases currently being introduced in all European countries, and facilitate the matching of graduates with occupations.

The second insight (Chapter 4 ) is that both the learning environment at the higher education institute and the time allocation of students over different study activities, determine to a great extent the type and level of competencies that students have at the time of graduation. When aiming higher education ar a discipline-specific output the teacher needs to be given a central role in transferring cognitive knowledge, attending formal education needs to be stimulated and higher education institutes need to facilitate students in finding work that is closely related to the field of study followed at that moment of time. On the other hand, when targeting higher education at an academic competence output, there is a clear need for activating learning envinomments. It is allso of relevance to observe that implementing an activating llearning environment does not harm the acquisition of discipline-specific competencies and, as a matter of fact, combining an activating learning environment with a strongly present teacher enables a shift beyond the learning frontier with respect to both academic and discipline-specific competencies, compared to conventional lecture-based teaching methods.

The policy implications of these findings are fairly clear-cut. First, the claim that academic competencies are increasingly being regarded as of crucial value in the labour market should be combined with strong stimulation of activating learning environments in higher education. "This holds in particular in traditional discipline-specifically oriented systems (e.g. in the Netherlands, Germany and Austria). Second, the finding that activating learning environments promote the acquisition of academic competencies, providing a strong basis for further learning, needs to be taken into consideration wher deciding on reshaping the curriculum contents according to the setup of a Bachelor/Master structure. Applying activating learning environments in the Bachelor phase allows students to enter the Master phase with a strong basis of academic competencies, yielding an effective accuisition of the specialized disciplinespecific comperencies raught at that level.

The third main funding (Chapter s) is that discipline-specific and academic competencies play a distinct role in the transition from higher education to work. "Their role seems to be related to the institutional rules of the labour market, that is, internal versus occu- 
pational labour market. We found that in an occupational labour market settirg (e.g. the Nerherlands, Austria or Germany), the discipline-specific competence level of graduates is a primary devminant in the allocation outcone. Moreover, a lack with respect ro eidher the level or the type of discipline-specific comperencies reduces productivity considerably, and hence also the wage rate In contrast, we found that in internal labour market cowntries (e.g. the Unired Kingdom or France), the discipline-specific competence level does not influence the allocation outcome, hor does a lack in the required lewel of discipline-specific competencies affect the wage rate. The role of academic competencies, independently of the labour market setting, is that of enabling the graduate to be flexible and to get access to further learning situations, that is, on-the-job training. Accordingly, these results indicate that there is a complementary relation between the level of academic comperencies taught in higher education and further on-the-job training.

The finding that in countries with an occupationally oriented labour marker, the level of discipline-specific competencies that graduates possess still plays a relatively more important role than the level of academic competencies, must not be interpreted as a reassurance that higher education institutes would do well to focus on discipline-specific competencies. Rather, combining a strong teacher presence with an activating learning environment, helping to increase the effectiveness with which both academic and discipline-specific competencies are acquired, would allow the matching between graduates and occupations to work further in an effective manner and at the same time prepare students in these countries better for changes that are taking place.

Lastly, the fourth insight (Chapter 6) seems to reassert that higher education programmes target the competencies taught to their students in line with labour market requirements. We foand that higher education programmes that provide a strong discipline-specific outcome are more likely to place their graduates in the occupational domain with related competencies. Programmes that provide a strong academically oriented outcome place their graduates in the domain that asks for academic comperencies. However, to guarantee an effective transition from higher education to the labour market, it is not enough just to focus on one cype of comperencies, but institutes also need to target a standardized output. The analyses show that reducing the wariability between graduates, in terms of the level of competencies they possess, improves the information prowided to employers. This reduces selection and adjustment costs and facilitates a higher remuneration of the graduates.

Considering the distinction berween countries with an occupational labour market and countrites with an internal labour market, our findings seem to indicate in particular the following: higher education institutes that prepare graduates for an occuparional labour market should focus on the acquisition of a standardized discipline-specific competence ourcome; higher education institures that prepare graduates for an internal labour market should focus on the acquisition of a standardized academic competence level.

This study has answered several important questions with respect to the acquisition of discipline-specific and academic competencies in higher education, their role in the allocation across occupational domains, the selection for on-the-job training and their monetary walue in the labour marker. However, the study leaves room for relevant research in different directions in the future. We will point our some aspects for future research. 
The focus of this study was on two types of competencies namely discipline-specific and academic ones, and we restricted the analyses to the first three to four years in the labour market. In spite of the benefits of these restrictions, expanding the set of comperencies and the time frame under consideration seems a fruitful area for further rexearch.

Considering, as is often stated, the growing need for higher education graduates to be properly prepared for responsible management positions in a post-industrial economy with global competition, the question to what extent comperencies characteristic for managerial behaviour, such as leadership, negotiation skills but also a variety of "people skills', are effectively tanght in higher education, is of particular interest. Are activating learning environments as effective in teaching competencies needed for managerial tasks as they are in teaching academic competencies? Does the number of hours that students attend formal education marter, as it does for discipline-specific comperencies, or are such comperencies acquired through extra-curricular activities and active working experience?

With respect to the short time period under consideration, we may ask to what extent these findings are influenced by this aspect. In particular, looking at the first three to four years may be too shorr to reveal the full impact of academic comperencies, measuring the graduates' Hexibility, adjustability and ability ro (re)learn (new) competencies. Extending the time frame may reveal interesting findings with respect to long-term labour market careers of higher education graduates. Does a high level of academic competencies enable graduates to acquire competencies later on in their careers which are less likely to be acquired effectively in school (e.g. management competencies) but which may infuence their long-term labour market success? Are graduates with a high level of academic competencies better equipped for re-entry into the labour market if they (voluntarily) drop out of the labour market for some time?

Lastly, we contrasted where appropriate the findings with the institutional labour marker setting of a country, focusing on internal versus occupational labour markets. One may go further along this line and argue that cultural differences between countries resonate in many aspects of social life and steer selection and sorting processes of employees in the labour market. This is because general cultural differences at the national level infuence the overall psychological construction of the self (see e.g. Kitayama, Matsumoto, Markus, Norasakkunki, 1997). To the extent that individuals are imprinted with these values, cultural norms and values determine what people regard as important and what they value in the labour market. Employers may be inclined to design jobs with characteristics that are congrwent with imprinted national cultural walues and they fawour employees whose characteristics and comperencies fit these values. Employees may value jobs that require competencies which fir their cultural "self" more than jobs which do not. Analyzing the extent to which work that matches the cultural "self" of the employee is more rewarding, yielding a more productive and satisfied employee, is an interesting line for future research. Moreover, this line would allow an analysis of the extent to which internationalization and globalization of the economy reduces the cultural differences and harmonizes the labour markets in terms of, for example, job characteristics. Lastly, it allows further cross-national comparisons resulting in important insights in the chances and risks of cross-national mergers. 



\section{Summary}

Research on the measurement of competencies, considered to be an accurate and relable way of representing individual capacities valued in the labour matket, seems to be a conditio sine qua mon to enhance our understanding of the transition from higher education to the labour market. For this reason, this study first presents a discussion on the rype of competencies that are regarded as key competencies for higher education graduates to suoced in the labour market. Second, it presents analyses on the questions how to define human capital in terms of competencies, how competencies are acquired in higher education, and what the role and value are of the competence outpur of higher education in the labour makket, borh ar an individual and at a study programme levell.

To stant with, Chapter 2 has a twofold objective. First, there is a discussion of the theoretical notions on the impact of education on labour productivity. Second, we addressed the topic of a qualification granted to higher education graduates as a vector of heterogeneous competencies. We indicated that common economic theories, and in particular models in line with the assignment theory, provide a good basis for this study. Nevertheless, we argued that static labels generally used in previous research to describe higher education output; such as the study field or the type of higher education completed (e.g. Fachhochschulen), cannot cope with the constantly evolving competence mix demanded in the labour market and taught in higher education programmes. As a result, we discussed the different types of comperencies which make up the human capital that graduates acquire. The term 'competency' is used to indicate a group of skills, referring to one underlying dimension and forming the condition to fulfil complex tasks inside and outside the working sphere. In this way, the ability to heat up the oven, the ability to cut the meat, and the ability to name different herbs are regarded as skills, whereas the combined knowledge of these skills is what makes a chef competent. We propose that in particular a distinction between discipline-specific competencies and academic competencies is important for a study on higher educarion graduares. Disciplinespecific competencies constiture the cognitive knowledge of a graduate, which allows him to perform productively in an often restricted labour market area. Academic conpetencies cover the ability of knowing how to (re)learn, how to address problems and how to deal with information and ideas. In contrast to discipline-specific competencies, academic competencies allow the graduate to adapt easily and Hexibly to changes in the labour rnarket and to acquire, if needed, newly required comperencies.

In Chapter 3, we put theory into practice. We discussed and proposed a flexible way of measuring the output of higher education in terms of the level of academic and disciplinespecific comperencies acquired by graduates. To do 50 , we first discussed the Careers after Higher Education: a European Research Study (CHEERS), which provided the data. The data covers students from all types of higher education in mine European countries who graduated in $1994 / 1995$. The countries included are Italy, Spain, France, Austria, Germany, the Netherlands, the United Kingdom, Finland and Norway. As central element of this study, 
the written questionnaite asked respondents to indicare the levels of different skills they possessed at the time of graduation and the levels of the skills required in their current occupation (approximately 3 years after graduation). Using hierarchical clustering methods, we established that thete are two Europe-wide clusters of skills resembling the above-mentioned theoretical constructs of discipline-specific and academic competencies. The former consists of "field-specific theoretical knowledge" and 'field-spectic knowledge of methods". The latter includes 'documenting ideas and information', 'problem-solving ability", "analytical competencies, "learning abilities" and 'reflective thinking, assessing one's own work'. These two competence clusters form the higher educarion output measurement set which is at the centre of this study. The otiginality of this measurement lies mainly in two particular fearures. First, it allows one to get a clear insight in the competence heterogeneity of graduates of a given study programme. Second, it is flexible and is able cope with the above-mentioned constantly evolving mix of competencies taught at higher education and competencies required in the labour market.

Next to capture the individual heterogeneity in output achievements, we showed that the proposed measurement provides an innovative way of characterizing higher education programmes and higher education systems. Previous typologies located programmes or systems only at two extreme poles (academic or discipline-specific). Our approach locates them on the continuous scale between these two extreme poles. According to this measurement, Germany, Austria and the Netherlands in particular have discipline-specifically oriented higher education systems that are well-suited to their occupationally oriented labour markers. The United Kingdom, Spain, France, and to a lesser extent Finland, can be classified as countries with academically oriented higher education systems, in line with the characterization of their labour markets as internal labour markets.

In Cbapter 4, we addressed the production of discipline-specific and academic competencies in higher education. In the last decades, the upcoming criticism on tradirional teaching styles has led to a widespread implementation of activating learning methods, such as problem-based or project-based learning, placing the learner at the centre and expecting him to be an active discoverer instead of a passively fed student.

Consequently, the first objecrive of Chapter 4 is to analyze the extent to which activating learning environments are more effective in teaching competencies in general and academic competencies in particular. In addition to the learning environment, the student's individual time allocation over different study activities (e.g. attending formal education, self-study or paid work activities) is regarded as a core element of the production process discussed. The results indicate that the setup of higher education needs to be in line with the targeted output and hence the requirements of the labour market. To prepare students for their entry in an occupational labour market (traditionally found in countries such as Austria, Germany and the Netherlands), expecting from graduates a strong congruence berween the acquired type of discipline-specific competencies and the type of discipline-specific competencies required in the labour market, reachers need to transfer discipline-specific knowledge to students (independent of the question whether the institute implements activating learning methods or not), class attendance needs to be emphasized and institures need to facilitate the matching of students with study-related occupations if students intend to work alongside to their studies. All of these aspects guarantee that students acquire a high level of discipline-specific compe- 
tencies. In contrast, to prepare students tor the requirements of an intemal labour market as found for example in France and the United Kingdom, actwating learning environments are an obvious necessiry. In addition, emphasis needs to be put on selfistudy and, wh the case above, on study-related paid work.

In Chapter swe invescigated the role and walue of discipline-specific and acadenic competencies acquired in higher education th the labour market. We focused on the sirution in the Netherlands, with its traditionally occupationally oriented labour market (similar to Austria and Germany). However, where appropriate, we pointed ond differences found when considering countries such as the United Kungdom on France, wh a relatively higher degree of internal labour market. "To start with, we examined a possible direct link berween the competence lewel present at the cime of graduacion and the wage rate received three years later. Neither for the level of academic comperencies nor for the level of discipline-specific competencies was such a direct link established. However, we found that a lack in either the rype or the level of discipline-specific competencies in relation to the required type or level significanty reduced the wage rate. A result that is rypical for occupational labour market countries, but is not found in countries with an internal labour narket.

Then we analyzed the roles of the competence constructs in the allocation of graduates over different occupational domains and on the selection of graduates for further on-the-job training. The results indicate, first, that the extent to which Dutch graduates are matched to an occupation that matches their field of study is strongly infuenced by the level of discipline-specific competencies which the graduares possess. As these occupations are better paid, being selected for them is important for graduates from a monetary point of view. Comparable situations are found in other occupationally oriented Lutopean countries, but a less significant role of the acquired level of discipline-specific competencies in the allocation ourcome is found in acaderrically oriented countries such as the United Kingdom or France. Second, we showed that academic competencies acquired in higher education play a major role in who is selected for further training, which in itself increases productivity and hence wage rates. So, training and the level of academic competencies acquired in higher education are complements, and academic competencies are used to adjust the discipline-specific comperencies of graduates to the requirements of the labour market. In contast to the earlier findings in this chapter, this result is independent of the competence orientation of the higher edwcation system or the institutional serting of the labour market.

There is no doubt that individual characteristics are crucial for success in the labour market. However, given the fact that the transition from higher education to work takes places in a context with asymmetric and private information on both sides of the narket, group characteristics may provide relevant signals to employers with respect to the true productive capabilicies of the applicants. To address this feature, Chapter 6 analyses the impact of five typical characteristics of higher education programmes on the allocation outcome and the performance of graduates in the labour market. The characteristics considered are the competence orientarion (discipline-specific versus academic), the standardization with respect to the acquired competencies, the extent to which the programme is international, the exrent to which it integrates studying and working, and the extent to which the proguamme provides exclusive encrance to certain occupations (e.g. health studies). 
We showed that programmes providing a strong discipline-specifically oriented outcome are most likely to place their graduates in the occupational domain with a related type of competencies. Comparably; programmes providing a strong academically oriented outcome place their graduates in the academic competence domain. As programmes in occupationally oriented countries are relatuvely more discipline-specifically oriented and programmes in countries with an internal labour manket are relatively more academically oriented, this observation reasserts that higher education programmes target their output in line with the general institutional serup of the labour marker (i.e. internal or occupational). However, it is not enough for a programme to focus on a particular competence type (academic or disciplinespecific); but programmes should preferably also create a group of graduates that is strongly harmonized with respect to the central competence type. Standardization of the comperence outcome provides employers with better information on the true productive capabilities of graduates, reducing selection and adjustment costs and allowing for a higher remuneration of workers. In other words, to guarantee a successful transition from higher education to the labour market in countries with an occupational labour market (e.g. Austria, Germany or the Netherlands), the preparation of graduates for the relatively discipline-specifically oriented labour market needs to go hand in hand with a standardized outcome in discipline-specific competencies. In countries with a strong internal labour market (e.g. the United Kingdom or France), preparing graduates for the academic orientation of this labour market type has to be in line with a standardized outcome in academic competencies. No significant impact on the labour market outcome was found for the internationalization of the study programme and its integration between studying and working. However, graduates from programmes providing exclusive entrance to certain occupations are more likely to be matched to occupations that correspond to their discipline-specific comperencies.

Chapter 7 summarizes the main findings. We also discussed some shortcomings of the study and pointed out topics for future research. With respect to the larter point, we argued that in particular an expansion of the set of competencies taken into account (e.g. management competencies) and the time frame under consideration (e.g. 5 or ro years after graduation) should yield fruitful areas for further research. 


\section{Samenvatting}

Onderzoek naar het meten van competenties, dat wordt gezien als een nawwkeurige en betrouwbare manier om individuele capaciteiten weer te geven waarop de arbeidsmarkt prijs stelt, lijkt een condirio sine qua non woor een beter inzicht in de overgang van hoger onderwijs naar de arbeidsmarkt. Om deze teden wordt in dit onderzoek eerst besproken welke soorten competenties worden beschouwd als kemcompetenties voor afgestudeerden wit het hoger onderwijs on met succes te kunnen opereren op de arbeidsmarkt. Ten tweede worden analyses gepresenteerd met betrekking tot de waag hoe menselijk kapitaal moet worden gedefinieerd in termen van competenties, hoe competenties worden verworven in her hoger onderwijs, en wat de rol en waarde zijn van de competenties die het hoger onderwijs levert aan de arbeidsmarkt, zowel op het niveau van individuen als van opleidingen.

Hoofdstuk 2, om te beginnen, heeft een tweeledig doel. Ten eerste worden de theoretische ideeën besproken over de invloed van onderwijs op arbeidsproductiviteit. Ten tweede gaan we in op het onderwerp wan een kwalificatie toegekend aan afgestudeerden uir her hoget onderwijs die een vector is van heterogene competenties. We geven aan dat de gebruikelijke conomische theorieën, en met name modellen die aansluiten bij de toewijzingstheorie, een goede basis vormen voor dit onderzoek. Niettemin beweren we dat de statische labels, die over het algerneen worden gebruikt in eerder onderzoek om de productie van het hoger onderwijs te beschrijven, zoals thet vakgebied of het gevolgde type hoger onderwijs: (bijv. Fachhochschulen), geen antwoord bieden voor de zich constant ontwikkelendle combinatie van competenties die op de arbeidsmarkt wordt gevraagd en in het hoger onderwijs word t onderwezen. Daarom bespreken we de verschillende soorten competenties wataruit her menselijk kapitaal bestaar dac afgestudeerden wergaren. De rerm "comperentie" worde gebruikt om een groep vaardigheden aan te duiden, die verwijzen naar één ondertiggende dimensie en de voorwaarde wormen voor het kunnen uirvoeten wan complexe taken zowel binnen als buiten de werksfeer. Zo wordt het opwarmen van een oven, het snijden van wlees en het kunnen benoemen van verschillende kruiden aangeduid met de term 'vaardigheden', terwijl de combinatie van deze vaardigheden bepaalt of iemand zich kok mag noemen. We stellen woor dat met name een onderscheid tussen vakspecifieke en academische competenties van belang is voor een onderzoek onder afgestudeerden van het hoger onderwijs. Vakspecifieke competenties vormen de cognitieve vaardigheden varn een afgestudeerde, waarmee hij productief kan opereren in een wak beperkt deel van de arbeidsmarkt. Academische competenties staan voot de mogelijhheid om te weten hoe men moet (bij)leren, hoe problemen moeten worden aangepakt en hoe moet worden omgegaan met informatie en ideeen. In tegenstelling rot vakspecifieke competenties stellen academische competenties de afgestudecte in staat zich eenwoudig en Alexibel aan te passen aan weranderingen op de arbeidsmarkt en, indien nodig, nieuwe comperenties die gevraagd worden te verwerven.

In hoofdstuk 3 wordt de theorie in de prakrijk gebracht. Daar doen wij een voorstel voor een Alexibele manier om de output wan het hoger onderwijs te meren in termen van het 
niveau van academische en vakspecifieke competenties dat afgestudeerden bereiken. Hierno geven we eerst een beschrijving van de Careers after Higher Education: a European Research Study (CHEERS), waaruit de gegevens afkomstig zijn. De gegevens betreffen studenten van alle soorten hoger onderwijs in negen Europese landen, die zijn afgestudeerd in 1994/1995. De betreffende landen zijn Italië, Spanje, Frankrijk, Oostenrijk, Duitsland, Nederland, het Verenigd Koninkrijk, Finland en Noorwegen. Een centraal element van dit onderzoek is een schrifrelike vragenligst waarin deelnemers werd gevraagd om an te geven welke wardigheden zif bezaten op het moment van afsuderen, alsmede welke vaardigheden nodig zijn in han thidige beroep (ongeveer drie jaar na afstuderen). Mer behulp van hierarchische clistermethoden stellen we vast dat er op Europees niveau wee clusters van vaardigheden zijn die overeenkomen met de bovengenoemde theoretische concepten wan wakspecifieke en academische competenties. De eerste bestaat uit 'vakgebiedspecifieke theoretische kennis' en vakgebiedspecifieke kennis van methoden'. De tweede omvat 'ideeèn en informatie documenteren', 'probleemoplossend vermogen', 'analytisch vermogen', 'leervermogen' en 'bespiegelend denken, eigen werk beoordelen'. Deze twee competentieclusters vormen de productiemeetset wan het hoger onderwijs die centraal staat in dit onderzoek. De originalteit van deze meting is voornamelijk gelegen in twee specifieke eigenschappen. Ten eerste biedt de meting de mogelijkheid om duidelijk inzicht te krijgen in de heterogeniteit van competenties van afgestudeerden van een bepaalde opleiding. Ten tweede is deze flexibel en geschikt voor de bovengenoemde constant veranderende combinatie van competenties die in hiet lioger onderwijs worden onderwezen en de competenties die worden gevraagd op de arbeidsmarkt.

Verder tonen we aan dat de voorgestelcle meting een innovatieve manier vormt om opleidingen in het hoger onderwijs en systemen in het hoger onderwijs te kenschetsen. In bestaande typologieèn werden opleidingen of systemen slechts op éen wan de wwee uiterste posities geplaatst (academisch of valkspecifiek). In onze benadering worden ze op cen schaal tussen deze twee uitersten geplaatst. Op basis van deze meting hebben met name Duitsland, Oostenrijk en Nederland een vakspecifiek georiënteerd hoger onderwijssysteem dat goed aansluit bij hun beroepsgerichte arbeidsmarkten. Het Verenigd Koninkrijk, Spanje, Frankrijk, en in mindere mate ook Finland, kunnen worden gekenmerkt als landen met een academisch gericht hoger onderwijssysteem, aansluitend bij de classificatie van hun arbeidsmarkten als interme arbeidsmarkten.

In hoofdstuk behandelen we de productie van vakspecifieke en academische comperenties in het hoger onderwijs. De afgelopen decennia heeft de toenemende kritiek op rraditionele onderwijsmethoden geleid tot en brede invoering van activerende leermethoden, zoals probleemgestuurd en projectgestuurd onderwijs, waarbij de student centraal wordt gesteld en wan hem/haar wordt werwacht dat hij/zij een actieve ontdekker is in plaats van iemand die passief met lkennis wordt gevoerd. Daarom is het eerste doel van hoofdstuk 4 te analyseren in hoeverre activerende leeromgevingen doelmatiger zijn bij het aanbrengen van competenties in her algemeen en academische competenties in het bijzonder. Naast de leeromgeving wordt ook de individuele verdeling van tijd door de student over de verschillende studieactiviteiten (bijw. het bijwonen van formeel onderwijs, zelfstudie of betaald werk) gezien als een kernelement van het besproken productieproces. De resultaten geven aan dat de opzet van het hoger onderwijs moet aansluiten bij de beoogde output en dus bij de eisen van de arbeidsmarkt. Om 
studenten voor te bereiden op hun toetreden tot een beroepsgerichte arbeidsmarkt (traditioneel te vinden in landen als Oostenrijk, Duitsland en Nederland), waarbij van afgestudeerden een sterke overeenkomst wordt werwacht tussen het soort vakspecifieke competenties dat zij hebben opgedaan en het rype valsspecifieke competenties dat de arbeidsmarkt vraagt, moeten onderwijsgevenden vakspecifieke kennis overbrengen op studenten (los van de vratg of de instelling activerende leermethoden gebruikt of nier), moet de nadruk liggen op anwezigtheid in de les en moeten instellingen mogelijkheden bieden om studenten een koppeling te لlaten maken met studiegerelateerde werkzaamheden als studenten naast hun studie willen werken. Al deze aspecten garanderen dat studenten in hoge mate valspecifieke competerties opdoen. In tegenstelling hiermee zijn activerende leeromgevingen een absolute noodzaak wanneer studenten moeten worden voorbereid op een interne arbeidsmarkt, zoals te vinden is in Frankrijk en het Verenigd Koninkrijk. Daarnaast moet de nadruk worden gelegd op zelfstudie en, zoals hierboven aangegeven, op studiegerelateerd betaald werk.

In boofdstuk 5 onderzoeken we de rol en waarde op de arbeidsmarkt van vakspecifieke en academische competenties die zijn verkregen in het hoger onderwijs. We richten ons datarbij op de situatie in Nederland, met een traditionele beroepsgerichte arbeidsmarkt (te vergelijken met Oostenrijk en Duitsland). Indien van toepassing, wijzen we echter ook op versehillen die we aantroffen bij het vergelijken van landen zoals her Verenigd Koninkrijk en Frankijijk, met een relatief prominentere interne arbeidsmarkt. Om te beginnen kijken we naar een mogelijk rechtstreeks verband tussen het competentieniveau dat aanwezig was op het moment van afstuderen en het salarisniveau drie jaar later. Noch voor het niveau van academische competenties, noch voor het niveau van vakspecifieke competenties kan een dergelijk rechtstreeks verband worden aangetoond. We hebben echter wel kunnen vaststellen dat een gebrek aan hetzij her type, hetzij het niveau van vakspecifieke competenties in relatie tor her gevraagde type of niveau leidt tot een aanzienlijk lager salarisniveau. Dit is een uitkomst die kenmerkend is voor landen met een beroepsgerichte arbeidsmarkt, maar niet wordt aangetroffen in landen met een interne arbeidsmarkt.

Vervolgens analyseren we de rol die de twee competentieconcepten spelen bij de toewijzing van afgestudeerden aan verschillende beroepenvelden en bij de selectie van afgestudeerden voor verdere scholing in de praktijk. De resultaten geven aan dat, ten cerste, de mate waarin Nederlandse afgestudeenden terechtkomen in een baan dic past bij hum opleiding sterk samentiangr mer her niweau aan vakspecifieke competenties dat de afgestudeerden bezitten. Omdat dit beter betaalde banen zijn, is het uit financieel oogpunt voor afgestu deerden belangrijk om hiervoor te worden geselecteerd. Vergelijkbare sitwaties worden angetroffen in andere beroepsgerichte Europese landen, maar een minder belangrijke rol van her bereikte niveau van vakspecifieke competenties in de toewijzing is te zien in academisch georienteerde landen, zoals het Verenigd Koninkrijk en Frankrijk. Ten tweede tonen we aan dat academische competenties die zijn werkregen in thet hoger onderwijs een grote rol spelen bij de selectie voor bijscholing, hetgeen op zichzelf bijdraagt aan ew verhoging van de productiviteit en derhalve het salaris. Scholing en het niveau van academische competenties die zijn opgedaan in het hoger onderwijs vullen elkaar dus aan en academische competenties worden gebruikt om de vakspecifieke competenties van afgestudeerder aan te passen an de eisen van de arbeidsmarkt. In tegenstelling tot eerdere bevindingen in dit hoofdstuk, is dit 
resultaat niet afhankelijk wan de competentiegerichtheid van het hoger onderwijssysteem of wan de institutionele instelling wan de arbeidsmarkt.

Er bestaat geen twijtel dat individuele eigenschappen van cruciaal belang zijn voor succes op de arbeidmarkx. Maar, gegeven het feir dat de overgang van hoger onderwijs naar werk platsvindt in een context met asymmetrische en onvolledige informatie aan beide kanten van de marke, kunnen groepskenmerken relevante signalen geven aan werkgevers aangaande de werkelijke productieve mogelijkheden van sollicitanten. Om hierop een antwoord te geven, wordt in boofdstulk 6 een analyse uitgevoerd naar de invloed van vijf vell voorkomende kenmerken wan opleidingen in het hoger onderwijs op de toewijzingstresultaten en prestaties van afgestudeerden op de arbeidsmarkt. De kenmerken die worden bekeken zijn de competentierichting (vakspecifek versus academisch), de standaardisering met betrekking tot de verkregen competentiles, de mate watrin de opleiding internationaal georiënteerd is, de mate watrin studeren en werken zijn geintegreend, en de mate waarin de opleiding exclusief roegang biedt tot bepaalde beroepen (bijv in de gezondheidszorg).

We tonen aan dat afgestudeerden van opleidingen met een sterk vakspecifiek gerichte output het vaakst terechikomen in het beroepenveld met een verwant soort comperenties. Op vergelijkbare manier komen afgestudeerden van opleidingen met een sterk academisch: gerichte output terecht in het academische competentieveld. Omdat opleidingen in landen met een beroepsgerichte arbeidsmarkt relatief vaker vakspecifiek gericht zijn en opleidingen in landen met een interne arbeidsmarkt relatief vaker academisch gericht zijn, bevestigt deze constatering dat opleidingen in het hoger onderwijs hun resultaten sturen overeenkomstig de algemene institutionele opzet van de arbeidsmarkt (d.w.z. intern of beroepsgericht). Het is echter niet genoeg dat een opleidling zich richt op een bepaald soort competentie (academische of vakspecifiek), maar opleidingen moeten bij woorkeur ook een groep afgestudeerden afleveren die sterk overeenkomt met betrekking tot het centrale soort competenties. Gestanclaardiseerde competentieresultaten bieden werkgevers beter inzicht in de werkelijke productieve mogelijkheden wan afgestudeerden, waardoor de selectie- en aanpassingskosten afnemen en werknemers een hogere beloning kunnen krijgen. Met andere woorden: om een succesvolle overgang van het hoger onderwijs naat de arbeidsmarkt te garanderen in landen met een beroepsgerichte arbeidsmarkt (bijv. Oostenrijk, Duitsland en Nederland), moer de voorbereiding van afgestudeerden woor de relatief vakspecifiek gerichte arbeidsmarkr gekoppeld zijn an gestandaardiseerde resulltaren in vakspecifieke competenties. In landen met een sterk interne arbeidsmarkt (bijw. het Verenigd Koninkrijk en Frankrijk) moet de voorbereiding van afgestudeerden voor de academische gerichtheid van dit soort arbeidsmarkt aansluiten bij een gestandaardiseerd resultat op her gebied van academische compecencies. Er is geen significante invloed op het resultat op de arbeidsmarkt gevonden voor de mate van internationaLisering van opleidingen of de integratie wan studeren ew werken hiervan. Afgestudeerden van opleidingen die exclusief toegang bieden tot bepaalde beroepen hebben echter een grotere kans om werk te vinden in beroepen die passen bij hun wakspecifieke competenties.

In hoofdstuk 7 worden de belangrijkste bevindingen samengevat. We bespreken tevens enkele tekortkomingen van het onderzoek en geven aan welke onderwerpen in de toekomst bestudeerd zouden kunnen worden. Wat betrefic het laatste voeren we met name aan dat een uitbreiding van de ser competenties waarmee rekening wordt gehouden (bijv leidinggevende capaciteiten) en de tijdsperiode die in ogenschouw wordt genomen (bijv. 5 of ro jaar na afstuderen) gebieden voor toekomstig onderzoek kunnen zijn die vruchtbare resultaten kunnen opleveren. 


\section{References}

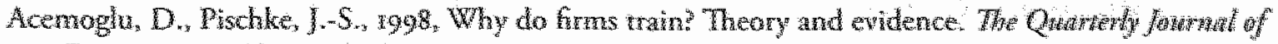

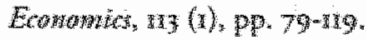

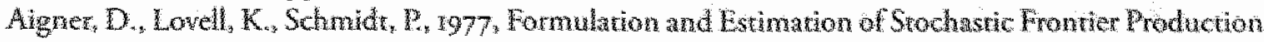

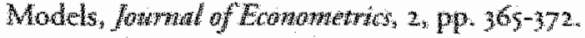

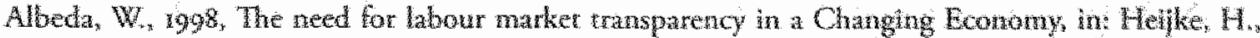

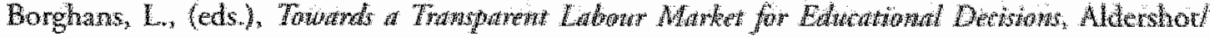
Brookfreld (USA)/Singapore/Sydney: Ashgate, pp. xin-kvit.

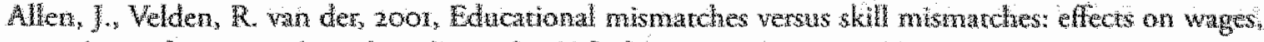

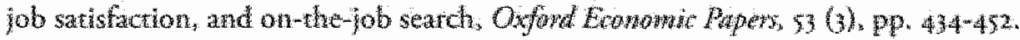

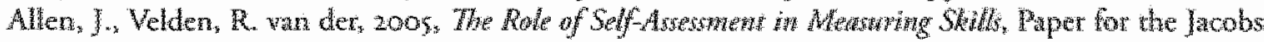
Foundation Conference "Intertisciphinaty and Cross-Natronal perspedives on Skll Formation and

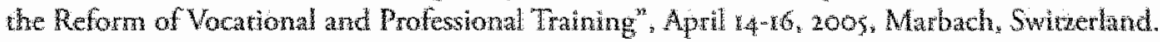

Alen, J., Ramadicrs, $G$, Velden, $R$, wan der, forthcoming, Mearuring comperencies of higher efucation graduates, New Directions for Instinution Reseranch.

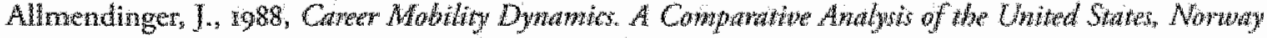
and West Germary, Thesis, Cambridge Massachuserts: Haryard Universiry.

Alstadsaeter, A. 2003, Merswring the consumption whe of higher whothon, paper presented at Econometric Society 2004 Austratasian Meetings, Metbourne.

Alonin, yoseph $\mathrm{G}_{0,3}$ 1985, The Effects of High School Curriculum on Education and Labour Maxket

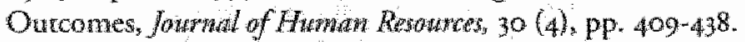

Alronj, Joseph G. Pieret, Chrtes R, 2oor, Employer learning and statistical Discrimination, Qmaterly Jownal of Econowics, $16(1)$, pp. 313-350.

Ashton, D, Green, F, 1996, Education, training and he global economy, Chelrenham: Edward Elgat.

Australsan Government Deparment of Employment, Education and Trating* 1987 , Policy Discussion Paper on Higher Edxcation, Canberra: Australian Government Printing Service.

Australian National Training Authoricy, 2003, Defming generic skills at a glance, Adelaide: NCVER Litd.

Baker, T.L., 1988, Doing Sociad Researh, New York, etc,: McGraw-Hill Intemational Editions.

Barmow, B., Cain, G., Goldberger, A., 1981, Issues in the andysis of selectivity bias, in: Stromsdorfer; E., Farkas, G., (eds.), Evaluation Studies Revieu Anwiat, vol. 5., Beverly Hills: Sage Publications. Pp. $43-59$.

Bart, R., Tagg, J., 1995, From Teaching to Learning - A New Paradign for Undergraduate Education, Change, November/December, pp. 13-25.

Barro, RJ., 199r, Economic growth in a cross secrion of countries, Quarterly foumal of Economics, to6 (2). pp. $407-443$.

Barrio, R.J., Sala-I-Martin, X, 1995. Economic Growth. New York: McGraw-Hill, Inc.

Barron, J.M., Loewenstein, M.A., 1985, On employer specific information and internal labour matkets, Sowthern Economic Journal, 52, pp. 431-445.

Barron, J.M., Black, D.A., Loewenstein, M.A., 1989, Job matching and on the job training, Journal of Labour Economics, 7 (I), pp. I-Ity.

Barrows, H.S., Tamblyn, R.M., 1980, Problem-based Leaming: An Approach to Medical Eduation, New York: Springer Publishing Company. 
Bartel, A.P. Sicherman, N, 998 , Technological change and the skill acquisition of young workers. Jowrnal of Labour Economics, 16 (4), pp. 718-75\%.

Battese, G.E., Codli, T. ., 1988, Prediction of Firm-Level Technical Efficiencies Wirh a Generallised Frontier Production Funcrion and Panel Data, Jourual of Econometrics, 38, pp. 387-399.

Becker, G.S., 1962, Inwestment into human capital: a theoretical analysis, The fournat of Political Economy, 70 (5), supplement, pp. 9-49.

Becker, G.S., 1964. Hom Capial: A Theoreticat and Empirical Analysis with Special Reference to Education; New York NBER

Berger, M,C., 1988a, Predicted furure earnings and choice of college major, Industrial and Labout Rolutions Revieu, 4il (3), pp. $418-429$.

Berger, M.C., 1988b, Cohort size effects on earnings: differences by college major, Economics of eductwonal revitw, 7, pp. $375-383$.

Biggs, J, 2003, Teaching for gudaty Learning at universigy: what the student does, $2^{\text {tal }}$ edition, Berkshire: Open University Press.

Bijornavold, J., Tissot, $\mathrm{P}, 2000$, Glossary on identification, assessment and validation of qualificanions and competences: transparency and transferability of qualifications, CEDEFOP Working document, Thessaloniki: CEDEFOR.

Bills, M., Klenow; O.J., 2000, Does schooling cause growth, American Econowic Revieu, 90 (5). pp. $1160-1183$.

Bishop. J.H., 1989, Is the test scote decline responsible for the productivity growth decline? American Economic Review 79 (1), pp.178-197.

Bishop, J.H., Kang, N., 1989 , Vocational and academic education in high school: complements or substitures?, Economics of Education Review, 8 (2), pp. 133-148.

Bishop, J.H., 1991. Achieverivent, test scores, and relative wages, in: Kosters, Marvin H., (ed.), Workers and their watges, Wasthington, DC: The AEI Press, pp. 146-18r.

Bishop, J.H., 1992. The impact of academic competencies of wages, unemployment, and job performance, Camegie-Rochester Conference Series an Public Policy, 37 (December), Pp. 127-194.

Bishop, J.H., I995, Vocational education and at-risk youth in the United States. Vocational Training European Journal, 6 , pp. 34-42.

Blackburn, Mckinley L., Neumark, D., 1993, Omitted-ability bias and the increase in the return to Schooling, fournat of Labour Econownics nn (3), pp. 521 m 544 .

Blackburn, McKinley L., Neumark, D., r995. Are OLS estimates of the return to schooling biased downward? Another look, Review of Ecomomicr and Statistics, 77 (2), pp. 217-230.

Bloom, B.S., 1956. Taxowomy of edncationd abjectives: The chasification of educational goats. Handbook 1 : Cogrative domain. New York: Mckay.

Borglans, L., Green, F., Mayhew, K., 20or, Skills mensurement and economic analysis: an introducrion, Oxford Econowic Papers, $53(3), \mathrm{Pp}, 375-384$ :

Bossche, P. van den, Segers, M., Gijbels, D., Dochy, F, 2oon, Effecten van het probleemgestuurd economisch curriculum [Effects of a problemmased economic curriculum], Tijdschrift voor Hoger Onderwijs, 19. (4), pp. 254-277.

Bowden, J. Masters, G.N., 1993. Implications for Higher Edtucation of a Competency Based Appraach to Eduation and Training Canberia AGPS.

Bowden. J., Marton, F, rg98, The University of Ledring, Beyond Quality awd Comperence, London: Kogan Page.

Bowen. H.R. (1977), Inwestment in Learning, San Francisco: Jossey-Bass Inc.

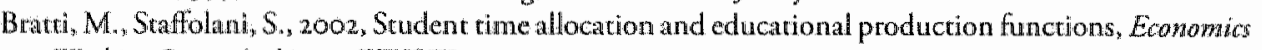
Working Paper Archiue wU WTL.

Brown. J., 1989, Why do wages increase with tenure? On the job training and life cycle wage grown observed wirhin firms, American Economic Reviews.79, pp. 971-991. 
Brumello, G., 20o, On the complementary beween education and tranimg in Europe, $12 A$ Dhowstow Paper, vol 309, Bonn: IZA.

Burris, V, rg83, The social and policical consequences of overeducation, American Sociological Review; 48 , pP. $454-467$.

Burnows, A. Harvey, L., Green, D., 1993, Is anybody listening? Employers witews on quality in higher education, in: Harvey, L., (ed), Quality Assessment in Higher Education: Collecred Papers of the QHE Project, Birmingham: QHE.

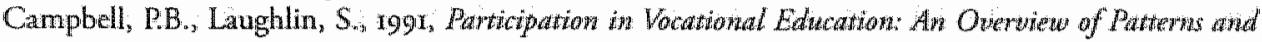
their Outcomes, Columbus OH: Naxional Centre for Research in Vocational Education.

Card, D., Krueger, A., 1992, Does School Qualiry Matrer?, The Joumal of Palitical Ecomomy; noo (r), pp. $11-40$.

Case, A., Yogo, M. 1999 , Does School Quality Matter? Returns to Education and the Characteristics of Schools in South Africa, NBER Working Paper No. 7309, National Bureau of Economic Research, Inc..

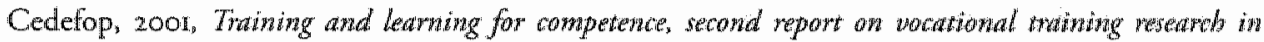
Europe: synthesis report, Thessaloniki: CEDEFOR.

Chan, K. C., Shum, C., Wright, D.I., I997, Class Attendance and Student Performance in Principles of Finance, Financial Practice and Education, $7(2)$, pp. $58-65$.

Cohn, E., Kahn, S.P., 1995. "The wage effects of owerschooling revisited, Labout" Lowownics, 2, pp. 67 76.

Collins COBULLD English Language Dicrionary, 1990.

Corte, E. de, 1990, Toward powerful learning environments for the acquisition of Problem solwing skills, European journal of psychology of education, $5_{n}$ ( 1 ), pp. 5-10.

Dearing Report, National Committee of Inquiry inw Higher Education, r997, Hghet education in the Learning society, London: The Stationery Office.

Devadoss, S., Foltz, J., 1996, Evaluation of Factors Influencing Student Class Arrendance and Performance, Americin Jotmal of Agricultural Econonits, 78(3), pp. 499-507.

Dewey, 1., 1916, Democracy and Education, The Macmillian Company.

Dochy, F, Segers, M., Bossche, P, van den, Gijlbels, D., zooy, Effects of problem-based learning: a meta analysis, Learning and Instruction, 13 , $\mathrm{pp}, 533-568$.

Dolron, P., Marcenaro , O.D., Navarro, L., 2001, The Effertive Use of Student Thme" A Stochastie Fronticer Producrion Function Case Study, Center for the Economics of Education, London: London School of Economics.

Ducatel, K., 1998, Learning and Skills in the knowledge economy. DRUID Working paper 98-2. Danish Research Unit for Industrial Dynamics, Copenhagen.

Duncan, B., 1968, Trends in Output and Distributhon of Shbooling, in Sheldon, E. B., Moore, W.E. (Eds.), Indicators of Social Change, New York: Russell Sage Foundation, pp. 601-672,

Duncan, G., Hoffman, S., 1981, The incidence and wage effects of avereducation, Economics of Education Review 1, pp. 75-86.

Dupuy, A, 2004, Assigmment and Substitution in the Labour Market, PhD thesis, Maastricht: ROA.

Durden, G.C., Ellis, L.V., 2995 . The Effects of Attendance on Student Learning in principles of Economics, Anterican Fonamic Review, 85 (2), pp. $3433-346$.

EC, 2002, Eurostat yearbook 2002 - the statistrical gride to Europe - daka xpgo-2000, Office for official publications of the European communities.

Ehrlich, I., 1975, On the relacion between education and crime, in: Juster, F.T. (ed.), Edtucation, income, and buman behatiour, New York: McGraw-Hill, pp. 313-338.

Ennis, C., 1987, A taxonomy of critical thinking dispositions and abilities, in Baron, J.B., Sternberg, R.J. (eds.) Teaching thinking skills. New York: Freeman, pp. 9-26.

Eurydice, 2002a, Key Competencies: a developing concept in general compulsory education, retricved from www.eurydice.org. 
Eurylice; $2002 \mathrm{~b}$, Two decades of reform in higher education in Europe: 980 onwardis, retrieved from www eurydice. ong

Eurydice, 2003, The Education System in the United Kingtom, retrieved from www.eurydice org.

Everwijn, S.E.M., 1999, Het hoe, wat en waarom wan competentiegericht onderwijs [The how, whar and why of competency-oriented education\}, int Schlusmans, K., Slorman, R, Nagtegaal C. and Kinkhorst, $G_{, ;}(\mathrm{eds})$, Competentiggerichte leeromgewingen [Competency-oriented learning environments), Utrecht: Uitgeverij Lemma, pp. $6 \hat{j}-78$.

Eyraud, F, Marsden, D., Sylvestre; J.-J., 1990, Occupational and internal labour markets in Britain and France, Intmational Latbour Rewiew; 129, pp. 5or-517.

Felstead, A, Gallic, D., Green, F, 20oz; Work Skills In Britain 1986-2001. Nottingham: DFES Publications.

Finni, $\mathbb{R}$, Frenetre, $M_{\text {.; }}$ 2003, Earnings differences by major field of study: Evidence from three cohorts of recent Camadiar graduates, Economics of Educotion Revieu 22 (2), pp. 179-198.

Gangl, M., 200i, European patterns of labour market enryy. A dichotomy of occupationalized vs. nonoccupationalized systems, European Societies, 3, pp $47 \mathrm{I}-494$.

Gerritsen, R., 1999, Do students study more thoroughly within a problem-based learning course, in: Hommes, J., Keizer, B.K, Petrigrew, M., Troy, J., (eds.), Edwational Irnouation in Economics and Business IV: Leakning in a Changing Environment, Dordrecht/Boston/London: Kuwwer Academic Publishers, pp. 127-141.

Goux, D., Maurin, E., 2000, Returns to firm provided training: evidence from French worker- frrm matched data, Labour Econonics, 7, pp. 1-19.

Green, F, 1998, The Value of Skills, Studies in Economics Series, Deparment of Economics, Kenn OH. University of Kent.

Green, F, McLntosh, S. Vignoles, A., 1999, Overeducation and Skills - Clarifying the Concepts, CEP Discussion Papers 0435, Centre for Economic Performance, LSE.

Green, F, Asthton, D., Felstead, A., zoor, Escimating the determinants of supply of computing, problem-solwing, communicarion, social, and teamworking skills, Oxford Ecanomic Papers, Vol. 53 (3), pp. 406-33.

Green, $F^{*}, M c I n t o s h, S \times 2002$, Is there a genuine underutilization of skills amongst the over-qualified? SKOPE Research Paper No. 30, ESRC, funded Centre on Skills, Knowledge and Organisational Performance Oxford and Warwick Universities.

Greene, W.H., 2000, Econosnetric Analysis, 4 th ed., New Jersey: Prentice-Hall.

Grogger, J.T., Eidex E., 1993, Charges in college skills and the rise in the college wage premium, Joumal of Human Resanwes, 30 (2), pp. 280-310.

Halpern, D.F. 1998 , Teaching critical thinking for transfer across domains. Dispositions, skills, structure training, and meracognitive monitoring, Americal Psychologist, 53, pp. 449-455.

Hannan, D., Raffe, D., Smyth, E., 1996, Cross-Mational Research on School to Work Transitions. Ant Analyric Framewrow, Chaprer presented at the 1996 Workshop of the Nerwork Transirions in Youth, September, Lát Ciotat.

Hanushek, E. 2002, The Failure of Input-based Schooling Policies, NBER Working Papers gou, National Bureau of Economic Research, Inc.

Hanushek, E., 2004, Some Simple Analytics of School Qualicy, NBER Working Paper so2.29, National Bureatu of Economic Research, Inc.

Hartog, J., Oosterbeek, H., 1988 , Education, Allocation and Earnings in the Netherlands: Overschooling?, Economics of Education Review, 7 (2), pp. 185-194.

Hartog, J., 1992, Capabilities, allocation, and eamings, Dordrecht: Kluwer Academic Publishers Group.

Hartog. J., 2000. Over-education and earnings: where are we, where should we go? Economics of Education Revieu, 19, pp. 13I-147.

Harvey, A., 1993, Employer satisfaction; interim report, presented to the Quality in Higher Education 24-hour Seminar, Uniwersity of Warwick. 
Harvey, L., Burrows, A., Green, D. 1993, Someone who can make an impression: report of the QHE employers" survey of qualines of higher education graduates, Repont of we Employers Survey of Qualities of Higher Eduction Graduates, Second edition, January, Birmingham: QHE.

Heckman, J., 1976, The common structure of statistical models of truncation, sample selection; and limired dependent variables and a simple estimator for such nodels. Amouls of Economic and Sockat Measwement, 5. Pp. $475-492$.

Heckman, J., Layne-Farrar, A., Todd, P., 1996, Human capital pricing equarions with an application to estimating the effect of schooling quality on earnings, The Review of Economics and Statisties; 78 ; pp. $5,62-6 \mathrm{ro}$.

Heckman, J., Lochner, J., Todd, P., 2003, Fify Years of Mincer Earnings Regressions, NBER Working papers 9732 , National Bureau of Economic Research, Inc.

Heijke, H., Koeslag, M., Velden, R. van der, 1998 , Educarion, skillis and wages, in Heijke, H., Borghans, L. (eds.), Towards a Transparent Labour Mavket for Educational Decisions, Aldershot, UK; Brookfeld, VT and Sydney: Ashgate, pp. 253-271.

Heijke, H., Meng, C., Ramaekers, $G$., 2003, An investigation into the role of humain capital conpetencies and their pay-off, Intemational fonmal of Manponser, Vol. 24 (7), Pp. 743-749.

Heijkc, H., Meng, C, Ris, C., 2003, Fitting to the Job: the role of generic and wocational competencies in adjustment and performance, Labour Economics, no (2), pp. 215-229.

Heijlke, H., Ramaekers, G., Ris, C., 2005, Do Business Administration Studies, Offer Better Preparation for Supervisory Jobs than Traditional Economics Studies?, Education Economics, 13 (3), pp. 315-329.

Heijke, H., Meng, C., (forthcoming), The effects of higher educational programme characteristics on allocation and performance of the graduates; Reseatrh Memorowdum, ROA Masustricht.

Hövells, B., 2003, The Knowledge Econony: learning and work integrated, Preparatory background chapter for the 2003 WACE conference in Rotrerdam.

James, E., Alsalam, N., Conaty, J.C., To, D.L.L., 1989;, College quality and future earnings: where should you sent your child to college?, American Economic Rewiens, 79, pp. 247-252.

Johnson, W:R., 1979, The demand for general and specific education with occupational mobility, Revieu of Economic Studies, 46 . pp. 695-705.

Jorgenson, D.W., Fraumeni, B.M, I.992, Investment in education and U.S. economic growth, Scandinavian Jaurnal of Econamics, 94 (Supplement), pp. $5 \mathbf{1}-70$.

Jovanovic, B., 1979; Job marching and the theory of curnover. Journal of Political Economy, 87, pp. $1246-1260$.

Jovanovic, B., 1984, Matching, thrnever and unemployment, fowmal of Political Economy, 92, pp. 10822.

Juster, F. Stafford, F, iggr, The Allocation of Time: Empirical Findings, Behavioral Models, and Problems of Measurement, Joumal of Economic Literature, XXIX (June), pp. 471-522.

Kessels, J.W.M.; 1998, Opleiden in een kenniseconomie. [Education in a knowledge economy] in: Gent: van B., Zee, van der H.J. M. (eds.), Comperentie en arbeidsmarkt. Een multidisciplinatre wiste op ontwikkelingen rond mus en werk [Competencies and labour market. A multidisciplinary wision on evolvements around human beings and work], Den Haag: Elsevier Bedrijfsinformatie, pp. 75-8 $\mathrm{n}$.

Kessells, J.W.M., Wijngatrden, P. wan, 2003, A competency-based approad to cooperative education in the university curriculum, Chapter presented at we 2003 WACE conference in Rotterdam.

Kim, A. Kim, K.W., 2003, Returns to tertiary education in Germany and the UK: Effects of field of study and gender, MZES Working Paper Series, Nr. 62, Mannheimer Zentrum for Europaitische Sozialforschung, University of Mannheim.

Kitayama, S., Matsumoto, H., Markus, H.R., and Norasakkunkit, V., 1997, Individual and collecrive processes in the construction of the self: self-enhancement in the United States and self-criticism in Japan, Journal of Personalicy and Social Psychology 72 , pp. 1245-1267.

Latin, J., Carroll, J., Green, P., 2003, Analyzing multivariate data, London: Brooks/Cole - Thomson Learning. 


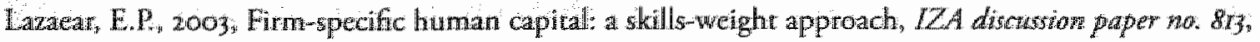
Bonn: IZA.

Leckey, J.F., McGügan, MA, 1997, Right Tracks - Wrong Rails: The Development of Generic Skills in Higher Education, Rexearch in Higher Edwation, 38 (3), pp. $365-378$.

Levy, R, Mumane; RJ, 2oo, Key Competencies Critical to Economic Success, in: Rychen, D.S., Salgank. L.H., (eds.) Defining and seletting key competencies, Göttingen: Hogrefe \& Huber Publistiers, pp. 151-173.

Lochner, L, Morett, E, zaor, The effect of education on crimer evidence from prison inmates, arrests and self-reports, W78605, Cambridge, MA: National Bureau of Economic Research.

Lucas, R.E, 1988, On the mechanics of economic development, Joumal of Monetary Economics, 22, pp. $3-42$.

Lundvall, B., Johnson, B, 1994, The Learning Economy, Joumal of Industrial Studies, 2, pp. 23-42.

Lynd:, L, 1992, Priwate sector training and earnings of young workers, American Economic Review, 8 2, pp. 299-312.

Maddala, G.S., Lee, L., 1976, Recursive models with qualitative endogenous variables, Ammals of Economic and Social Measurement, si pp. \$25-545.

Mane, F., 1998, Trends in the payoft to academic and occupation-specific competencies: the shorr and medium run returns to acadsmic and vocational high school courses for non-college-bound students, Economics of Education Review, $18, \mathrm{pp} .417-437$.

Marsden, D., I99o, Institutions and labour mobility. Occuparional and internal labour markets in Britain, Prance, Itally and West Germany, in: Brunetta, R, Dell'Aringa, C., (eds.), Labour relations and economic penformance. Houndsmills: Macmillian, pp. 414-438.

Maurice, M., Sellier, F. Sylvestre, J.J., 1982, Politigue d"édtuation et organisation industrielle en France et en Allenagne, Paris: Presses Universiraires de France.

McCall, M.W., Lombardo, M.M., Morrison, A.M., r988, The Lessons of Experience, How Successful Execuitues Develop on the Job, New York: The Free Press.

Mchntosh, S., Vignoles, A., 20or, Measuring and assessing the impact of basic skills on labour market outcones, Oxford Econowic Papers, Vol. 53 (3), pp. 453-81.

Meeusen, W., Broeck, J. van den, 1977, Efficiency Estimation from Cobb-Douglas Production Funcrions with Composed Error, International Economic Reviute, 18, pp. $435-444$.

Meng, $\mathrm{C}$, Heijke, $\mathrm{H}_{\text {. }}, 200$; , Student time allocation, the learning environment and the acquisition of competencies, ROA-RM-20os/RE, ROA, Maastricht.

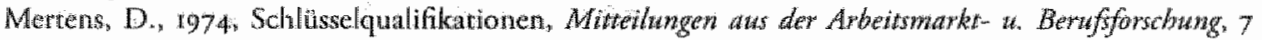
$(\mathrm{H}, \mathrm{I}), \mathrm{pp} \cdot 36-43$.

Mertens, D., 1999, labour competence : emergence, analytical framework and institutionall models, ILO (Cinterfor/LO).

Milter, R.G., Stinsons, J.E., 1995, Education leaders for the new comperitive environment, in: Gijselaers, W.H.,Tempelaar, D.T., Keizer, P.K., Blommaer, J.M., Bernard, E.M., Kasper, H., (eds.), Eatucational Inmowation in Econowits and Business Administration: The Case of Problem-Based Learning, Dordrecht: Kluwer Academic Publishers.

Mincer, I. 1970, The distribution of labour incomes: a surwey with special reference to the human capital approach, Journal of Econowic Literature, 8 (r), pp.I-26.

Mincer, J., 1974, Schooling, Experience and Extmings, New York: Columbia University Press.

Mortensen, D., 1986, Job search and labour marker analysis, in: Ashenfelter, O., Layard, R., (eds.) Handbook of Labour Economics, wol. 2, Amsterdam: North Holland, pp. 849-920.

Moulton, B., 1986, Random Group Eftects and the Precision of Regression Estimates, Journal of Econownetricis, 32, 2, pp. 385-397.

Mulligan, C., Schneider, B. Wolfe, R, zooo, Time Use and Population Representation in the Sloan Study of Adolescents, NBER Technional Working Paper 265 . 
Murnane, R. J., Willet, J.B., Levy, F, 1995, The growing importance of cognitive skills in wage detemination, Reviez of Economics and Statimics, 77 (2) pp. $251-266$.

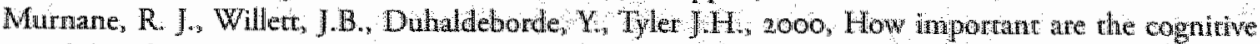

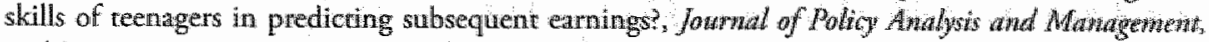
19 (4), pp. 547-568.

Murnane, R. J., Willet. J B., Braatz, M.J, Duhaldeborde, Y, 20or, Do different dimensions of male. high school students skills predict labour market success a decade later? Evidence from the NISY, Economics of Edtucation Renieu, 20 (4), pp.31 -320.

Murphy, K., Topel, R, 198 ; Estimation and inference in two step econometric models, Jowrual of Business and Econowic Statistics, 3, pp. 370-379.

Mitller, W, Shavit, Y, 1998, The Institutional Embeddedness of the Stratification Process: A Comparative Study of Qualifications and Occupations in Thirteen Courtries, in: Shavit, $Y_{\text {., }}$ Müller,

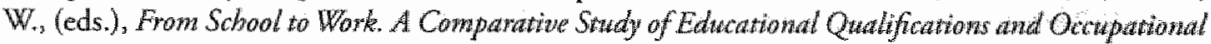
Destinations, Oxford: Clarendon Press; ppi I-48.

Müller, W., Steinmann, S., El, R., 1998, Education and labour market entry in Germany, in: Shavin, Y., Müller, W., (eds.), From School to Work: A Companative Sindy of Educational Qualifications and Occupational Destionations, Oxford: Clarendon Press, pp. 143-188.

Neal, D. A., Johnson, W.R., 1996, The role of pre-market factors in black-white differences, Joumal of Political Economy 104 (5), pp. 869-895.

Norman, G.R., Schmidt, H.G., 2000 , Effectiveness of problem based learning curricula: theory, practice and paper darts, Medical Educavion, 34 ( $(9)$, pp. $721-728$.

Nunually, J.C., 1978, Psychometric Theory, 2nd ed, New York: McGraw-Hill.

OECD, 2004, Lifelong learning, OECD Policy Brief february 2004 .

$\mathrm{O}^{\prime}$ Neill, $J$, 1990. The role of human capital in earnings differences between black and white men, Journal of Economic Perspectives, 4 (4), Pp. $25-46$.

Payne, J., 2000 The unbearable lightness of skill: the clanging meaning of skill in UK policy discourse and some implications for education and training, Joumal of Education Policy, 15, pp, 353-369.

Petcy, W, 1662, A Treatise an Taxes and Contributions, London.

Pietro, G. di, Urwin, P, 2002, Education and Skills mismatch in the Iralian Graduate Labour Marker, paper presented at the Policy Studies Institute, Employment Group Seminar Series, October 2002.

Pischke, J.-S., 2000, Continuous training in Germany, IZA Discussion Paper, woL 137, Bonn: IZA.

Planas, J., Giret, J.F, Sala, $G$., Vincencs, $G_{2}$ 2000, The skills marker: dynamics and regulation, in: Descy, P. Tessaring, M., (eds.), Training and Learning for competence. Second report on wacational education and trawing research in Europe: synthesis repor, CEDEFOP Reference series, Luxemboung: EUR-OR, pP. 313-381.

Pratzner, F.C., 1978, Occupational Adaptability and Transferable Skills: Project Final Report, Information Series I29, National Center for Research in Vocational Education, "The Ohio State University.

Prosser, M., Trigwell, K., 1999, Understanding Learing and veaching: the experience in bigher edwathow, Buckingham: SRHE and Open Universicy Press.

Rainbird, H., 1994, The social construction of skill, Paper presented for the CNRS conference 1994.

Ramsden P, 2003, Learning to teach in higher education, London: RoutledgFalmer.

Report of the Expert Panell on Skills, 2000. Stepting Up Skills and Oppowntivies in the Knowlledge Economy "Her Majesty the Queen in Right of Canada (Industry Canada).

Rey, B., 1996, Les compétences transversales en question. Collection Pédagogies. Paris: ESF éditeut.

Romer, P., 5990, Endogenous rechnological change, Joumat of Poltitical Econowy, 99 (5, pe T.T), pp. S7TSroz.

Romer, D., 1993, Do Students Go to Class? Should They?, Joumal of Economic Perspectives, $7(x)$, pp. $167-174$.

Rosen, $S_{3}$ 1.983, Specializarion and human capital, Jostmal of Labour Economics, I (i), pp. 43-49. 
Rumberger, $\mathrm{R}$, 1987 , The impact of surplus schooling on productivity and eamingrs, fow rad of Hanan Rewources, $22(1), \mathrm{pp} .2450$.

Rumberger, $\mathrm{R}$, Thomas, SL, rgg:, The economic retums to college major, quallity and performance A mulrilevel analysis of recent graduates, Economics of Education Revieu, 12, pp. 1-19.

Rychen, D.S, Salganik, L.H, 2003 ; A holistic model of competence, in: Rychen, D.S., Salganik, L.H., (eds.) Key conpetencies for a successul life and a well-fanctioning socieny, Götingen: Hogrefe \& Huber Publishers.

Say, J.-B., I802, A Treatise on Political Economy, English translation of the $4^{\text {th }} \rightarrow 5^{\text {th }}$ ed., 1885 edn, Philadelphia: Grambo \& $\mathrm{Co}$.

Schmidr, RM. 1983, Who Maximizes What A Srudy in Student Time Allocarion, American Economic Revilew, $73(2)$, Pp. 23-28.

Schmidt, H. Bouhuijs, P., 1985 , Ondeywijs in takakerichte groepen. Spectrum, Utrechr and Antwerp: Aula Books:

Schultz, T.W., I96r, Inwestment in human capital, The American Ecomomic Review. 11, pp. $11-17$.

Shaughnessy, K.C., Levine, D.I. and Cappelli, P., 2001, Changes un managerial pay structures 1986 1992. and rising returns to skill, Oxford Economic Papers, Vol. 53 (3), pp. $482-507$.

Sicherman. $N_{\text {, }} 1991$, "Overschooling" in the labour market, Journat of Labour economics, 9 (2), pp. 1.01-122.

Smith, A, 1776, An Inquitry into the Nature and Causes of the Wealth of Nations, Glasgow edition, Oxford: Clarendon Press.

Smoorenburg, M.S.M. van, Velden, R. van der, 2000, The training of school-eavers, complementarity or substitution? Econonics of Education Revietw 19, pp. 207-217.

Spence, A., 1973. Job Market Signaling, The Quarterly Journal of Economics, vol. 87(3), Pp. 355-74.

Squires; G., 1987, The Curriculum. Beyond School, London: Hodder and Stoughton.

Stasz, C., Ramsey, K., Eden, R., DaVanzo, J., Farris, H., Lewis, M., 1993, Classirooms that Work: Teaching Generic Skills in Acadernic and Vocational Setrings, MR-r6g-NCRVE/UCB, Santa Monica CA: RAND.

Stasz, C., 1998, Generic skills at work: implications for occupationally-oriented education, in Nijhof, W. J., Streumer, J. (eds.), Key Qualifications in Work and Education, KJuwer Academic Publishers, Dordrecht, pp. 187-206.

Stasz, C., 200I, Assessing skills for work: two perspectiwes, Oxford Economic Papers, 53 (3), pp. 385-405.

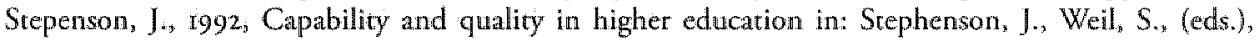
Qualiny in Exrning: A capabitity Approach in Higher Edwation. London: Kogan Page, pp. I-9.

Sternberg, J. R., 2003, "What is an expert student", Editutionat Resedrcher, 32 (8), pp. 5-9.

Sunday Thmes, 2003, The Sunday Thimes Unimersity Leagne Table, in Sunday Tines edicion of $1.4 .09 .200 \%$

"Teichler, U., 1999, Higher education policy and the world of work: changing conditions and challenges, Higher Education Policy, 12, pp. $285-312$.

Thurow, L. C. 1975. Education in Production, Joumal of Political Economy 78 (1), pp. $35-59$.

"Topel, R., 1986, Job mobiliry, search and earnings growth" Research in Lathour Ecomomias 8, pp. 199-233.

Tsang, M., Levin, H., 1985, The economics of overeducation, Economics of Edwation Revitu, 4, pp. 93:104.

Vatstra, R., Vries, R. de, (2003). De relatie russen onderwijsvorm, competenties en arbeidsmarkr lThe relation berween educational form, competencies and the labour marker]. Tijolschrift woor Hoger Onderwijs, 2t, (i), pp 144-158.

VSNU, 2003, WO-Monitor 2000-200r, Utrecht: VSNU.

Weel, B. ter 2002 , The computerization of the labour anarker, PhD thesis, Mastricht: Maastricht Universiry.

Weinert, E E, zoor, Concept of Comperence: A Conceptual Clarification, in: Rychen, D. S, Salganik, L.H., (eds.) Defining änd selecting key competenckes, Göttingen: Hogrefe \& Huber Publishers, pp. 43-65. 
Welch, F, 1975, Human capital theory edication, discrimination and life oydes, Amertoda Evowomic Review, Paper and Proceedings $\mathbb{L X V}(\mathrm{B}), \mathrm{PP}, 63-7$, .

Werfhorst, H.G. van, 2002, Fields of study, acquired skills and the wage benefie from a matching job, ACTA Sociologita, 45. pp. 287-303.

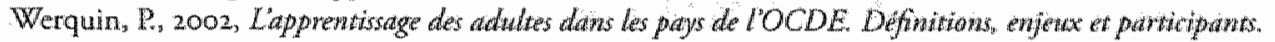
Rennes: Céreq.

Whetten, D.A, and Cameron, K.S., 1995, Developing Management Skilk, New York: HarperCollins College Publishers.

Willis, R.J., 1986, Wage Determinants: A Survey and Reinterpretation of Human Capical Earnings Functions, in: Ashenfelter, O. Layard, $\mathbb{R}_{\text {. }}$ (eds.). Hotndbook of Labour Econownics, pp. 525-602.

Woerden, W. van, 1997, De ontwikkeling van acriverend onderwijs: probleemgestuurd leren en projectonderwijs [The evolucion of activating education; problem-based leaning and project-based edica tion], in: Ten Dam, G.T.M., Van Hout, J.FM.J., Terloww, C., Willems, J. (eds.). Onderwiyshunde Hoger Onderwijs [Educationally based higher education]. Assen: Van Gorcum, pp. 186-213.

Wolbers, M. 200y, Job Mismarches and ther Labour-Market Effects among Schooll-Leavers in Europe, European Socialogical Review, 19 (3). pp. 249-266.

World Bank, 1998, World Development Report ygg8/gg: Knouledge for Developmen, New York: Oxford Universiry Press.

Wösmann, L., 2002, Schooling and the quality of buman capital, Berlin: Springer. 
$\because \quad \cdots \quad \therefore$

$$
\begin{aligned}
& \therefore \quad \therefore \\
& \cdots \quad \cdots \\
& \frac{1}{3} \quad \therefore \quad \cdots \\
& \therefore \\
& \therefore \quad:
\end{aligned}
$$




\section{Annex: The CHEERS questionnaire}

This annex shows the questionnaire of the CHEERS study that was used in the United Kingdom. Some of the examples of questions and answers presented in the questionnaire below may have been slightly adapted in other countries to match the national setup of the higher education system or training system. The original questionnaires used in Austria, Czech Republic, Germany, Spain and Sweden are available from the CHEERS website: http://www.uni-kassel.de/wzr/tseregs.htm. The Dutch questionnaire is awailable on request from the author. 


\title{
Higher Education and Graduate Employment in Europe
}

\section{Survey of Graduates in ... [NatCat]}

\author{
(Rovised Master Qhesitionnaire, 29, 10,1996 )
}

[NatCat $=$ where national adaptations are needed]

Dear Graduates, NatCat the whole cover page is opronal]

As heads of the research group. we request your participation in a representarive sumey of persons graduating in 1994 or 1995 from institutions of higher education in 11 European cowniries and in dapan.

In reporting the experiences you personally made in the course of your study and after graduation you might contribute to a representative feedback most valuable for those responsible in higher edication and as well for those setring the framework conditions for employment and other life spheres.

The survey is undertaken in Austria, Czech Republic, Finland, France, Gerpnany, Italy, Japan, Nomay, Spain. Sweden, the Netherlands, and in the United Kingdom. In your commo; researchers from the Open University [NatCat] are responsible for the data collection and analys is. The project is financially supported by the European Commission. Directorate General XII through the Targeted Socio-Economic Research Programme.

We assure you that your replies will be used anly in the framework of this research project. The results will be pwblished in such a way that identification of individual persons is excluded.

YOUR INFORMATION WILL BE TREATED STRICTLY CONFIDENTIALLY.

If you wish we will send you a summary of the most important results. Please retum the completed questomatre as soon as possible to the address mentioned below.

Thank you very much for you" kind support.

Signature

John Brentan [NatCat]

Sernd the questionware to:

[Nabcat]rohn Homenn

The Open University, Quality Support Centre

344-354 Gruy's lam Koad, WCIX 3BP London

$0171.472506-\operatorname{Fax} 0171.837 .0290$

gatual jill.brennan@open.ac.uk [NatCan]
Signature

Prof: Dr. Ulrich Teichler

Prof. Dr. Ulrion Toichler

Project Comordinaion

Uniwersity of Knssal,

Germany 


\section{Explanatory Notes [NatCat this notes are optional]}

\section{How tong does it take to fill in the questionnaire?}

Mast of you will need abont one hou - less than a movie. It dopends of course on the knd of experiences you hove made diung the last years.

We have deweloped a high standardized auestionmane, which manty expect from you to wark boxes which refer to relewant answers. With this appratach we hope that we have ntate it easy for pow to answer the questions.

\section{How' to answer the questions?}

Please answer all questions applicable to vou. In some cases, you will note that the questionnaire suggests you to disregard some questions not applicable to you (e.g. $\rightarrow$ Go ro QUESTION ....).

Since the questionnaire will be captured with the help of a scamer, pleasefill it in peadable.

If questions are itemised, please mark the most appropriate answer hike this $\rightarrow X$.

In some quesions we have employed answer scales from $/$ to 5 (eg I = wery good to 5 a wery bad).

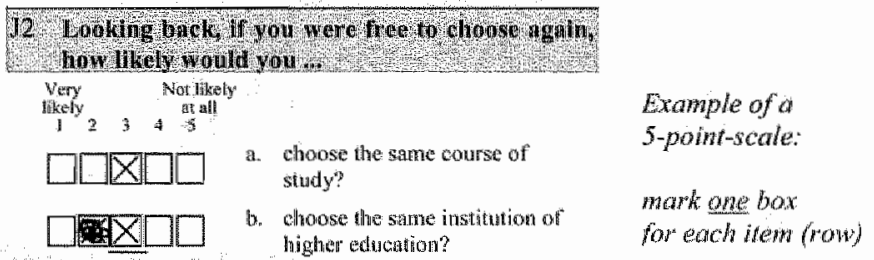

If you would like to correct your answer, make the wrong one black and mark and wulderscore the right one:

In some cases we ask you for mumbers andy e.g. 02,98

and in ohers we leave space for you to write an ans wer (....................).

If you are asked for numbers, please fill in $\mathrm{O} O \mathrm{O}$ if your answer" wawd be "zere".

If the space for your replies is not sufficient, please inctide an additional shege of paper.

\section{Your comments and additional information are welcome}

This questionwate is used in more than 12 countries with a wide range of differew fields of study and differen institutions of higher educalion. We could not take isto consideration ewery specific detail of study and work, which anght be velevan for the survey. Therefore we would appriciate your commests and additional information. 
4

\section{Educational Background prior to Study}

Please ponowde informalion on you educational developinent and your work experiences bejore your first enrolmen in higher edwcation.

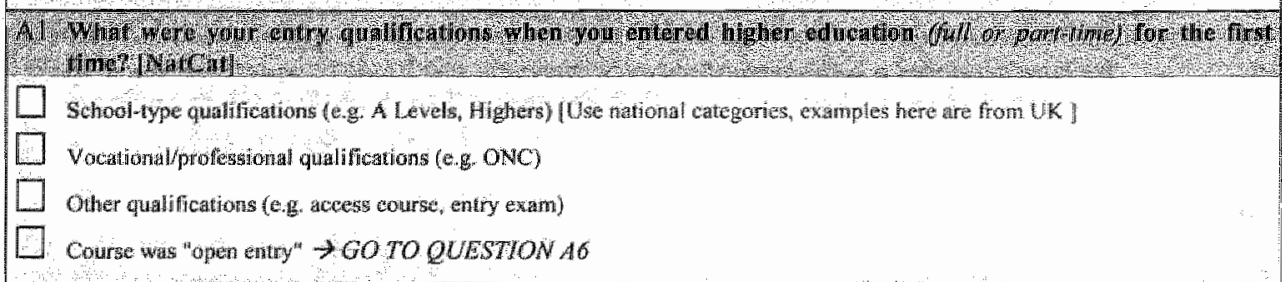

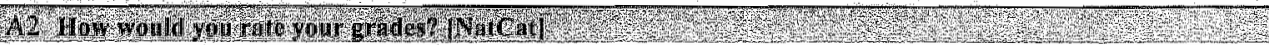

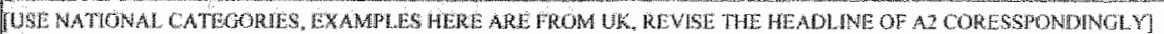
DHagh
$\square$ Medium
DLow

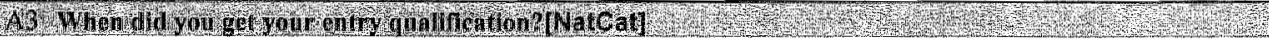

L Monti $19 L \perp$ Y Y Y

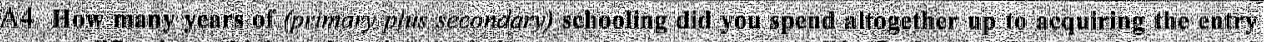

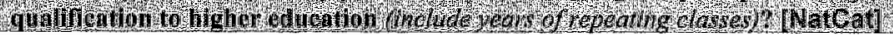

L_.

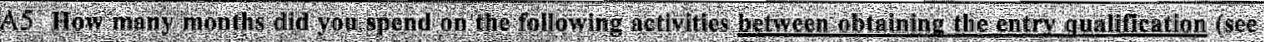

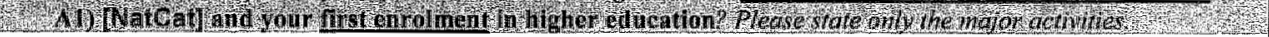
Monthe

$L+1 \mid$ Other education/training/apprenticeship: (pleats grkestify)

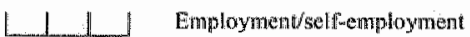

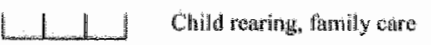

L.1. Military on chillian servere [NatCal]

L_ l_ _ Not employed, seeking employntent

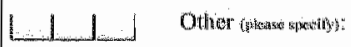

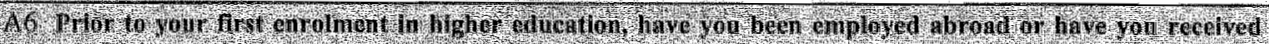

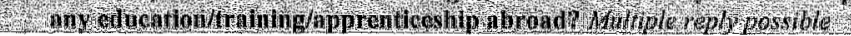

$\square$ No $\rightarrow$ GO hO QUESTION B

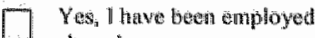
abroad:

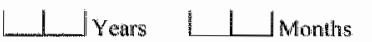

Connitry:

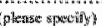

$7 \mathrm{res}, 1$ received education/training/ appprenticeship abrodad.

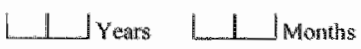

Country: (p) sease spotiby 


\section{B. Higher Education Courses Taken}

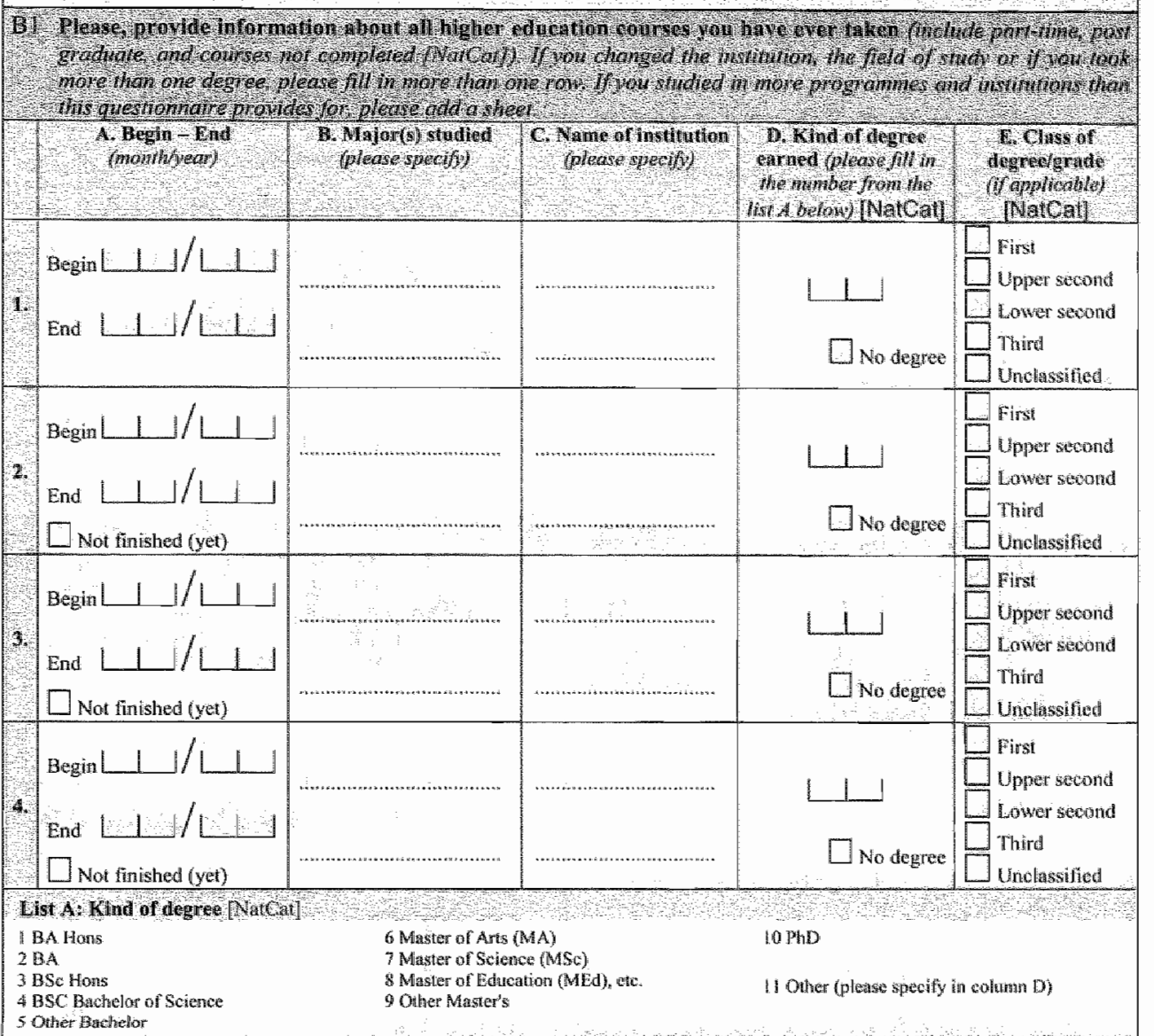

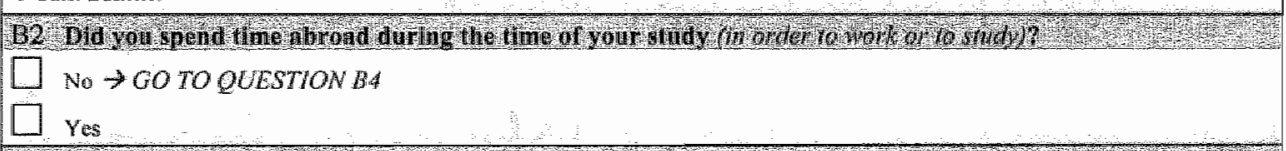

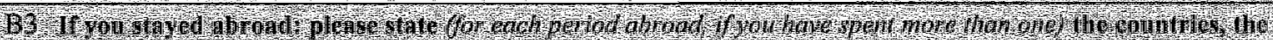

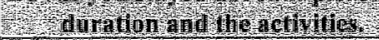

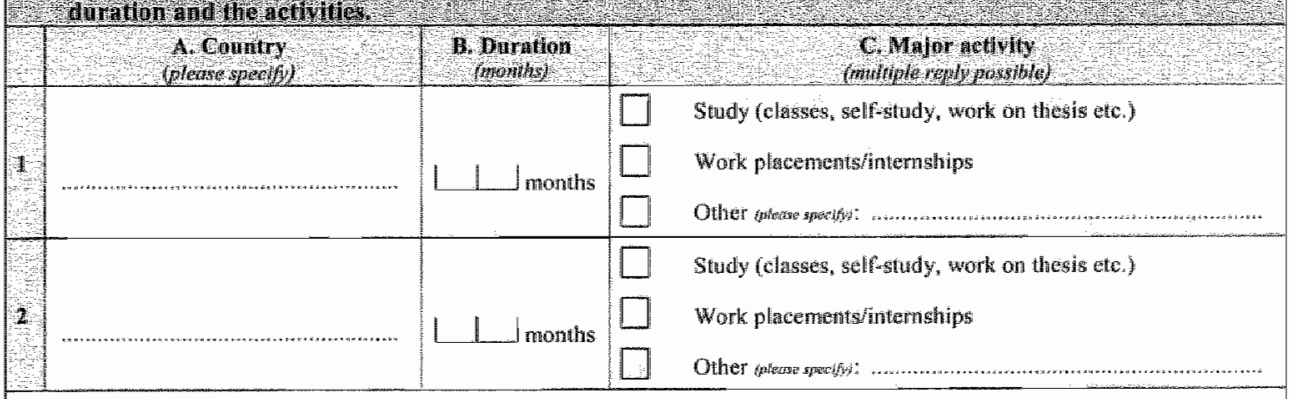




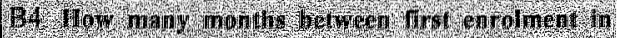
higher eductilon and gradunion 1996 or 1995

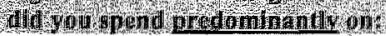

\begin{tabular}{|c|c|}
\hline bonition & \\
\hline & 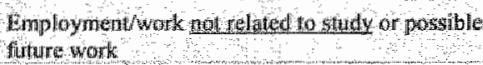 \\
\hline & $\begin{array}{l}\text { Employmen/work reltede to study or possibie } \\
\text { future work }\end{array}$ \\
\hline & 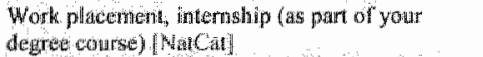 \\
\hline & Chisd returing fanioly care \\
\hline & Military or eivflan service [NatCal] \\
\hline & Not enployed, seeking employment \\
\hline 1 & 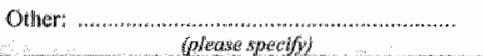 \\
\hline
\end{tabular}

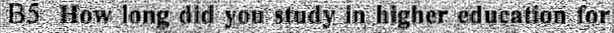

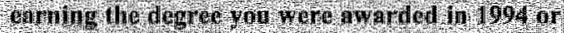

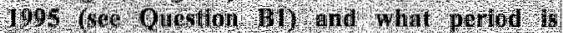

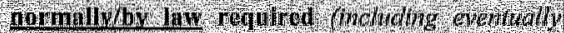

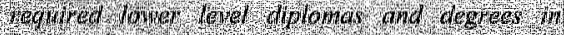

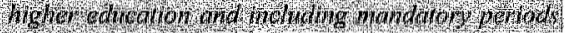

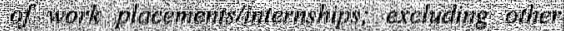

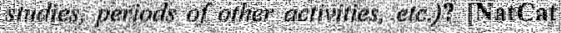

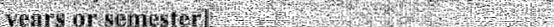

II actually studied

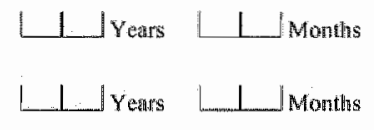

Normally/by law

required anre

[NTICAs]

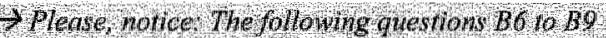

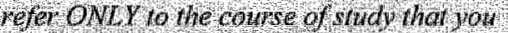

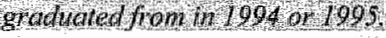

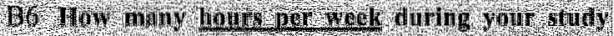

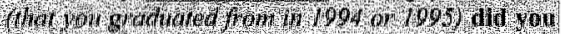

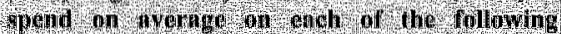

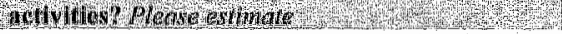

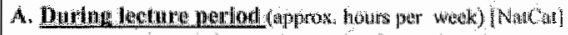

\begin{tabular}{|c|c|}
\hline & Major subjects: aftending lectures \\
\hline & $\begin{array}{l}\text { Major subjetts: ather shicly activities (inac. self- } \\
\text { studtes etc) }\end{array}$ \\
\hline & Other whyeds \\
\hline & 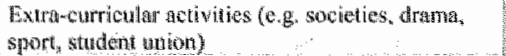 \\
\hline & $\begin{array}{l}\text { Employment/work (excluding work } \\
\text { placements/uternships) }\end{array}$ \\
\hline & 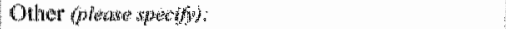 \\
\hline
\end{tabular}

A outside lecture period fapprox. hours per week horras

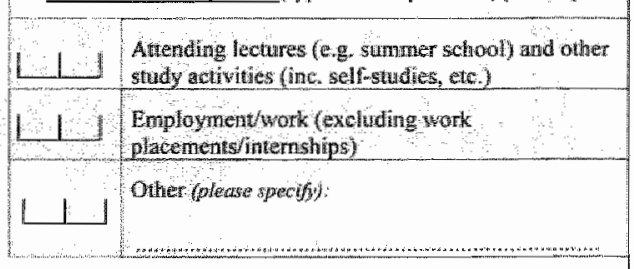

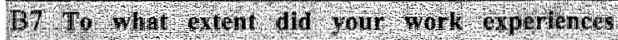

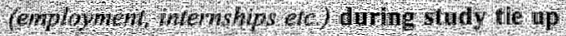

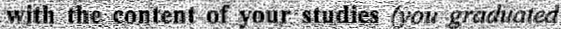

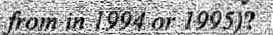

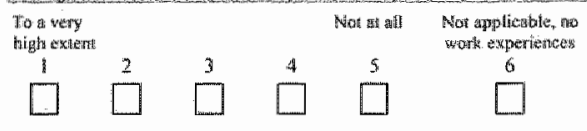

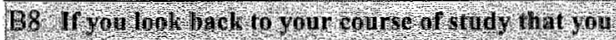
grad wated fom 11 1994 or 1995, to halat extent Were the following nodes of tohilin and

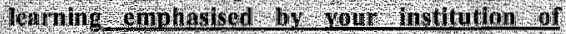

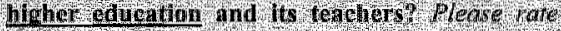

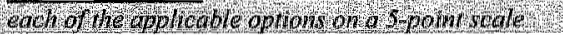
Togivery
high
exientil

$\square \square \square \square \square$ a. Faets and instrumental knowledge

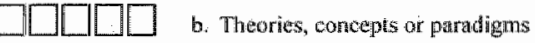

- $\square \square \square$ c. Attitudes and sociocommunicative skills:

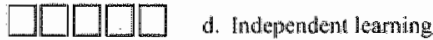

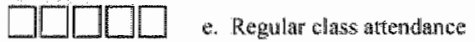

$\square \square \square \square \square$ fi. Teacher ats the main source of information and understanding

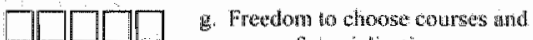
areas of specialisation

h. Project and problem-based learning

i. Direct acquisition of work experience

j. Out-of-ellass communication batween students and staff

k. Writing a thesis [NatCat; Thesis or other substantial academic assignment?

1. Detailed regular assessment of acadernic progress 


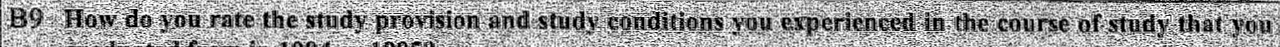

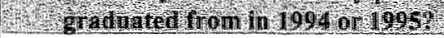
$\sqrt{x+2 y}$
Wery
$1,3,4$
$\square \square \square \square \square$
a. Acsademic advice offered in genteral
$\square \square \square \square \square$
b. Assistaricedadvice for your final examination
$\square \square \square \square \square$
c. Course content of major
$\square \square \square \square \square$
d. Variety of courses offered
$\square \square \square \square \square$
e. Design of degree program
$\square \square \square[\square$
f. Testing/grading system
$\square \square \square \square \square$
g. Opportunity to choose courses and areas of specialization
$\square \square \square \square \square$
h. Practical emphasis of teaching and learning
$\square \square \square \square \square$
i. Teaching quality
$\square \square \square \square \square$
j. Chances to participaie in research projects
$\square \square \square \square \square$
k. Research emphasis of teaching and learning
$\square \square \square \square \square$
1. Provision of work placements and other work experticnce
$\square \square \square \square \square$
m. Opportunity of out-ofeclass contacts with teaching sidetf
$\square \square \square \square \square$
n. Contacts with fellow students
$\square \square \square \square \square$
o. Chance for students to have ank inpact on university policies

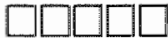
p. Equipment and stocking of libraries

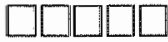
q. Supply of teaching ntraterial
$\square \square \square \square \square$

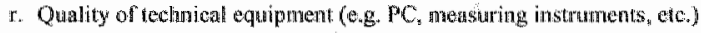

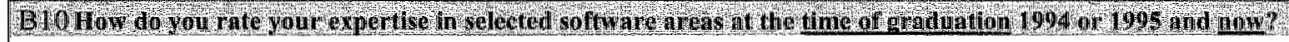

\section{Ar time of griad uation 1994 or 1995}

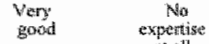

gatida

$\square \square \square \square$

5

a. Word processor

$\square \square[\square \square]$

b. Programming languages

$\square \square \square \square \square$

a. Spresad shem

$\square \square \square \square \square$

4. Denta brase

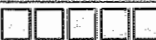

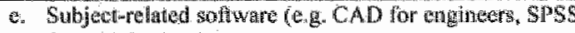
for social scitentisis)

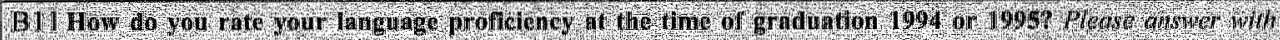

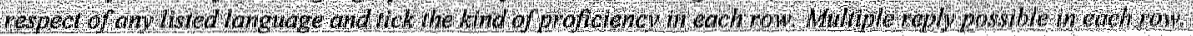

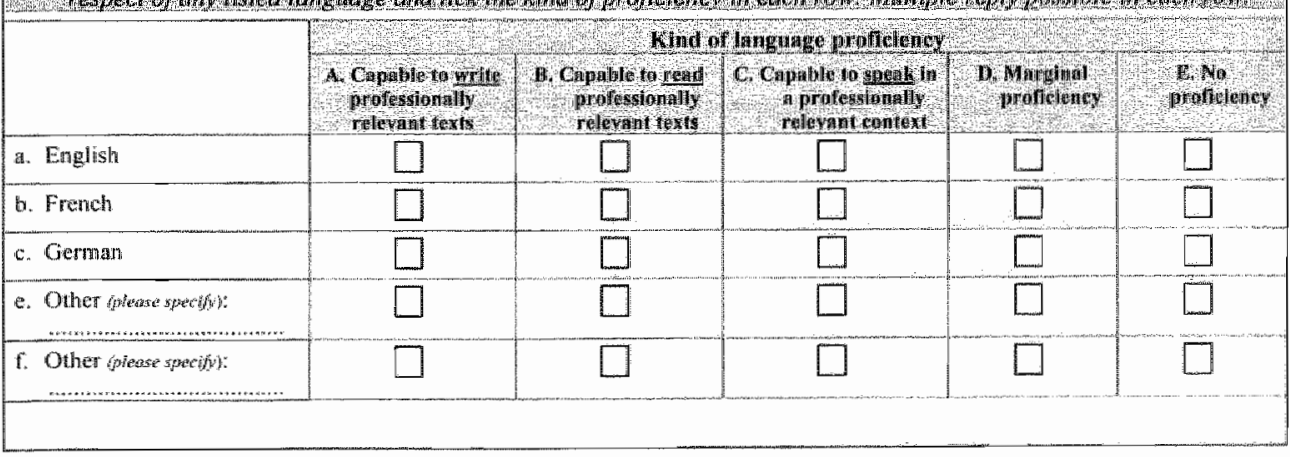




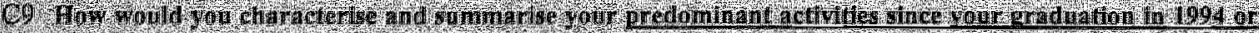

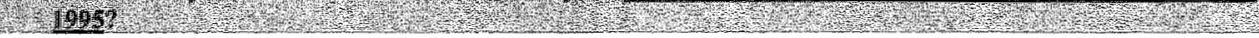

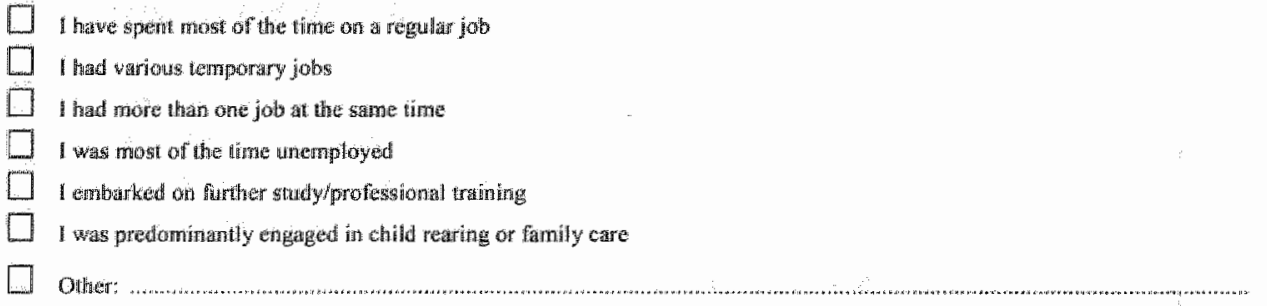

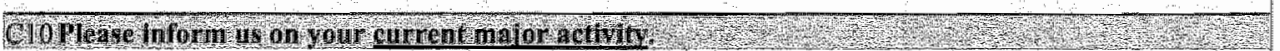

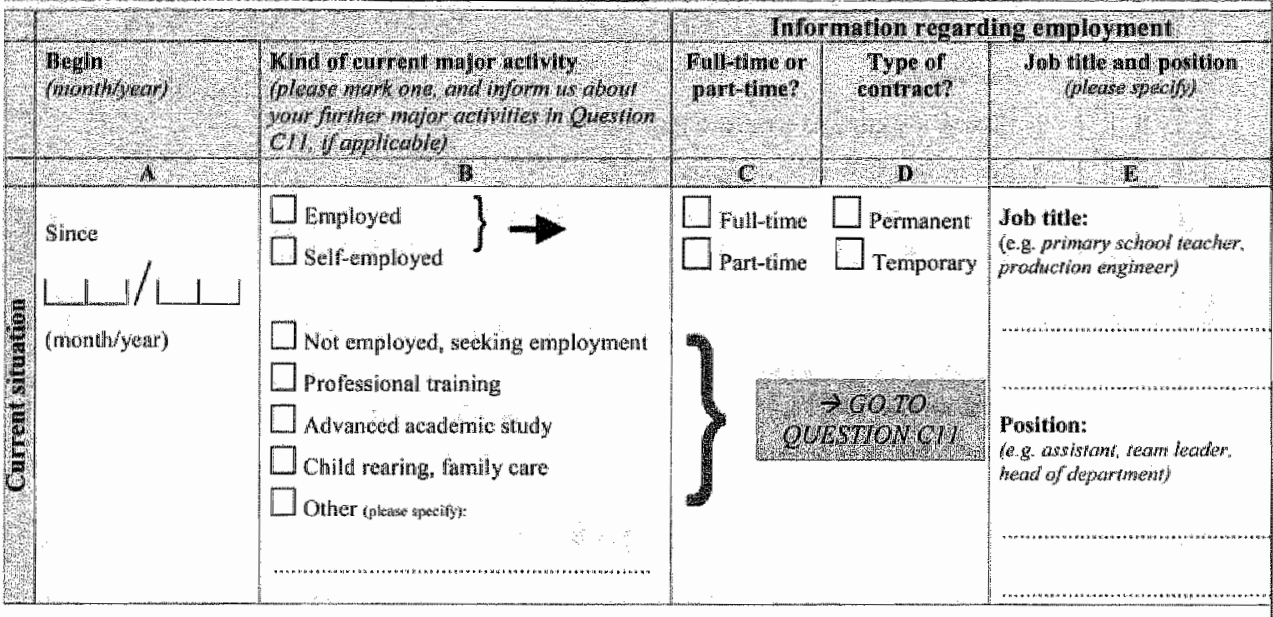

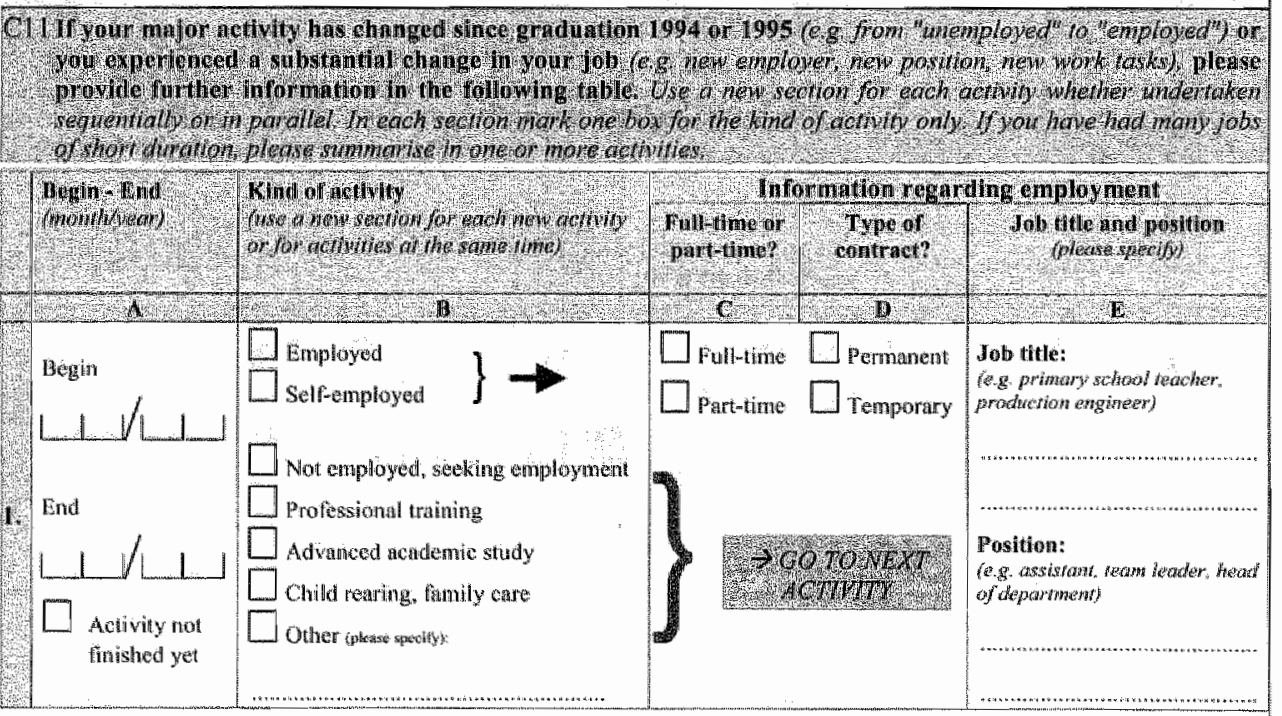




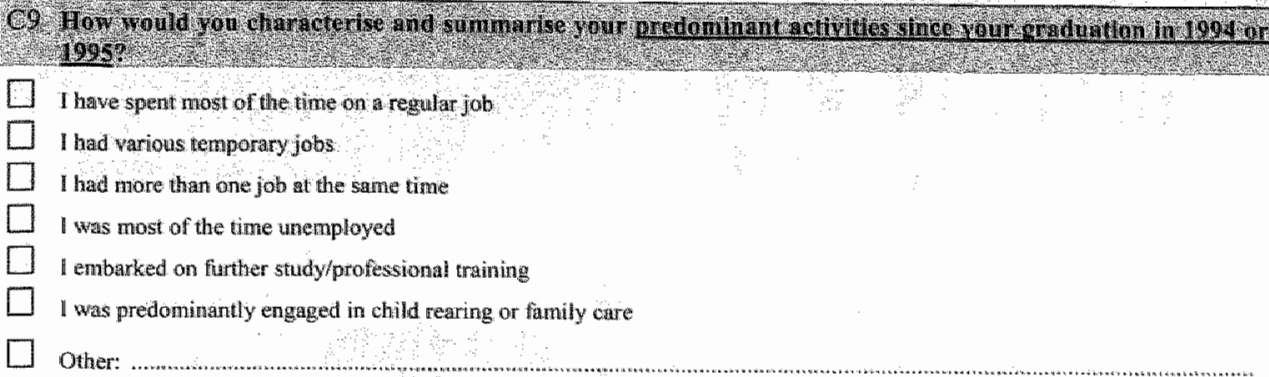

\section{C10 Please iform us oin youn curremt maner activity.}

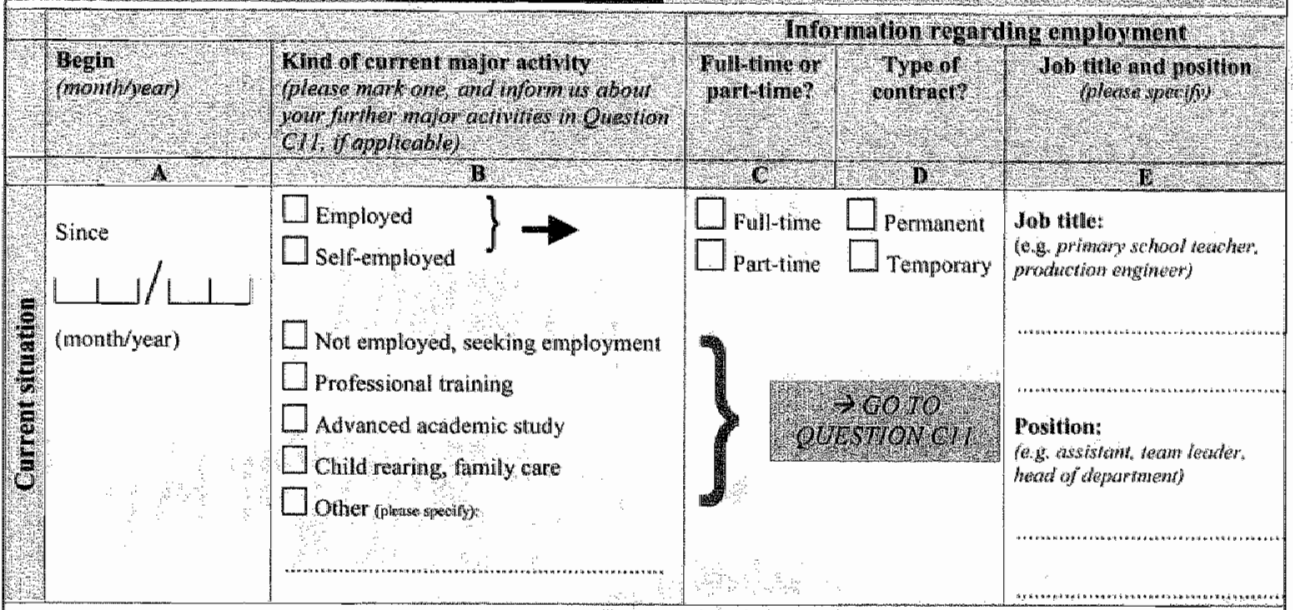

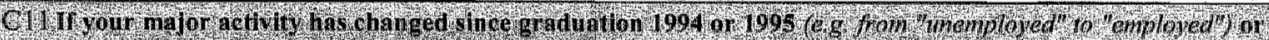

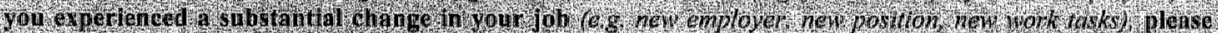

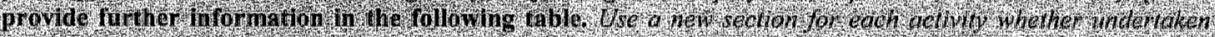

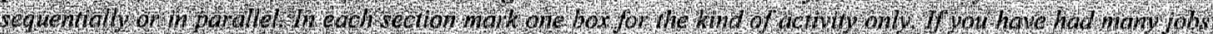

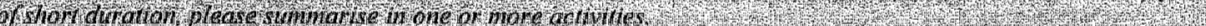

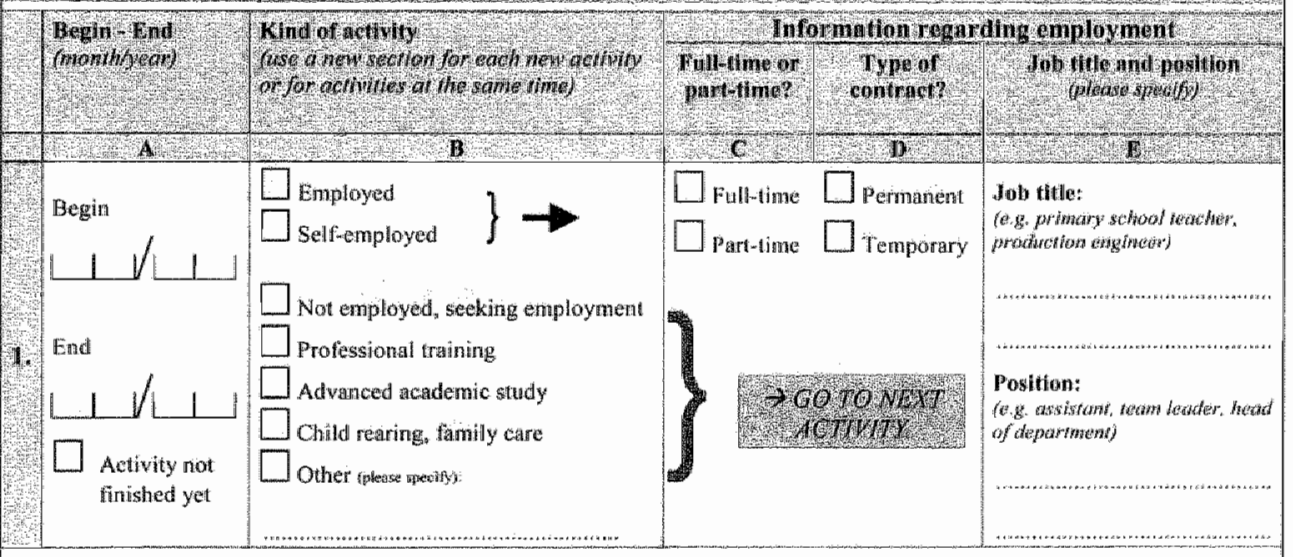




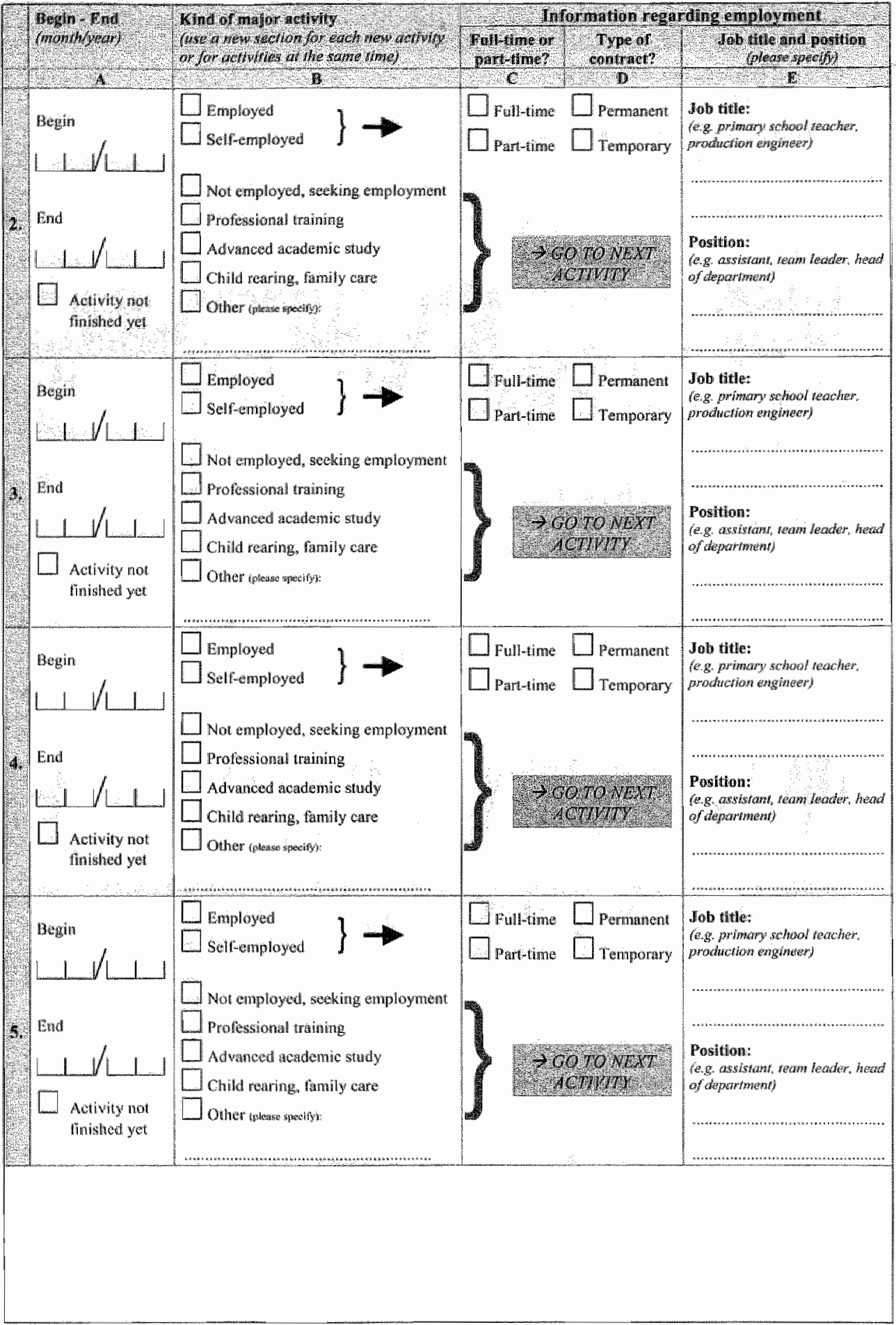




\section{Current Activities, Employment and Work}

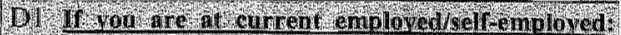

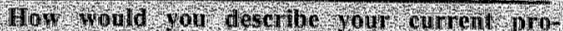

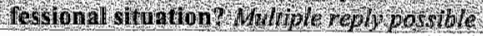

I thave a regular employmend/l am selfemployed

I hive casual gobs related to my study"

Thave casual jobs mol reated to my study

I have more than one job

I an currently doing military or civilian service

Other:

(phiterese ifecily?

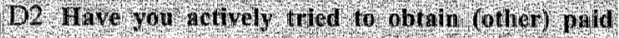
work In the wast 4 weds?

\section{$\mathrm{N} \rightarrow$ PLEASE GO TO QUESTION D}

No, but I am awaiting the results of easlier job applications

Yes, and 1 could start working within the nexi two weeks

Yes, but I could not start working within the next two weeks

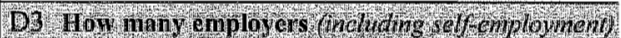

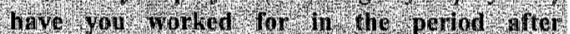

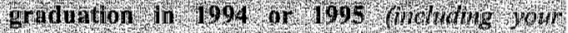

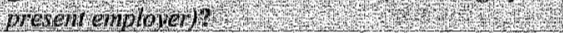

L. I. I Number of employers

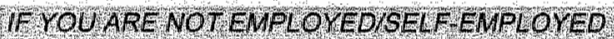

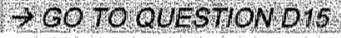

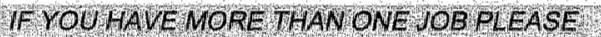
REFER TO YOUR MAORNOB

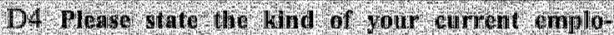

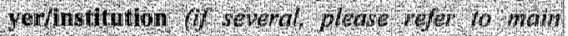

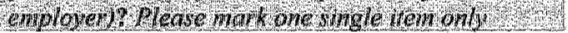

Dutblic employar

[ Non-profit organization

Drivale employer

$\square$ Sell employed

Other:

$$
\text { (phomse: spuseldy }
$$

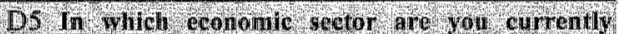

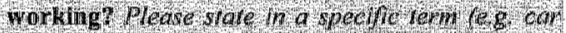

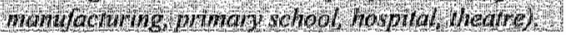

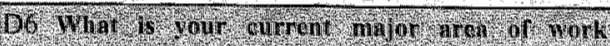

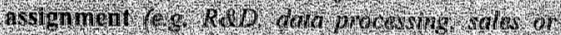

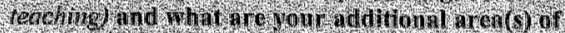

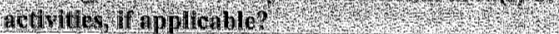

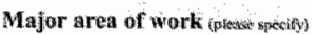

Additional arrea(s) work work inteac specify;

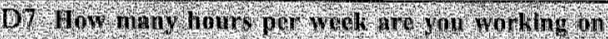

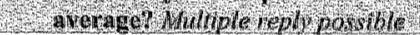

Working houis por week

$L 1$ Contract hours of my maior assignnent

Addional working howrs of my anjor

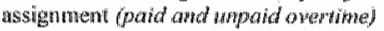

Working hours on other assignments fecond occuparion. silde jobss en.,

Total working hours fincl, wefl(omploymert)

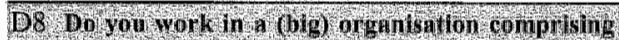

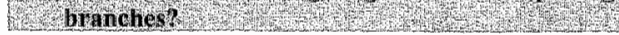

$\square$ Yes, l'm working in a brandh

$\square$ Yes, l'm working in the head office/central wnit of an organization comprising branches

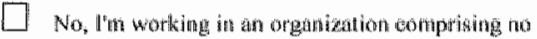
branches

Not spplicablon, fam self armployed

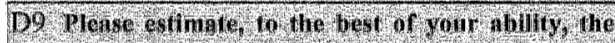

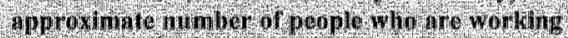
Wh

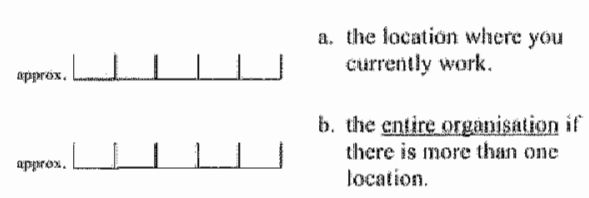




\begin{tabular}{|c|c|}
\hline & 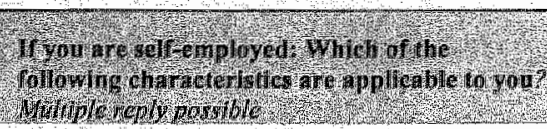 \\
\hline & A. Hom serving a single contrabtor \\
\hline 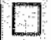 & b. Thook over an existing timnolfice ote: \\
\hline 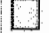 & c. Il established anew firm/office ere: \\
\hline & 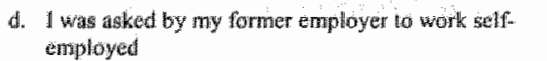 \\
\hline & e. I arrit working thome \\
\hline & f. Thave no employeres \\
\hline$L$ & g. I live a parther \\
\hline & 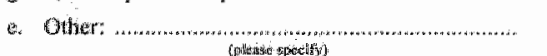 \\
\hline
\end{tabular}

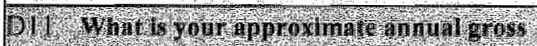

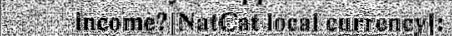

Thousand Whatcat]

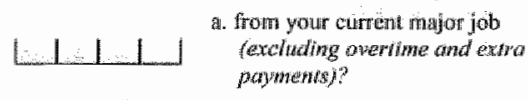

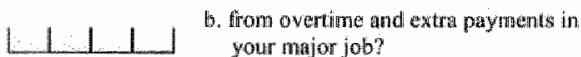
your major job?

$1.1+1$ a. from other jobs?

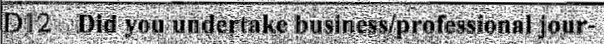

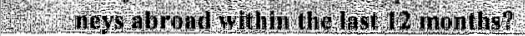

Li: No

$\square$ Yes, allogetherL_L Weeks

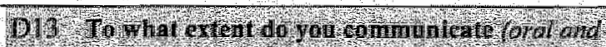

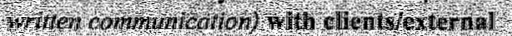
partiners:

Wors: Not

exsiand isth

12345

$\square \square \square \square \square$ aid. in a foreigm languager?

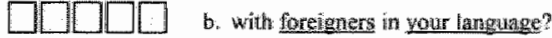

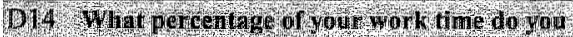

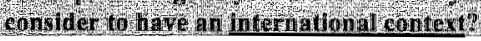

\section{$1 \quad 1 \quad$ Percentage of work time ( $\%$ )}

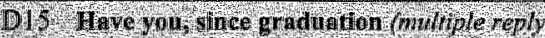

\section{3. po (x)}

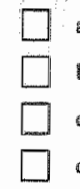

a. constdered warksng abroad"?

b. sought employment abroad?

c. actually received an offer to work abroad?

d. actual ly had regular employment abrowd since gex dyation?

e. extually been sent abroad by your employer on work assignments?

f. NonE $\rightarrow$ GO TO QUESTION EI

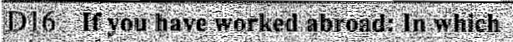

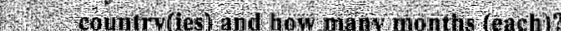

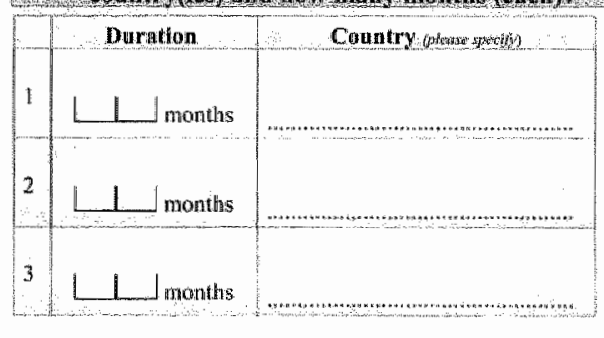




\section{E Competencles and Their Application}

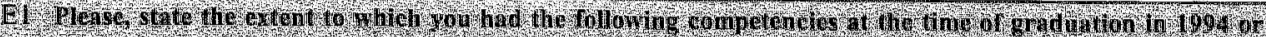

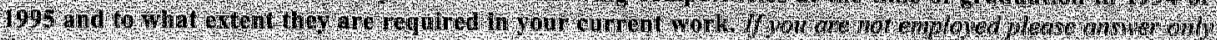
(1)

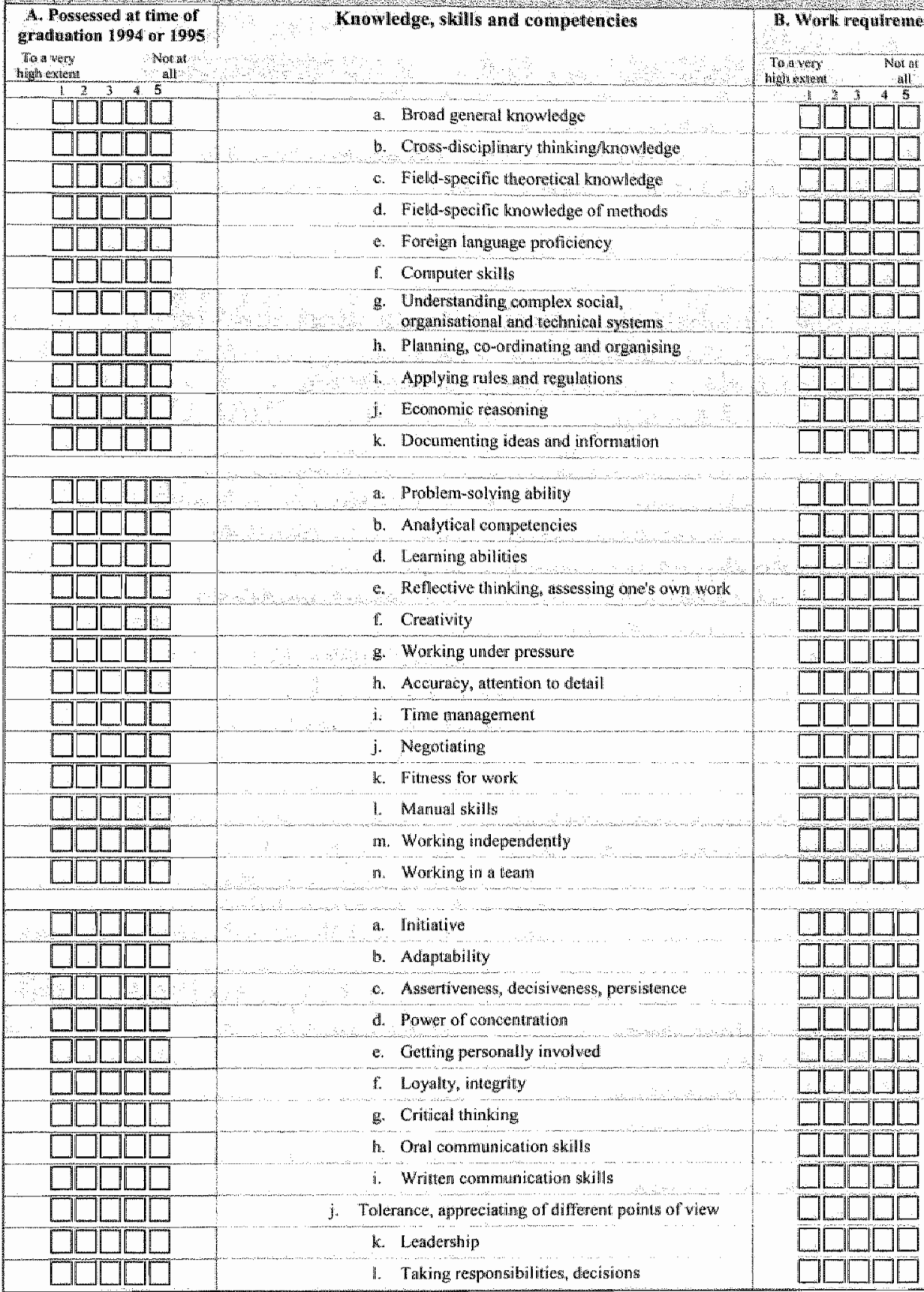




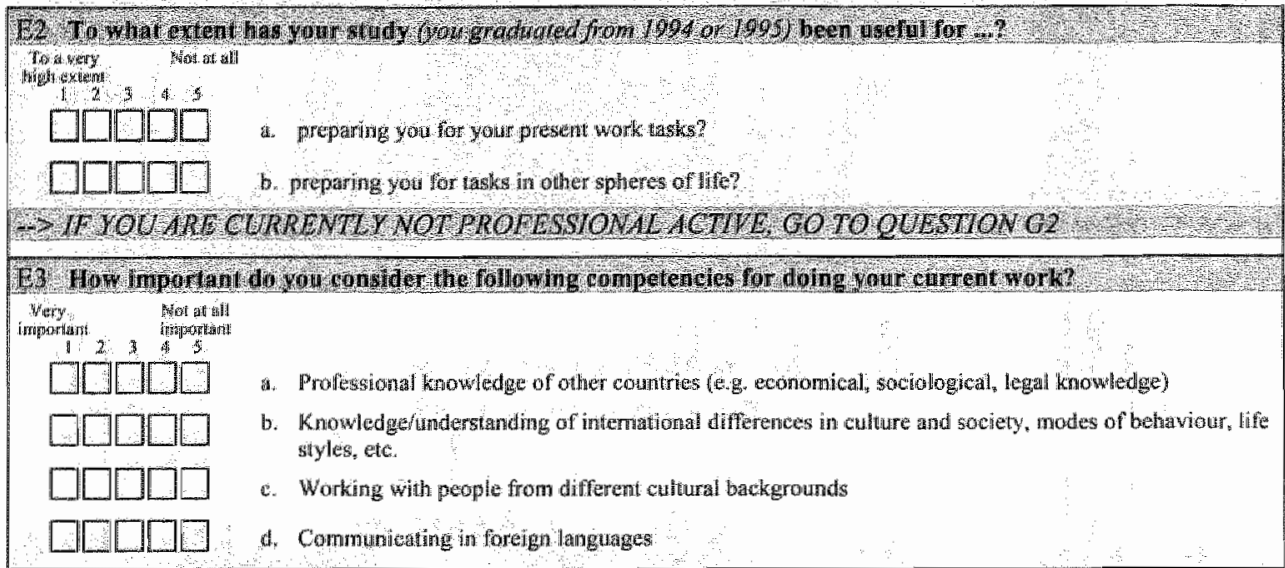

\section{F. Relationships Betwoen uigher Education and Work}

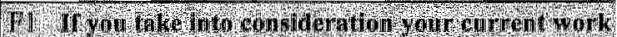

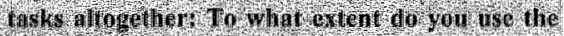

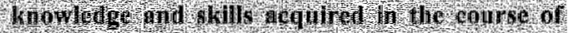

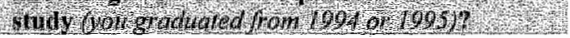

Tio s very thigh extent

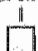

บit

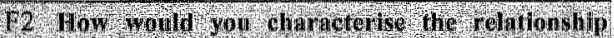

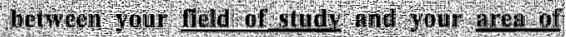

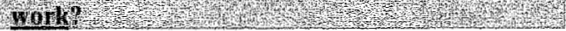

$\square$ My field of study is the only possibledby far the best factd

[ Some other fields could prepare for the area of work as wel

0 Another lield would hiave been more useful

D. The field of study does not matter very nuch

D. Higher education studies are not at all relatied to my areas of work

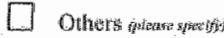

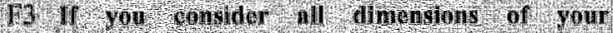

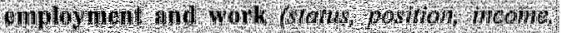

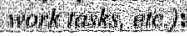

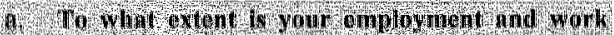
W.

Complitely

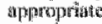

$\square$
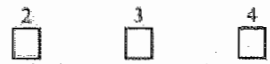

Not at all appropatinte

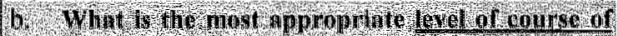

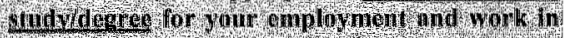

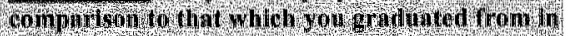
1004 or 1005

D A higher level than the one I graduated from

$\square$ The same lowel

¿ A lower lawel of highertertiary education

D No higherhertiary educution at all

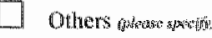

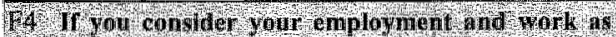

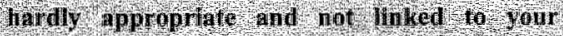

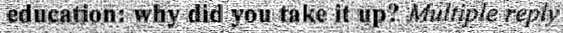
posiblet 2 ?

$\square$ a. I have not (yed) berat able to find a job more appropropriate

b. In doirg this job thave better carcer prospects

c. I prefer an occupartion which is not closely connected lo iny studies

d. I was pronnoted to a position less linked to miy studies than my prewious posit ion(s)

e. I can get a bigher income in my current job

f. My curren job offers me more security

g. My current job is more interesting

fi. My curtent job provides the opportunity for parttime/flexible sollediules etc.

i. My curremt job etabilates me wo work in a locality, which I prefer

f. My current job anllaws ne to take inho accournt fantily needs

k. At the begimuing of the career envisaged I thave to acecol work hardly linked to my study

1. Ollyer:

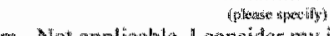

m. Not applicable, I consider my job closely liniked to niny studies

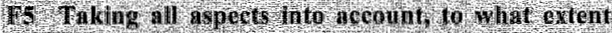

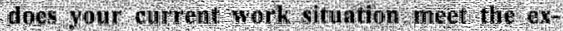

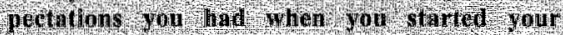
1

$\begin{array}{ccc}\text { Much } & \text { Mukh } & \text { Not inpplicables } 1 \\ \text { better than } & \text { honet than } & \text { have had no } \\ \text { expected } & \text { expected } & \text { expectations }\end{array}$




\section{G. Work Orientations and Job Satisfaction}

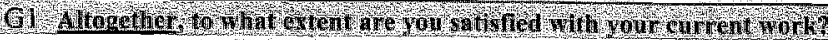

very satistied
$\square$

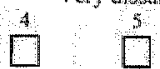

Wery dissunthed

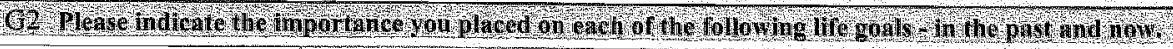

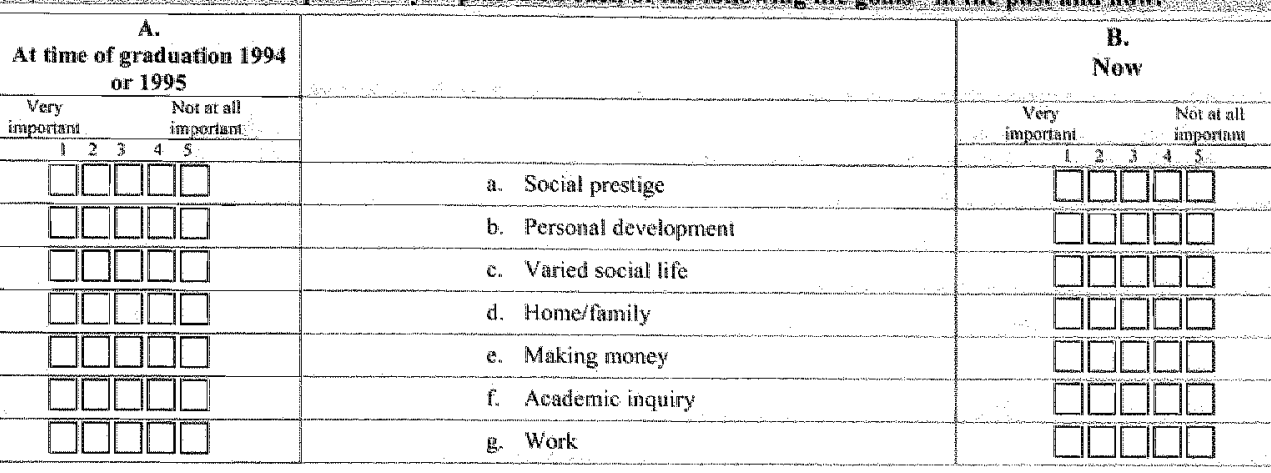

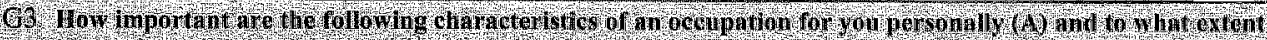

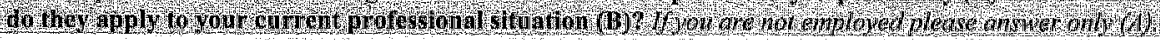

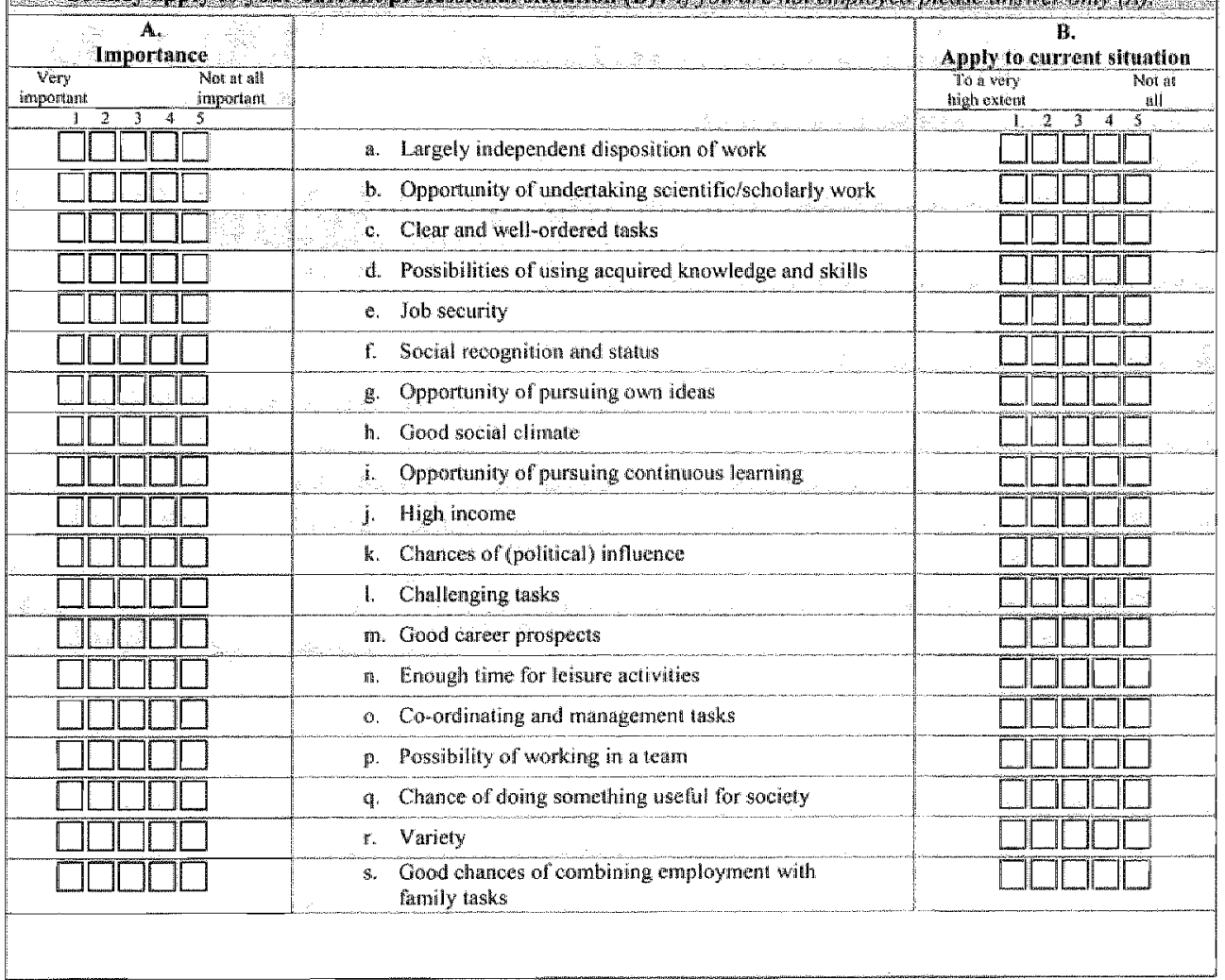




\section{H. Further Education and Trainthy}

Please provide us wh sowe more information regaraing yow further education and training (not

inchuding doctoral study or other additional stucty you hove mentioned already in Question BI.

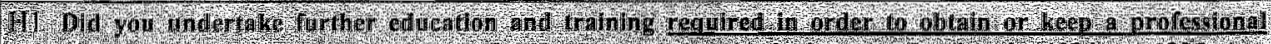

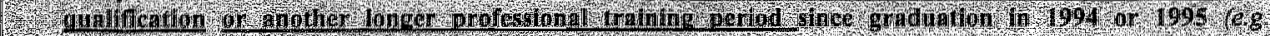

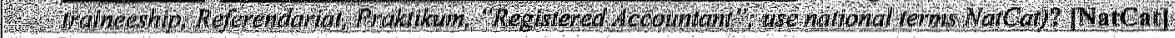

[ WO $\rightarrow$ GOTOQUESTIONH2

Yes, please specify:

\begin{tabular}{|c|c|c|}
\hline (4) Ammethind of r ralining & 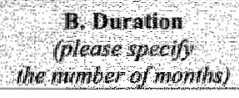 & $\begin{array}{l}\text { CKind of cervication earned } \\
\text { (fropplicoble) [Nateat }\end{array}$ \\
\hline nopros & $\begin{array}{l}\square \perp \text { Months } \\
\square \text { Wot frnished yet. }\end{array}$ & , n \\
\hline 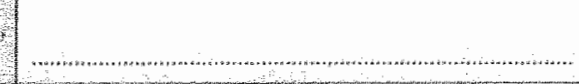 & $\begin{array}{l}1 \\
\square / \text { Mot Inished yet }\end{array}$ & 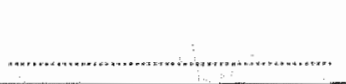 \\
\hline on & $\begin{array}{l}11 \text { Months } \\
\square \text { Wot flunished yet }\end{array}$ & 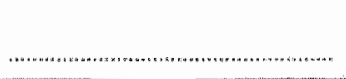 \\
\hline
\end{tabular}

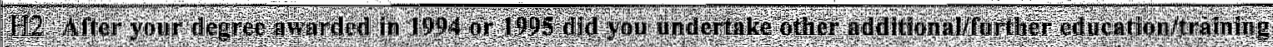

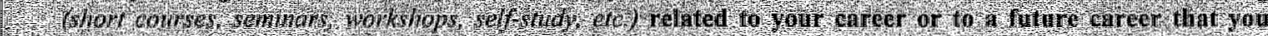

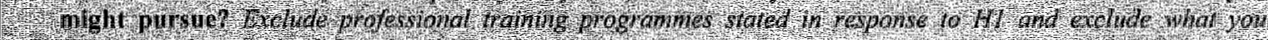

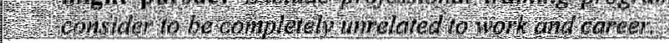

$\square$ No $\rightarrow$ GO TO QUESTIONHO

Yes

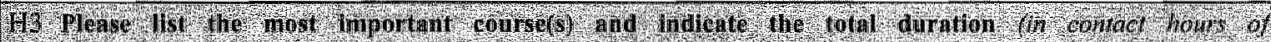

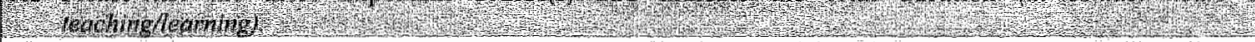

\begin{tabular}{|c|c|}
\hline 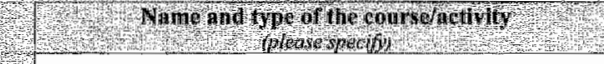 & Duration \\
\hline 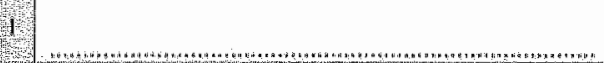 & $\square_{1 \text { to } 10 \text { hours }} \square_{\| 1}$ to 50 howrs $\square$ 51 and more hours \\
\hline 12 & $\square_{\text {i to } 10 \text { hours }} \square$ i1 to 50 hours $\square$ si and more hours \\
\hline 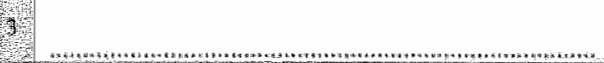 & $\square_{\text {I ta lo hours }} \square_{11}$ to 50 hours $\square_{51}$ and in \\
\hline
\end{tabular}

$\rightarrow$ The following quasions $H 4$ vo $H 9$ apply to your fiother education activines in genteral mentioned in HS.

W4. Who is (wir) responivilo for provaling this

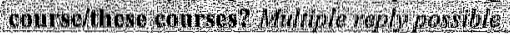

$\square$ a. A higher education institutions

[ b. Priwate institute offering seminerytraning

c. la-sompany or ith-serwice training

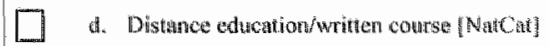

$\square$ e. Otller apheaces spevingt

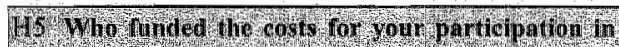

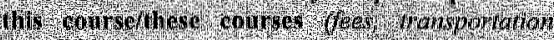
W

D a. Therewere no costs

b. Mainly my employer

c. Maimly myself

d. Mainly public funds

e. I don't know

i. Other (pitenes spexity) 


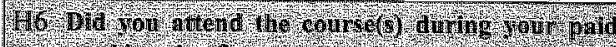
W. Worluing tone?

$\square$ Yes, completely during paid working the
$\square$ Yes, partly during paid working time
$\square$ No, completely oufside paid working time
$\square$ Not applicable, I was not employed

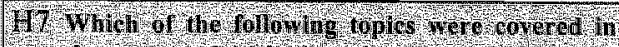

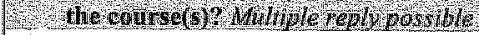

\begin{tabular}{|c|c|}
\hline $\begin{array}{l}\text { a. } \\
\text { b. }\end{array}$ & $\begin{array}{l}\text { New scholarly knowledge in your discipline } \\
\text { Cross disciplinary scholarly knowledge of various } \\
\text { fields }\end{array}$ \\
\hline$c$ & Methodological competenties \\
\hline d. & Manual skills \\
\hline e. & Foreign language proficiency \\
\hline f. & Computer skills \\
\hline$g$. & Soctal/political or philosophical topics \\
\hline h. & Competencles in bussiness administration. \\
\hline i. & Managennent/leadership conpetenciex \\
\hline $\mathrm{j}$. & Legal topics \\
\hline k. & Hunan ecology/enwironmental matters \\
\hline 1. & $\begin{array}{l}\text { Oral or written communication aud presentation } \\
\text { skills }\end{array}$ \\
\hline m. & Rellationships with customers/lients \\
\hline & ㄷ..., \\
\hline
\end{tabular}
(p)ipatse specility)

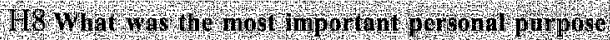

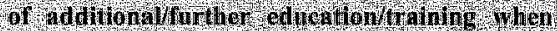

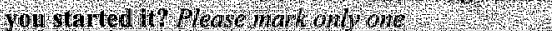

Enhancing career, getting promoted, ete

Updating your knowledge

Re fraining (i,e preparation for oflet occupations/capecrs)

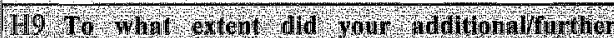

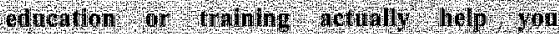
Antrindst?

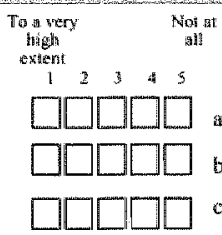
곌

a. to get employed?

b. to get along with the work tasks?

c. to enrich the job (e.g. more interesting tasksy?

6. to raise the status (e.g. promotion, higher incoma',

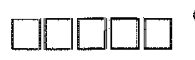

e. lo cope with requirements from other life spheres than employment and work

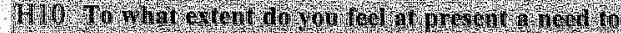

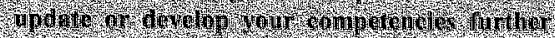

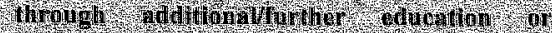

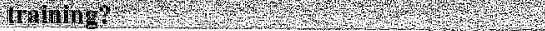
To very high exient

$\square \quad \square^{2} \quad 3 \quad \square \quad \square$

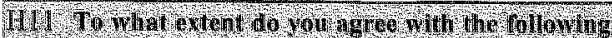

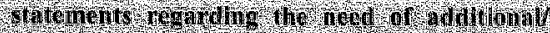

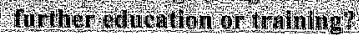

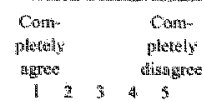

1 . 345

Additionals further education or tratining is necessary $\mathrm{n}$.

$\square \square \square$ a. ... in onder to cope with tasks which could not be ervisaged at the thene of initial education

$\square \square \square \square$ b. ... beceluse of shortconings in inititl finst study

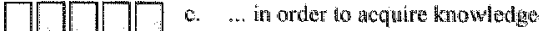
which can be leamed betier on the job

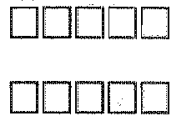

d. Initial linst shudy provides a sufficient training in relevart skill accuassition

e. Initisl firsi situdy constitutes a good bass for continuous updating of knowledge and skills

\begin{tabular}{|c|c|c|c|c|}
\hline 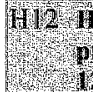 & $\begin{array}{l}\text { orron } \\
\text { ociopial } \\
\text { onitis? }\end{array}$ & how & Mols & He \\
\hline $\begin{array}{l}\text { At lleast } \\
\text { once al } \\
\text { week }\end{array}$ & Manthly & $\begin{array}{l}\text { About } \\
\text { eweny three } \\
\text { monthiss }\end{array}$ & Seldom & Never \\
\hline
\end{tabular}

MB How ofien did y ou at tend professional re levant

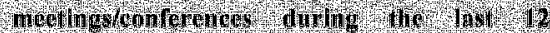
nowithis?
[and thes and nore
D 103 thmes
Neven

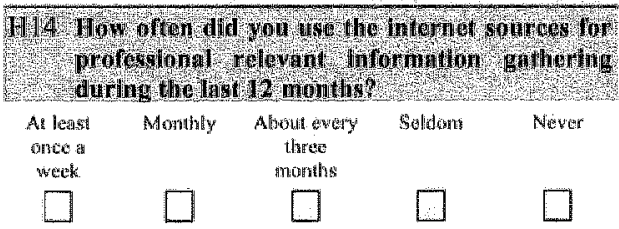




\section{F Socio-blographic data}

Please provde details about yourself in arder to enable us to interpret your work biography as accurately as possible

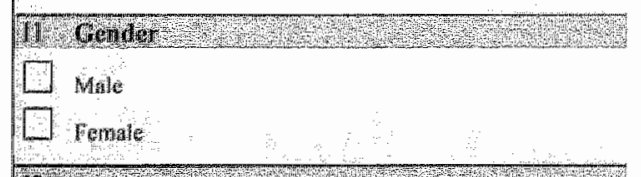

12. Tear 0 6urth

$19 L \perp$ Year

13. Nease, provide some in formation abovit vaur

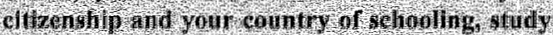
And worl

\begin{tabular}{|c|c|c|}
\hline & $x$ & Other perasenterify \\
\hline 9. Current cilizenstint & & с \\
\hline b. Cinzenship w bith & & 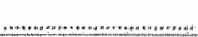 \\
\hline $\begin{array}{l}\text { Country where you } \\
\text { completed secondary } \\
\text { education }\end{array}$ & & \\
\hline $\begin{array}{l}\text { d. Coningy of first employ- } \\
\text { mont after graduation }\end{array}$ & & $(n+\cdots$ \\
\hline $\begin{array}{l}\text { C. Country of current } \\
\text { enploymentw work }\end{array}$ & & …nonten \\
\hline $\begin{array}{l}\text { 1. Country of curtent } \\
\text { residence }\end{array}$ & & \\
\hline
\end{tabular}

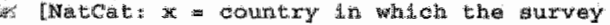
in indertatian]

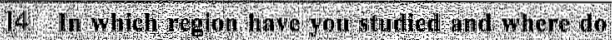

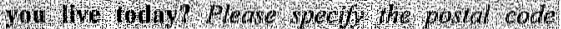

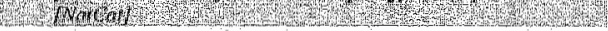
Tostal Thodh

L_._. (Main wegion during lime of studies

H. . . Heghon of enrent residence

L. I Region of emplayment, if appliciable

W (Nationad adaptation of boxem for postal cold or aglomi

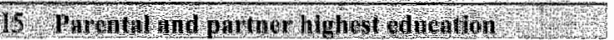 Father Mother Partumet

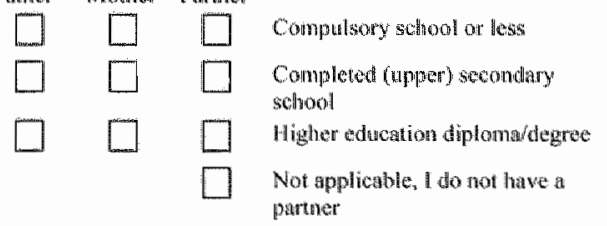

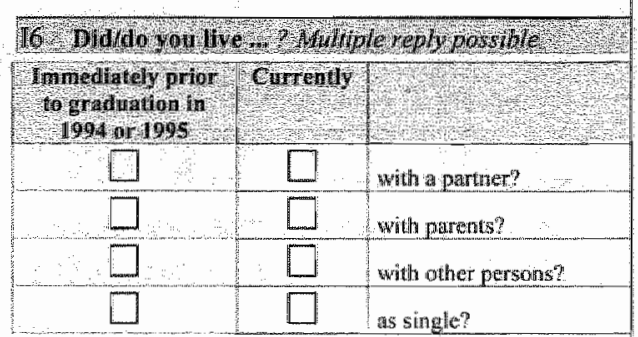

17 Are there difidren in your liousahold?

$\square$ No $\rightarrow$ GO TO QUESTION I8

$\square$ res How many? $\quad 1$

How old are they:

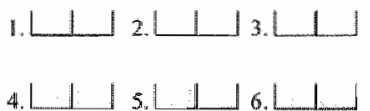

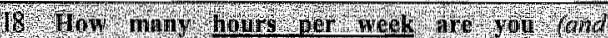
cuentwotiv pont parwity working in you

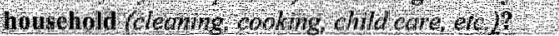

$L \perp$ Hours per week myself

1 Hours per week my partner

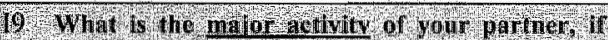

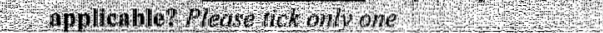

T Not applacable, I don't thave a partuer

$\square$ Employert

Self-employed

$D$ Not employed seaking employment

D professional training

D. Adranced actadennic study

$\square$ Child rearing thmilly care

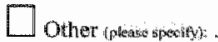


I Retrospective Assessment of Your Studies (you finished 1994 or 1995)

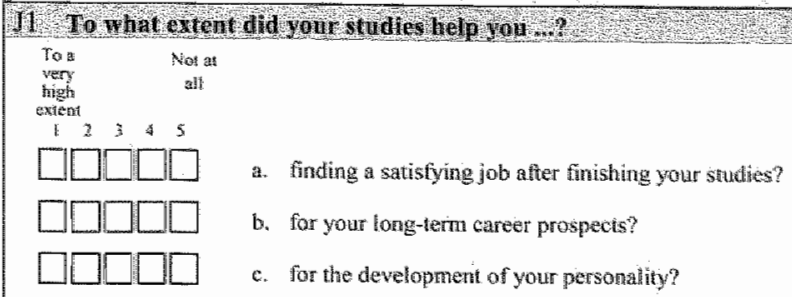

12 Hoking bach of ou were free o choose again how bikely would you Vers
likgly $\square \square \square \square \square$ a. clhoose the same course of stacty?

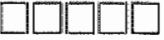
b. choose the same institution of higher education? TILU⿴囗十 c. choose a thigher dogree level of higher education? [NaCa! Q $\square[\square[\square$

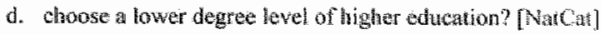
e. decide not to study at all?

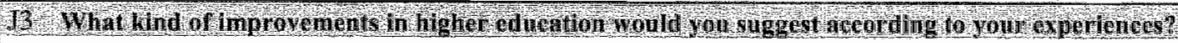

Thank you very much for completing the questionnaire. 
$\therefore \quad 3 \quad-\quad 3$

$\begin{array}{llllll}3 & \ddots & \ddots & \ddots\end{array}$ 


\section{Curriculum Vitae}

Christoph Michael Meng was born in Zürich, Switzerland, on April 4th, I97r. He arrended pre-university education at the Wirtschaftsgymnasium - Kantonsschule Zürich (Switzerland), from 1986-1990. In 1997 heobtained his lic.oec.publ degree at the Faculty of General Economics, University of Zürich (Switzerland), and in 1998 his Masters' degree in International Economics ar Maastricht University. Since then, Christoph Michael Meng has worked as a lecrurer at the Economic Faculty of Maastricht University and since 2000 as a researcher at the Research Centre for Education and the Labour Marker (ROA), where he starred his PhD research.

Christoph Michael Meng is op 4 april 1971 geboren in Zürich (Zwitserland). Van 1986 tot 1990 volgde hij zijn gymnasiumopleiding aan het Wirtschaftsgymnasium - Kantonsschule Zürich (Zwitserland). In 1997 studeerde hij af aan de Economische Faculteit van de Universiteit Zürich (Zwitserland) en in 1998 aan de Economische Faculteit wan de Universiteit Maastricht. Sinds 1998 is Christoph Michael Meng als docent werkzaam aan de Universiteit Maastricht en sinds 2000 als onderzoeker verbonden aan het Research Centrum voor Onderwijs en Arbeidsmarkt (ROA), waar hij zijn PhD-studie begon. 


\section{Roa Dissertation Series}

I. Lex Borghans (1993), Edwcational Choice and Labour Market Information, Maastricht: Research Centre for Educarion and the Labour Market (ROA).

2. Frank Cörvers (1999), The Impatet of Human Capital on International Compertivivenass and Thade Performance of Mamufacturing Sectors, Maastricht: Research Centre for Education and the Labour Market (ROA).

3. Ben Kriechel (2003), Heterogemeity among Displaced Workers, Maastricht: Research Centre for Education and the Labour Market (ROA).

4. Arnaud Dupuy (2004), Assignment and Substitution in the Labour Market Maastricht: Research Centre for Education and the Labour Market (ROA).

5. Wendy Smits (2005), The Quality of Apprenticeship Training. Conflicting Interests of Fimms and Apprentices, Maastricht: Research Centre for Education and the Labour Market (ROA).

6. Judith Semeijn (2005), Academic Competences and Labour Market Entry; studies among Dutch graduates, Maastricht: Research Centre for Education and the Labour Market (ROA).

7. Jasper van Loo (2005), Training, Labor Market Outcomes and Self-Management, Maastricht: Research Centre for Education and the Labour Market (ROA).

8. Christoph Meng (2005), Disciptine-Specific or Academic? Acgwisition, Role and Vathe of Higher Edacation Competencies, Maastricht: Research Centre for Education and the Labour Marker (ROA). 